\title{
SERTUM ANGOLENSE,
}

SIVE

STIRPIUM QUARUNDAM NOVARUM VEL MINUS COGNITARUM

IN ITINERE PER

\author{
ANGOLAM ET BENGUELLAM \\ OBSERVATARUM \\ DESCRIPTIO ICONIBUS ILLUSTRATA.
}

TENTAVIT

FRIDERICUS WELWITSCH.

VOL. XXVII. 
PREFATIO.

INTER cunctos orbis terrestris tractus quos circuli æquinoctiales includunt, illi Continentis Africanæ omnium longius scientiæ occulti remanserunt, ac nonnisi nostris temporibus, et quidem non sine perplurimorum peregrinatorum animi fortitudine et audacia prompta pariter ac doctrina et genio insignium sacrificio, scientiæ paullatim paullatimque innotuerunt.

Ingentes tamen ejusdem Continentis plagæ centrales, intra zonam æquinoctialem cis et trans æquatorem extensæ, ad hodiernum usque diem adhuc penitus ignotæ permanent, in mappis imo recentissimis solum latis spatiis vacuis delineatæ, in scientia, inprimis historiam naturalem spectante, hiatibus profundis indigitata.

Attamen jam hodie Africæ æquinoctialis terræ litorales plures, nec non penetralia quædam ipsis propiora, tam in orientali quam occidentali rasti continentis plaga sita, scientiæ naturalis scrutinio quodammodo aperta prostant, id quod respectu plagæ orientalis præcipue laboribus curisque celebratorum peregrinatorum Kirk, Speke, et Grant et inprimis Prof. Guilh. Peters debetur, qui Floram atque Faunam terræ Mossambicensis et descriptionibus et iconibus numerosis iisque elegantissimis illustravit.

Terras æquinoctiales in plaga occidentali sitas quod attinet, Guineæ superioris Flora tam explorationibus clar. Chr. Smith, Palisot, Thonning, aliorumque, quam, præcipue tempore ulteriore, conamine et industria nunquam satis laudanda clar. peregrinatorum E. Vogel, Barter, et inprimis G. Mann, saltem pro majore parte, jamjam cognita patet.

Floræ Guineæ inferioris fragmenta quædam colligere mihi tandem licitum fuit, dum Gubernii Lusitani jussu honoratus ejusdemque auxiliis munitus, annis 1854 usque ad 1860 Regni Congo partem, dein Angolam et denique Benguellam perlustravi. Iter hoc meum sat longum fuit ac summopere arduum; sæpius atque sæpius morbis in istis terris endemicis nec non Nigritarum invadentium bellis interruptum, aliis locis imo ipsarum terrarum ob perdurantem nimiam siccitatem desolatione perturbatum, nihilominus, Deo favente, feliciter peractum, non tamen sine gravi valetudinis meæ detrimento absolutum.

Varia hujusce explorationis eventa, inprimis quæ ad Floram Angolensem spectant, jam curis benevolis celeber. Jos. D. Hooker, G. Bentham, Alph. de Candolle, Dan. Oliver, G. Reichenbach, fil., aliorumque rei herbariæ peritissimorum virorum in lucem edita prostant, et siquidem hæc uti et illa, in posterum edenda, quidquam ad Africæ æquinoctialis historiam naturalem elucidandam contribuunt, hoc omnino Augustissimo Regi Populoque Lusitano debetur, quorum auxilium admodum validum, durante omni itinere mihi præstitum, hic publice et gratissimo animo lætus agnosco.

Inter stirpes novas vel parum cognitas quas ex terris Angolensibus reportavi, non paucæ prostant, quæ vel ob florum habitusve totius elegantiam aut singularitatem, vel ob qualitatum suarum in autochthonum colonorumque vita quotidiana et sanandis morbis præstantiam, vel denique respectu earum distributionis geographicæ præ ceteris notabiles, illustratione iconographica satis dignæ videbantur. 
Hunc in finem proinde earum plurium icones analyticas delineandas curavi et descriptiones uberiores elaboravi, quas hodie sub Serti Angolensis titulo Floræ Africanæ fautoribus offero, scriptuli mei imperfectionum nequaquam immemor, simulque magnopere deplorans, ejusdem absolutionem et crebris valetudinis meæ vicissitudinibus aliisque vitæ eventis omnino inopinatis longius retardatam fuisse.

Priusquam autem ad ipsarum stirpium descriptionem progredior, pauca quædam, sed non levioris momenti, præmonenda habeo, quæ inprimis circa Regni Angolensis situm, extensionem et divisionem, ejusdemque territorii in variis latitudinis gradibus variam supra mare elevationem versantur, quibus denique notulas breves, præcipue de montium fluviorumque directione et indole, nec non de temporum imbriumque introitu et decursu agentes, addere liceat, ut quæ infra de specierum singularum stationibus vel habitationibus narranda sunt, melius intelligantur.

Nomine "Provincia Angola" sensu generali sumpto, Lusitani omnem illum immensum terrarum tractum, ab ipsis olim detectum eorumque nunc dominio subjectum comprehendunt, qui in Africæ tropicæ transæquatorialis plaga occidentali inter $5^{\circ} 12^{\prime}$ et $18^{\circ}$ lat. austr.* sese extendit, et penetralia dicti continentis nunc ad 200 , nunc fere ad 350 mil. geogr. petit, limitibus tamen his orientem versus necdum ubique rite constitutis.

Vastissimum hocce territorium juxta Oceani Atlantici oram orientalem per tredecim fere latitudinis gradus extensum, quatuor illa antiqua Nigritarum regna, Loango, Congo, Angola et Benguella dicta amplectitur, quæ cuncta olim unita regique potentissimo "Mani-Congo" appellato subjecta, nomine communi "Congo" designabantur $\dagger$. Postea autem, et quidem jam a seculo XV.\$ ad hodiernum diem usque hic idem terrarum tractus apud geographos et in mappis plurimis nomine " Guinea inferior," et apud historiographos Lusitanos "Guiné Portuguez," i. e. Guinea Lusitana, designatus invenitur, nominibus tamen antiquis pro singulis regnis nihilominus conservatis.

Antiqui regni "Loango" Lusitani hodierni solummodo partem meridionalem inter flumina "Cacondo" et "Zaire" sitam, in mappa supra citata sub denominatione "Districto de Cabinda" indicatam, sibi vindicant, quam, cum illam perlustrare non mihi licuit, hoc loco obiter commemoratam prætermitto.

Regnum Congo, sensu hodierno sumptum, ad septentrionem flumine Zaire, ad austrum flumine Loge, a quibusdam geographis perperam "Ambriz" nuncupato, limitatur. Angola proprie sic dicta inter flumina Loge et Cuanza comprehenditur, dum Benguella a sinistris ripis ejusdem fluminis Cuanza ad flumen Cunene et quidquam ultra sese extendit, territorium Benguellense, sensu strictiore sic denominatum, simulque ad meridiem terras Mossamedenses, continentis interiora orientem versus late longeque pervagantes, includens. Secundum fluviorum indicatorum variam inter se quoad eorum ostia distantiam, etiam cujusvis adductorum regnorum extensionem litoralem variare obvium est, sicque territorii

* Conf. Mappam nitide delineatam nuper Olissipone editam sub titulo: “Angola, mappa coordenado pelo Visconde de Sá de Bandeira, Tenente general, Ministro da Guerra, e por Fernando da Costa Leal, Tenente Coronel, Governador de Mossamedes. Lisboa 1864. Fol. sing. max.

$\uparrow$ Conf. Cavazzi ap. Labat (T. 1. pag. 21), \& Demanet, Nouvelle histoire de l'Afrique etc. Paris, 1767, vol. i. pag. 13.

$\ddagger$ Inter Lusitaniæ reges qui primus titulum "Senhor de Guiné” id est, Guineæ dominus, assumpsit, fuit Dom Joaõ II. ; Conf. De Barros Asia, Dee. 1. Lib. III. Cap. 3, nee non Lopes de Lima, Ensaios sobre a statistica, etc., Lib. III. pag. v. 
Congo litus circiter a $6^{\circ} 10^{\prime}$ ad $7^{\circ} 50^{\prime}$, illud Angolæ a $7^{\circ} 50^{\prime}$ ad $9^{\circ} 20^{\prime}$, Benguellæ demum ab hoc ultimo ad $18^{\circ}$ lat. austr. usque sese extendit.

Præter flumina supra notata, non pauca alia, in longinquis penetralium terris nascentia, Oceanum Atlanticum petunt, inter quæ in Congo flumina Lilundo et Ambrige, in Angola, Lifune, Dande et Bengo, in Benguella denique Cuvo, Cutumbella et Bero notabiliora sunt, permultis aliis minoribus rivisque innumeris hic prætermissis, quæ, etiamsi durante pluviarum periodo non raro sat profunda ac dilatata, hiberno tamen tempore (i.e. imbribus omnino carente) vix aquis suis oceanum attingunt, sed versus eorum ostia, arenis ardentibus absorbta sensim sensimque disparent, vel ad stagna hinc inde in lacus extensa ab oceano vicino arena accumulata separata restringuntur.

Totius hujus territorii limites occidentales sive oceanici vel planitiebus formantur nunc angustioribus arenosis suaviter undulatis, nunc latius versus terras internas extensis, hinc inde limosis aut paludosis, vel rarius collibus rupestribus clivisve abruptis, ad 100-300 ped. elevatis, quorum cacumina sæpius horizontaliter truncata, præsertim juxta litora Benguellæ australioris frequenter obvia, et jam a primis navigatoribus Lusitanis apte cum mensis comparata, illis litoribus aspectum admodum peculiarem impertiunt, simulque vegetatione peculiari, sparsa quidem sed admodum distincta, arborum pygmæarum ornantur, inter quas Vitis macropus et Bainesii, Pachypodium Lealii, Sesamothamnus Benguellensis et Welwitschia mirabilis maxime notabiles.

Orientem versus omne territorium ab ora maritima per gradus ad terras internas modo suavius modo abruptius ascendit, montium catenis nempe pluribus, a Lusitanis "Serras" sive "Morros" nuncupatis, interiora versus gradatim altioribus percurritur, quarum summa juga in Angolæ penetralibus ad 4000, in Benguellæ interioribus ad circiter 6000 ped. elevantur. In universum hæ montium series a septentrione austrum versus decurrunt, latere suo orientali sensim ad radices catenæ sequentis ascendentes, dum contra latere occidentali, oceanum spectante, plerumque abruptius descendunt, unde facile perspicitur quamobrem rivi plurimi et flumina fere omnia nonnisi cataractis pluries repetitis præcipitata, ex terris interioribus in regiones inferiores profluunt. Attamen harum catenarum decursus nequaquam semper continuus, neque ubique directionem supra indicatam sequitur, sed in variis locis illarum una alterave vel omnes magis versus orientem retrocedunt, uti prope urbem "Loanda," dum aliis locis litori propiores emergunt, uti hoc pone urbem "Benguella" observatur; hinc etiam catenarum singularum inter se distantia, montiumque quibus componuntur amplitudo magnopere variant, etiamsi generaliter et catenæ ipsæ et montes singuli versus territorii interiora sensim ampliores. Catenæ singulæ rarius insigniter deprimuntur, sed frequentius montibus disjunctis variæ altitudinis interceptæ vel aliis locis jugorum transversorum ope cum proxima interiore serie conjunctæe sunt vel etiam vallibus angustis plus minusve profundis, tempore pluviarum totidem torrentium alveis, persulcatæ. Seriei interioris juga excelsiora, quæ in Benguella jam ad 80-100 mil. geog. a litore distantiam eminent, in Angola autem nonnisi 150-180 mil. intervallo ab oceano divisa surgere incipiunt, pluribus in locis in planities undulatas deplanata inveniuntur, ex quibus dein iterum vel monticuli disjuncti, obtuse aut acutius conici, non raro ad summum usque cacumen silvis fruticetisve ornati, prominent, uti e. g. in Districtu Huilla, vel rupes ingentes, 
parietibus fere perpendiculariter erectis, nunc vegetatione denudatis nunc fruticulorum variorum viriditate vestitis, columnarum angulatarum ad instar repentius surgunt, quemadmodum hoc in Districtu Pungo-Andongo observare licet, ubi petræ giganteæ undique præruptæ, a colonis nomine "Pedras negras" dictæ, nec non aliæ, circiter 15 mil. geog. orientem versus ab his distantes "Pedras de Guinga" nuncupatæ, et quoad aspectum non minus singulares, vallem fluminis Cuanza ad septentrionem supereminent, in eorum cacuminum rimis faucibusque numerosam herbarum aromaticarum catervam nutrientes, dum juxta basim hinc pascuis latissimis, illine silvis sempervirentibus cinguntur.

In Benguella maxime australis (i.e. Districtus Mossamedes) interioribus, montium catenæ, inter quos illa "Serra de Xella" (sive Chella) dicta, inprimis notabilis, non solummodo latere occidentali sed simul etiam austrum versus, hoc autem latere suavius sensimque descendunt, qua ratione planitiei Huillensis rivi omnes et imo fluvius "Cacolovar" qui cunctos pedetentim absorbet, directionem australem sequuntur, fluvio ipso Cacolovar demum prope pagum munitum "Humbe" in flumen Cunene sese effundente.

Lacus [Lusitanis "Lagoas"] minoris majorisve extensionis in nulla fere territorii parte desunt, sed in universum in Angola paullo quam in Congo et Benguella frequentiores, omnesque, paucissimis exceptis, in fluminum rivorumque vicinitate siti inveniuntur, eorumque plurimi plantarum aquaticarum, inprimis Nymphaarum et Pistiarum uberrima copia superbientes, Cyperorum, præsertim Papyri denso agmine marginati, simul Crocodilorum et, si profundiores, Hippopotamorum delicix, ast accolarum Europensium sanitatis, pro dolor! inimici. Plerique, et majorum omnes, fluviis ipsis vel rivis quibus proximis originem suam et, si persistentes, etiam eorum durationem debent, quapropter una cum illis Jove pluvio ampliores, tempore sicco vero valde angustati vel omnino exsiccati, sicque æstate piscatoribus, hyeme contra agricultoribus magnum proventum suppeditantes. Margines enim fere omnium, post aquarum recessum successivum limo relicto lætificati, opimas fructuum agrestium, inprimis Zea Mayidis, Phaseolorum, Cucurbitarum nec non Arachis hypogea messes largiuntur.

Etiamsi territorii Angolensis lacus, imo eorum amplissimi, nequaquam cum illis immensis lacubus comparari possunt, qui in ejusdem continentis plaga orientali cis et trans æquatorem jure celebrantur, ipsis tamen quoad stirpium aquaticarum, quibus ornantur, numerum et varietatem vix inferiores sunt.

Inter illos, quos plantis natantibus præsertim abundantes vel fere omnino obtectos reperi, Lagoa de Quizembo in Congo, Lagoas de Bombo, de Libongo, de Foto, de Quilundo et de Quibinda in Angola, nec non Lagoa de Giraúl prope Mossamedes et demum Lagoa Ivantalla [sive Yavantalla] in Districtu Huilla sita, primum locum tenent, omnes non solummodo plantis aquaticis sed simul et aliis, quæ eorum ripas palustres vel limo humido tectas inhabitant, ditissimi, et ob stirpium cultarum messes amplas, in eorum areis exsiccatis quolibet anno obtentas, incolis utilissimi. Præter supra indicatos permulti alii lacus, tam in plaga litorali quam in Provinciæ penetralibus siti, nigritis ac colonis ejusdam fere utilitatis sunt, inter quos ii, qui juxta ripas fluminis Cuanza, intra oppi- 
dulum "Massangano" et dicti fluminis faucem se extendunt, et numero et amplitudine æque insignes.

Supra commemorata vasti territorii per gradus elevatio, quacum, uti facile intelligitur, etiam imbrium copia increscit earumque duratio protrahitur, dum contra aëris pressio ac soli temperatura sensim diminuuntur, similem quoque vegetationis, qua diversæ elevationis terræ vestiuntur, graduationem sive modificationem provocat, quæ omni peregrinatori e regione inferiore in altiorem penetranti, prompte sub oculis cadet, nam non solummodo, herbarum singularum fruticumque atque arborum, quæ tum apparent, ab iis regionis inferioris diversitate indicatur, sed simul etiam agrorum silvarumque diversa indole et vigore, fontium et rivorum numero et frigore aucto, totius demum terrarum ipsorumque habitantium charactere physiognomico mutato interpretatur.

Notabilis hæc naturæ scenarum mutatio, viatori ab ora maritima ad terras internas elatiores progredienti primum ad earum circiter 1000 pedum supra mare elevationem sese manifestat, ubi loco pratorum languescentium virgultorumque sæpius spinosorum nonnisi rarius silvulis claris interruptarum regionis inferioris modo relictæ propemodum repente prata intensius virentia, herbæ elatiores, fruticeta robustiora et silvæ extensæ arboribus altioribus densiusque sociatis ac frequenter scandentium agmine multiformi ornatis compositæ apparent, nec non rivuli et fontes nunc muscorum amœna viriditate marginati alteram diversam vegetationis regionem annunciant, quæ ad peregrinatorem esurientem, terræ relictæ ardore cruciatum potu refrigerante silvarumque primævarum gratissima umbra benefaciat, et phytologum repentina presentia complurium stirpium prius non observatarum oblectet. Arbores nunc vastissimæ ac formosissimæ, partim solitariæ partim in sylvas densissimas congestæ apparent, inprimis ex ordinibus Mimosearum, Meliacearum, Myrtacearum, Myristicacearum et Rubiacearum, et Palma plures, præcipue Elais guineensis et Raphiæe species, formosas suas comas ubique ostentant.

Hæc autem totius fere terrarum circumjacentium indolis immutatio ipsaque silvarum primitivarum magnificentia vix altius quam ad 2500-3000 pedum altitudinem supra oceanum ascendunt; tum enim viator iterum aliam Floræ regionem attingit, non minus generali vestitus vegetabilis sui aspectu quam generum et specierum ibidem occurrentium ab iis præcedentis regionis diversitate indigitatam. Silvæ enim nunc minus densæ et humiliores, pratorum herbæ graciliores arctiusque gregatæ, pascua extensiora et sæpius, modo Labiatis vel Acanthaceis pygmæis, modo Orchidearum terrestrium, Liliacearum Iridiarumve floribus fulgidis variegata sese repræsentant, et una cum rivorum fontiumque numero aucto, fruticum quoque atque arborum species mire multiplicantur, ita quidem ut in dato quodam circuitu hujus regionis facile duplus vel hinc inde imo triplus specierum diversarum numerus quam in æquali ambitu regionum inferiorum reperitur. Ast non solum specierum et generum Floram constituentium numerus his locis insigniter auctus invenitur, sed etiam plures plantarum ordines, in terris inferioribus rarissime vel nullibi visi, uti Santalacee, Daphnoidece, Proteacee, Selaginee, Cyrtandreœ, et Ericacea, ceteris stirpibus associatæ obveniunt, sicque alteram tertiam vegetationis regionem, stirpium habitu, numero et indole definitam pronunciant.

Accidit quidem nonnunquam ut species singulæ quædam, terris altioribus peculiares, vel ibidem frequentes, juxta fluminum aut rivorum ripas in regiones inferiores vel 
imo ad fluminum ostia usque descendant, sed hoc rarius obvenit, tumque stirpes tali modo migrantes in his locis potius ceu hospites adventicii quam incolæ stabiles considerandæ, et plerumque etiam habitus sui quadam mutatione originem suam denunciant. Sic exempli gratia Phcenix spinosa Thon., riparum fluminis Cuanza in Districtu Pungo Andongo decus formosissimum, hine inde fere ad limites internos territorii litoralis descendit, sed ibidem, etiamsi fructifera, nana sæpiusque fere acaulis, vel solummodo trunco brevi 1-4-pedali munita permanet. Pari modo etiam Umbelliferarum arbor (Alvardice spec.) quæ in Districtus Golungo Alto silvis primævis trunco ad 25 ped. alto et semipedem crasso vel crassiore occurrit, in territorii litoralis collibus quos hine inde invadit, solummodo fruticulum vix bipedalem, trunculo fere herbaceo, ægre digitum crasso donatum repræsentat.

Hac stirpium diversarum per tres diversos terrarum elevationis gradus inter limites definitos distributione inductus, etiam tres Floræ Angolensis Regiones phytogeographicas statui posse opinor*, quarum prima regio litoralis est $\dagger$, quæ ab ora maritima ad terras internas circiter 1000 pedes elevatas, nunc longius nunc brevius sese extendit; secunda dein sive intermedia, " montoso-sylvatica" denominanda, terras inter 1000 et 2500 circiter pedum altitudinis sitas comprehendens, inprimis silvarum primævarum late extensarum præsentia distincta $\$$, et denique regio superior sive alto-plana, quæ omnes illas terras internas amplectitur quarum elevatio supra oceanum 2500 pedes excedit $\$$.

Harum regionum indolis expositionem fusiorem jam olim in commentatione Annalibus maritimis Olissipone editis inserta $\|$, exhibere tentavi, eodemque loco etiam ordinum singulorum fere omnium Floram Angolensem constituentium inter dictas tres regiones distributionem indicare studui, simulque plantarum ab autochthonibus vel colonis in qualibet régione cultarum enumerationem cuivis ordini adducto adnexi, persuasus quod tam totius territorii quam regionum singularum qualitates ac relationes climatologicæ, ex plantarum in una alterave vel in omnibus tribus regionibus majore vel minore abundantia cultarum indice melius tutiusque pateant, quam si istæ solummodo secundum observationes thermometricas, ombrometricas etc. alioquin durante itinere vix sat exacte instituendas interpretentur.

Imbres primi, post hibernum mensibus Junio, Julio, et Augusto regnantem, pluviisque omnino carentem, versus medium vel finem Septembris, veris initium, advenire solent, plerumque, ne dicam semper, inter fulgura et tonitrua summæ vehementiæ de cœlo

* Conf. Journ. Linn. Soc. Lond. 1858, vol. iii. pag. 150 seq., et Diar. ejusdem, 1861, pag. 182 seq.

† Conf. respectu hujus regionis indolis, "Observations on the Origin and the Geographical Distribution of the Gum Copal in Angola," by Fred. Welwitsch, Journ. Linn. Soc. Lond. vol. ix. pp. 287-302. Necnon: Sertum Benguellense, \&c. Bearbeitet von Med. Dr. H. Wawra und T. Peyritsch. Wien, 1860.

¥ Quoad arbores notabiliores silvas istas constituentes conf. 'Synopse explicativa das amostras de madeiras e drogas medicinaes, \&c., collegidas na Provincia de Angola, enviadas a exposicaõ internacional de Londres em 1862, por Frederico Welwitsch.' Lisboa, 1862.

$\S$ Conf. "Lettre du Dr. Welwitsch à M. Alph. de Candolle, sur la végétation du plateau de Huilla, et observations de M. de Candolle, à ce sujet," in Bibliothèque Universelle [Archives des Sciences Physiques et Naturelles], Livr. Juillet 1861.

|| Apontamentos phytogeographicos sobre a Flora da Provincia de Angola, etc., por Fred. Welwitsch. [Annaes do Conselho ultramarino, 1858, n. 55.] 
cadentes. Sunt autem hæ pluviæ vernales, etiamsi non raro et inprimis in terris interioribus ad Novembris finem vel Decembris medium repetitæ, nec tam continuæ nec tam copiosæ quam autumnales, quæ mensibus Martio et Aprili adveniunt, quapropter hæ a colonis pluvia magna [chuvas grandes] et illæ pluvia parce [chuvas pequenas] nominantur. Quibusdam vero annis pluviæ vernales per longius tempus, etiamsi nequaquam quotidie cadentes, continuantur, simulque autumnales præcocius cadunt, ita ut ab Octobris initio ad Aprilis finem, pluvia paucis tantum hebdomadibus interrupta perdurat, et tum plantarum omnium, ac totius naturæ vegetabilis ubique luxuria summa, sed, pro dolor! etiam inundationes, arva et segetes, pascua et silvas nec non raro domicilia pagosque integros repentino impetu devastantes, præsertim in regionibus inferioribus timendæ. Hoc autem rarius accidit, et in universum cunctæ totius Provinciæ Angolensis terræ, præcipue vero australiores et oceano propiores, magis siccitate quam humiditatis excessu laborant. Perpensa hac imbrium tam in totius territorii ambitu quam in ejus districtibus singulis vicissitudine facile colligitur quod de pluviarum quantitate annua generatim vix aliquid certi ac definiti statui possit.

Idem fere de aëris temperatura valet, quæ in diversis terrarum elevationibus, et in ejusdem elevationis locis nunc ventis magis expositis nunc in vallibus profundioribus reclusis, uti facile expectandum, admodum variat. Generaliter tamen temperatura anni media in regione superiore altoplana, et quidem non ob calorem diurnum, qui ibidem, jugis excelsis exceptis, fere idem, sed ob noctes insigniter frigidiores, ab illa regionum inferiorum 15-20 grad. thermom. F. recedit; in regione superiore secundum observationes plures in Pungo Andongo et Huilla institutis temperatura anni media inter $55^{\circ}$ et $60^{\circ} \mathrm{F}$., in regionibus vero inferiorioribus inter $77^{\circ}$ et $80^{\circ} \mathrm{F}$. vacillare videtur, excepto tamen districtu litorali de Mossamedes, qui ob ventorum refrigerantium, sæpius ex austro vel austro-occidente flantium accessum liberum, nec non minus ob oceani aquarum ex austri regionibus frigidis affluentium et juxta hæc litora maximo impetu septentrionem versus decurrentium vim moderantem, climate multo frigidiore gaudet, quam hoc in territorio circulum æquinoctialem tangente vel imo pro parte ab ipso incluso, esset exspectandum. Hac eadem ex ratione etiam Flora Mossamedensis vix indolem reapse tropicam repræsentat, sed potius subtropicam vel fere Capensem, uti hoc præsentia specierum plurium ex generibus Juncus, Triglochin, Ceratogonum, Cressa, Euclea, Mesembryanthemum, etc., et ipsius Vogelia Africance aliarumque stirpium Capensium frequentia indigitatur, et simul cerealium Europæorum atque Vitis viniferce cultura prospera illustratur.

Generalibus hisce de Provinciæ Angolæ constitutione physica et vetegabilium in ejusdem territorio distributione præmissis, pauca quædam adhuc de mensuris et numeri signis adhibitis, nec non respectu nominum locorum natalium specierum describendarum hic adjungere liceat.

Mensuræ hine inde in specierum descriptione usitatæ, uti et illæ quæ ad terrarum supra mare elevationem spectant, pedem Anglicum, in 12 pollices et pollicem in 12 lineas divisum, indicant. Terrarum altitudines methodo thermometrica a cl. Princep * indicata determinare studui, observationibus hunc in finem institutis in eodem loco pluries et non

* Conf. Table for aseertaining the Heights of Mountains from the Boiling-point of Water. By James Princep. London, 1841. 
raro etiam ad diversas diei horas repetitis demumque inter se comparatis; valores hacce methodo partos non omnino exactos esse, omnibus notum est, sed ad stirpis cujuscumque loci natalis altitudinem statuendam satis habere veritatis videntur.

Nomina locorum natalium specierum descriptionibus appensa secundum orthographiam Lusitanicam scripsi; sunt autem hæc nomina nunc linguæ Nigritarum illis terris autochthonum omnino propria, nunc Lusitanica, id est a colonis Lusitanicis ibidem introducta, nonnumquam etiam ex ambabus his linguis hybrida, sed jam longo usu vindicata simulque indigenis bene cognita et proinde peregrinatoribus futuris quam nomina scriptis quibusdam vel mappis antiquioribus exarata, duces fideliores.

Nomina vernacula, quibus stirpes quædam vulgariores vel frequentius obvenientes in locis suis natalibus a Nigritis vel colonis designantur, non nisi rarius et caute speciebus singulis adnexi, quoniam ex istorum perplurium, primum sedule collectorum et dein inter se et una cum stirpibus quibus addicta fuerunt comparatorum studio cognovi, eorum plurima nonnisi ambigui valoris, vel solummodo paucis incolis cujusdam loci cognita esse, vel non raro, et imo in uno eodemque loco, stirpibus inter se valde diversis, vel vix habitu aliquantulum similibus attribui.

His missis restat ut viris illustribus qui in conficienda hac commentatione mihi opem tulerunt, gratias meas maximas atque sincerissimas agam, quos inter clarissimi Dr. Jos. D. Hooker, Horti Museique botanici Kewensis omnium amplissimi ac ditissimi Director, nec non Prof. Dan. Oliver, ejusdem Musei custos et bibliothecarius, primo loco prædicandi: viri generosi, eruditione et humanitate æque insignes, quorum benevolo consilio auxilioque efficacissimo, si quid meriti huic scriptulo inhæret, omnimodo et juste tribuendum.

Pariter clarissimis viris Joh. J. Bennett, herbarii Musei Britannici præfecto, et Guilh. Carruthers, ejusdem herbarii curatori, pro singulari et semper prompta urbanitate, qua illius herbarii locupletissimi usum mihi faciliorem reddiderunt, me summopere gratum confiteor; lectoris autem benignæ indulgentiæ harum paginarum imperfectiones iterum atque iterum commendo.

\section{DE S C R I P T I O N E S.}

\section{Ordo ANONACE正.}

Trib. III. Mitrephoree, Benth. et Hook. f. Gen. Pl. p. 21.

Monodora Angolensis, Welw. n. sp.* (Tab. I.) Glaberrima, foliis membranaceis vel demum plus minusve coriaceis, obovato- vel elliptico-oblongis, breviter acuminatis cuspidatisve, basi cuneatis, herbaceo viridibus, floribus pendulis, sæpius in ramulis brevibus lateralibus foliiferis solitariis oppositifoliis; sepalis e basi latiuscula lanceolatis crispatis, petalis exterioribus amplis ovatis acuminatis incurvis, lateribus utrinque reflexis, interioribus unguinculatis conniventibus laminis transversim ellipticis

* Primam tam hujus speciei novae quam Monodoræe Myristicce, Dun., olim perperam Floræ Americanæ vindicatæ, in Angola certe indigenæ notitiam jam olim clar. W. W. Saunders in litteris (Loandæ, Sept. 1857) communicavi, denique anno sequente, ambas species in "Apontamentos phytogeographicos sobre a Flora de Angola, p. 587," commemoravi. 
abrupte cuspidatis basi exauriculatis; fructu ovato-ellipsoideo longitudinaliter sulcis levibus latiusculis percurso.

Habitat in silvis primævis editioribus Distr. Golungo Alto et paullo frequentius in silvaticis rupestribus Distr. Pungo-Andongo ad 2500-3500 ped. altit. A Novembr. usque Januarium florens, MaioJulio fructificans. Exsic. Welw. Iter Angol. n. 774 et 776 .

Arbor 20-30-pedalis, coma densiuscula ovoidea, trunco recto ad basim $1-1 \frac{1}{2}$ ped. diametri, cortice obiter rimoso aspero nigrescente; rami primarii erecto-patentes, secundarii et ramuli patentissimi cylindracei, juniores et floriferi purpurascentes, subdistiche foliati. Folia alterna, petiolo brevi 2 lin. longo canaliculato suffulta, obovato- vel elliptico-oblonga, nunc ovato-lanceolata, 4-5 $\frac{1}{2}$ poll. longa, 2 poll. lata, basi cuneato-angustata, apice abrupte acuminata vel breviter cuspidata, margine integro, penninervia, supra intense viridia nitidula, subtus absque nitore pallide virentia, secundum expositionem arboris nunc membranacea et decidua, nunc plus minusve coriacea et persistentia. Flores speciosi, totius ordinis facile elegantissimi, multicolores, suaviter odori, in ramulorum extremorum ramellis abbreviatis solitarii, longius pedunculati, nutantes, demum penduli, pedunculo oppositifolio, gracili, circiter 2 poll. longo, medio bractea ampla, membranacea, herbaceo-viridi, late ovata, vel cordato-ovata acuminata, longitudinaliter plurinervia, semiamplectente, demum decidua munito. Sepala a lata basi lanceolata, petalis multoties breviora, herbaceo-viridia, undulato-crispa, a basi supra pedunculum reflexa, longe persistentia. Petala (basi semper inter se coalita mox post fecundationem a calyce annulatim soluta et junctim secedentia) tenuiter carnosa, exteriora elongato-ovata sensim acuminata, obtusiuscula, 2-2 $\frac{1}{2}$ poll. longa, utraque superficie reticulatim scrobiculata, a basi patula arcuatim incurva, lateribus undulato-crispis recurvis, primum e viridi purpurascentia basi nivea, demum maculis circularibus rubris, aurantiacis et flavicantibus undique variegata, interiora exterioribus multoties breviora et duplo angustiora, erecto-conniventia, omnino albida vel albido-rosea, levia, margine plano, spathulata, unguibus latiusculis fere laminæ æquilongis, lamina nunc transverse elliptica, nunc obcuneata abrupte cuspidata, cuspide obtusiuscula barbulata. Stamina et gyncecium generis ; antheræ badio-albidæ, loculis contiguis; pollen albidum. Ovarium bene efformatum, mox post fecundationem verticaliter pluristriatum; stigma nunc integrum peltatum, nunc obscure plurilobulatum vel solummodo obiter radiato-striatum. Fructus in pedunculo nunc lignose indurato et incrassato pendulus, suberoso-lignosus, glabriusculus, ovato- vel oblongo-ellipsoideus, 6 poll. circiter longus, $3 \frac{1}{2}-3 \frac{3}{4}$ poll. diametro, basi obtusus, vertice breviter apiculatus, secundum longitudinem sulcis pluribus latis sed parum profundis costisque obiter prominentibus percursus, unilocularis, pulpa farinosa fuscescente semina involvente farctus, indehiscens, vel rima longitudinali apertus. Semina numerosa, oblongo-obovoidea, 5-7 lin. Ionga, ad hilum oblique truncata, mutua pressione non raro varie gibba vel angulata ; testa tenuiter coriacea, tenax, levigata, fusco-badia, nitida ; albuminis ceraceo-carnosi gratissime et fortiter fragrantis lamellæ numerosæ, planiusculæ, æquali fere inter se crassitudine, respectu peripheriæ seminis verticaliter seriatæ. Embryo minutus, hilo proximus.

Observatio.- Semina Monodora Angolensis, uti illa Monodor a Myristica ab autochthonibus ob nuclei aroma gratissimum, illud Myristice moschate æmulans, nec non ol) virtutem egregie stimulantem et restaurantem magni æstimata, hinc inde etiam in condiendis cibis usitata multoque commercio circumvecta, in omnibus mercatoriis Angolensibus prostant et sub nomine "Xipepe" vel "Gipepe" venduntur. .Arbores ipsæ ambarum specierum in Angola plerumque " $N$-pepe, in Insula Sti. Thomæ autem" "Jobo" nuncupantur. Nomen vero "Xipepe" vix idiomati Bundico proprium, sed spurium, et ni fallor, a vocabulo "pepper" (Piper) olim a mercatoribus Anglicis ibidem introducto, derivatum et a Nigritis, commercii gratia, genio linguæ Bundicæ accommodatum. 
Trib. IV. Xylopies, Benth. et Hook. f. l.c.p. 27.

Xylopia odoratissima, Welw. n. sp. Arbor parva ramosissima, ramulis pubescentibus, foliis petiolatis coriaceis, ellipticis vel oblongo-ellipticis, obtusis, basi rotundatis, supra glabrescentibus, subtus præcipue in costa piloso-pubescentibus ; floribus axillaribus subsessilibus vel breviter pedicellatis solitariis vel 2-3 fasciculatis; calyce trifido lobis ovato-deltoideis; petalis exterioribus elongatis, interioribus sæpius paullo brevioribus lineari-subulatis; antheris connectivo truncato leviter dilatato, disco staminifero denique deciduo ; ovariis circa 10, pilosis, stylo subulato andrœcium superante, ovulis 4-6; carpellis maturis obliquis, breviter stipitatis, mono- oligospermis, longitudinaliter nervosis glabris.

Habitat frequens in montosis silvaticis editioribus ad plagam australem de Morro de Lopollo Distr. Huilla, inter 5000 et 5500 ped. altit., Decemb.-Febr. florens, Apr. et Maio fructificans. Exsic. Welw. Iter Angol. no. 757.

Arbuscula in silvis densioribus circiter 10-15 pedes alta, comæ tunc laxioris forma sat variabili, ramis valde inæquilongis fere horizontaliter patentibus, ramulis extimis vario modo curvis inter arborum vicinarum ramificationes subscandentibus; in declivibus vero apricis petrosisque plerumque frutex 4-6-pedalis, jam paullo supra basim ramosus, ramis erectiusculis, cylindricis, glabratis, crebre et patentim ramulosis comulas dense foliosas efformantibus; ramuli juniores et floriferi plus minusve sericeo-pubescentes. Folia persistentia, in vivo molliter coriacea, supra halitu glaucescente læatius, subtus pallide viridia, exsiccatione utrinque multo pallidiora et rigidiora, petiolo 2 lin. longo, leviter canaliculato cum ramulo articulato suffulta; lamina $1 \frac{1}{2}-2$ poll. longa, $1-1 \frac{1}{3}$ poll. lata, apice obtusa vel rarius subacuminata, basi rotundata vel hinc inde subcordata, subtus inprimis ad petiolum et costam molliter pubescens. Flores creberrimi, suavissime fragrantes, ad axillas foliorum solitarii vel plerumque 2-3 fasciculati, brevissime pedicellati, carnosuli, rigiduli, fragiles, extus undique sericeotomentelli, primum albidi, demum flavescentes. Calycis profunde 3-partiti lobi deltoidei, circiter lineam longi, apice apiculati. Petala exteriora $\frac{2}{3}-\frac{3}{4}$ poll. longa, obtuse carinata, a basi ovata concava abrupte linearia obtusiuscula; interiora angustiora, paullo breviora et apicem versus subulata, sub anthesi erecto-patula, prompte decidua. Andracium et ovaria descripta. Carpella matura 4-8, omnino glabra, nitidulo-rubra, stipite recto 2-3 lin. longo, crassiusculo, subangulato suffulta, nunc monosperma, obovoidea, pisi majoris mole, nunc 2-4-sperma, oblique obovoidea vel claviformia pollicaria, omnia juxta apicem appendice alæformi rostrata.

Observatio.—Stirps ob florum miram copiam eorumque odorem gratissimum, quem late spargunt, inter affines insignis, nec non propter corticem aromatico-amaricantem pharmacographis de futura Africæ tropicæ materia medica scripturis commendanda. 'Autochthonum illius regionis medici circumforanei (quibanda dicti), non semper omnino imperiti, e florum vix apertorum infusione tepida potum parant stimulantem simulque subnarcoticum, de cujus tamen applicatione speciali non edoctus fui.

\section{Ordo VIOLARIE $\nexists$.}

Trib. III. Alsodeiex, Benth. et Hook. f. Gen. Pl. p. 118.

Alsodeta (Ceranthera) ilicifolia, Welw. n. sp. (Tab. II.) Fruticosa vel subarborescens, glabra; foliis coriaceis, ovali-oblongis, elongatis, acutis, argute et grosse spinuloso-serratis; floribus flavis, brevissime pedicellatis, recurvis, in paniculas angustas terminales folio breviores fasciculatim dispositis ; sepalis ovato-ellipticis, 
obtusis; petalis obtusis (sepalis subbrevioribus*); tubo stamineo brevi, extus haud producto, antheris connectivo dorsali ovato obtuso, appendicem anteriorem ovalem integram vel emarginatam superante ; capsula coriacea, ruguloso-aspera.

Habitat sporadica in rupium convallibus umbrosis Distr. Pungo Andongo, ubi prope Præsidium ipsum, loco dicto "Barrancos de Catete," Febr. c. alabastris et fructu submaturo, Maio denique iterum cum alabastris legi, ad altit. circiter 3500 ped. supra mare. Exsic. Welw. Iter Angol. no. 889.

Frutex validus, sive arbuscula, 8-12-pedalis, Ilicis aquifolice habitum quodammodo simulans, rigiditate omnium partium insignis, sempervirens. Trunculus rectus cortice cinereo-virescente parum aspero, ligno albido compacto, sæpius jam ad 3 vel 4 pedes altitudinis supra basim ramosus ; rami erecto-patuli, laxe ramulosi, cylindrici, adultiores levigati et nitenti-virides ; ramulli novelli plus minusve angulati, erectiusculi, firmi et tenaces. Folia alterna, breviter petiolata, rigidicoriacea, glaberrima, supra intense viridia, subtus ex albido virentia et prominule venulosa, nunc ovali-oblonga, elongata et acuminata, nunc breviora et late elliptica, penninervia, nervo mediano valido subtus valde prominente, in petiolo firmo erecto-patula; petioli in uno eodemque ramo longitudine variantes, nunc vix semipollicem, nunc plus quam sesquipollicem longi, semiteretes, canaliculati, ad

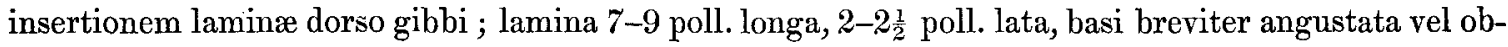
tusiuscula, apice acuta vel acuminata, margine argute serrata, serraturis sinu lato obtusissimo sejunctis apice rigido-spinulosis, spinulis $1-1 \frac{1}{2}$ lin. longis, subulatis. Panicule terminales, erectæ, angustæ, 5-7 pollices longæ, aphyllæ; pedunculi communis angulati, sub lente tenuiter velutino-pubescentis rami basi bracteis brevibus crassiusculis ovatis muniti, inferiores 1-2 poll. longi, parce ramulosi, erectiusculi, superiores sensim breviores, summi brevissimi. Flores (nonnisi in alabastris observati) flavi, ceraceo-carnosuli, pedicellati, juxta ramulos pedunculi per fasciculos pauciflores $\frac{1}{3}-\frac{1}{2}$ pollicis inter se distantes dispositi, ex pedicello ipsis sæpius dimidio breviore basi bibracteolato, crassiusculo, angulato, arcuatim recurvato nutantes vel fere penduli, vix tres lineas longi. Sepala a basi lata ovato-elliptica, erecto-imbricata, concava, obtusissima, margine ciliolata, crassiuscula, rigida, dorso tenuiter pubescentia et sulcato-striata, petalis latiora, in fructu persistentia. Petala juvenilia ejusdem fere figuræ ac sepala sed iis angustiora et breviora. Stamina descripta. Ovarium glabriusculum; placentæ pauci(uni-?) ovulatæ; stylus terminalis, rectus, pro more floris crassiusculus, cylindricus, medio quidquam incrassatus, apice obtusiusculo stigmatosus, staminibus paullo brevior. Capsula ovoidea, coriacea, calyce indurato stipata, extus rubro-purpurea, undique rugulis papillisque aspera, elastice dehiscens, 3-valvata, 3-sperma, vel placentæ unius abortu disperma, valvis cymbimorphis sublignosis, medio placentiferis. Semina (vix bene matura) subglobosa vel sublenticulari-compressa, diametro longiore circiter 5 lineas longa, pone umbilicum excavatum obtuse rostrata, testa crustacea, levigata, nitidula badio-flavescente. Embryo in albumine copioso axilis excentricus, umbilico approximatus; cotyledones obovato-ellipticæ, planiusculæ, vaginatim conferruminatæ, radicula hilo proxima.

\section{Ordo BIXACE 玉.}

Trib. II. Oncoвez, Benth. et Hook. f. Gen. Pl. 125.

Oncoba WeLwitschit, Oliv. Flora of Trop. Afr. MS. (Tab. III.) Arborescens, inermis, glabra; foliis membranaceis, longe petiolatis, ovatis, acuminatis, basi late rotundatis; floribus pedunculatis, ad ramulos annotinos vel vetustiores nascentibus 3-5 fasciculatis; sepalis 3 late ellipticis; petalis circiter 10 obovatis longiuscule unguiculatis, sepalis plus quam duplo longioribus ; antheris linearibus quam filamenta capillaria multo brevioribus; ovario papilloso-setoso, placentis 5-6; stylo gracili longiusculo

* Flores in nostris speciminibus necdum bene evoluti et solummodo in alabastris anthesi proximis examinati; relatio proinde inter sepala et petala in postero accuratius statuenda. 
apice in lobos 5-6 breves patentes diviso, stigmatibus truncatis; capsula ovoidea, dense echinata, 5-6-valvata, valvis intus nudis medio placentiferis post dehiscentiam recurvis ; seminibus dense verruculosis.

Habitat sporadica in silvis primævis Distr. Golungo Alto prope Bungo Aquitamba, ad 2300 ped. altit., necnon sub forma fruticis in silvis sccundariis circa Sange. Floret Novemb. usque Febr., Martio usque Jul. fruct. maturat. Exsic. Welw. Iter Angol. no. 537.

Arbuscula 12-15-pedalis, hinc frutex vix 8 pedes altus. Truncus in forma arborescente rectus, diametro semipedali, raro crassior, cortice minute rimuloso badio-cinerascente, ligno albido denso, sæpius jam ad altitudinem 4-5 pedum supra basim ramosus, ramis robustis elongatis ascendentibus, infra longe denudatis, apicem versus parce ramulosis; ramuli graciles, patentes, tenuiter sulcati, lenticellis ellipticis obsiti, novelli levigati apice densius foliosi. Folia alterna, longe petiolata, ampla, ovata, longe acuminata, supra læte viridia, verniceo-nitidula, subtus pallide virentia, glabra; petioli $3-4 \frac{1}{2}$ pollices longi, graciles, patuli, basi obiter canaliculati, ad insertionem laminæ quidquam incrassati et curvati; lamina (in foliis adultis ex apice petioli fere pendula) 6-10 poll. longa, 3-5 poll. lata, margine integro vel obscure repando, basi rotundato-obtusa, apice nunc sensim, rarius abrupte in acumen 1 poll. circiter longum attenuata; stipulæ laterales geminæ, foliaceæ, lineari-subulatæ, semipollicem circiter longæ, erectæ, deciduæ. Flores polygami, ex speciosissimis inter congeneres, diametro 4-pollicares, quondam in eodem ramo multo minoribus mixti, ad ramulos vetustiores vel imo ad truncum ipsum nascentes, plerumque $3 \mathrm{vel} 4$ fasciculati, pedunculis $1-1 \frac{1}{2}$ poll. longis coloratis basi minute bracteolatis suffulti, evolutione successiva aperti. Alabastra globosa, apiculata, paullo ante anthesim vesiculose turgescentia. Calyx tenuiter coriaceus, triphyllus, sepalis æstivatione late imbricatis, concavis, obtuse carinatis, pollicem longis, semipollice latioribus, extus pube minutissima caduca subvelutinis, fusco-rubentibus, demum deciduis. Petala 9-12, plerumque 10 vel 11, alba vel albido-rosea, obovato-spathulata, patentia, membranacea; lamina obovata 1-1 $\frac{1}{2}$ poll. longa, venulis sursum divergentibus percursa, margine integro obiter undulata, sensim in unguem $\frac{1}{2}-\frac{3}{4}$ poll. longum compresso-planum 1 lineam latum attenuata, una cum staminibus decidua. Stamina numerosissima; filamenta filiformia, ascendentia, albida, pollicem longa ; antheræ terminales, intense flavæ, oblongo-lineares, basi subcordatæ, quam filamenta multoties breviora, biloculares, longitudinaliter dehiscentes; pollinis granula globoso-ellipsoidea, levia. Ovarium ovoideum, papillis acutiusculis undique echinulatum; ovula juxta placentas parietales 5 vel 6 perplurima; stylus rectus, cylindricus, fere pollicem longus, apice radiato 5-6-lobus, demum indurescens, in fructu persistens. Capsula matura globosa vel sæpius ovoidea, undique aculeis rigidulis 1 pollicem longis læte aureo-flavis echinata, tarde dehiscens, 5- vel 6-valvata, valvis crassis, lignoso-duris, demum arcuato-recurvis, intus nudiusculis, medio placentiferis. Semina permulta in pulpa nidulantia, par. vula, duabus lineis vix longiora, ovoidea, fuscula, crebre verruculosa, vertice truncato areola in centro umbonata instructa ; testa crustacea ; embryo rectus; cotyledones planæ, ovatæ; radicula crassiuscula cotyledonum fere longitudine, hilo proxima.

\section{Ordo POLYGALE $\notin$.}

Polygala Gomesiana, Welw. n. sp. (Tab. IV.) Perennis, herbacea; caule erecto 2-5-pedali; foliis lineari-lanceolatis linearibusve, utrinque sæpius angustatis, glabris vel sparse pilosulis; racemis terminalibus amplis multifloris, bracteis bracteolisque membranaceo-scariosis ovato-lanceolatis acuminatis persistentibus, pedicellis patentissimis pilosis; sepalis anterioribus liberis, alis suborbicularibus diametro semipollicaribus, coloratis; capsulis obcordatis, alis dimidio brevioribus anguste marginatis. 
Habitat in pratis humidis altius herbidis juxta rivulos Distr. Huilla, frequens circa Lopollo, ad 5000 ped. altit. A Decembr. usque Apr. florens et fructificans. Exsic. Welw. Iter Angol. no. 1032.

Herba elata, radice lignescente oblique descendente, oligocephala, perennans. Caules e radicis collo 1-3 erecti, virgati, tri- vel quatuor- rarius quinquepedales, simplices vel apicem versus parce ramosi, cylindrici, obiter sulcato-angulati, pilis raris mox deciduis glabrentes, a basi ad medium densius, supra remote foliati. Folia alterna, erecto-patula, subsessilia, plerumque omnino glabra, late herbaceoviridia ; inferiora et media approximata, lineari-lanceolata, $1 \frac{1}{2}-3$ poll. longa, scmipollice vix latiora, utrinque sensim angustata, subacuta vel apice obtusiusculo breviter apiculata, margine integro, nervo inprimis subtus ad basim prominulo flavescente percursa; superiora magis distantia, sensimque angustiora, breviora et acutiora, sæpius linearia; floralia sub anthesi plerumque decidua. Racemi in caule et ramulis terminales, erecti, stricti, ampli, $\frac{1}{4}-1$-pedales, multiflori, juveniles bracteis apice densius congestis breviter comosi. Flores ex majoribus et speciosissimis totius generis, in pedunculo communi pilis brevibus patulis vestito densiuscule gregati, una cum bracteis, bracteolis pedicellisque amœnissime rosei vel roseo-purpurascentes, subnutantes. Bractea tenuiter membranaceo. scariosæ, 3-4 lin. longæ, ovato-lanceolatæ, longe acuminatæ, patulæ, una cum bracteolis itidem patulis paullo brevioribus obtusioribusque persistentes. Pedicelli graciles, $\frac{1}{2}-\frac{3}{4}$ poll. longi, albido-pilosi, sub anthesi horizontaliter patentes, demum arcuato-deflexi, fructiferi cernui. Sepala 5, omnia libera; tria exteriora inter se subæqualia, parva, $1 \frac{1}{2}-2$ lin. longa, obovato-elliptica, obtusiuscula, extus sparse pilosa ; interiora (alæ) multo majora, lætissime roseo-purpurea, oblique lato-obovata vel fere orbicularia, diametro circiter semipollicaria, ima basi abrupte attenuata, glabra, tenuiter venulosa, obiter convexa, petala occultantia. Petala tria, basi inter se et cum staminum vagina concreta; inferius (carina) concavo-galeatum, dorso crista latiuscula intense purpurea profunde bifida auctum, ad verticem leviter emarginatum, ad marginem prope basim utrinque plus minusve profunde sinuatum et pilosum; lateralia quam carina breviora, ovato-oblonga, margine superiore inflexa laxe crispata, ad faciem internam laminæ partis cum vagina staminali connatæ piloso-pubescentia, ad ejusdem partem liberam glabra, verticaliter sursum curvata, apice obtusa vel subtruncata. Staminum vagina basi juxta margines piloso-ciliolata; antheræ oblongo-ovoideæ, obiter compressæ, subtiliter puberulæ vel sæpius omnino glabræ, apice oblique truncato biporosæ (septulo parum efformato vel deliquescente?) uniloculares. Pollinis granula (in una eademque anthera) nunc sphæroidea nunc breviter-ellipsoidea, longitudinaliter costato-striata, sensu directioni costularum contrario et non raro jam intra antheras necdum apertas tubificantia. Ovarium obovatum, vertice circa styli insertionem pilosum; stylus compressus latiusculus, medio dilatatus, paullo supra medium arcuatus, ad apicem plus minusve oblique truncatus vel obscure angulatus, anguste stigmatosus. Capsula obcordata, rigidulo-membranacea, $2 \frac{1}{2}-3$ lineis vix longior, compressa, anguste marginata, ad apicem nunc pilis raris obsita nunc omminu glabra, disco utrinque bigibba. Semina oblongo-obovoidea, circiter $1 \frac{1}{2}$ lin. longa, pilosa, vertice areola depressa notata, caruncula pro seminis mole parva; albumen parcum.

Observatio.-Nomine specifico hujusce stirpis elegantirsimæ ac culturæ dignissimæ virum saluto, doctrina et urbanitate pariter insignem, clar. Bernard. Ant. Gomes, Med. Doctorem, horti scholæ medico-chirurgici Olissiponensis fundatorem, Floræ fossilis Lusitaniæ scrutatorem sedulum, nec non medicum expertissimum, studiorumque meorum fautorem.

\section{Ordo DIPTEROCARPEÆ.}

VAtica Africhna, Welw. n. sp. (Tab. V.) Frutex vel arbor parva; ramulis novellis tomentoso-pubescentibus, raro glabris ; foliis coriaceis, oblongo-ellipticis, obtusis, basi vel obtusis vel anguste rotundatis, nune subcordatis, supra glabrescentibus, subtus ferrugineo vel albo tomentosis; cymis racemiformibus axillaribus folio brevioribus vel 
floribus apices ramulorum versus fasciculatis ; sepalis subliberis ovatis obtusis, petalis oblongo-lanceolatis sepalis triplo longioribus; staminibus indefinitis bi- (vel pluri-) seriatis, filamentis filiformibus, antheris ellipticis ovatisve, connectivo breviter apiculatis; fructu globoso subapiculato, calycis fructiferi lobis inter se subæqualibus patentibus oblanceolatis vel oblongo-obovatis, obtusis acutisve, nervis anastomosantibus prominulis grosse reticulatis.

Habitat in silvis et dumetis arenosis Distr. Huilla, inter 4000 et 5500 ped. altit., inprimis frequens ad basim de "Morro de Lopollo." Floret Octobr. usque ad Januar., Apr. et Maio fructificat.

Stirpis hujusce polymorphæ præcipue duæ in Angola mihi obvenerunt formæ, inter se habitu et magis adhuc foliorum indumento diversæ, junctimque vix commode describendæ, quapropter eas hic seorsim tractandas et characteribus utrique peculiaribus limitandas esse existimavi, ut sequitur.

a. denudans. (Tab. V. fig. 1.) Forma plerumque fruticosa, foliis subtus laxe ferrugineotomentosis pubescentibusve vel glabratis.

Frutex humanæ altitudinis resinosus, paullo supra basim ramosus, rarius arbuscula vix 8-pedalis, habitu Grewia speciem æmulans; rami cylindrici, inferiores et superiores breves, medii elongati, patentes, glabrentes, ramulis novellis et florigeris gracilibus subangulatis tomento laxiusculo pubescentibus vel hine inde furfuraceo tomentellis. Folia alterna, petiolata, chartaceo-coriacea, quoad figuram sat varia, plerumque oblongo-elliptica, ad basim et apicem rotundato-obtusa, nunc ad basim angustatorotundata vel subcordata, ad apicem emarginata, rarius utrinque subangustata fere lanceolata, supra glabrescentia, halitu flavescente virentia, nervis impressis oblique striata, prope basim paullo supra petioli insertionem glandula concava rubra orbiculari vel subelliptica notata, subtus basi ferrugineo-tomentosa vel villoso-pubescentia, aut fere deglabrata æneo-viridia, nervo medio et lateralibus valde prominentibus elevatim costata, inter nervos prominule reticulato-venulosa*; petioli 3-6 lin. longi, cum ramulis articulati, cylindrici, villoso-pubescentes, nunc adultiores glabrentes vel tenuiter verruculosi; lamina $1-2 \frac{1}{2}$ poll. longa, $\frac{1}{2}-1 \frac{1}{3}$ poll. lata, ast plerumque pollice angustior. Stipula petiolares geminæ, linearilanceolatæ acuminatæ, sub folii evolutione caducæ. Inflorescentia cymoso-racemosa, axillaris vel spurie terminalis, pedunculo communi tunc ex penultimi folii axilla infra gemmam apicalem evoluto. Pedunculus, pedicelli, bracteolæe et calyx villoso-pubescentes. Sepala basi breviter coalita, in alabastro linea vix longiora, evidenter imbricata, ovata, obtusa, erecto-subpatula, persistentia, post anthesim sensim aucta. Petala oblongo-lanceolata, sepalis duplo subtriplove longiora, sub anthesi patentia, extus tenuissime velutino-tomentella albida, intus flavicantia glabra, solum medio basin versus pilosula, prompte decidua. Stamina perplura, ultra 50, circa ovarium annulatim seriata, patula ; filamenta gracilia, compressiuscula, plerumque biserialia, albida ; antheræ flavæ, connectivo nunc magis producto et robustiore ovatæ, nune illo breviore subellipticæ, loculis inter se fere semper magnitudine inæqualibus, introrsum dehiscentibus. Ovarium ovoideum, pilosum, tri-, rarissime biloculare, loculis biovulatis ; stylus firmulus, rectus, cylindricus, apicem versus parum attenuatus, stigmate breviter tri-, rarissime bilobo, lobulis teretibus patulis apice subtilissime fimbriatis. Fructus calycis nunc valde aucti fundo insidens, globosus vel ovoideo-globosus, pisi magni mole vel imo paullo major, plus minus pubescens vel subtomentosus, durus, styli basi indurata apiculatus, vix dehiscens, uni-, rarissime bilocularis, mono-, rarissime dispermus ; calycis fructiferi sepala basi breviter coalita in alas subæquales foliiformes

* Facies inferior foliorum, oculis nudis aspecta, tomentosa quidem apparet, et in quibusdam formis revera tomento tenui undique obducta est; sed lente fortiore examinata plerumque solum nervi et venularum acies pilis crispulis plus minus dense obsita inveniuntur, areolæ autem e venularum anastomosi ortæ solummodo pilis raris adspersæ vel plerumque centro omnino glabras sese manifestant, id quod in varietate $\beta$. hypoleuca nunquam observare mihi licuit. 
scariose-rigidulas, oblanceolatas, apice obtusiusculo apiculatas, læte rubentes, obiter pubescentes, $I_{3}^{2}$ poll. longas, 6-8 lin. latas, utrinque elevatim reticulato-venosas expansa. Semina perfecta non visa. Crescit hæe varietas satis frequens in collinis apricis arenosis inter pagum Lopollo et Morro de Lopollo, ad 5000 circiter pedum elevationem; Decembr.-Januar. florentem, Maio demum 1860 fructificantem legi. Exsic. Welw. Iter Angol. no. 1035 .

Observatio.-Stirps, ut videtur, late per Africam austro-tropicam diffusa, a clar. Dre. Kirk (fide spec. herb. Kew.) etiam in Zambesix editioribus (Highlands of Batoca-country, Jul.-Octobr. 1860) lecta.

ß. hypoleuca. (Tab. V. fig. 12.)

Forma arborea, foliis subtus dense albo-tomentosis.

Arbor parva, 12-pedalis et altior, habitu Cratago Arice Linn. non dissimilis, trunco recto, $\frac{1}{2}-1$ ped. prope basin crasso, coma laxissima, depresso-dilatata ; rami patenti-divaricati, crassi, varie curvi, ramulis abbreviatis robustis, apice ad ultimorum foliorum axillas florigeris. Folia quoad figuram iis varietatis præcedentis subsimilia, etiam ad petioli insertionem glandulifera, sed omni sensu triplo majora et crassiora, petiolis $\frac{1}{2}-1$ poll. longis, lamina $2 \frac{1}{2}-5 \frac{1}{2}$ poll. longa, $1 \frac{2}{3}-1 \frac{3}{4}$ poll. lata, apice obtuso sæpius emarginata, basi non raro subcordata; juniora utrinque tomentosa, adultiora supra lete viridia et tenuiter pubescentia, subtus tomento denso albido obtecta. Flores majores, petala villoso-tomentosa. Fructus non observatus. Crescit sporadica et rarior in silvis subumbrosis maxime e Leguminosis constantibus ad altit. 4000-4500 ped., inter Mumpulla et Nene, ubi Octobr. 1859 c. alabastris et Decembri cum flore legi. Exsic. Welw. Iter Angol. no. 1036 [Vatica hypoleuca].

Observatio.-Varietas admodum conspicua, extra Angolæ limites hucusque nondum observata, forsan species propria, sed fructu nondum cognito vix bene limitanda. Ceterum monendum habeo, stirpes perennes generatim, et inprimis arborescentes Floræ Huillensis aliorumque districtuum Angolæ et Benguellæ interiorum, ob silvarum incendia a pastoribus ibidem vagantibus per secula quolibet anno repetita, quoad habitum et variarum partium indumentum maximopere variare, id quod præcipue in variis Syzygii, Parinarii, Anona et Fici speciebus observare licet, quæ in silvis nullo adhuc incendio mutilatis qua arbores proceræ superbiunt, dum eædem species in pascuis proximis post combustionem silvarum enatis (a nobis nomine "dumeta secundaria" indicatis) nonnisi sub formis pygmæis, ceu fruticuli humiles sæpius vix palmares sive pedales, ast densis cæespitibus crescentes, et nihilominus hocce in statu læte florentes atque fructificantes occurrunt.

\section{Ordo STERCULIACEA.}

Trib. 1. Stenculiex, Benth. et Hook. f. Gen. Pl. i. p. 217.

Octolobus, Welw. gen. $n$.

Flores unisexuales. Calyx campanulatus, tubo subcylindrico limbo octofido; lobi coriacei marginibus late membranaceis induplicatis undulato-crispulis. Petala nulla. Staminum columna brevis, cylindrica, androphoro elongato-conico tomentoso imposita; antheræ perplurimæ in discum orbicularem vertice depressum connatæ. Ovarii carpella perplurima, multiseriata, in capitulum globosum gynophoro brevi impositum conferta, capitulo basi verticillo staminum imperfectorum cincto; carpella turgida, libera, elongato-ovoidea, dense tomentosa, unilocularia; stylus subnullus ; stigma sessile obiter bilobum; ovula plurima biseriata. Carpella matura 8-10 distincte stipitata, turgida, obovoidea vel VOL. XXVII. 
clavata, gibba, rostro obliquo terminata, tarde dehiscentia, 1-3-sperma. Semina subglobosa, hilo lato sessilia, testa lævigata, subcoriacea; albumen nullum. Embryo subglobosus; cotyledones crassæ, hemisphæricæ; radicula brevissima, inclusa; plumula pilosa.-Arbor Africæ tropicæ austro-occidentalis, laxe comosa, ramulis robustis. Folia alterna, indivisa, longiuscule petiolata, petiolis apice incrassatis, obovato-lanceolata, obtuse acuminata, obscure sinuata, coriacea, glaberrima. Stipula geminæ laterales caducæ. Flores magni ad ramulos sessiles, subsolitarii, fulvo-villosi. Genus antheris uniseriatim annulatis, albuminis defectu et ovarii loculis pluriovulatis Cola, Schott, proximum et affine, sed calyce constanter 8-fido, coriaceo, carpellorumque numero indefinito sine negotio distinguendum. Species unica.

Oc'rolobus spectabilis, Welw. sp. n. (Tab. VI.)

Habitat sporadica in silvaticis rupestribus Distr. Pungo Andongo, præsertim prope Præsidium loco dicto "Barranco da Pedra Songue” Jan. 1857 cum flore, Apr. c. fr. legi. Exsic. It. Angol. no. 1202.

Arbor 15-20-pedalis, rarius altior, trunco recto, gracili, basi 1-2 ped. circumferentiæ, cortice albidogriseo leviter rugoso, coma laxa sursum dilatata vertice depressa. Rami vagi, elongati, erectopatentes, longe denudati, albicantes, apicem versus parce ramulosi, ramulis patulis, cylindricis, pennæ anserinæ vel hinc olorinæ crassitudine, novellis et junioribus angulato-sulcatis villoque fulvescente mollissimo demum deciduo vestitis, adultis glabris, longitudinaliter rugulosis, albescentibus. Folia alterna, versus apicem ramulorum congesta, integra, petiolata, obovato-lanceolata, coriacea, supra late, subtus pallide viridia, juventute bistipulata; petiolus $\frac{1}{2}-2 \frac{1}{2}$-pollicaris, angulatus, junior laxe villosus demum glabratus, basi tumescens, subcanaliculatus, apice abrupte calloso-incrassatus, callo subcylindrico 2-3 lin. longo transverse ruguloso, subviscido, modice arcuato ad basim laminæ termi-

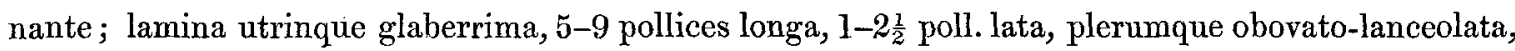
nunc, præsertim in ramulorum extremis, lanceolata, basi sensim attenuata, ad insertionem subtruncata, apice obliquo obtusiuscule acuminata, margine integro vel hinc inde obscure sinuato, penninervia, nervo medio basi valido ad apicem usque producto, lateralibus multo tenuioribus in utraque pagina sed subtus argutius prominentibus, versus marginem evanescentibus. Stipula geminæ, juxta basin petiolorum laterales, liberæ, anguste lineari-lanceolatæ, subulato-acuminatæ, erectæ, rigidulæ, 2-3 lineas longæ, ad ramulorum novellorum apices comoso-gregatæ, caducissimæ. Flores unisexuales, monoici, apetali, sat magni, imo totius tribus maximi, ad ramulos infra foliorum comam apicalem sessiles vel breviter pedunculati, solitarii, vel rarissime 2-3 gregati, bracteis pluribus brevibus, scariosis, late ovatis, extus tomentellis, intus nudis, striatis, demum deciduis, quodammodo calyculati. Alabastra globosa vel obovoidea. Calyx turbinato-campanulatus, sesquipollicem longus, carnoso-coriaceus, extus undique villoso-tomentosus, villo fulvo-cinnamomeo, post fecundationem deciduus; tubus cylindricus sursum quidquam dilatatus, diametro semipollicari, jntus plurisulcatus et papillis minimis cinnamomeo-aurantiacis plus minus dense obsitus; limbi octofidi, rstivatione induplicato-valvati ; laciniæ lanceolatæ, $\frac{3}{4}$ pollic. longæ, erecto-patulæ, margine circumcirca membrana latiuscula, tenuiter carnosa, fragili, induplicata, undulato-crispula cinctæ, facie interna papillis tenuibus brevissimis cinnamomeis densissime gregatis velutino-tomentosæ. Androphorum anguste conicum, dense tomentellum, una cum staminum columna brevi glaberrima et antherarum disco circiter calycis tubo æquilongum ; antheræ numerosæ (25 et plures), rectæ, biloculares, arcte inter se in discum vertice truncatum connatæ, singulæ fere lineam longæ, cinnamomeæ. Gynecii circumscriptione obovoidei carpella perplurima (60-80) pluriseriatim dense congesta, ascendentia, inter se libera, oblique elongato-ovoidea, dense canescentia, unilocularia, biseriatim pluriovulata, ovulis horizontalibus; stigma ad carpellorum apicem oblique sessile, turgidum, obtusum, plus minusve evidenter bilobum, atropurpureum, dense papillosum. Staminum imperfectorum basim gynophori annuli ad instar cingentium antheræ liberæ, plus minusve arcuatæ, dorso connectivo crasso sursum curvato adnatæ, illis androphori plerumque breviores, vel varie defiguratæ, omnino steriles. Carpella matura 6-10, rarius plura, 
distincta, stipite 2-4 lin. longo, cylindrico vel subcompresso villoso suffulta, magnitudine et figura inter se inæqualia, obovoidea vel clavata, lateribus subcompressa, ceteroquin turgida, $1 \frac{1}{4}-1 \frac{2}{3}$ poll. longa, coriacea, oblique vel recurvato-rostrata, extus tomentosa e viridi flavicantia, interna facie plicato-rugulosa denseque resinoso-punctata, unilocularia, 2- rarius 3-4-sperma, tarde dehiscentia. Semina subglobosa vel obovoidea pisi maximi mole et majora, hilo latissimo orbiculato vel ellipsoideo sessilia; testa subcoriacea, lævigata, atra vel atropurpurea, nitida, strato interiori tenaci reticulatim fibroso. Embryo exalbuminosus, semini conformis, rectus; cotyledones crassæ, hemisphæricæ, radiculam brevissimam obtuse conicam, plumula pilosa superatam, arcte includentes.

Observatio.-Gynæcii structura et configuratio generis præsentis notabilem cum illa quarumdam Anonacearum offert similitudinem, etiamsi vera affinitas has inter et Sterculiaceas, in systemate sub cohorte longius distante militantes, vix, ac ne vix quidem invenienda.

\section{Ordo ZYGOPHYLLE 2 .}

\section{Zygophyllum. Sectio A. Fabago.}

Subsectio a. Simplicifolia.

Zygophyllum orbiculatum, Welw. n. sp. Glabrum, glaucum, fruticulosum, caulibus obliquis vel ascendentibus vix sesquipedalibus, crassis, succulentis, rigidis, cylindricis, subflexuosis, ramis patulis, articulatis, ad nodos leviter incrassatis, foliis planis crassissimis, flabellato-orbiculatis vel summis obovato-spathulatis, bene adultis $2-2 \frac{1}{2}$ pollices latis, glaucis, glaberrimis, margine rotundato integris, basi in petiolum brevem cuneato-angustatis, internodiis longioribus, stipulis carnosis ovatis obtusis 3-4 lin. longis, pedunculis geminis (vel ternis!) $\mathbf{3 - 5}$ lin. longis, fructiferis pollicaribus, floribus pentameris, calycis tarde decidui carnosuli laciniis obtusis, petalis albis longe unguiculatis, calyce duplo longioribus, stamina superantibus, squamis quam filamenta paullo brevioribus, subliberis, albido-membranaceis, apice fimbriatis ; ovario clavato, obtuse 5-gono, stylo staminum longitudine; fructu majusculo late pentaptero, depresse obovoideo, vertice parum emarginato stylo apiculato (axi 9- diametro 7-8-lineari, alis semiobovatis elevatim reticulatis), loculicide 5-valvi, loculis endocarpio solubili 1-2-spermis, seminibus dense foveolatis, raphe ex parte libera.

Habitat frequentissimum in sabulosis et petrosis maritimis Distr. Mossamedes, ex Giraul usque Cabo negro, sæpius in Zygophylli simplicis, Sesuviorum et Vogelia Africance consortio. Maio-Julio flor., mox et usque ad Sept. fructificat. Exsic. Welw. Iter Angol. no. 1637.

Fruticulus dumosus, rigidissimus, 1-2-pedalis, succulentus, quibusdam Sccevola vel Crassule speciebus habitu non absimilis, plagæ maritimæ sabulosæ vel rupestris decus triste. Caules pennæ olorinæ vel hinc inde digiti minimi crassitudine, plerumque tortuosi, lignescentes epidermide tenui flavofuscescente facile secedente tecti, nunc opposite nunc dichotome ramosi. Internodia circiter pollicaria. Folia simplicia (anne ceu phyllodia consideranda ?), inferiora et adultiora, petiolo brevi cuneato excepto, fere orbiculata, diametro non raro bipollicari et majore (lamina $\frac{1}{4}$ poll. crassa, succoso-carnosa, in viva planta, more phyllodiorum Acaciarum verticaliter sita), ea ramulorum novellorum flabellatospathulata, nervis $3-5$, solum in folio exsiccato prominentibus percursa et minus glauca; pedunculi 2 vel 3 (rarius sed quondam certe plures ad 5) ex eadem stipularum axilla erecti, fructiferi elongati et patentes. Calycis herbaceo-viridis laciniæ carnoso-tumidulæ, obovato-oblongæ, obtusæ, concaviusculæ, post anthesin reflexæ. Petala flabellata, ungue longo, lateribus integra, apice rotundato 
denticulata, nervis purpurascentibus flabellatim partitis percursa, una cum ungue $3 \frac{1}{2}-4$ lin. longa. Squamce circiter $\frac{2}{3}$ longitudinis filamentorum, filamenta quasi vaginantes. Ovarium in disco leviter concavo sessile 5-loculare, ovula in loculis 4 vel 5 . Fructus plene maturus scariosus, plerumque calyce reflexo suffultus, circumscriptione obovoideus, basi truncatus, vertice quidquam depresso sive emarginato styloque indurato $1-1 \frac{1}{2}$ lin. longo superatus, ad axim usque pentapterus ; alæ compressæ, nervo hinc inde evanescente marginatæ, demum ab axi centrali solubiles; loculorum endocarpium solubile, tenuiter pergameum, nitidulum. Semina in loculis 1 vel 2, obovato-subreniformia, lenticulari-compressa, marginata, $2-2 \frac{1}{2}$ lin. longa, testa brunnea foveolis alveoliformibus dense obsita.

\section{Ordo BURSERACE $A$.}

Trib. I. Burserea, Benth. et Hook. f. Gen. Pl. v. i. p. 321.

Patvaeusa, Welw. gen. nov.

Flores unisexuales, axillares, apetali ; masculi subsessiles, plures in capitula involucrata breve pedunculata dense congesti ; feminei solitarii vel foliorum abortu subfasciculati, breviter pedunculati.

Flores masculr. Caly $x$ subobliquus, profunde 6-8-fidus, laciniis obtusis, erectis, sæpius inæqualibus, æstivatione imbricatis. Stamina 6-8 fundo calycis circa discum crenatum inserta, exserta; filamenta filiformia glabra; antheræ breves, erectæ, biloculares, loculis basi subliberis lateraliter dehiscentibus. Ovarii rudimentum obsoletum.

FLor. FEM. Caly $x$ maris, sed amplior et basi ad latus externum tribracteolatus. Ovarium ovoideum in stylum attenuatum, basi squamulis 6-7 brevibus minutis ciliatis non raro in discum confluentibus cinctum, biloculare; stylus brevis ; stigmata duo reniformia ; ovula in loculis gemina prope apicem loculi septo inserta, pendula. Fructus (immaturus) pedunculo elongato tribracteolato et calyce persistente stipatus, ovoideus, longitudinaliter bicostulatus, stigmatibus persistentibus terminatus, tomentosus ; epicarpium coriaceum bivalve; putamen chartaceum incomplete biloculare, pyrenibus 1-2 in quoque loculo; pyrenes ossei, compressi, membrana carnosulo-mucosa obducti, ex apice columellæ centralis funiculo crasso penduli, liberi, monospermi. Semen loculo conforme, inversum, compressiusculum, testa membranacea, endopleura solubili. Albumen 0. Cotyledones rectæ, planæ, late obcordatæ, ad radiculæ insertionem emarginatæ, tenuiter membranaceæ, virides; radicula brevis, recta, cylindricoconoidea, obtusiuscula, supera.

Arbor parva Africæ austro-tropicalis, coma laxa ramulis crassis tuberculato-cicatrisatis, cinerascentibus, gemmis novellis rufo-tomentosis. Folia ad apices ramulorum patentia, longe petiolata, digitato 5-foliolata, foliolis subsessilibus lanceolato- vel obovato-oblongis obtusiusculis integerrimis cum petiolo articulatis, coriaceis, subtus tomentosis. Flores parvi, inconspicui ; feminei subsolitarii, masculi numerosi cymoso-fasciculati, cymis in capitula densa bracteis involucrata contractis.

Genus insigne sed valde anomalum, Burseraceis quidem absque fere dubio adnumerandum, ast nulli ex generibus cognitis arcte affine, imo ab omnibus hucusque descriptis floribus apetalis, cotyledonibus omnino planis foliisque digitatim 5-foliolatis longius distans, et probabiliter novæ inter tribum Burseracearum sectionis typus. Calyx 6-8fidus una cum staminibus 6-8 prope marginem disci insertis et inæqualibus necnon pyrenes liberi aliquam cum genere Protium affinitatem indigitant; petalorum defectus forsitan ex cymularum perplurium arcta condensatione florumque singulorum mutua pressione explicandus.

Dicatum est genus hocce clarissimo domino Barão do Castello de Paiva, botanices in Academia Portensi Professori, Faunæ malacologicæ Maderensis etc. fortunato exploratori. 
Species unica :-

Paivaeusa dactylophylla, Welw. (Tab. VII.)

Habitat in silvis parum densis siccioribus Districtus Huilla, ad 5000 ped. circiter altitud., inprimis inter pagum Lopollo et flumen Monino, ubi specimina c. flore et alia cum fructu immaturo legi Februario 1860. Exsic. Welw. Iter Angol. no. 452.

Arbuscula 8-15-pedalis, aspectu Viticis speciem quodammodo referens, trunco recto $\frac{1}{3}-\frac{1}{2}$ ped. diametri, cortice aspero late rimoso, cinerascente vel fere nigrescente, coma laxiuscula sursum dilatata; rami patuli arcuato-ascendentes, crassi, rigidissimi, fere cinerei, undique foliorum delapsorum cicatricibus in tubercula aspera elevatis obsiti, sæpius varie curvi vel tortuosi, parce ramellosi, ramellis crassiusculis abbreviatis, novellis fulvo-sericeis vel rufo-tomentosis, apicem versus foliiferis. Folia patentia, alterna, longe petiolata digitato-5- rarius 3- rarissime 7 -foliolata, paullo ante florescentiæe periodum decidua; petioli 2-3 pollices longi,rigidi, subteretes, molliter sericeo-tomentosi, basi tumescente cum ramulo articulati, apice subcompresso-dilatati ; foliola penninervia, obovato-oblonga, nunc fere lanceolata vel lineari-oblonga, apice obtusa vel rarius breviter acuminata, basi sensim angustata, subsessilia vel breve petiolulata, cum petiolo communi articulata, supra,inprimis juniora, pube tenui adspersa pallidevirentia, juxta costam mediam densius pubescentia, adulta fere glabra et nitidula, subtus nervo mediano crasso pinnatim venuloso percursa, dense molliter tomentosa, tomento primum ex albido cinereo, demum flavo-fuscescente ; foliola 3 superiora inter se subæqualia, $2 \frac{1}{2}-5$ poll. longa, 1-1 $\frac{2}{3}$ poll. lata, intermedium longius petiolulatum, infima duo reliquis duplo triplove breviora angustioraque et plerumque sessilia vel brevissime petiolulata. Flores dioici, versus apicem ramulorum axillares, nunc foliorum sum-

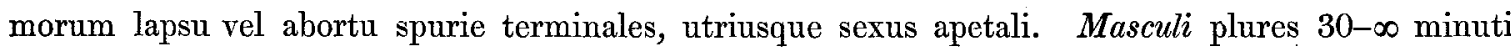
ad pedunculi communis perbrevis crassiusculi cylindrici apicem carnoso-incrassatum [quasi anthodium fingentem] sessiles vel uno alterove brevissime pedicellato, subcymuloso-fasiculati, densissime in capitulum involucratum congesti ; involucrum obliquum 6-8-lobum, lobis ovato-oblongis vel suborbicularibus, florum capitulo fere dimidio brevioribus ipsoque adpressis. Calyx viridescens, sæpius obliquus, plus minusve profunde 6-8-fidus, laciniis erectis, æstivatione imbricatis, lineari-oblongis vel spathulatis, inæquilongis, etiam latitudine inter se non raro variantibus, dorso, inprimis apicem versus, barbulatis, margine ciliolatis, intus nudis. Stamina 6-8 circa basim disci crenulati parum elevati, ob mutuam florum pressionem sat polymorphi inserta, calycis laciniis longiora; filamenta filiformia, compressiuscula, glabra, albida; antheræ erectæ, flamentis multo breviores, paullo supra basim insertæ, flavæ, loculis turgidis, minute glanduloso-punctatis basi subliberis, latere dehiscentibus. Ovarii rudimentum rarissime minimum, plerumque nullum. Flores feminei quam masculi multo ampliores, nunc solitarii, rarius folii unius alteriusve abortu 2-3 fasciculati, subsessiles vel breve pedunculati, rigidi. Calyx maris sed ipso multoties major et crassior, minus profunde et plerumque 6-partitus, dense rufo-tomentosus, intus glaber, basi tribracteolatus, bracteolis calycis laciniis similibus, pariter rufo-tomentosis sed iis multo brevioribus. Squamulæ ovarii basim cingentes sæpius in annulum disciformem confluentes, minutæ, tenuiter ciliatæ. Ovarium ovoideum, æque rufo-tomentosum, calycis limbum erecto-patulum parum superans; stigmata turgida fusco-purpurea. Cetera ex charactere generis.

\section{Ordo MELIACE $Æ$.}

Trib. MeLiex, Hook. et Benth. gen. pl. i. 330.

Naregamia alata, Wight et Arn. $\beta$ Africana, Welw. Forma vel, si mavis, varietas, a specie typica in Wight Icon. Pl. Ind. Orient. i. tab. 90 depicta, et in ejusdem auctoris Prodr. Floræ Penins. Ind. Orient. i. 116, descripta, caulibus et foliis calycibusque hirtulo-pubescentibus nec non calycis lobis latioribus fere deltoideo-ovatis acutiusculis discrepans. 
Habitat in arenoso-humosis subumbrosis juxta margines silvarum pro maxima parte e Macrolobii et Pterocarpi speciebus consistentium Distr. Pungo-Andongo, ad 3100 ped. circiter altit. supra mare, inprimis ad sinistram rivi Lutete. Ineunte Octobr. cum fl. lecta. Exsic. Welw. Iter Angol. no. 1301.

Suffrutex humilis, subcæspitose crescens, totius Meliacearum Ordinis stirps minima, ast floribus pro more permagnis ornata, habitu quodammodo Turrea speciem pygmæam referens; rhizoma repens vel oblique dependens, pennæ corvinæ vel rarius anserinæ crassitudine, dure lignosum, tortuosum, fibris lateralibus tenacibus stipatum, collo pluricipite. Cauliculi $2-3$ vel interdum plures, 1-3 pollices alti, teretes, subsimplices, basi nudiusculi, superne pubescentes, foliis alternis paucis (5-8), superioribus in eorum axillis flores gerentibus vestiti. Foliorum trifoliolatorum petioli 3-6 lin. longi, anguste alati pubescentes; foliola subsessilia obovata, apice rotundato integra vel obiter emarginata, rarius ovato-acuminata, omnia facie utraque pubescentia et margine dense ciliata. Pedunculi axillares petiolis subæquilongi, erecto-patuli, puberuli, sæpius bi- trifori, pedicellis bracteolatis inæquilongis, lateralibus abbreviatis plerumque flores abortientes gerentibus, intermedio longiore, calycem versus quidquam dilatato et flore perfecto terminato. Calyx vix lineam longus, pubescens hirtulusve ; corolla 1-1 poll. longa, splendide alba, parum sed suaviter odora; petala anguste spathulata longe unguiculata apice obtuso concaviuscula, sub prima anthesi conniventia, demum apice patula. $A n$ therce quidem sæpius 5, ast hinc inde etiam 6, et in uno flore imo 7 observavi, earumque appendiculæ fere semper latiores et obtusiores quam in speciminibus Indicis herbarii Kewensis, ab ipso clar. Wight collectis. Ceteroquin stirps Angolensis quoad characteres essentiales et habitum omnino cum specie Indica convenit, novumque Floræ Indiæ Orientalis cum Tropicali-Africana nexus argumentum sistit.

\section{Ordo HAMAMELIDEÆ.}

\section{Mrrothameus, Welw. gen. nov.}

Flores dioici spicati; spicæ amentiformes squamis unifloris.

Flos masc. Perianthium nullum. Stamina 4-8, sæpius 5 ; filamenta brevissima in stipitem brevem basi squamæ insertum concreta; antheræ magnæ, basifixæ, oblongo-quadratæ, loculis adnatis, rimis lateralibus dehiscentibus, connectivo in rostrum subulatum breviter producto. Ovarii rudimenta nulla.

Flos femin. Perianthium nullum. Staminum rudimenta nulla. Ovarium sessile, squama longius, oblongo-ovoideum, obtuse trigonum, tricarpellare, triloculare, apice trilobum, carpellis apice in stylos breves recurvos subspathulatos intus late stigmatosos productis; ovula numerosa, angulo interiori loculorum biseriatim inserta. Capsula coriacea, ovario similis, sed pauco turgidior, carpellorum apice divaricato intus dehiscente, polysperma. Semina minuta, ovoidea, oblique pendula, funiculo brevi, hilo vix conspicuo, testa tenuiter coriacea, raphe tenui ; albumen copiosum carnosum. $E m$ bryo minutus, albumini immersus, oblongus, cotyledonibus brevissimis, radicula brevi crassa.-Fruticulus 1-3-pedalis, rarius frutex 6-7-pedaln, Africæ australis tropicæ et subtropicæ, balsameo-resinosus, rigidus, virgatus, glaberrimus, a basi ramosus, ramis ramulisque strictis oppositis, petiolis stipulisque persistentibus subspinulosis. Folia opposita brevissime petiolata, cum petiolo articulata, coriacea, flabellato-cuneiformia, subacuta, apice crenato-dentata, longitudinaliter plicato-nervosa, in petiolum brevem latiusculum subvaginantem angustata; stipulæ parvæ, subulatæ, in apice vaginæ petioli sitæ. Spica strictæ, cylindraceæ, erectæ, ramulos breves crebros terminantes.

Myrothamnus flabellifolia, Welw. Apont. phytogeogr. Angol. p. 578, nota 8 (1858).

Cliffortia? flabellifolia, Sond. in Harvey et Sond. Fl. Cap. ii. 597 (1862). 
Planta exogena anomala, \&c., Thomson in Append. ad Speke, 'Journ. of the Discovery of the Source of the Nile,' p. 468 (1863). [Clar. Dr. Thomson solum pl. masc. vidit.]

Genus summopere curiosum ast quoad ordinem, cui subscribendum, quidquam dubium, secundum acutissimi Hook. fil. sententiam Hamamelideas inter et Saxifragaceas ambiguans. Hamamelideis tamen affinius videtur. Habitu hine Tetracarpeam Tasmanicam Hook. fil. (Saxifragacea) illine quasdam Myrica vel Cliffortiae species simulat, a quibus tamen florum, inprimis femineorum, et fructus forma longius distat. A Saxifrageis, cum quibus genus nostrum notis non paucis, et præcipue gynæcii structura trimera, ovulorum numero et situ nec non albumine copioso congruit, tamen floribus strictim dioicis, absentia omnis perianthii et disci, staminibus denique basi in stipitem concretis nec liberis et, quod forsan non omnino prætervidendum, succo balsameo-resinoso omnium partium differre videtur. A Rosaceis, quas inter planta nostra Spircearum tribui gynæcii fabrica aliquantulum accedit, nihilominus ob flores dioicos, calycis et corollæ defectum, staminum numero diminuto et albuminis copiosi præsentiam excludenda erit.

Juxta systematis Endlicheriani principia genus Myrothamnus prope Salicineas collocandum esse videtur, quocum ordine floribus unisexualibus, absque ullo perianthio, in amentis ramulos terminantibus dispositis, staminum numero variante et filamentis inferne coalitis, carpellorum stigmatumque dilatatorum structura, eorumque ovulis numerosis, succo denique balsameo, in quibusdam Populi speciebus pariter obvio, et quodammodo etiam habitu et vitæ tenacitate convenit, etiamsi imo hac in vicinitate ob ovarium trimerum, albumen copiosum et folia opposita anomalum genus remanet.

Species unica.

Mrrothameus flabelitfolia, Welw. l.c. t. viii.

Habitat in dumetosis rupestribus editioribus Distr. Pungo Andongo, inprimis in Serra de "Pedras de Guinga" inter 3000 et 4000 ped. altit., nec non in Distr. Huilla ad 5000-5500 ped. altit. loco "Morro de Lopollo" dicto. Decembr. Jan. foret; Apr. Maio fructificat. Exsic. Welw. Iter Angol. no. 1278 et 1279 .

Stirps singularis fruticulum sistit plerumque 1-3-pedalem, sed in editis Distr. Huilla etiam humilem vidi et prostratum, Salicum alpestrium more Lichenum Muscorumque cæspitibus incumbentem; e contrario, expositione et solo magis faventibus semper erectus crescit et altitudinem multo majorem attingit; sic in Distr. Pungo Andongo, ubi in rupibus giganteis "Pedras de Guinga" dictis circa earum summa juga ultimam et fere unicam vegetationem fruticosam offert, frequens ceu frutex 5-7pedalis occurrit, trunco interdum prope basim circumferentia 3-5-pollicari. Cortex cinerascens, longitudinaliter late lamellosus, lamellis tenuibus facile secedentibus. Lignum album, densum, durum, grate aromaticum. Rami inferiores pauci, distantes, medium caulis versus frequentiores et densiores ramulisque crebre ramellosis decussatim oppositis, strictis, virgatis, novellis quadrangulis læte purpurascentibus, adultioribus cylindricis et cinereis, $\frac{1}{2}-1$ pollicem inter se distantibus, ad apicem usque foliosis. Folia 5-7 lineas longa, 3-4 lin. lata, quoad figuram descripta apice plus minusve profunde dentata [dentibus 3-10, sæpius 6, obtusis vel acutiusculis, apice glandula terminatis], tempore humido erecto-patula, flabellatim expansa, utrinque glauco-viridia, durante autem hieme sicco arcte plicata et convoluta, brunneo-nigrescentia, et ramulis strictim adpressa; petioli semiamplectentes, longe decurrentes, superiore parte carinati, apice excepto adnati et internodium vaginantes, adultiorum foliorum lamina delapsa, a ramulis subsoluti et una cum stipulis induratis per 
longius tempus persistunt, demum per lamellas secedunt ramulosque denudant. Spica utriusque sexus amentiformes, in ramellis lateralibus crebris abbreviatis foliosis terminales, strictiusculæ, graciles, $\frac{2}{3}-1$ pollicem longæ, ad $1 \frac{1}{2}-2$ lin. latæ, cylindraceæ, obtusiusculæ, masculæ fere semper omnino rubentes, femineæ virescentes. Squame florigeræ lato-ovatæ, obtusiusculæ, basi subcordatæ, rachin semiamplectentes, per paria oppositæ, concavæ, dorso obiter carinatæ, herbaceo-virides vel leviter rubentes, margine subscariosæ, quoad substantiam subcoriaceæ et rigidulæ, illæ florum masculorum staminibus fere æquilongæ, dum quæ flores femineos stipant, ovario multo breviores. Stamina 4-8, sæpius 5, basi squamæ inserta, sub anthesi ob squamam patulam exserta ; filamenta perbrevia, supra libera, basi in stipitem brevem coalita; antheræ ex aurantiaco rubentes, loculis valde turgidis, post dehiscentiam late hiantibus exsiccato-induratis; pollen intense flavum. Ovarium herbaceo viride; stigmata atropurpurea, dense papillosa. Ovula in quoque carpello 12-16, quorum tamen perpauca plenam maturitatem attingunt, nam sæpius solummodo 2-5 semina in capsula dehiscente inveniuntur. Capsula $1 \frac{1}{2}$ lin. longa, lineam lata, stylis induratis persistentibus tricornis, trivalvis, valvis (carpellis) apice hiantibus, interne juxta suturas omnino solutis, unilocularis, pleiosperma. Semina etc. descripta.

Observatio.-Stirps in vivo admodum elegans et ob aroma gratissimum quod spargit, apud Nigritas Angolenses nomine "Cachinde candange" ceu tonicum validum celebrata, per Africam austro-tropicam, ut videtur, late diffusa, a celeb. peregrinatoribus Speke et Grant etiam ex Africa centrali [ $6^{\circ}$ lat. austr.], sed solum floribus masculis adlata, a clar. Zeyher quoque trans Cancrum, in interioribus territorii Capensis [Magalisberg], ast solum modo sterilis, lecta.

Vis vitalis fruticis hujus ingens est; per anni dimidium enim, nempe a Maio ad Octobrem, imbribus tum omnino deficientibus solis ardore adustus, in statu quasi exsiccato perdurat, foliis nunc arcte convolutis, induratis, ramulo strictim adpressis, nigrescentibus siccisque, imo digitorum tritu facile pulverizandis, fere emortuus adparet, patriæ suæ ardentis tristis imago; ast statim primas post pluvias vernales omnimodo reviviscit, foliorum nunc de novo viridium flabella expandit, sieque læto virore ornatus flores fructusque progignit.

\section{Ordo COMBRETACEE.}

\section{Subordo I. CombRetex.}

\section{CACoucia, Aubl. nec Walp.* [Schousbœa, Willd. nec Schum.]}

Cacodcia Platyptera, Welw. n. sp. C. fruticosa, scandens, hinc arbuscula stans, ramis patentibus, elongatis, arcuatis, ramulisque rigidis cylindricis juventute pubentibus; foliis oppositis v. rarius alternis, coriaceis, glabris, lucidis, breviter petiolatis, oblongis, ovatis v. ovato-lanceolatis, integerrimis apice sensim v. abrupte in cacumen obtusum productis, basi breviter attenuatis, rotundatisve v. subcordatis ; racemis ad ramulos laterales et apices caulis terminalibus, amplis, elongatis, subdensis, undique sericeo-tomentosis, strictis; bracteis flore evoluto plus quam dimidio bre-

* Cacoucia cordifolia, Walp. Rep. ii. p. 68, certe non est Combretacea, sed Euphorbiacea, et probabiliter Alchornece species, a Schum. Descr. of Guin. Plant. ii. p. 223 [edit. separ.] sub nomine "Schousbcea cordifolia" descripta. Beat. Schumacher l.c. expressis verbis affirmat Schousboeam suam a genere homonymo Willdenovii diversam esse, et $a b$ ipso institutam, quoniam Willdenovii Schousboa, lege prioritatis, generi "Cacousia," Aubl., ceu synonymum subscribenda. 
vioribus; tubo calycino obtuse pentagono, limbo intus ad basin disco carnoso cupuliformi margine libero 5-plicato fasciculatimque piloso vestito; fructu membranaceo late 5-alato, circumscriptione, alis inclusis, ellipsoideo-sphærico, diametro sesquipollicari, alis xqualibus, semiorbicularibus, levigatis, chartaceo-rigidulis, transverse striolatis, singulis medio 8-9 lin. latis, margine obscure denticulato- vel crenulatociliatis, nucleo lineari-oblongo, medio tumidulo verticaliter impositis.

Habitat in Districtus Golungo Alto dumetosis altioribus juxta margines silvarum primitivarum, inprimis in Serra de Alto Queta, ad 2000-2300 ped. alt. Floret Aprili, Maio; fructificat Aug., Sept. Exsic. Welw. Iter Angol. no. 1752.

Caulis primarius rectus, cylindricus, cortice e viridi cinerascente sublevigato, ad altitudinem 3-5 ped. nudus, mox inordinate elongato-ramosus, ramis plerumque sursum arcuatis, vetustioribus glabratis e viridi purpurascentibus, ramulis oppositis, novellis pube albido-sericea obtectis. Folia majora una cum petiolo $\frac{1}{4}-\frac{1}{2}$-pollicari basi plerumque plus minusve curvato 5 pollices longa, $2-2 \frac{1}{4}$ poll. lata, perennantia, utraque facie et inprimis supra valde nitentia, intensissime viridia, rigidula, subtus paullo pallidiora, costa valida elevatim semicylindrica percursa, penninervia, reticulatim venosa, non raro in eodem specimine opposita vel alterna, rarius ternatim verticillata. Racemi spicæformes, validi, substricti, elongati, robustiores pedales vel etiam sesquipedales, nunc simplices nunc basi patentim ramosi, subdensi, undique, id est inclusis bracteis, calycibus et dorso petalorum, tomento sericeo, in vivo albido, exsiccatione demum ferrugineo vel fuscescente obducti. Bractece florum inferiorum perfecte evolutorum calycis medium vix attingentes, lanceolatæ, acutatæ, demum deciduæ. Flores speciosi, demtis staminibus longe exsertis pollicares vel paullo longiores, amœenissime roseo-coccinei, breve pedicellati, sub plena anthesi plus minusve patentes, subcarnoso-rigiduli, in racemos ambitu cylindrico-conicos apicem versus densiores dispositi. Tubus calycinus, ovarium obducens, obtuse pentagonus, vix 2 lin. longus, lineam latus, medio tumidulus, supra ovarium abrupte in limbum (demum caducum) tubuloso-campanulatum, modice arcuatum, intus pilosulum dilatatus, ore 5 -fido, lobis deltoideis erecto-subpatulis; discus fundum limbi calycini ovario insidentem vestiens, carnosus, cupuliformis, adnatus, ore libero 5-crenato, crenis plicæformibus obtusis, læte flavis, glandulas fingentibus, apice fasciculatim barbatis. Petala ovata vel ovato-lanceolata, brevissime unguiculata, calycis lobis parum longiora, abrupte acuminata, intense coccinea, carnosula, dorso pube albida, in vivo vix sine lente perceptibili, demum rufescente vestita, planiuscula et recta. Stamina 10, calycis limbo prope medium inserta, longe adnatim decurrentia, alterna altius adnata, omnia longe exserta; filamenta filiformia juxta tubi calycini directionem curva, æstivatione inflexa; antheræ cordato-ovoideæ, dorso ad emarginaturam fixæ, intense flavæ. Ovula plerumque 4, ex apice pendula. Stylus filiformis, staminibus vix brevior, stigmate subtruncato vel rarius tenuissime lobulato. Fructus adolescentes primum lineari-oblongi, dein oblongo-ellipsoidei, una cum alis, illo tempore adhuc brevibus, flaccidis et margine subundulatis carnosuli et ex albido virentes, solummodo versus ulteriorem maturationis periodum formam in diagnosi notatam coloremque roseum et rigiditatem chartaceam acquirunt. Fructus maturi corpus, demtis alis, elongato-ellipsoideum, obtuse pentagonum, utrinque æqualiter attenuatum, membranaceo-fibrosum et subspongiosum. Semen, a me nonnisi in speciminibus siccis examinatum, fructus cavitati pentagonæ conforme, aliquantulum compressum, circiter 9-10 lin. longum, testa membranacea laxiuscula fusca. Embryonis recti cotyledones crassiusculæ, carnosæ, convexo-planæ vel subsemicylindricæ, anguste oblongæ, obtusæ, dorso convexo longitudinaliter paucisulcatæ, interna facie plana levigatæ, apicem versus quidpiam concavæ ibidemque marginibus breviter inflexis semivaginatim conjunctæ. Radicula perbrevis obtuse conica.

Stirps perbella, sempervirens, ob fructus pro more amplos et colore roseo insignitos in statu fructifero non minus quam in florifero decora, inter Combretaceas Angolæ et forsan Africæ totius facile VOL. XXVII. 
formosissima, quodammodo florum Alö̈s arborescentis spicas fulgidas frutici lucide frondoso impositas exhibens; nunc ad arbores vicinas altius scandens, nunc sub forma arbusculæ 6-8-pedalis laxe comosæ in dumetis silvas densas cingentibus hinc una cum Bandeirae speciosa et Dalhousiea bracteata superbiens, illinc in Camoënsia maxime et Eureiandra formosa societate fruticeta adornans et una cum socialibus indicatis Adonistis admodum commendanda.

Observatio.-Species typica hujus generis Tropico-Americana, Caconcia coccinea, Aubl. Plant. Guian. i. p. 450, t. 159, habitu cum nostrate Africana fere omnino convenit, sed præter alias notas inprimis fructu coriaceo pentagono exalato facile a nostrate distinguenda.

Subordo II. Grrocarpex (Benth. \& H. f. Gen. Pl. i. p. 689).

ILLIGERA PENTAPHYLLA, Welw. n. sp. I. caule basi lignescente, obiter angulato, sparse hirtulo, late scandente, ramis patentibus elongatis, junioribus cano tomentellis ; foliis sparsis longe petiolatis, digitatim quinquefoliolatis, foliolis breve petiolulatis, ovatis, oblongo-ellipticis vel ovato-lanceolatis obtuse acuminatis, basi rotundata subemarginatis, margine integerrimis, utrinque glabris, juvenilibus crebre pellucidopunctatis, adultis coriaceis, intense viridibus, subtus pallidis, inter nervos pilis adspersos venis atropurpureis elevatim reticulatis, sub lente dense punctulatis; floribus laxe cymosis, in paniculas axillares et terminales foliis longiores dispositis, pedunculo, cymarum ramulis bracteolisque et calycis tubo dense cano tomentellis; petalis calycis lobos herbaceos subæquantibus sed iis angustioribus et flavescentibus, sub anthesi stellatim patentibus; fructu rigide chartaceo, corpore elongato-ovoideo subcompresso-4-gono, utrinque attenuato, late verticaliter bialato, alis circiter 15 lin. altis et sesquipollicem latis, rotundato-obtusis, planis et dense transversim parallelivenosis.

Habitat in Districtus Golongo Alto editioribus de "Serra do Alto Queta" juxta oras silv. primitivarum, sed sporadica. Nov.-Decbr. florens, Martio-Maio fructificans. Exsic. Welw. It. Angol. no. 1753.

Frutex parum alte lignescens, sempervirens, habitu et crescendi modo varias Cissi vel Vitis species eximie æmulans. Caulis primarius cylindraceus, mox ad 2 vel 4 ped. altitudinis in ramos 6-15 pedes longos divisus. Rami paullo supra foliorum axillas oriundi, late patentes, parum angulati, tenuiter dense sulcati, etiam adultiores hinc inde pilis raris adspersi, petiolorum reflexorum ope vel ipsorum torsione spirali per arborum vicinarum coronas scandentes vel ex iis penduli ; ramuli novelli et inflorescentia tota, calycis limbo petalisque exceptis, tomento plus minusve denso, canescente, exsiccatione demum rufescente obducta. Petioli circiter 2 pollices longi, rigiduli, basi gibboso-incrassati, initio recti, horizontaliter patentes, demum deorsum flexi, medio non raro bis terve spiraliter intorti, apice paullo incrassato in petiolulos quinque circiter 3-5 lineas longos, canaliculatos, juxta excavationem hirtulos, cum petiolo articulatos, fere umbellatim dispositos divisi. Foliola quoad laminæ figuram inter se æqualia (terminale tamen ceteris majus, paullo longius petiolulatum, circiter 3 poll. longum, medio 2 poll. latum), penninervia (nervo mediano costisque utrinque binis tribusve arcuatis inferne prominentibus, apicem versus sensim evanescentibus), supra intensissime lucido-viridia, subtus multo pallidiora, juxta nervos pilis raris rectis rigidulis obsita, margine integerrimo obiter reflexo. Panicule laxæ, pyramidatim thyrsoideæ, terminales, non raro sesquipedales, axillares breviores. Pedunculus communis obtuse angulatus, aphyllus, ramis fere horizontaliter patentibus, ad insertionem tumidis, inferne longius nudis, a medio ad apicem usque ramulis cymuligeris, pluries dichotome partitis, extremis basi bractea elongato-ovali munitis, vestitus. Pedicelli brevissimi cum flore articu- 
lati ibidemque bracteolis tribus ovato-lanceolatis, tubum calycis longitudine vix superantibus, patulis vel recurvatis instructi. Florum sub plena anthesi diameter transversalis circiter semipollicaris vel saltem 5-linearis. Calycis tubus oblongus, rectus, linea una vix longior, obtuse tetragonus, dense canescens, supra ovarium abrupte in limbum subcampanulatum, carnosulum, glabrescentem, herbaceo-viridem, $2 \frac{1}{2}-3$ lin. longum, fere ad basin 5-fidum (in alabastro late ovoideum) dilatatus, laciniis sub anthesi stellatim patentibus. Petala calycis laciniis æquilonga sed iis angustiora, acutiora, tenuiora et pallide flavescentia, basi pilosula. Staminodia ad externam cujusvis filamenti basim gemina, in alabastro late ovata, obtusa, filamentis paulo breviora, in flore expanso angustiora, subspathulata, dorso obiter excavata, filamentis multoties breviora, turgidula, albida. Filamenta filiformia, firma, pubescentia ; antheræ amplæ, adnatæ, oblongo-clavatæ; loculi oppositi connectivo crassiusculo late purpureo apice obtuso separati, valvulis modice convexis, flavis, rigidulis, oblique extrorsum [nec uti in Laurineis sursum] flexis dehiscentes; pollinis granula intense flava, pro more sat magna, sphæroidea et undique tenuissime echinulata. Disci pilosi glandulæ in pluribus floribus obliteratæ, vel saltem mihi non conspicuæ. Ovarium generis. Stylus staminibus vix longior, inferne cylindricus puberulus, apicem versus infundibuliformis, hinc latere fissus, limbo reniformi-dilatato margine incrassato undulatoque stigmatoso. Fructus plene maturus, inclusis alis transversim $3 \frac{1}{4}$ poll. latus, $1 \frac{1}{2}$ poll. altus, subsiccus, rigidus, fusco-badius, corpore [drupa] spongioso-coriaceo, elongatoovoideo, compresse tetragono, angulis facierum brevissime vel vix alatis, lateralibus vero in alas amplas supra descriptas extensis. Semen e cylindrico subcompressum, circiter semipollicem vel 7 lineas longum, testa membranacea. Cotyledones rectæ, crassæ, amygdaloideo-carnosæ, fere semicylindricæ, 5 lin. longæ, interna facie concaviusculæ, evidenter petiolate, radiculam superam, retractam, acutiuscule conicam, plumula sat conspicua coronatam amplectentes.

Observatio.-Omnes sex Illigere species hucusque descriptæ aut indicatæ [De C. Prod. xvi. p. 250] vel Indiæ orientalis peninsulam, vel insulas Java, Sumatra et Timor inhabitant, omnesque a specie supra proposita Tropico-Africana foliis tri-nec quinquefoliolatis sine negotio distinguendæ. In eodem territorio distr. Golungo Alto, sed locis humidioribus magisque umbrosis varietas obvenit, a forma supra descripta foliolis duplo longioribus nec tamen latioribus sed basi evidentius emarginatis discrepans, ceteris autem characteribus omnibus optime cum forma typica conveniens.

\section{Ord. PASSIFLORE}

I. Basananthe (Peyr. in Schlecht. Bot. Zeit. 1859, p. 101, et in Wawra und Peyr. Sert. Benguel. p. 29.)

Charact. Reformatus.-Flores hermaphroditi. Calyx profunde 5-partitus, tubo brevi explanato, limbi laciniis lineari-oblongis, obtusiusculis, campanulatim conniventibus vel patulis. Petala 5, linearia, calycis laciniis subæquilonga, iisque angustiora. Corona membranacea simplex, filamentosa. Gynophorum cupulare, breviter stipitatum, stipite simplici vel annulo carnoso cincto. Stamina 5, basi ovarii inserta, filamentis hypogynis filiformibus; antheræ lineari-oblongæ, sagittatæ, apice obtusæ, connectivo non producto. Ovarium ovoideum, sessile, basi attenuatum; stylus gracilis, mox trifidus, cruribus filiformibus, stigmatibus capitellatis. Ovula 3 placentis totidem inserta. Capsula ovoidea, subcoriacea vel crustacea, 3-valvis, 3-sperma. Semina oblongo-subreniformia, compressa, testa scrobiculata, uno latere tenuiter marginata, arillo nullo, funiculo crasso elongato arcuato.

Herbæ perennes vel suffrutices graciles, in regni Benguellæ littore nec non interioribus editis hucusque observatæ, a basi ramosæ, caulibus ascendentibus vel decumbentibus, undique glaberrimæ. Folia alterna, petiolata, cordata vel lanceolata, serrata. Stipule subulatæ vel filiformes. Cirrhi proprii 
nulli, nisi pedunculorum in caulis parte inferiore frequenter abortientium cruribus, apice obtuso glanduliferis, bracteolisque setiformibus induratis et varie incurvis instructis, repræsentati. Flores axillares pedunculati, in pedunculo bifurco gemini vel rarius solitarii, albidi, suberecti vel nutantes, pedicellis 3-bracteolatis. Fructus penduli. Genus floribus hermaphroditis et corona filamentosa Eu-Passifloreis, placentis autem pauciovulatis et habitu, quodammodo Tryphostemati, Harv., simili, Modeccarum Tribui accedens, inter ambos, uti optime monuit clar. generis auctor, intermedium. Duæ hucusque mihi cognitæ species: typica nempe, ob characteris specifici expositionem huc inserenda, et altera nova, mox infra exponenda.

1. Basananthe litorauts, Peyr. Sert. Beng. p. 30. Suffruticosa, 1-2-pedalis, a basi ramosa, ramis virgatis arcuato-ascendentibus, simplicibus vel medio patenti-ramulosis, foliis membranaceis, petiolatis, lanceolatis, basi in petiolo utrinque papillis elongatis fimbriato decurrentibus, apice mucronatis, margine acute serratis; pedunculis bi-, rarius unifloris, erecto-patulis; pedicellorum bracteolis verticillatis, calycis laciniis petalisque sub anthesi stellatim expansis. Descript. uberior apud Peyr. l.c.

Habitat in arenosis maritimis breve dumetosis inter urbem Benguella et flumen Catumbella, præcipue ad dextram rivi Maribondo, ubi Junio 1860 floriferam et fructiferam legi. In eodem fere loco a cl. Wawra mense Januario c. flore et fr. lecta fuit. Exsic. Welw. Iter Angol. no. 872.

Observatio.-Specimen typicum hujus speciei examinare non mihi licuit, ast mea specimina cum descriptione auctoris optime congruunt, notis solummodo minoris momenti, ex. gr. petiolorum fimbriis etc. discrepantia.

2. Basananthe nummularia, Welw. n. sp. (Tab. IX.) Herbacea, basi suffruticulosa, vix palmaris, caulibus cæspitosis decumbentibus crebre ramulosis, ramulis ascendentibus foliosis, foliis chartaceo-rigidulis, breve petiolatis, cordato-suborbiculatis, basi in petiolo canaliculato breviter decurrentibus, apice rotundatis rel emarginatis, margine undique dentato-serratis, pedunculis arcuatim deflexis uni-, rarius bifloris, bracteolis pedicellorum subalternis, calycibus petalisque sub anthesi campanulatim conniventibus.

Habitat in pascuis breve herbidis, subarenosis District. Huilla, non procul a Lopollo, inter 5000 et 5500 ped. alt.; mensibus Januar. et Febr. c. flore et fructu legi. Exsic. Welw. Iter Angol. no. 871.

Herba perennis cæspitosa, vix palmaris, glaberrima, e glauco virescens. Radix carnoso-fibrosa, digitum fere crassa, cylindrica vel subfusiformis, multiceps, plerumque oblique descendens, infra in fibras paucas elongatas, terram profunde penetrantes partita. Caules numerosi, basi nudiusculi, angulati, decumbentes, mox in ramos graciles 3-5 pollices longos, ascendentes vel erectos, subflexuosos, obiter angulatos, dense foliosos divisi, cæspites non raro semipedalis diametri et latiores formantes. Folia alterna, approximata, petiolis $1 \frac{1}{2}-2 \frac{1}{2}$ lin. longis suffulta, utrinque glaucescentia, carnosula, rigidescentia, cordato-orbicularia vel subreniformia ; lamina semipollice paullo latior, apice plus minus emarginata vel rotundata, basi in petiolo canaliculato breviter decurrens, circumcirca inæqualiter dentato-serrata, dentibus nunc acutis nunc obtusioribus, omnibus mucronulatis, nervo medio et lateralibus divergentibus subtus magis prominulis. Stipulæ geminæ, filiformes, gracillimæ, petiolo æquilongæ vel ipso paulo breviores, erecto-patulæ, longius persistentes. Pedunculi axillares $2-4$ lin. longi, plerumque bifurci, inferiores fere semper abortientes, cruribus tunc in apice truncato glandulifero bracteolis subuliformibus varie flexis coronatis; superiores, crure uno sæpius abortiente, plerumque uni-, rarius biflori, nutantes, pedicellis basi articulatis et tribracteolatis, bracteolis subulatis, 
alternis vel sæpius approximatis, patulis. Calycis herbaceo-viridis tubus brevissimus ima basi gibberosus; laciniæ lanceolato-oblongæ, obtusæ, sub anthesi campanulatim conniventes, 2-21 lin. longæ, dorso nervis tenuibus parallelis percursæ, intus e viridi flavescentes. Petala lineari-oblonga, calycis laciniis paulo breviora iisque dimidio angustiora, albida, tenerrima, una cum calyce (in fructu) marcescenti-persistentia. Coronæ tenuiter membranaceæ tubus filis biserialibus, iis seriei internæ basi deorsum appendiculatis, dimidio brevior. Gynophori cupularis stipes brevissimus, crassiusculus et simplex. Stamina petalis subbreviora; antheræ lineari-oblongæ, basi sagittatæ, lobis obtusis, in filamentis subulatis erectæ, apice obtusæ vel leviter emarginatæ. Ovarium basi attenuata subsessile. Ovula 3, e funiculis longiusculis, medio placentarum trium insertis, demum ascendentibus pendula. Stylus staminibus altior, profunde trifidus, cruribus æequilongis erecto-patulis, apice capitellatim stigmatosis. Capsula ellipsoidea, basi calyce emarcido cincta, pendula, $3 \frac{1}{2}-4 \frac{1}{2}$ lin. longa, crustacea, levigata, e badio flavescens, 3-2-sperma. Semina pro more capsulæ et totius plantæ sat magna, oblongo-subreniformia, compressa, funiculo crasso arcuato suspensa, testa fusca seriatim scrobiculata, latere convexiore membranaceo-marginata.

Observatio.-Basananthe litoralis habitu Sauvagesiam erectam simulat, dum Basananthe nummularia habitum Viole æmulat, adeoque genus hoc affinitatem inter Passifloreas et Violarieas, ab Endlichero aliisque auctoribus, inprimis ex fructus structura indicatam, etiam habitu ambarum specierum indigitat.

\section{Machadoa, Welw. gen. nov.}

Flores hermaphroditi. Calycis tubus infundifuliformi-campanulatus, limbi 5-lobi lobis coriaceis obtusis, patentibus, imbricatis. Petala 5, basi calycis inserta et eo inclusa, ligulata, apice dentata. Stamina 5, hypogyna, filamentis filiformi-subulatis, basi breviter connatis, processibus totidem alterna ; antheræ lineares, connectivo subulato breviter producto. Ovarium breviter stipitatum, oblongum; stylus brevis, integer, stigmate capitato, trilobo; ovula $\infty$ placentis tribus biseriatim inserta. Capsula longius stipitata, e calyce erecto pendula, obovoideo-oblonga, obscure trisulcata, polysperma. Semina ovoideo-oblonga, compressa, testa scrobiculata; embryo non visus.

Herba glaberrima, radice crassa fusiformi, caule tereti, erecto, brevi, parce ramoso. Folia anguste linearilanceolata, utrinque angustata, integerrima. Stipule parvæ, subulatæ, petiolo adnatæ. Cirrhi nulli. Flores inter minores, in racemos breves axillares pauciflores dispositi, pedunculis bracteatis, bracteis subulatis, pedicellis articulatis.

Genus Modecca absque dubio affine, attamen ab ipsa inprimis floribus hermaphroditis, styli indivisi stigmate capitato, glandularum demum coronæ vices gerentium absentia et habitu alieno differt. Dicatum est memoriæe beati Joach. Januarii de Saldanha Machado, de horticultura inter Olisiponenses optime meriti.

Species unica :-

Machadoa Hulluensis, Welw. (Tab. X.)

Habitat in collinis breve dumetosis atque petrosis subsiccis territorii de Huilla, ad 5000 ped. circiter altitudinis, non procul a Lopollo, ubi socialem cum variis Daphnoideis et Irideis Decbr. 1859, c. flore et fructu necdum bene maturo legi. Exsic. Welw. Iter Angol. no. 865.

Herba perennis, erecta, omnino glabra. Radix crasse fusiformis, intus dense farcta, sublignosa, inferne fibris paucis simplicibus elongatis stipata, perpendiculariter terram penetrans. Caules e colo radicis pauci, 1-3, recti, palmares vel pedales, penna corvina paulo crassiores, obiter sulcati, e livido virescentes, vix ramosi, juniores jam a basi, fructiferi solummodo apicem versus foliati. Folia alterna, remotiuscula, tenuiter carnosa, rigidula, e livido glaucescentia, integerrima, elongato-linearilanceolata, 4-5 pollices longa, medio ad duas lineas lata, apice longe acutata, basim versus in petio- 
lum brevem angustata, secundum nervum medium parum prominentem longitudinaliter plicata, subtus inter nervum et marginem transverse venulosa, patula, hinc subfalcata. Stipule breves subulatæ, petiolo utrinque adnatæ. Flores axillares, in racemo breviusculo depauperato erecti, $3 \frac{1}{2}$ lin. longi, breviter pedunculati, pedunculis cum pedicellis vix lineam longis, articulatis. Calycis extus e flavo rubescentis modice carnosi et subcoriacei lobi oblongi, obtusi, margine membranaceo cincti, duo interiores magis concavi et margine crispuli, sub anthesi erecto-patuli. Corone sive glandularum in fundo calycis vestigium nullum. Petala ligulata, apice denticulata, albida, tenerrima, calycis lobis alterna iisque multo breviora. Stamina petalis paulo breviora; filamenta erecta, subulata, basi in annulum brevissimum connata, cum denticulis singulis, quam filamenta ipsa dimidio brevioribus, alternantia. Anthere lineares, basi obiter cordatæ, sinu fixæ et erectæ, apice connectivo subuliformi superatæ. Ovarium et stylus generis. Capsula e calyce erecto marcescenti-permanente pendula, pro more plantæe sat magna, obovato-ellipsoidea, ultra pollicem longa et plus quam semipollicem lata, coriacea, flavicans, levigata, trisulcata, sulcis cum costis tribus parum prominulis alternantibus, apice obtuso styli residuo apiculata, polysperma. Semina ovoideooblonga, modice compressa, uno latere marginata, testa fuscescente, seriatim scrobiculata, perfecte matura non visa.

Observatio.-Habitum omnino erectum plantæ nostræ, inter Passifloreas rarius obvium, quod attinet, hoc loco observare liceat quod, saltem in Africa tropica, plures plantarum ordines, qui in regionum inferiorum silvis umbrosis humidisque e speciebus fere semper scandentibus componuntur, in regionibus elevatis et in apricis solo macro, arenoso-petroso donatis, speciebus vel harum varietatibus habitu erecto insignibus repræsentantur. Síc, exempli gratia, Ampelidee, quarum species numerosæ in silvis primitivis Districtus Golungo Alto et vicinis omnes scandentes sunt, in regione Huillensi, ad 6000 fere ped. supra mare elevata, plures species caule omnino erecto vix unquam scandente offerunt. Idem inter Cucurbitaceas de generibus Heterosicyos et Acanthosicyos, mox infra describendis valet, nec non de Gloriosa abyssinica, qux, in editioribus Districtuum Pungo Andongo et Huilla non rara, tantum non Gloriose superba, Linn., formam vel, si mavis, varietatem erectam sistit; Clematides etiam, quæ in regionibus inferioribus et silvaticis humidis omnes scandunt, in Districtibus elevatis speciebus erectis repræsentantur, et pariter Dilleniacearum genus Tetracera in Angolæ inferioris silvaticis species sat late scandentes, in regione autem elevata interiore, speciem humilem, caule erecto vel ascendente insignem offert.

\section{Ord. CUCURBITACEE.}

\section{Subordo CUCURBITEe.}

\section{Acanthosicyos, Welw. gen. nov.}

Flores dioici? Masculi solitarii vel fasciculati. Calycis tubus turbinatus, limbi quinquefidi lobi breves, crasse coriacei, sæpe inæquales, late ovati vel suborbiculares, apice cornei vel ungue corneo terminati. Petala quinque, coriacea, sulcata, obtusiuscula, ima basi cohærentia. Stamina tria, calycis fauci inserta ; filamenta brevia, libera ; antheræ exsertæ, unica unilocularis, ceteræ biloculares, connectivo dilatato, sinuato, loculis sigmoideo-flexuosis. Ovarii rudimentum nullum. Flores feminei ignoti. Fructus globosus, corticatus, polyspermus. Semina breviter oblonga, tumida, testa crustacea levi. Frutex Africæ tropicæ et subtropicæ occidentalis, erectus vel ascendens, rigidus, a basi ramosissimus, foliis ad squamas reductis aphyllus, Ulicem vel Salsolam quodammodo referens, ramis ramulisque divaricatis, sulcatis, spinis geminis (? stipulis in spinas abortientibus) horridus. Flores 
tomentosi, in axillis foliorum squamiformium inter spinas subglomerati, mediocres, inexpansi tantum visi. Fructus diametri Aurantii vel majores, edules.

Species unica :-

Acanthosicyos horrida, Welw. n. sp. Tab. XI. A et B.

Habitat in desertis sabulosis maxime aridis ad austrum territorii Mossamedensis prope Cabo negro (16 L. a.) ubi, inter "Porto Pinda" et Pagum Nigritarum "Caroca" dictum, ad 10-15 mill. distantiam ab oceano, Septembre 1859 frequentem ast parce florentem vidi. Similibus locis hæc eadem stirps in terris Numacensibus (Namaqua Land) et in interioribus de Whalfish Bay a cel. peregrinatoribus Anderson, Baines, et Chapman, observata fuit. Exsic. Iter Angol. no. 806.

Plantæ juvenilis, nunc in horto Kewensi cultæ, cauliculus palmaris est, simplex et rectus, sed jam hac ætate spinularum paribus, squamula parva suffultis, pollicem circiter inter se distantibus obsitus, dum basi adhuc foliis cotyledonariis spathulatis, crassiusculis, margine integerrimo leviter revolutis, pollice paulo longioribus onustus. Planta adulta, qualis in loco natali a me observata, plerumque 2-3-pedalis, caule erecto vel ascendente, sed hinc inde etiam 5-pedalis et altior evadit; dum nempe individua plura agmine densiore crescentia, ventorum vehementia arena volatili obteguntur, nihilominus vegetationem continuant, ramulis extimis suis stratum sabulosum perforant, statimque ramificant et cæspites plus minus densos et extensos efformant, qui demum, arenæ accumulatione sæpius repetita monticulos arenosos sistunt, 5-7 ped. altitudinis et 15-30 ped. circumferentiæ, undique ramulis spinosis matricis sepultæ horridos. Sed hoc de vivendi modo plantæ singularis dictum sit. Caulis patentim ramosissimus, tenacissimus, cylindricus, pennæ olorinæ crassitudine, profunde plurisulcatus, ceteroquin levigatus, pallide virescens, hinc inde flexuosus, succo viscido resinoso scatens, qui circa ramorum basin exsudans ibidemque inspissatus, gummi elastici speciem æmulat, colore tamen intense aurantiaco insignis. Rami et ramuli alterni, subvirgati, extimi pubescentes. Folia squamiformia, cauli adpressa, crustacea, ovata, vix lineam longa, apice cornea, plerumque cito decidua, in eorum axilla ramos emittunt, ad basim utrinque spina recta, subulata, sulcata, apice cornea, semipollicem longa, rigida et patente (stipularum vel cirrhorum vices gerente?) suffultos. Ramuli floriferi 2-5 pollices longi, erecto-patuli, tomento laxo undique obducti. Flores in axillis foliorum sæpe abortientium inter spinas geminas subsessiles, singuli vel plerumque glomerato-fasciculati, extus cano tomentosi, nobis solummodo in alabastris visi, quoad magnitudinem pro more ordinis mediocres. Calycis crasso-coriacei tomentosi lobi sæpius inæquales, duo vel tres eorum ovati, ceteris vel suborbiculatis apice obtuso cartilagineo-marginatis, vel obcordatis cum unguiculo corneo emarginaturæ inserto ; rarius omnes 5 inter se inæquales, et tum a lata basi ovatoacuminati, vel apice obtuso corneo-unguiculati. Corolla lutescentis petala basi (in alabastro saltem) subcoalita, late ovata, obtusiuscula, extus tomentella, intus levigata et obscure striata. Staminum filamenta carnosa, flabelliformia, ad basim internam pilis tenuibus hyalinis articulatis barbulata; antheræ descriptæ. Fructus* (pepo) globosus, aurantiacus, quoad magnitudinem secundum soli et expositionis diversitatem inter pomi Aurantiæ et ovi Struthionis molem varians, vertice depressiusculo calycis rudimentis apiculatus, cortice crustaceo 1 lineam circiter crasso, levigato sed verrucis distantibus hemisphæricis, in centro aculeo recto breviter conico acutiusculo armatis obsito, demum irregulariter rumpente, pulpa aurantiaca grate acidula, semina numerosa involvente, farctus. Semina latiuscule oblonga vel subellipsoidea, 6-7 lineas longa, 4-5 lineas lata, ex albido pallide flavescentia, faciebus turgida, circiter $2 \frac{1}{2}-3$ lin. crassa, basi suboblique truncata, margine obtuso, solum basim versus magis prominulo cincta ; testa levigata, suberose crustacea; endopleura tenuissima, albescens,

* Tab. XI. B. Fructus maturus exsiccatus, una cum seminibus et pulpæ fragmentis nuper ab ill. peregrinatore Alfred B. Wollaston ex Namaqua Land adlatus fuit, et a clar. Frid. Currey, F.R.S., Secr. Linn. Soc., mecum benevole communicatus. 
diaphana, demum a testa solubilis. Cotyledones semini conformes, oleoso-pingues, facie externa tumidulæ levigatæ, interna subplanæ ast sulcis 3-5 latiusculis obtusis longitudinaliter percursæ; plumula parum conspicua; radicula brevis, late conica, quidpiam compressa, apice suo hilum attingens.

Observatio.-Stirps omni respectu memorabilis et habitu suo ab omnibus hucusque cognitis Cucurbitacearum speciebus omnimodo discrepans, a Nigritis per ista deserta errantibus Nara, M-nara sive Naras dicitur, et ab ipsis ob fructus satis ampli pulpam succoso-carnosam grate acidulam nec non propter semina edulia summo jure magni æstimatur. $\mathrm{Ob}$ vivendi modum in arenosis, vitæque ipsius tenacitatem, qua climatis ardentissimi efficientiæ fortiter resistit, stirpis hujusce cultura etiam colonis Europæis Africæ tropicalis maximopere commendanda, nam planta ipsa, e seminibus sat facile educanda, ad solidandas arenas volatiles inprimis idonea videtur, dum ejus fructus hominibus sub cælo fervente degentibus jusculum grate refrigerans simulque pluribus animalibus pabulum jucundum præbent. Monendum tamen est pulpam hujusce peponis, majore copia ingestam, nauseam causare nec non dolores prurientes faucium excitare, quod quidem ego non expertus sum, sed hic juxta relationem peregrinatorum supra laudatorum refero.

\section{Coralmocarpus, Welw. gen. nov.}

Flores monoici, masculi ad apicem pedunculi elongati aggregati, feminei sessiles vel breviter pedicellati, solitarii vel aggregati.

MAsc. Calycis tubus late campanulatus; lobi 5, breves. Corolla 5-partita, segmentis ovato-oblongis. Stamina 3, tubo calycis inserta, filamentis brevissimis; antheræ glabræ, integræ vel 2-partitæ, unica unilocularis, ceteræ biloculares, loculis rectis, connectivo simplici vel denticulato, ultra loculos producto. Ovarii rudimentum nullum vel minutum.

Femin. Calyx et corolla maris. Staminum rudimenta nulla vel minuta. Ovarium ovoideum, rostratum, 1-3-loculare; stylus rectus, disco basi nullo, stigmate 3-, rarius 2-4-lobato. Ovula in loculis pauca, horizontalia. Bacca carnosa, ovoidea vel ellipsoidea, obtusa vel rostrata, basi operculatim dehiscens, parte inferiore coriaceo-carnosa, oligosperma. Semina obovoidea, tumida basi plus minus truncata. Herba Africæ et Asiæ tropicæ, scandentes vel prostratæ, subscabrulæ v. subtomentosæ. Folia rotundata vel cordata, lobata vel palmata. Cirrhi simplices. Flores minuti. Genus, quoad florum structuram et habitum, Rhynchocarpe absque dubio affine, sed fructus dehiscentia valde distinctum, duas species Africanas et tres Asia tropicæ includit, hic infra post speciem typicam breviter enumerandas.

Corallocarpus Welwitschil, Hook. fil. MS. Tab. XII.

Rhynchocarpa Welwitschii, Naud., Ann. Sc. Nat. ser. 4, xviii. p. 198, t. 10 (planta culta).

Habitat non infrequens in dumetis arenosis maritimis Districtus Loanda, circa urbem Loanda et prope Cacuaco, ad varios frutices scandens, per totum fere annum, maxime mensibus Januar. et Febr. florens et fructificans.

Herba glaucescens, radice juvenili fibrosa, mox circa ejus colum et caulis basim infimam fusiformivel napiformi-incrassata perennans. Caulis gracilis, succulentus, glaberrimus, 5-8-pedalis, inferne subangulatus, simplex, demum parce et distanter ramosus, late scandens, ramis carnosulis, rigidiusculis, fragilibus, subteretibus ramulisque flagelliformibus ad nodos geniculatis, glaucissimis, fructiferis non raro aphyllis et dependentibus. Folia petiolo 1-2-pollicari suffulta, lamina $2-2 \frac{1}{2}$ pollices longa, $1-3$ poll. lata, quoad figuram et indumentum nec non respectu coloris sæpe in 
uno eodemque individuo mirum in modum ludentia; nunc fere simplicia cordato-ovata, basi subinæqualia, margine repando-dentata vel breviter lobata, apice acuminata vel obtusiuscula; nunc palmato3-5-loba, lobis lateralibus divaricatis, obtuse bilobulatis, medio magis producto et latiore breviter acuminato, vel obtuso et cuspidato; hine inde in aliis individuis profunde quinquepartita lobis elongatis, lineari-lanceolatis, repando-dentatis, apice cuspidatis; nervo in facie superiore laminæ parum, subtus vero magis prominulo et pilis brevibus rigidis aspero ; indumentum denique foliorum secundum plantæ expositionem et ætatem nune pilis densis rigidulis scabrum vel papuloso-asperum et cinerascens, nunc (præsertim in umbrosioribus) velutino-pubescens et coloris glaucescentis ; in ramulis demum extimis, hyeme sicca fructiferis, folia fere omnia abortiunt, ramulique ipsi aphylli, solum fructibus coralliformibus onusti, solito crassiores fiunt et fragiliores, nec non ad nodos evidentius geniculati et eximie glaucescentes. Cirrhi simplices, elongati, demum arcte spiraliter torti. Flores crebri, in ordine ex minutissimis, e viridi pallide flavescentes, masculi et feminei coaxillares. Fl. masculi in pedunculo circiter pollicari crassiusculo, erecto-patuli, apice 3-6 cymulatim gregati, brevissime pedicellati ; calycis campanulati lobi ovato-lanceolati, patuli ; corollæ segmenta late ovata, obtusiuscula, margine tenuissime ciliata, erecto-patula, calycis lobis latiora et longiora; antheræ subsessiles, una connectivo simpliciter apiculato unilocularis, ceteræ connectivo apice denticulato biloculares, loculis rectis, turgentibus. Rudimentum germinis vix ullum. Fl. feminei nunc solitarii et subsessiles, nunc 2-3 gregati, uno alterove tunc quidpiam longius pedicellato, pedicello crassiusculo, firmo et erecto ; calyx et corolla maris sed paullo majores. Ovarium oblongo-ovoideum 2-, rarius 3-, rarissime 1-loculare, loculis pauciovulatis. Stylus firmulus, sursum modice incrassatus, stigmati 2-3 vel imo obscure 5 -lobulato, lobulis patulis obtusis, ciliolatis, intus stigmatosis. Bacce elliptico-ovoideæ, $\frac{1}{2}-\frac{2}{3}$ poll. longæ, intense rubræ vel coccineæ, molliter carnosæ, apice obtuso calycis et corollæ limbo exsiccato coronatæ, paullo supra basim a pedunculo nunc incrassato-dilatato operculatim secedentes. Semina in pulpa viscidula subhyalina nidulantia, obovoidea, tumida, fuscula, margine tenui, versus basim truncatam incrassato cincta, faciebus minute et seriatim transverse squamulata.

Observatio.-Corallocarpi generi denique ceu species subscribendæ sunt:-1, AEchmandra epigaa Arn.; 2, Achmandra conocarpa Dalzell ; 3, Echmandra velutina Dalz., et probabiliter etiam planta Africæ australis subtropicæ herbarii Burchellii no. 2031, in herb. Kewensi deposita et foliis lanceolatis basi sagittato-lobatis insignis.

\section{Heterosicyos, Welw. gen. nov.}

Flores dioici.

Frones masculi solitarii, bini vel racemosi. Calycis tubus cylindricus, dentibus quinque minutis. Corolla rotata, profunde quinquepartita, segmentis oblongo- vel lineari-lanceolatis papillosis, tubum calycis subæquantibus. Stamina tria, tubo calycis inserta, filamentis liberis ; antheræ inclusæ, lineari-elongatæ, leviter cohærentes, unica unilocularis, ceteræ biloculares, loculis longitudinaliter conduplicatis, connectivo apice villoso vel papilloso. Ovarii rudimentum, globosum vel conicum.

Flores feminer solitarii. Calyx et corolla maris. Staminum rudimenta setiformia. Ovarium ovoideum, apice productum; stylus columnaris, apice clavatus, stigmatibus tribus subulatis incurvis ; ovula $\infty$, horizontalia. Fructus ovoideus, oblongus vel subglobosus, oligospermus. Semina oblonga vel obovoideo-pyriformia, lineis duabus exsculptis circumdata ; testa ossea.

Herba Tropico-Africanæ, parvulæ, erectæ, puberulæ, radice tubera napiformia emittente, collo bi- pluricipiti, caulibus flexuosis sulcatis. Folia breviter petiolata vel subsessilia, integra, lobata vel 3-partita. Cirrhi nulli. Flores inter minores, breviter pedunculati, penduli vel cernui.

Genus quoad florum structuram Trichomerice Hook. fil. (Benth. et Hook. f. Genera Pl.) arcte affine, ast præter alias notas inprimis habitu omnino erecto nec non cirrhorum absentia diversum.

VOL. XXVII. 
1. Heterosicyos polymorpia, Welw. n. sp. Caule erecto subramoso flexuoso; foliis breviter petiolatis 3-7-nerviis polymorphis, lanceolatis, ovato-lanceolatis vel late ovatis aut obcuneatis, basi breviter attenuatis vel subcordatis, apice integris acutis vel plus minus profunde 3-, rarius 5-lobis, lobis sursum spectantibus, intermedio reliquis latiore et longiore; corollæ limbo fusco-purpureo; bacca obovoidea vel subglobosa, levigata, 2-8-sperma.

Habitat nequaquam frequens in collinis breve herbidis petrosis apricis, Districtus Huilla circa Lopollo, socialis cum Daphnoideis, Thesiis atque Trideis pusillis ; mensibus Novembri et Decembr. 1859 c. flore et fr. legi. Exsic. It. Angol. no. 804.

Herba 4, pumila, in vivo obscure viridis. Radix tuberosa, globosa vel napiformis, dense farcta, fibris paucis elongatis subsimplicibus stipata, tubere non raro ad medium usque epigæo. Caules ex collo radicis crasso sublignoso plures, 3-6 pollices alti, erecti, pennæ corvinæ vix crassiores, inter angulos obtusos sulcati, simplices vel ramo uno alterove patulo muniti, ad nodos $\frac{1}{3}-1$ pollicem inter se distantes angulis obtusis flexuosi, juniores pubescentes, demum glabrati, mox supra basim foliis vestiti. Folia petiolo brevi, lineam circiter longo, latiusculo, obiter canaliculato suffulta, undique sed præcipue subtus et ad nervos pilis brevibus rigidulis adpressis pubescenti-scabrulæ, quoad figuram et circumscriptionem laminæ in speciminibus utriusque sexus, imo non raro in uno eodemque caule admodum polymorpha, nec minus quoad magnitudinem variantia; nunc integra, lanceolata, ovatolanceolata vel imo cordato-ovata, apice plus minus acuminata et mucronulata, nunc late ovata, obcuneata, vel fere lyrata, basi abrupte attenuata vel subcordata, apice 3-vel rarius 5-loba, lobis sursum spectantibus, lateralibus non raro inter se inæqualibus, hinc dentiformibus, intermedio semper longiore latioreque, plerumque ovato-triangulari, omnibus acutiusculis herbaceo-mucronulatis ; lamina angustiorum 3 pollices longa, semipollicem lata, latiorum $2 \frac{1}{2}$ poll. longa et sesquipollicem lata; in quibusdam individuis omnia folia integra lanceolata, in aliis omnia apice 3-5-loba, vel inferiora lobata, superiora integra et angustiora occurrunt. Cirrhorum vel stipularum vestigium nullum. Inflorescentia axillaris, tota puberula. Flores dioici ; masculi cernui, in racemulos depauperatos 2-6 floros, basi nonnumquam bractea foliiformi, anguste lineari-lanceolata, elongata, quasi stipulam mentiente, munitos collecti, vel solitarii, pedunculo gracili foliis multo breviore, pedicellis vix lineam longis bracteolatis,

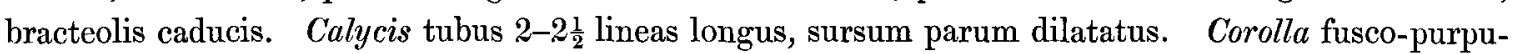
rascens, limbi segmentis oblongo-lanceolatis $I_{\frac{1}{2}}-2$ lin. longis, horizontaliter patentibus, intus dense tenuiter papillosis. Flores feminei masculis similes, primum erecto-patuli, post fecundationem nutantes, tubo calycino magis elongato, supra ovarium constricto. Stamina et ovarium generis. Bacca obovoidea, late clavata vel subglobosa, e viridi flavicans, nunc nucis avellanæ majoris mole, nunc multo minor, levigata, non raro ex seminibus maturitate valde turgescentibus inæqualiter plurigibbosa, septis pro parte resolutis unilocularis, pulpa viscida parca farcta, 2-7-, rarius monosperma, indehiscens. Semina pro more plantæ sat magna, obovoideo-pyriformia, recentia albida, mox badiofuscula, basi obtuse conica subrostellata, circumcirca profunde bisulcata, testa dura leviuscula.

2. Heterostcyos stenoloba, Welw. n. sp. Caule erecto, subramoso, flexuoso, dense pubescente; foliis subsessilibus, isomorphis, omnibus profundissime tripartitis, segmentis elongatis, anguste linearibus, uninerviis, apice abrupte acutatis, intermedio lateralibus parum latiore sed multo longiore; floribus masculis nutantibus, solitariis vel rarius depauperato-racemulosis, corollæ limbo stramineo-flavescente.

Habitat in collinis parce dumetosis Distr. Huilla prope Lopollo, socialis cum priore specie, ast ea multo rarior. Cum florib. masc. Decembr. 1859 legi.

Herba gracilis, pallide virescens, radice napiformi perennans. Caules ex collo radicis duo vel plures, 
erecti, flexuosi, 5-8 pollices alti, plurisulcati, dense pubescentes, pennæe corvinæ crassitudine vel imo tenuiores. Folia brevissime petiolata, nunc fere sessilia, utrinque pubescentia, ad basin usque tripartita, segmentis elongatis, divaricatis, anguste linearibus, $\frac{1}{2}-1$ lineam latis, $2-4$ pollices longis, apice breviter acutatis, per totam longitudinem nervo unico subtus latiore et magis prominulo densiusque pubescente et asperulo percursis, margine pilis brevibus spinuliformibus patulis, ciliatis. Flores masculi axillares nutantes, plerumque solitarii, rarius racemulosi, pedicellis bracteolatis, quoad structuram et formam iis speciei præcedentis sat similes, sed corollæ stramineo-flavescentis limbi laciniis angustioribus acutioribusque. Flores feminei et fructus non visi.

Observatio.-Species habitu multo graciliore et præsertim foliorum isomorphorum figura $a b$ antecedente (H. polymorpha) absque difficultate distinguenda, sed in paucis solummodo speciminibus masculinis a me lecta, proinde ulteriori peregrinatorum observationi commendanda.

\section{Ordo CACTACE $Æ$.}

Trib. Opuntie e, Benth. et Hook. f. Gen. Pl. i. 846.

Rhipsalis Cassyta, Gärtn. Sem. i. 137 (Pfeif. Enum. p. 133).

Habitat omnino indigena in Angolæ interioris silvis primævis et rupestribus editis Distr. Golungo Alto et Pungo Andongo, inter 2400 et 3500 ped. altit., ex arborum ramis vel rupium fissuris longe pendula. Novembr.-Jan. floret, Febr.-Mart. fructus maturat. Exsic. Welw. Iter Angol. n. 876 et 878.

Rhipsalis, spec., Welw. Apontam. p. 555 !

Caules 4-9 ped. longi, cylindrici, glauco-virides, in juventute fasciculis setularum rubrarum obsiti, adulti glaberrimi, di-, trichotome vel fasciculatim ramosi, internodiis a pollicari ad pedis usque longitudinem variantibus, hinc inde radicantibus. Flores crebri, laterales, horizontaliter patentes, una cum calyce 3 lin. longi, 2 circiter lin. diametri, albi vel pallidissime flavescentes. Stigma fere semper 4-fidum, lobulis oblongis obtusiusculis. Bacca plene matura albida, pisi minoris mole, ceraceo-nitens, subpellucida, pulpa aquoso-viscosa farcta. Semina minuta, 12-20, oblique obovata vel plerumque subreniformia, testa atra nitidula, sub lente fortiore dense striolata.-Specimina Angolensia cum stirpe Americana, ex insula Jamaica Ind. occid. oriunda, in horto Kewensi Apr. 1866 læte florente et fructifera accuratius comparavi, nullamque inter plantam Americanam et Angolensem discrepantiam notabilem observare mihi licuit.-Plantæ juveniles, e seminibus enatæ, quales ad Cole acuminate et Adansonice ramos muscosos in silvis primitivis Distr. Golungo Alto mihi sæpius obviæ, a planta adulta quoad aspectum magnopere differunt; rami nempe atque ramuli stirpis junioris solito crassiores, apice clavati et undique setulis rubris 2-3 lin. longis, fasciculatim gregatis, ad apicem ramulorum novellorum in comam congestis horriduli.

Observatio.-Cactearum in Africæ continente præsentia indigena inter phytogeographos acriter disputata, imo a R. Brown, Endlicher* et Lindley $\dagger$ prorsus negata fuit. Hæc nostra quidem, Rhipsalis Cassyta nempe, etiamsi simul Americæ incola, certissime etiam Africæ calidioris indigena, in Caffrorum terris quoque a Drege aliisque peregrinatoribus reperta. Nec hoc unicum Floræ Africanæ cum Americana homogeneitatis exemplum, nam plures species Americanæ generum Symphonia, Cacoucia, etc. etc., et ipsa Cyrtopera

- "Quæ a peregrinatoribus de Cactis in Arabia, Madagascaria etc. crescentibus legimus, fabulis adnumeranda sunt. Cactece omnes in America nascuntur."-Endl. Enchir. p. 497.

+ "America is the exclusive station of the Order [Cactacece ], no species appearing to be native of any other part of the world."-Lindl. Veg. K. p. 747. 
longifolic Reichb. f. (Orchidea!) in eodem loco cum Rhipsalide Cassyta sociales a me repertie fuerunt, et genera non pauca, typice Americana, speciebus sat affinibus in Angola interiore aliisque Africæ tropicalis territoriis repræsentata inveniuntur. Quod autem hoc respectu mihi multo majoris momenti, et omni phytogeographorum attentione dignum esse videtur, est quod major numerus illarum specierum, in Africa tropicali et America simul obvenientium, non in ora maritima continentem Americanam spectante, nec in regionis litoralis silvaticis, sed in regione interiore elevata, silvisque primitivis, longe $a b$ ora maritima remotis occurrit. Ipsa Brasenia peltata Pursh, nunc etiam Floræ Africæ tropicalis vindicata, nullibi in tot et tantis regionis litoralis lacubus a me observata, sed solummodo in lacu "Ivantalla" Distr. Huilla, circiter 5000 ped. supra mare elevato et plus quam 120 millia geograph. ab oceani Atlantici litore distante reperta fuit.

Trib. Gardeniez, Endl. G. Pl. 557.

Mussanda (Sect. Belilla), De C. Prod. iv. 370.

Muss.enda splendidd, Welw. n. sp. (Tab. XIII.) Fruticosa, scandens, tota molliter pubescens vel villosa; foliis modice petiolatis, ovatis acuminatis, penninerviis ; stipulis subfoliaceis, ovatis, bifidis, recurvis, intus glabris ; cymis subbreviter pedunculatis, densifloris, trichotome ramosis, dense puniceo villosis ; bracteis ad axillas patentibus subfoliaceis 3-5-fidis; floribus breviter pedicellatis; calycis tubo oblongo-cylindrico, lobis nunc omnibus æqualibus, nunc quatuor æqualibus lanceolatis, quinto maximo, late ovato molliter piloso puniceo ; corollæ tubo calycis lobis 2-3-plo longiore, limbo horizontali leviter obtuse 5-lobo, fauce hirsuta, extus patentim villoso; bacca ellipsoideo-oblonga, villosa, calycis limbo coronata.

Habitat freq. in montosis dumetosis humidiusculis, inprimis juxta silvarum primævarum oras Districtuum Golungo Alto et Pungo Andongo, inter 2500 et 3500 ped. altit., a Januario usque ad Maium florens, Junio ad Augustum fructificans. Exsic. Welw. It. Angol. no. 1116.

Caules e radice lignosa plerumque plures, 5-10 pedes longi, basi ascendentes, vetustiores obtuse angulati, glabrati et purpurascentes, juniores et rami vario modo curvi vel flexuosi, late scandentes, virides, teretiusculi, pilis mollibus rubescentibus patulis plus minus dense obsiti. Folia petiolata, membranacea, late ovata vel elliptico-ovata, 3-6 poll. longa, 1-3 poll. lata, basi nunc subcordata nunc rotundata, rarius breve attenuata, apice acuminata, margine integro ciliata, penninervia, in utraque pagina, sed subtus densius, pilis adpressis molliter pubescentia, supra læte viridia, subtus multo pallidiora, ibique nervo et costis magis prominulis venulisque crebris purpurascentibus picta; petioli $\frac{1}{2}-2$ pollices longi, iis foliorum superiorum sensim brevioribus, obiter canaliculati, patentim rubro-villosi ; stipulæ e lata basi ovatæ, $\frac{1}{3}-\frac{1}{2}$ pollicem longæ, plus minus profunde bifidæ, rarius subintegræ vel trifidæ, recurvo-patentes, pilis longiusculis rubris ciliatæ, intus glabræ et atropurpureæ, longius persistentes. Inflorescentia cymoso-paniculata, cymis densifloris, initio breviter, mox longius pedunculatis, trichotomo-ramosis, undique patentim puniceo-villosis ; bracteæ quoad consistentiam subfoliaceam, colorem et longitudinem stipulis subsimiles, sed 3-5-fidæ, laciniis angustioribus acutioribusque, post anthesim deciduæ. Flores in cynas densas congesti, alii subsessiles, alii breviter pedicellati, steriles (masculi) cum fertilibus in eadem cyma obvii. Calycis puniceo-villosi tubus florum centralium, sæpius sterilium, breviter oboroideus, limbi lobis omnibus inter se æqualibus; is florum exteriorum plerumque fertilium oblongo-cylindricus, limbi lobis nunc omnibus æqualibus, lanceolatis, erecto-patulis, nunc (plerumque unius floris in quaque cyma) quatuor æqualibus lanceolatis, quinto in folium maximum, 
bracteiforme, petiolatum, late ovatum, nervis 5-7 percursum, molliter pilosum, intense puniceum, horizontaliter patens producto. Corolla extus undique villo patente puniceo vestitæ tubus cylindricus, sursum modice ampliatus, calycis lobis duplo triplove longior, eo florum sterilium graciliore, limbi transversim vix $\frac{3}{4}$-pollicaris lobis obtusissimis, brevissime apiculatis, intus subglabris, pallide aurantiacis, fance pilis paleæformibus rigidulis, dense congestis, erectiusculis, sulphureis obsita. Anthere generis. Ovarium constanter biloculare; discus modice elevatus, glaber; stylus corollæ tubo æquilongus, pariter glaber, stigmate incrassato obiter bilobo vix exserto. Bacca elliptico-oblonga, $\frac{2}{3}-\frac{3}{4}$ poll. longa, tenuiter coriacea, parum succosa, bilocularis, calycis limbo indurato superata, dense et patentim puniceo-villosa. Semina numerosissima, valde minuta, in pulpa viscida nidulantia, atra, lenticularia, testa subtiliter scrobiculata.

Observatio.-Species inter congeneres facile ornatissima, Mussanda erythrophylla Schum. et Thon. (Bescriv. p. 136) affinis videtur, quæ tamen, secundum clar. auct. descriptionem a nostrate foliis subtus albo-tomentosis, stipulis angustis, calycis lobo phyllomorpho pariter tomentoso corollæque laciniis acutis recedit.

\section{Ordo RUBIACEA.}

\section{Trib. Cinchonea, Subtr. Eucinchoneæ.}

Corynanthe, Welw. gen. nov.

Calycis tubus ovoideus vel subglobosus, limbi 5-fidi lobis lanceolatis, apice subulatis, erectis, persistentibus. Corolle infundibuliformis tubus rectus, teres, sursum ampliatus; limbi explanati 5-lobi lobis late ovatis subacutis, dorso infra apicem appendice elongato-clavata, patula, corollæ fere longitudine, instructis. Stamina 5, corollæ fauci inserta, exserta, patentia. Anthere sessiles, lineari-oblongæ, basi profunde bilobæ. Ovarium biloculare, ovula in loculis $\infty$, ascendentia. Stylus filiformis, rectus, stigmate clavato. Capsula coriacea, lineari-oblonga, parum compressa, bisulca, calycis limbo indurato apiculata, bilocularis, loculicide bivalvis, polysperma. Semina compressa, ascendentim imbricata, nucleo minutissimo, ala lata membranacea, elongata, lineari-oblonga, basi attenuata profunde bifida cincto.

Arbor, excepto calyce hirtulo, glaberrima, in Angolæ interioribus editioribus inter 1200 et 2200 ped. elev. hinc inde silvas constituens, trunco stricto, coma ovato-pyramidata. Folia oblongo-lanceolata, nune fere elliptica, modice coriacea, perennantia. Stipule solitariæ, elongatæ, caducæ. Flores parvi, albidi, in paniculam multifloram trichotome ramosam dispositi, ramis inferioribus verticillatis.

Observatio.-Genus "Hymenodyction" Wall. nostro hic proposito certe proximum, inflorescentia tamen racemosa bracteisque petiolatis suffulta a Corynanthe facili negotio discernitur. Genera "Nauclea et Uncaria," etiam quodammodo affinia, floribus capitatis, supra receptaculum globosum aggregatis fructusque fabrica a nostro genere recedunt, quod insuper ab omnibus Eucinchoneam generibus hucusque descriptis " appendicibus elongato-clavatis, corollæ loborum dorso insidentibus" facile distinguitur. Species unica :-

Corynanthe Paniculata, Welw. n. sp. (Tab. XIV.)

Habitat in Angolæ interioris Districtibus elevatis, inprimis "Golungo Alto, Cazengo et Dembos," ubi in montium declivibus borealibus non raro silvas densissimas atque umbrosissimas, ab incolis Lusitanis nomine "Matas de Mangue" jure celebratas efformat. Floret a Januario usque ad Maium, et a Martio usque ad Julium fructificat. Arbor ipsa a Lusitanis et uunc etiam a Nigritis Angolensibus " Mangue 
branco" vel "Mangue do Monte" et hinc inde etiam "Paco de Golungo Alto" vocatur. Exsic. Welw. Iter Angol. n. 1508.

Arbor 25-40-pedalis, raro altior, corona ovato-pyramidata, dense frondosa, sempervirente, trunco recto, imo plerumque strictissimo, basi 2-5 ped. circumferentiæ; cortex pro more arboris sat tenuis, parum rimosus, griseo-fuscus, in juventute arboris et in adultæ ramis junioribus albidus, trunco tenaciter adhærens, saporis amaricantis. Rami vagi vel superiores oppositi, erecto-patuli, crebre ramulosi, ramulis obtusangulis ad nodos compresso-dilatatis, novellis atropurpureis. Folia petiolo circiter semipollicari canaliculato suffulta, $\frac{1}{2}$ ad $1 \frac{1}{2}$ pollicem in ramulis distantia, oblongo- vel ovato-lanceolata, obtuse acuminata, basi breviter in petiolum attenuata, margine integerrima, tenuiter coriacea, supra lucido-viridia, subtus pallidiora, pinnatinervia, nervo medio valido, lateralibus sursum arcuatis laminæ marginem vix attingentibus, omnibus atropurpureis. Stipula intrafoliaceæ, solitariæ, e lata basi ovato-lanceolatæ, obtusiusculæ, cito caducæ. Inflorescentia terminalis. Flores paniculati; singuli nempe pedicellis brevissimis in cymulas sive umbellas spurias capituliformes 5-20-radiatas collecti, his demum in pedunculi communis (basi verticillatim, superne trichotome ramosi) ramulis gracilibus varie congestis, paniculam multifloram, densam, obtusiusculam efformantibus. Calyx ovoideus vel fere globosus, sub lente undique hirtulus, e viridi albidus; limbi 5-fidi lobi erecti, rigiduli, lanceolati, extus convexi, apice subulati, tubo ipso æquilongi, corollæ tubum longe exsertum laxe ambientes, indurescendo persistentes. Corolla infundibuliformis (tenuiter carnosa, alba), tubo recto, cylindrico, apicem versus quidpiam dilatato, raro semilinea longiore; limbi 5-fidi laciniæ late ovatæ, concaviusculæ, apice breviter acuto cucullatæ, dorso infra apicem appendice claviformi, ipsa lacinia duplo longiore, patente, auctæ, intus juxta lineam mediam pilis tenuuissimis crispulis adspersæ, in alabastro induplicato-valvatæ, sub anthesi patentes. Stamina, antherce et ovarium descripta; stylus firmus, cylindricus, crassiusculus, totam tubi corollini cavitatem explens; stigma oblongo-clavatum, ex antherarum in alabastro pressione longitudinaliter plurisulcatum, exsertum. Capsula rigide corjacea, in maturitate fusco-purpurea, 3 lineas longa et linea vix latior, bisulcata, in pedicello lineam longo erecta, bilocularis, ab apice hiante loculicide bivalvis, valvis demum juxta sulcum bipartibilibus ; loculi 12-16-spermi. Semina descripta.

Qualitates et Usus.-Lignum nitido-albidum, densissimum, durum et sat durabile, in construendis domiciliis nec non in utensilium agrariorum fabrica tam inter colonos Lusitanos quam inter Nigritas multiplicis usus. Cortex arboris pulchræ amaricans et subadstringens est, et ob summam generis cum reliquis Eucinchoneis affininitatem, medicis in Angola artem suam nobilem exercentibus, inter Cinchone succedanea tentanda commendandus.

\section{Ordo JASMINACEA.}

\section{Subordo OLEACEx.}

\section{SCHREBERA, Roxb.*}

Genus "Schrebera" primum a Roxburghio ad arborem Indiæ orientalis conditum, fere per semiseculum in plantarum enumerationibus aut specierum catalogis monotypicum, et quidem inter Bignoniacearum gregem militans, remansit, donec Endlicher (Gen. Pl. p. 714) illud inter Bignoniaceas dubias collocavit, qua forsan ratione ductus, Lindley in Veg. Kingd. Schreberam Roxburghii penitus negligens, genus hoc ne nomine quidem

* Schrebera Roxburgh, Plant. Corom. ii. p. 1, tab. 101, nec al. auct. Schrebera Retz. est Elcoodendron glaucum Pers. Schrebera Thunb. Nov. Act. Upsal. postea ab ipso auctore in Dissert. Nov. Pl. Gen. et in ejus Flora Cap. tamquam Hartogia capensis descripta exstat. Sehrebera Linn., secundum De C. Prodr. viii. p. 675, est Cuscuta species, in quadam Myrica crescens. 
in Bignoniacearum enumeratione commemorat. Sed paullo post cl. Fenzl*, genera quædam Bignoniacearum dubia novo examini subjiciens, Roxburghii genus Jasmineis subscribendum esse, præclare docuit, quam opinionem etiam Endlicher in Gen. Pl. Suppl. ii. p. 54, nec non cl. Alph. De C. Prodr. viii. p. 674, secuti sunt. Postea vero cl. Wight (Illustr. ii. p. 185) Schreberam iterum, et quidem tamquam Subordinem, Bignoniaceis adnumeravit, simulque aliquam generis cum Acanthaceis affinitatem suspectans. Durante hoc inter celeberrimos botanicos de generis loco in systemate certamine, altera species Schreberce a cl. Schimper in Abyssiniæ montibus detecta fuit, quæ a cl. Hochstetter $\dagger$ ceu novum Oleacearum genus sub nomine "Nathusia alata" descripta et in herbariis Schimperianis distributa, etiam in Endlicherii Gen. Pl. Suppl. ii. p. 55, et in De C. Prodr. viii. p. 281 recensita invenitur, et quidem ab Endlicherio Jasmineis, a cl. Alph. De C. autem Oleaceis associata. Nuper demum hæc ipsa Nathusia alata Hochst. quoque in Africæ australis extratropicalis ditione Natalensi a cl. Gerrard aliisque peregrinatoribus variis in locis reperta, mox ab acutissimo Harveyo tamquam vera Schreberce species recognita et ab ipso sub nomine Schrebera Saundersice descripta et depicta fuit \$. Eadem hæc species, etiam mihi in Angolæ et Benguellæ interioribus montosis sæpius obvia, latissime per Africam calidiorem distributa videtur, ast præter illam in Angola australiore duæ alteræ species ejusdem generis, ambæ foliis simplicibus integris (nec pinnatis) inter congeneres valde insignes, ceteroquin omnibus notis genericis Schreberce sat congruæ occurrunt, modo hic infra latius exponendæ.

Collocationem Schrebere in systemate naturali quod attinet, genus hoc Jasmineas inter et Oleaceas fluctuat, vel potius ambos hos ordines arcte conjungit. Florum structura, imprimis limbi in 5-8 lobos divisio, staminum insertio, antherarum connectivum amplum, embryo demum exalbuminosus, peridermio spongioso-tumido exceptus, nec non cotyledones plano-convexæ et carnosæ Jasminearum characteri respondent, dum ovula pendula, capsulæ dehiscentia loculicida, semina alata et radicula supera, habitus deinde, saltem in duabus speciebus eximie fraxineus, evidentem cum Oleaceis affinitatem indigitant, sicque genus, characteribus omnibus simul consideratis, amborum ordinum indicatorum limites obruit, eosque iterum, sensu Jussiæi, in unum contrahendos esse suadet.

Additis duabus speciebus novis Angolensibus, jam 1858 in Apontam. pp. 549 et 579 a me commemoratis, genus Schrebera nunc quatuor species bene inter se distinctas amplectitur, quæ commode sequente schemate disponuntur:-

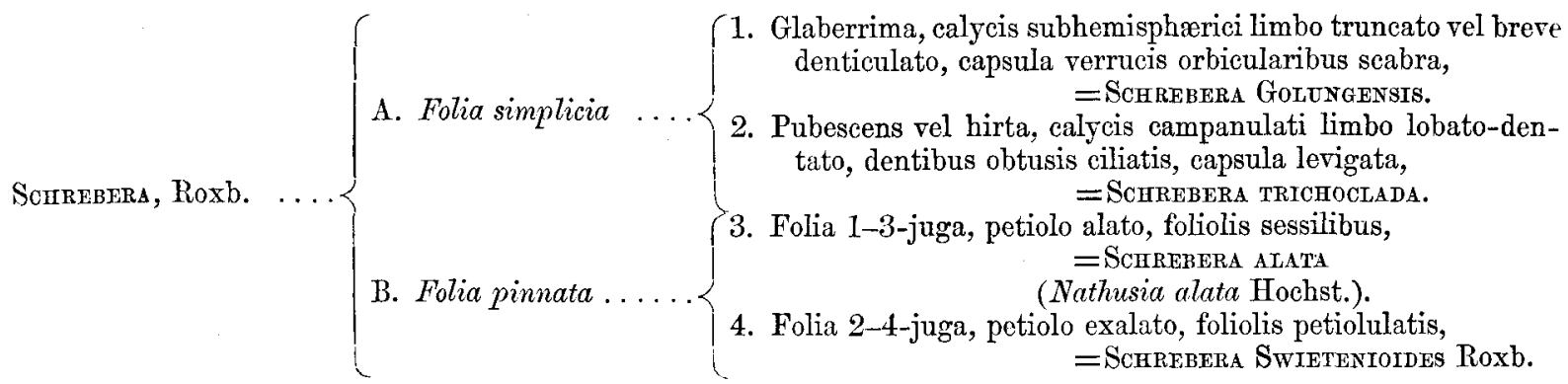

* Fenzl, Denkschr. Bot. Gesellschaft Regensb. iii. p. 246.

$\dagger$ Hochstetter (Chr. Fr.), Nova Genera Plantarum Africæ tum australis tum tropicæ borealis, p. 15; Schimper, Plant. exsiccatæ Abyss. Sect. I. Adoenses, no. 245.

¥ Harvey (Dr. W. H.), Thesaurus Capensis, vol, ii. p. 40, tab. 163. 
Schrebere omnes hucusque cognitæ arboree sunt, etiamsi hinc inde, præcipue in silvis secundariis, post silvas primitivas igne destructas enascentibus, sub forma fruticosa occurrunt; omnium denique flores suavissime et fortiter fragrantes, inprimis nocturno tempore aroma amoenissimum, illud Caryophyllorum æmulans, per lata spatia spargunt.

1. Schrebera Golungensis, Welw. n. sp. (Tab. XV.) Sch. glaberrima, foliis simplicibus oblongis, nunc ovato- vel lanceolato-oblongis, abrupte acuminatis, basi obtusis vel breviter in petiolum angustatis, supra nitenti-viridibus, subtus subglauco-virescentibus; calycibus levigatis, subhemisphæricis, ore truncatis vel minute repandodenticulatis; stylo incluso; capsula obtusa, bisulca, verrucoso-scabra.

Habitat in silvis primævis densioribus Distr. Golungo Alto, præcipue in montibus schisto-micaceis de Serra de Alto Queta, ad 2500 ped. alt. Floret Decembr.-Jan., fructific. Maio-Jul. Exsic. Welw. Iter Angol. n. 933.

Arbor 20-30-pedalis et altior; truncus rectus, basi 2-3 ped. circumferentiæ, cortice albido-griseo rimis minutis crebris aspero, coma elongato-ovoidea lucide denseque frondosa. Rami patentes, elongati, inferiores fere horizontales et tarde dejecti ; ramuli oppositi, graciles, angulati, glabri, ad nodos dilatato-compressi, novelli et florigeri gracillimi, purpurascentes et lenticellis albicantibus variegati, hisque asperuli. Folia opposita, petiolata, simplicia, penninervia, respectu circumscriptionis sat variantia, plerumque oblonga, non raro ovato-oblonga vel fere elliptica, nunc late lanceolata, ea ad basim ramulorum novellorum superioribus semper duplo triplove minora, omnia constanter glaberrima, supra intense viridia et valde nitentia, subtus pallide virescentia, halitu glaucescente suffusa, costa prominente læte flava percursa, inter venas dense reticulato-venulosa; petioli 3-4 lin. longi, canali-

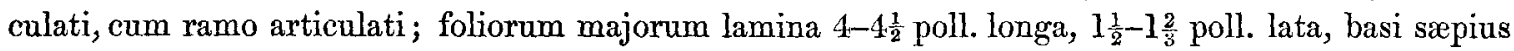
obtusa vel breviter attenuata, margine integra, apice plus minus oblique et abruptim acuminata, substantia tenuiter coriacea vel chartaceo-rigida. Inflorescentia terminalis, omnino glabra, cymulosopaniculata, paniculæ depauperatæ ramis di-, trichotomis pedicellisque basi articulata minute bibracteolatis, cymulis sæpius trifloris. Flores circiter pollicares, omnium specierum mihi cognitarum fragrantissimi ; calyx obhemisphæricus, fere cupuliformis, circiter $1 \frac{1}{2}$ lin. longus et latus, ore inæqualiter repando 5-6- vel rarius 7-denticulatus, nunc ommino edentulus, truncatus, corollæ basim laxe excipiens ; corolla carnosula, primum viridi-flavescens, mox tota cinamomeo-fusca, limbi plerumque 6-fidi lobis ad internam faciem papillis minutis fusco-rubris dense gregatis velutino-puberulis, æestivatione quincunciali-imbricatis sed vix contortis; tubus intus ad basim pilis raris adspersus, ceterum nudus. Stamina 2 paullo infra faucem inserta, inclusa; filamenta brevissima, compressa; antheræ linearioblongæ, medio dorso fixæ, biloculares, loculis connectivum crassum marginantibus, eoque paullo brevioribus, longitudinaliter dehiscentibus. Ovarium ovoideum, biloculare; ovula in quoque loculo 4 ; stylus filiformis, rectus, inclusus, apice sensim in stigma breviter bilobum incrassatus. Capsula lignosa, pyriformis, $1_{\frac{2}{3}}$ poll. longa, pollicem lata, basi teretiuscula calyce persistente arcte adpresso (vix uti in ceteris speciebus varie fisso) excepta, apice obiter convexo styli basi indurata apiculata, longitudinaliter obtuse bisulcata, fusco-badia, undique verrucis orbicularibus magnitudine variis plus minus gregatis asperulis adspersa, bilocularis, ex apice loculicide bivalvis, valvis crassis navicularibus, medio septum fere sesquilineam crassum gerentibus, intus infra verticem gibbis. Semina in quoque loculo 4, ex apice septi pendula, compressa, deorsum (i.e. in directione radiculæ opposita) in alam scariosam oblique lato-lanceolatam obtusiusculam faciebus subtrinervem prolongata, una cum ala

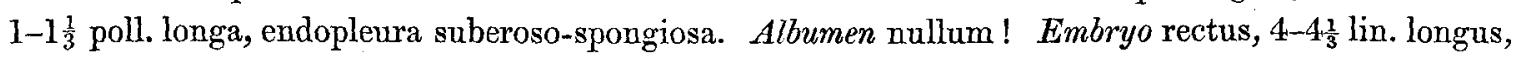
2 lin. latus ; cotyledones elongato-ovatæ, obtusæ, basi emarginatæ, carnosulæ, extus leviter convexæ, facie interna plana applicatæ (nequaquam plicatæ !) ; radicula supera, oblonga, tumidula, obtusissima, circiter $\frac{2}{3}$ lin. longa; ad hilum spectans. 
Observatio.-Semina in loculis quidem constanter quatuor inveniuntur, sed sæpius solummodo eorum duo embryone evoluto fœeunda, reliqua duo vero plerumque in laminam subduram, oblongo-lanceolatam, intus suberoso-spongiosam et embryone omnino carentem, extus ad unam faciem acute carinatam, inter se concreta, vel saltem arcte conglutinata. Vid. tab. nostr. fig. 11.

2. Schrebera trichoclada, Welw. n. sp. Sch. ramulis novellis et florigeris petiolisque pubescentibus; foliis simplicibus, late ellipticis, elliptico-ovatis vel rarius obovatis, apice obtusiusculis vel breviter acutatis, basi abruptim attenuatis, supra glabratis, subtus juxta costam venasque pubescentibus; calycibus campanulatis puberulis, sub pube sulcato-striatis, ore lobato-dentatis, dentibus conspicuis, inæqualibus, deltoideoovatis oblongisve, margine dense ciliatis ; stylo plus minusve exserto; capsula elongato-pyriformi, obtuse quadrangula, quadrisulca et levigata.

Habitat in silvaticis rupestribus Distr. Ambaca et Pungo Andongo, inter 3000 et 3500 ped. altit. Ab Octobr. usque ad Decembr. floret; fructiferam Junio 1857 legi. Exsic. Welw. Iter Angol. no. 936 et 934.

Arbor circiter 15-pedalis, patentim ramosa, coma laxa, rarius frutex 6-8-pedalis, ramis virgato-elongatis, obscure angulatis, cortice cinerascente vel fere albido; ramuli novelli et florigeri constanter plus minusve cano-pubescentes, etiam fructiferi pubem conservantes, vel patulo-villosi aut hirtuli. Folia circumscriptione non minus quam in specie antecedente variant, sed plerumque elliptica vel obovatooblonga, membranacea, herbaceo-viridia absque nitore, subtus secus costam et venas prominentes pubescentes; petioli 4-7 lin. longi cum ramulis articulati, constanter, et quidem etiam in foliis adultis, ceteroquin excepta costa omnino glabratis, pubescentes. Panicula depauperatæ 5-10-, rarissime 14-floræ, in ramulis terminales; pedunculi, rami et pedicelli pubescentes, basi articulati, bibracteolati, bracteolis puberulis vel dense villoso-barbulatis. Calyx tubuloso-campanulatus, quam in Schreb. Golungensi duplo major, fere 3 lin. longus, dense pubescens, sub pube obscure sulcato-striatus vel omnino deglabratus et tunc evidentius plurisulcatus, ore grosse dentato, dentibus nunc deltoideo-ovatis nunc lobuliformibus oblongis, juxta margines et præcipue apice semper ciliato-barbulatis. Corolla ejusdem magnitudinis et structuræ ac in specie antecedente, primum albida, limbi 5-7-fidi lobis pilis clavatis crispulis roseo-purpureis, circa faucem densioribus, demum una cum tota corolla cinnamomeis, obsitis. Antherarum loculi connectivo crasso subcompresso æquilongi. Ovarium conico-ovoideum; stylus modice exsertus. Capsula fere bipollicaris, badio-flavicans, levigata (nec verrucoso-aspera), obtusissime quadrangula, inter angulos apicem versus magis salientes late sulcata, sulcis in vertice obtuso, obiter apiculato, cruciatim confluentibus. Semina quam in Schreb. Golungensi quidpiam longiora, perfecte matura vero mihi non obvia. Cetera generis.

Observatio.-Species, priori omni respectu sat affinis, sed certe distincta, et ramulis petiolisque et nervo mediano subtus constanter pubescentibus, nec non calycis late dentati capsulæque levis configuratione ab illa absque difficultate distinguenda, ceteroquin ut videtur latissime per Africam austro-tropicam distributa, a clar. Kirk etiam (secundum specimen in herb. Kewensi, Zambesi Exped. 1863 Morumballa) e ditione Mossambicensi reportata.

\section{Schrebera alata.}

Nathusia alata, Hochst. Nov. Gen. Pl. Afr. p. 15, et in Schimper, Iter Abyss. Plant. Adoënses, no. 245; Endl. Gen. Pl. Suppl. ii. p. 55 ; DC. Prodr. viii. p. 281 ; A. Rich. Tent. Abyss. ii. p. 29 ; Welw. Apontam. p. 379.

Schrebera Saundersia, Harv. Thes. Cap. ii. p. 40, tab. 163.

VOL. XXVII. 
Habitat arborea in silvis primitivis Distr. Pungo Andongo ad 3000 ped. circiter altit., nec non in silvis secundariis densioribus Distr. Huilla inter 4000 et 5000 ped. alt, hic sæpius tamquam frutex 8-pedalis. Decembr. c. fl., Maio c. fr. necdum maturo lecta. Exsic. Welw. Iter Angol. no. 938.

Distrib. geogr.-Abyssinia, Angola, Port Natal.

Observatio.-Specimina Angolensia cum Abyssinicis a cl. Hochst. descriptis, et simul cum Icone Harveyana supra laudata optime conveniunt, calyces in stirpe Angolensi quidpiam puberulos (nec omnino glabros) si excipias. Ceterum nec mirandum, stirpem per Africam tropicam cis- et transaequatorialem divulgatam, et imo ditionem Natalensem invadentem maximopere variare. In silvis primæevis convallibusque solo humoso donatis arborea crescit, 15-30-pedalis, habitu fere omnino Fraxini, in silvaticis autem macrioribus solummodo frutex remanet, 5-8-pedalis, ramis elongatis tortuosis, hinc inde subscandentibus, et tunc Jasmini speciem non male fingens. Folia 3-5-vel, etsi rarius, 7-foliolata interdum in uno eodemque ramo obveniunt; petioli nunc latius nune angustius alati; foliola magis minusve acuminata; calyces nunc ore truncati nunc evidenter dentati, stamina inclusa vel subexserta etc. non raro in speciminibus unius ejusdemque arboris invenienda; maxime autem species hæc respectu indumenti ramulorum, foliorum atque calycis florigeri variat, quæ organa nunc fere penitus glabra, nunc obiter puberula vel pubescentia, nunc undique sericeo-tomentella inveniuntur. Hanc ulteriorem formam, in editissimis petrosis Distr. Huilla mihi obviam, et aspectu sat singularem, hic proponere liceat tamquam

3. tomentella. Ramulis, foliis calycibusque dense sericeo-pubescentibus vel albo-tomentellis.

Habitat in Distr. Huilla montibus editis petrosis breve dumetosis inter 5000 et 5600 ped. alt. socialis cum Protec, Xylopea, Dombeya et Tarchonanthi speciebus, præcipue in summis jugis de "Morro de Lopollo." Martio 1860 c. flore et fruct. immat. lecta. Exsic. Welw. Iter Angol. no. 939.

Frutex 5-pedalis, arbusculiformis, coma densius ramosa, præter indumentum sericeum formæ typicæ omnino fidelis. Etiam hac in varietate, primum facile pro specie distincta habenda, ramuli fructiferi et folia adulta indumentum pro parte dejiciunt, et calyces glabrescunt; fructus denique jam juveniles levigati sunt, quemadmodum in specie typica.

Ceteroquin folia pinnata hanc speciem strictim a duabus antecedentibus separant, petioli alati demum et foliola sessilia illam primo jam intuitu ab affini Schrebera Swietenioide Roxb., totius generis prototypo, distinguunt.

\section{Ordo APOCYNACE 2.}

Trib. Echite 2 , DC. Prodr. viii. p. 412.

Pachypodium, Lindl.

Pachypodii genus, jam olim ab acutissimo R. Br. ob Echitis specierum Thunbergianarum ab Americanis notabilem discrepantiam, obiter indigitatum, demum a cl. Lindley in Bot. Reg. [1830] tab. 1321 institutum, nuper a cl. A. DC. (Prodr. viii. p. 423) locupletatum, ne dicam reformatum fuit, characteri nempe generico "glandulas 5 hypogynas" addente, in Pachypodio [Echite Thbg.] succulento ab eo observatas, quas cl. Lindley in generis sui definitione expressis verbis "absentes sive nuillas" declarat*. Tres sunt species

* Glandulæ sive squamulæ quinque hypogynæ Echitis succulenta Thunb. jam in icone hujus speciei, a cl. Jacquin in Fragm. Bot. tab. 117 exhibita, pro illo tempore perfectissima, sat clare depictæ inveniuntur. 
generis hujusce, hoc modo ampliati, in Prodr. l. $c$. descripte, quibus quarta addenda venit, qua a clar. Harvey in Thes. Fl. Cap. tab. 117 depicta et sub nomine "Adenium Namaquanum" descripta, omnibus characteribus ibi, etiamsi nimis fragmentarie, exhibitis, bene cum Pachypodii genere convenit, et ob antherarum structuram, glandularumque hypogynarum præsentiam certe a genere "Adenium" excludenda. Omnes hæ quatuor species, præter essentiales notas genericas, simul etiam indumento variarum partium plus minusve pubescente vel tomentoso, nec non corollæ lobis æquilateris et planiusculis inter se congruunt atque Pachypodii Sectionem primam Eupachypodium constituentes considerari posunt, dum quinta, hic infra a me proponenda, species nova, et quidem sat formosa, "glandulis in discum cupuliformem concretis, limbi corollæ lobis valde inæquilateris crispatisque, nec non stirpis totius glabritie" insignis, alterius ejusdem generis Sectionis typum offert, nomine "Adeniopsis" salutandæ. Erunt itaque Pachypodii Sectiones duæ sequente modo limitandæ:

A. Eupachypodium: corollæ lobi planiusculi, equilateri; glandulæ hypogynæ 5 [vel inconspicuæ?]; stirpes indumento variarum partium pubescente vel tomentoso. Cotyledones (ex A. De C.) radicula breviores.

B. Adeniopsis : corollæ lobi incquilateri, hine crispati ; discus cupuliformis 5-crenatus; stirps glabriuscula. Cotyledones radicula duplo longiores!

Pachypodium [Adeniopsis] Lealir, Welw. n. sp. (Tab. XVI.) $P$. trunco succulento, erecto, elongato-conico, crebre aculeato, apice 2-3-chotome ramoso, ramis glaberrimis ; aculeis validis ; pedunculis firmis, terminalibus, multifloris ; calycis dentibus brevibus, triangulari-ovatis, acutis, glabris ; corollæ amplæ glaberrimæ lobis late oblique ovatis, apicibus obtusiusculis retortis, latere altero plano continuo, altero convexiore undulato-crispato; disco annulari obtuse quinquelobo.

Habitat non infrequens in montosis petrosis aridis Distr. Bumbo (territorii Mossamedensis interioris) præcipue inter Quitibe et Bumbo, ad 1500 ped. altit. supra mare. Octobr. 1859 et iterum Junio 1860 c. fl. et fr. matur. legi. Exsic. Welw. Iter Angol. no. 1510.

Arbuscula cactiformis, 10-15-pedalis, succo aquoso-resinoso viscido scatens, tota aculeis rigidis geminatim proximatis, fere pollicem longis, rectis, patulis, satis pungentibus horrida, ast floribus admodum speciosis grateque fragrantibus et per totum fere annum obviis inter congeneres valde insignis. Truncus succulentus strictus, prope basim non raro 2-3 ped. circumferentiæ, epidermide levi, tenui, plumbeo-grisea, facile secedente et corticem herbaceo-viridem denudante vestitus, inferne simplicissimus, a medio apicem versus parce patentimque dichotome ramosus; rami juniores et ramuli floriferi, uti etiam aculei, lætissime sanguineo-purpurei et nitido-levigati. Folia sparsa, minima, vix lineam longa, rare et nonnisi ad ramulorum novellorum apices hinc inde obvia, oblongo-lanceolata, basi articulato-sessilia, membranacea, nervo crasso in acumen subulatum excurrente percursa, quasi aculeum bialatum fingentia, caducissima, juxta basim utrinque aculeis rectis, stipularum lateralium vices gerentibus (?), post folium delapsum persistentibus munita. Aculei recti, in trunco et ramis ramulisque per paria sparsi, tuberculis oblongis verniceo-nitidulis insidentes, acutissime subulati, basi sub lente puberuli, majores sesquipollicem longi, juniores erecto-patuli, vetustiores late patentes, in cujusve paris axilla aut aculeo altero breviore aut gemmula e setis pluribus composita aucti, simulque inter eorum basim fossula circulari vel oblonga, folii delapsi cicatrice, instructi. Inflorescentia cymosa, in ramulis extimis terminalis, tota glaberrima; cymæ multifloræ, inordinate compositæ, amplæ, bene evolutæ non raro 6-7 pollic. diametri, pedunculo communi crasso, recto, longitudine vario, 
basi aculeolis gregatis circumcirca stipato, subsimplici vel parcius dichotome ramoso, herbaceo-viridi ; pedicelli crassi, longitudine inter $\frac{1}{2}$ et 4 lin. in eadem cyma variantes, superne incrassati, basi bracteolis squamiformibus, deltoideis, plus minusve acutis, caducissimis, cicatricem transversam relinquentibus semiamplexi. Calycis brevis, intus eglandulosi lobi subrquales, deltoideo-ovati, breviter subulato-acuminati, rigiduli, erecti. Corolla tubus purpurascens, $1 \frac{1}{2}-1 \frac{2}{3}$ poll. longus, rectus, medio circa stamina ampliatus, faucem versus angustatus, intus infra stamina pilis adspersus, superne nudiusculus, fauce omnino nuda ; limbi horizontaliter patentis $2 \frac{1}{2}-3$ poll. diametri transversalis lobi $l_{2} \frac{1}{2}$ poll. longi, $\frac{3}{4}$ poll. lati, in restivatione sinistrorsum contorti, externe rosei, interne splendido-albi, inæquilateri, latere in alabastro occultato convexiore denseque undulato-crispato. Stamina medio tubi inserta, inclusa; filamenta brevissima, basi interna pilosula; antheræ sagittatæ, sinu fixæ, $4, \frac{1}{2}-5$ lin. longæ, rigidæ, in appendicem lanceolatam polline destitutam acuminatæ, circa stigma inclusum pyramidatim conniventes, læte flavæ. Discus elevatus, urceolaris, ceraceo-carnosulus, obiter 5-lobus, lobis æqualibus obtusissimis. Ovaria duo, oblongo-ovoidea, glabra, disco longiora; ovula $\infty$; stylus filiformis, stigmate oblongo-cylindraceo, vertice obtuso obscure bilobo, basi annulo prominente subcrenulato antheris adhærente cincto. Folliculi juniores erceto-patuli, maturi angulo recto divergentes, 3-5 poll. Iongi, compresso-cylindracei, medio modice ventricosi, superficie glabri purpurascentes, ventre dehiscentes, intus nitidulo-albidi. Semina numerosa, pendula, obovoidea, compressa, dense imbricata, ad umbilicum comosa, coma duplo triplove breviora; testa fusco-badia, membranacea, scabrula; albumen parcum; cotyledones late ovatæ vel suborbiculares, basi cordatæ, planiusculæ, leves, margine integerrimæ; radicula oblonga apice conoidea, cotyledonibus fere duplo brevior, ad hilum spectans.

Speciem hanc, inter congeneres longe ornatissimam, dicatam velim viro clarissimo, Fernando da Costa Leal, in exercitu Lusitano legionis præfecto strenuo, Districtus Mossamedensis et inprimis Coloniæ Huillensis defensori intrepido, nee non Mappæ geographicæ Angolæ nuper in lucem editæ pro magna parte auctori.

Observatio.-Genera "Pachypodium Lindl." et "Adenium R. \& Sch.," etiamsi in DC. Prodr. loc. supra cit. sub diversis Apocynacearum tribubus militant, arcta affinitate junguntur, simulque omnium fere specierum habitu isomorpho, eademque vivendi ratione confirmata. Principalis tamen eorum differentia ex antherarum seminumque structura pendere videtur, dum reliquæ notæ genericæ, a diversis auctoribus indicatæ, in utroque genere sat variantes sive vacillantes sese denotant. In Adenio stamina exserta vel saltem fauci approximata, antherarum apices longe appendiculati et plus minusve spiraliter torti; semina demum subcylindrica vel cylindrico-subangulata et utraque extremitate comosa dicuntur et talia tam in icone Adenii multiflori Klotsch. [Peters, Reise, Bot. i. tab. 44] quoad antheras, quam in icone eximia sed necdum edita Adenii speciosi Fenzl, ab amicissimo auctore benevole mecum communicata, quoad antheras et seminum comas, depicta sunt. In Pachypodio stamina inclusa, antherarum apices sensim in acumen subcartilagineum, rigidulum, strictum angustati, seminadein compressa, obovata et solummodo ad umbilicum comosa. Discus denique in Adeniis veris brevissimus, annularis, continuus et ore nudo truncatus adesse dicitur, dum Pachypodii species vel glandulas 5 inter se separatas, vel in discum cupuliformem ore 5-lobatum coalitas offerunt. Squamulæ faucem corollæ coronantes in Pachypodiis vix obviæ, in nostrate hic descripto certe absentes, levioris momenti videntur, nam in Adeniis nunc manifeste obviæ [Ad. multiflorum Kl. l.c.] nunc omnino deficientes, v. g. in Ad. specioso Fenzl.

Hisce omnibus perpensis species amborum generum hucusque cognitæ forsan sequente 
modo commode exponendæ, simulque ob antherarum et seminum structuram sedule observandam peregrinatoribus futuris commendandæ:--

Adenium, R. \& Sch.

1. A. obesum, R. \& Sch. [Ad. Honghel, Lindl.].

2. A. Honghel, Alph. DC. [nec Lindl.].

3. A. multiflorum, Klotsch.

4. A. speciosum, Fenzl.

Pachypodum, Lindl.

1. P. tuberosum, Lindl.

2. P. succulentum, Alph. DC.

3. P. bispinosum, Alph. DC.

4. P. Namaquanum.

Adenium Namaquanum, Wyley in Harv. Thes. Cap. ii. tab. 117.

5. P. Lealii, Welw.

Speciebus utriusque generis in posterum exactius cognitis, et quoad antherarum seminumque structuram accuratius investigatis, ambo genera fortasse in unum conjungenda et tum Pachypodium atque Adeniopsis generi Adenio antiquiori ceu Sectiones subscribenda erunt, vix unquam vero, imo si reapse inter se diversa statuuntur, in diversas ordinis sui tribus divellenda.

\section{Ordo GENTIANACE}

Trib. I. Gentianee. Subtr. 2. Chlorea, DC. Prodr. ix. p. 49.

Faroa, Welw. gen. nov.*

Calyx subcampanulatus, ad medium quadrifidus, lobis erectis, obtuse carinatis. Corolla subhypocraterimorpha, marcescenti-persistens, tubo sensim ampliato infra faucem obiter constricto, limbi quadrifidi lobis patentibus; faux squamulis quatuor, staminibus oppositis, semilunaribus, margine tenuissime fimbriatis clausa. Stamina quatuor, ad sinus loborum inserta, longe exserta, filamentis suberectis filiformibus; antheræ breves, late oblongæ, basi cordatæ, dorso ad sinum fixæ, demum incumbentes, immutatæ. Ovarium obovoideum, basi in stipitem brevem angustatum, carpellorum marginibus introflexis subbiloculare, ovulis juxta suturas biserialibus. Stylus rectus, elongatus, filiformis, stigmate parvulo simplici, tenuissime papilloso vel brevissime bilobo. Capsula parva, oblonga, perianthio marcescente inclusa, bivalvis, septicida, semibilocularis, placentis juxta valvularum margines insertis. Semina numerosa, subglobsa, testa undique foveolata.

Herba parva, annua, glabra, radice pluricipite; caulibus erectis simplicibus vel apices versus trichotome ramosis, tetragonis. Flores parvi, gracile pedicellati, in cymas densas corymbiformes foliis 2 vel pluribus involucratas dispositi, violaceo-cærulei.

Genus ni fallor prope Hippion Spgl. [Enicostema Blum.] collocandum, cui ob flores

* Dicatum est clarissimo Doctori T. C. P. Lapa e Faro, Medico mossamedensi experientissimo, mearumque in Districtu Mossamedes institutarum peregrinationum fautori bumanissimo. 
in foliorum axillis pseudo-verticillatim gregatos, corollæ faucem squamigeram, capsulæ structuram et semina foveolata aliquantulum affine videtur. A Sebca generibusque huic vicinis tum habitu peculiari quum corollæ capsulæque fabrica interna longius distat.

Species unica:

Faroa salutaris, Welw. n. sp. (Tab. XVII.)

Habitat frequentissima in pascuis humidiusculis arenoso-argillaceis totius fere Distr. Huilla, inter 4000 et 5500 ped. altit., præcipue circa Mumpulla et Lopollo. Ab Octobre usque ad Januarium floret et fructificat. Exsic. Welw. Iter Angol. no. 1523.

Herba elegantula habitu Globulariam vel, si mavis, Iasionem fingens, pascua editiora et dumeta brevius herbida tempore vernali in Iridearum, Commelynearum et Indigoferarum consortio mira individuorum copia eximie decorans. Radix annua [vel plurennis ?]*, cylindracea, firmula, in speciminibus vetustioribus sat longa, perpendicularis, fibris lateralibus subsimplicibus elongatis stipata, ad collum incrassatum multiceps, foliorumque primordialium rosula, in planta florente non raro jam emarcida, coronata. Caules ex eadem radice 3-5 usque 20, erecti, vel laterales basi ascendentes, 2-4 poll. alti, quadranguli, nunc simplices, nunc a medio bis terve trichotome ramosi, foliorum paribus 3-6, semipollicem ad pollicem usque inter se distantibus vestiti, e viridi purpurascentes vel intensius purpurei, apice vel simul ad superiorum foliorum axillas capitulis florigeris ornati. Folia radicalia gregata, oblongo-lanceolata vel elongato-spathulata, trinervia, $1 \frac{1}{2}-3$ poll. longa, 3-4 lin. lata, obtusiuscula, basi sensim attenuata, caulina angustiora, lineari-lanceolata vel linearia, lata basi semiamplexicauli inter se connata, apice subobtusa, $\frac{1}{2}-1$ poll. longa, rarius linea latiora, nervis lateralibus evanescentibus subtrinervia, patula, intense viridia, carnosula, summa florum capitula involucrantia. Flores modice pedicellati, constanter tetrameri, in foliorum axillis superioribus et summis cymoso-fasciculati, cymis multifloris, foliorum internodiis versus apices caulium ramorumque valde abbreviatis in corymbos densissimos capituliformes congestis, capitulis 6-10 lin. diametri, nunc solitariis nunc (in speciminibus robustioribus) pluribus 2-4 in eodem caule superpositis. Pedicelli strictiusculi, fere setiformes, floribus (circiter duas lineas longis) paullo longiores, una cum calyce et corolla violaceo-cærulei vel roseo-violacei, rarius violaceo-albidi, exsiccatione mox pallide albescentes. Calycis tubus subquadrangulus; lobi ovati, inferne membranaceo-marginati, dorso obtuse carinati, apice carina excurrente obtuse apiculati, corollæ tubo paullo breviores. Corolle tubus sub prima anthesi a basi faucem versus sensim sed parum ampliatus, ovario demum increscente, inter hoc et faucem squamigeram plus minusve constrictus; limbi patentis lobi ovati, concaviusculi, obtusi, rarius subacuti, tubum longitudine subæquantes. Squamula faucis versus ejus centrum conniventes. Filamenta compresso-filiformia, violaceo-albida, una cum antheris intense purpureo-violaceis, exsiccatione albidis, longe persistentia. Stylus gracilis, stamina æquans vel iisdem paullo longior, stigmate exiguo nunc simplici, dense tenuiterque papilloso, nunc brevissime bilobo terminatus. Cetera generis.

Qualitates et Usus.-Inter plures Gentianaceas in Distr. Huilla a me observatas et ob principium amaricanti-tonicum, quo pollent, sub forma decocti caulium et radicis ceu remedium roborans, digestionis post febres intermittentes perturbatæ vigorem restaurans, adhibitas, hanc præsentem speciem ægro-

* Plurima loco citato a me collecta specimina habitu suo plantam quidem annuam indicant, ast simul alia robustiora adsunt, quorum radix circa collum valde incrassata et fere lignosa vitam plurennem vel saltem biennem indigitat. Plures enim in eadem regione Huillensi plantarum tum Monocotyledonearum quum Dicotyledonearum species observavi, quæ habitu pusillo, gracili et radice tenuiter fibrillosa plantam annuam simulant, dum reapse perennantibus vel saltem per plures annos viventibus adnumerandæ sunt. Sic ex. gr. variæ species Droseræe, in spongiosis editis Distr. Huilla frequenter obviæ, omnino habitum plantarum annuarum fingunt, sed tamen gemmula, in radicis collo intra foliorum radicalium rosulam emarcidam abseondita et quolibet anno sequente in plantam notam evoluta, vitam perennem ducunt. 
tantibus præ ceteris salutarem expertus sum, qua ratione ductus plantam nomine specifico "salutaris" designavi.

Observatio._Sebæa involucrata Klotsch, in Peters, Reis. Mossamb. i. p. 271, quantum e descriptione l. $c$. data concludere licet, forsan alteram Faroa speciem sistit, a nostra tamen foliis involucrantibus magnis cordato-lanceolatis scariosis et præecipue calycis laciniis obovato-spathulatis statim dignoscendam, cujus autem specimina nondum videre licuit.

\section{Belmontia, E. M.}

Belmontia gracilis, Welw. n. sp. $B$. caule erecto, 4 -gono, filiformi, simplici vel parce ramoso ; foliis anguste lineari-lanceolatis linearibusve, internodiis brevioribus, canaliculatis, basi semiamplexicaulibus ; calycis profunde 5-partiti segmentis lato-lanceolatis, longe acuminatis, margine late membranaceis, dorso alato-carinatis ; corollæ tubo gracili, sursum ampliato, limbi 5-fidi lobis ovatis apiculatis patulis; antheris quam filamenta brevioribus, glandula elongato-claviformi superatis; stigmate oblongo-clavato, stylo recto vix breviore, apice subbilobo.

Habitat in pratis spongiosis Districtus Huilla, ad 5000 ped. altit. socialis cum variis Utriculariis, Xyrideis et Eriocauloneis, inprimis inter Lopollo et Monino, ubi mense Aprili 1860 c. fl. et fr. legi. Exsic. Welw. Iter Angol. no. 1524.

Stirps annua, reliquis generis speciebus multo gracilior. Radix brevis, tenuiter fibrillosa. Cauliculus filiformis, 3-5 pollices altus, erectus, nune simplicissimus uniflorus, nunc ramulo uno alterove laterali bi- vel triflorus, foliorum paribus 3 vel 4 , pollicem vel sesquipollicem inter se distantibus vestitus. Folia ima superioribus duplo breviora et angustiora, illa in medio caulis sita 5-6 lin. longa, $\frac{1}{2}$ vel $\frac{2}{3}$ lin. lata, patula, herbaceo-viridia. Flores parvi, longe pedunculati, lutei, subnutantes; pedunculi nudi, in speciminibus unifloris $2-3$ pollices longi, erecti, cauliculum terminantes, iis ramulorum lateralium vix pollicaribus et erecto-patulis. Calycis segmenta a basi ad medium usque late membranaceo-marginata, demum subulatim acuminata, dorso carinato breviter alata, corollæ tubo paullo breviora. Corolla omnino Belmontice cordate var. micranthe, quacum etiam glandularum minutarum glomerulis inter calycem et corollam obviis convenit. Anthere in tubi parte superiore dilatata inclusæ, filamentis breviores, glandula gracili cylindrico-clavata, erecta, ceraceo-aurantiaca terminatæ. Ovarium oblongo-ovoideum, bisulcatum, biloculare, placentis latiusculis septulo contiguis. Stylus rectus, firmulus; stigma pro more floris sat magnum, elongato-clavatum, apice nunc obiter bilobum nunc integrum, fere styli longitudine, stamina vix superans. Capsula ovoidea, corolla marcescente vestita, bivalvis, bilocularis, placentis demum liberis induratis. Semina numerosissima, placentis immersa, quadrangulo-prismatica, testa tenuissime dense papillosa.

\section{ExochenIUM, Griseb.}

1. Exochentum Primuleflorum, Welw. n. sp. E. annuum, pumilum, erectum; caule a basi trichotome ramoso, quadrangulo, ramis fastigiatis foliosis; foliis erectis lanceolatis vel lineari-lanceolatis linearibusve, acuminatis, trinerviis, basi semiamplexicaulibus ; pedunculis axillaribus rectis inæquilongis, inferioribus elongatis, superioribus sensim brevioribus; calycis lobis anguste alato-carinatis, acuminatis, corollæ tubo sursum ampliato brevioribus ; corollæ flavæ lobis ovatis, basi angustatis, apice apiculatis; stylo filiformi, recto, glanduloso-puberulo, stigmate cylindrico-clavato, simplici vel subbilobo. 
3. nanum. Cauliculis abbreviatis $\frac{1}{2}-1$-pollicaribus, cæspitulosis vel fere nullis, pedunculis tune e foliorum radicalium rosula emergentibus, floribus non raro totius cæspituli altitudine longioribus, limbi corollæ lobis rotundatis, mucronato-apiculatis.

Habitat in spongiosis editioribus Distr. Huilla, inter 5000 et 5500 ped. altit., socialis cum Droseris, Xyrideis et Cyperaceis pusillis, inprimis in alta planitie inter Lopollo et Humpata. Martio floret et fructif. Var. $\beta$ in ejusdem Districtus declivibus uliginosis hyeme exsiccantibus juxta viam versus Gambos c. fl. Apr. 1860. Exsic. Welw. Iter Angol. no. 1513 et 1514.

Pulchra planta, e longinquo in pratis breve herbidis visa quasi Primulce acaulis corymbos aureos mentiens, hine inde cxspites 25-30-floros obferens. Radix e fibris tenuibus abbreviatis dense fasciculata. Caulis paullo supra basim in ramos plures 3-chotomos, fastigiatos, subpatulo-erectos divisus, non raro cespites multifloros 3-6 poll. diametri, sed solummodo 2 ad 5 pollices altos exhibens. Folia radicalia caulinis breviora et obtusiora, cito marcescentia, caulina $1-1 \frac{1}{2}$ poll. longa, 1-2 lin. lata, in aliis speciminibus angustissima vix lineam mediam lata, sensim longe acuminata. Pedunculi axillares vel in ramorum ramulorumque dichotomiis solitarii, erecti, basi subalato-quadranguli, inferiores 1-2 pollices longi, superiores sensim breviores, supremi brevissimi, vix lineam longi. Flores sulphureo-flavi vel non raro splendide aurantiaci, erecti, incluso calyce ad $\frac{3}{4}$ poll. longi ; limbi 9 lin. diametri, 5 -fidi (rarissime 4-fidi), tubo sursum dilatato dimidio brevioris, lobis late ovatis, nunc brevius nunc longius apiculatis. Stamina in parte inferiore tubi inclusa; antherarum glandula apicalis cylindraceoclavulata, fere loculis æquilonga, eæ ad basim antherarum sitæ minutæ, subglobosæ, loculis toties breviores. Stylus plerumque staminum longitudine, sed etiam is brevior vel paullo longior, una cum stigmate clavulato-incrassato apice vix bilobo puberulus. Capsula ventricoso-ovoidea, corolla marcescente vestita, styli residuis apiculata, bivalvis, bilocularis; placenta centralis, spongioso-carnosula, quadripartibilis, demum libera. Semina placentæ immersa, minutissima, subquadrangulari-prismatica.

Observatio.-Characteribus genericis bene cum Exochenio convenit; ab Exochanio grandi Griseb. radice autonoma nec parasitica, caule a basi fastigiatim ramoso, floribus erectis nec horizontaliter nutantibus, alis calycis basim versus evanescentibus nec dilatatis, tubo corollæe calycem longius superante etc. nec non habitu discernitur.

2. ExochenIUm DEBILE, Welw. n. sp. E. annuum (?), nanum, flaccidulum, rhizomate subcarnoso, crassiusculo, albido, repente, fibrillis fragilibus stipato ; cauliculis erectis, debilibus, quadrangulis, simplicibus vel parce tri- dichotome fastigiato-ramosis ; foliis internodiis subbrevioribus, oblongo- vel ovato-lanceolatis plerumque acutis, summis hinc inde linearibus; pedunculis axillaribus vel terminalibus, brevibus, fructiferis subelongatis; corollæ albæ tubo calyce longiore, sursum ampliato, limbi laciniis tubo subtriplo brevioribus, obovato-oblongis, apice rotundato vix apiculatis; stigmate elongato-clavato, glanduloso-pubescente, quam stylus longiore, apice obtusiusculo bilobo.

Habitat sparsion in limosis humidis breve herbidis Distr. Pungo Andongo, ad margines lacus magni dicti "Lagoa de Quibinda," ad dextram fluminis Cuije. Cum fl. et fr. Martio 1857. Exsic. Welw. It. Angol. no. 1511.

Herbula perparva, forsitan parasitica, habitu Sebæe pusilla (Lagenias pus. E. M.) non absimilis, 1-2 pollices alta. Rhizoma carnosulum, oblique descendens, fibrillis admodum fragilibus elongatis limum humidum perrepens, e collo caules paucos debiles vix bipollicares, simplices vel fastigiatim ramosos emittens. Folia in uno eodemque specimine varia, plerumque lanceolata et acuminata, rarius ovata et obtusiuscula, summa hinc inde anguste lanceolata vel linearia. Cymula fastigiatæ, paucifloræ, hic depauperatæ bi- unifloræ. Flores una cum calyce 6-7 lin. longi, erecti. Calycis alæ breves, ejusdem 
segmenta basi late membranaceo-marginata, apice subulata et divergentia. Corolla alba, tenera, tubo calycem constanter superante, faucem versus modice ampliato; limbi 5 -fidi lobi campanulatim patuli, tubo duplo subtriplove breviores, apice rotundato-obtusi, absque ullo mucrone vel apiculo. Stamina, antherarum fabrica et stigma nec non capsula et semina fere omnino speciei antecedentis, a qua tamen præsens rhizomatis natura, corolla alba duplo minore, tubo corollino elongato et limbi lobis rotundato-obtusis inapiculatis sine difficultate distinguitur.

Observatio.-Quoad herbulæ durationem incertus permaneo; habitus quidem et cauliculorum tenuitas plantam annuam indigitant, ast rhizoma crassiusculum et subcarnosum forsitan stirpem biennem vel imo per plures annos durantem sustentat. Conf. Observ. ad calcem Faroæ salutaris pag. 46.

3. Exochantum grande, Griseb. DC. Prodr. ix. p. 55.

Habitat freq. in spongiosis pratisque silvaticis uliginosis dense herbidis totius Distr. Huilla, ad 45005000 ped. alt., plerumque cum Droseris, Strigis et Scleriis etc. socialis, inter rhizomata aliarum plantarum, inprimis Cyperacearum, parasiticum. A Decembri usque ad Febr. flor. et fructif. Exsic. Welw. Iter Angol. no. 1516.

Observatio.-Stirps in DC. Prodr. l. c. a clar. Grisebach cum signo ? ceu annua enumerata certe annua est et quidem absque dubio parasitica, radicis pro more parvulæ fibrillis carnosulis, albidis, subsimplicibus, tortuosis, rigidulis et fragillimis aliarum plantarum, inprimis Cyperacearum rhizomatibus adnascens. Flores plerumque horizontaliter nutantes. Corollæ limbus subbilabiatus. Staminum et styli longitudo reciproca maximopere variat; in quibusdam floribus stylus antheris multo brevior et filamenta antheris longiora inveniuntur, in aliis stylus elongatus stamina longe superans simul cum filamentis abbreviatis, antheris subæquilongis, adest. Antherarum loculos in pluribus a me examinatis speciminibus inter se liberos nec pariete interno concretos, et quidem rimis lateraliter nec extrorsum dehiscentes inveni. Stylum in plerisque floribus simplicem nec bicrurem vidi et stigma elongato-clavatum sive oblongo-spathulatum, compressiusculum, glanduloso-pubescens, stylo ipso duplo longius. Ex hic allatis controversiæ resolvuntur, quæ in plantæ descriptione apud auctores occurrunt, neque mirandum cur cl. E. Meyer (Commentar. p. 183) stylum antheris breviorem dicit, dum cl. Griseb. l. c. ipsum elongatum, corolle tubum subexcedentem describit.

Ceterum genera Lagenias, Belmontia et Exochønium nimis affinia vixque notis validis inter se differe videntur, et, ni fallor, potius ceu totidem unius ejusdemque generis sectiones consideranda, a genere Sebcea, uti hodierno die constitutum, nonnisi staminibus inclusis et antherarum glanduliferarum fabrica tute distinguenda.

\section{Ordo BIGNONIACE Æ.}

Subordo Sesa Me Ex, Endl. G. Pl. 709.

Sesamothamnus, Welw. gen. nov.

Calyx parvus, obliquus, 5-dentatus, persistens. Corolla hypocraterimorpha; tubus elongatus, ampliatus, curvus, basi in calcar elongatum horizontale productus; limbus planiusculus, inæqualiter subbilabiatim quinquefidus, lobis rotundatis, tribus quam ceteri majoribus; faux nuda. Stamina 4, subdidynama, VOL. XXVII. 
infra faucem corollæ inserta, rudimento $5^{\text {th }}$ nullo; antheræ subsessiles, lineari-oblongæ, apiculatæ, basi cordatæ, loculis rimis lateralibus dehiscentibus. Ovarium cylindricum, oblique sessile, basi gibbosoincrassatum, quadriloculare; stylus elongatus filiformis, stigmatibus duobus obovato-ellipticis ; ovula juxta loculorum angulum centralem plurima, uniseriata, horizontalia. Capsula ampla, lignosa, planocompressa, obovato-oblonga, transversim septicide bivalvis, valvis planis, septis ab axi placentifera solutis incomplete quadrilocularis, loculis polyspermis. Semina in loculis numerosa, compressa, uniseriata, horizontalia, valvis parallela, transverse oblonga, late alata, nucleo obovoideo, alis membranaceis, planis. Embryo exalbuminosus, nucleo conformis. Cotyledones planæ, obovatæ, vertice cordato-emarginatæ, oleoso-carnosulæ; radicula recta, conica, acutiuscula, ad hilum spectans; plumula inconspicua.

Frutex Africæ trop. occidentalis, glabrescens, glaucescens, trunco brevi difformi, e basi tumida ramosissimus, ramis erectis, virgatis, spinosis. Folia decidua, parva, in axillis spinarum fasciculata, obovatospathulata, petiolis basi articulatis. Flores in racemos breves axillares dispositi, magni, pedicellis brevibus crassis suffulti, ex albido rosei.

Observatio.-Genus Sesamo proximum et affine, attamen corollæ tubo gracili elongato, basi longe calcarato, ovario basi gibboso, nec non caule lignoso, spinis firmis horrido ab omnibus Sesameis hucusque descriptis egregie distinctum, simulque Africæ calidæ Nanodendra admodum singularia, et usque huc jam ex Apocynearum, Asclepiadearum, Gnetacearum, Ampelidearumque familiis cognita, novo nunc socio e nobili Bignoniacearum ordine illustrans.

Species unica :

\section{Sesamothamnus Benguellensts, Welw. (Tab. XVIII.)}

Habitat sporadica in montosis rupestribus parce dumetosis Districtus Mossamedes (Subdistr. Bumbo) inter Cazimba et Quitibe ad 1000 ped. circiter altitud. supra mare. Octobr. 1859 c. floribus vix bene apertis, Junio 1860 cum fructu maturo legi. Exsic. Welw. Iter Angol. no. 1509.

Stirps secundum ætatem habitu admodum varians; juvenilis frutex gracilis, strictus, caule ad basim digiti crassitudine, 4-5-pedali, subsimplici vel parce ramoso, juxta totam longitudinem spinis alteris armato, apicem versus florifero, per majorem anni partem aphyllo; progrediente æate vero caulis, basi sensim circuitu increscens, truncum efformat non raro 4-6 pedum circumferentiæ sed humilem, modo supra basim in ramos breves, brachii crassitudine, erectos vel obliquos divisum, ex quibus demum ramuli crebres, erecti, virgati, hinc inde breve ramulosi, spinulis horridi, 4-6 pedes alti, ortum ducunt; truncus basalis ramique primordiales tunc spinis omnibus dejectis, cortice albidocinereo vel pallide fuscescente, transversim crebre et minute rugoloso sed parum aspero vestiuntur (vid. Tab. XVIII. fig. 1). Spince a basi lata, longe decurrente, anguste conicæ, $\frac{1}{3}-\frac{1}{2}$ pollicem longæ, apice truncatæ (!), juniores erecto-patulæ, vetustiores horizontaliter patentes vel imo quidpiam declinatæ. Folia in spinarum axillis fasciculata, nonnisi post flores evoluta, integra, membranacea, rigidula, pro magnitudine stirpis parvula, majora vix pollicem longa, 4w6 lin. lata, glaucescentia, obovato-spathulata, penninervia, margine integerrima, in petiolum basi articulatum sensim angustata, jam paullo ante fructus maturitatem decidua; petiolorum autem bases infimæ post folia delapsa persistentes, sensim in tubercula parva ovato-conica apice truncata increscunt, demumque indurescunt et lanugine albida intertexta, acervulos capituliformes, axillis spinarum insidentes, efformant, in omnibus ramis ramulisque plantæ, excepto trunco basali, obvios; nec tamen omnia hæc in quolibet acervulo axillari modo hic indicato congesta tubercula (i.e. petiolorum bases transformatæ) semper eodem in statu permanent, sed eorum adultiora, circa acervulorum basim sita, progrediente ramuli ætate, sensim prolongantur et pariter in spinulas excrescunt, quarum non raro $2-4$ in ipsis spinarum axillis, acer. 
vulos istos quasi stipantes, inveniuntur*. Flores pulchri, carnosulo-rigiduli, infra ramulorum apices in racemos abbreviatos 3-7-flores, erecto-patulos, e spinarum axillis oriundos, collecti ; pedunculus communis crassus, subsucculentus, cylindricus, e viridi violascens, basi cicatricibus foliorum delapsorum stipatus, hinc inde squamulis auctus, demum lignescens; pedicelli ejusdem fere ac pedunculus ipse, crassitudinis, 2-4 rarius 5 lin. longi, apice incrassati, medio opposite bibracteolati, bracteolis anguste ovatis sive lanceolatis, vix lineam longis, strictim erectis, in axilla sua gemmulam glandiformem foventibus, in fructu una cum gemmula abortiva persistentibus. Calycis laciniæ ovato-deltoideæ, breviter acutæ, 4 anteriores inter se subæquales, postica reliquis paullo brevior et angustior. Corolla subhypocraterimorpha, calyci oblique insidens, quasi equitans; tubo $2 \frac{1}{4}-2 \frac{1}{2}$ pollices longo, medio $1 \frac{1}{2}-2$ lin. crasso, albido-roseo, sursum arcuato, cylindrico, infra faucem dilatato, basi quidpiam ampliato et calcari elongato-conico, obtusiusculo, 1-1 $\frac{1}{4}$ poll. longo, horizontaliter protenso, cavo munito ; limbi planiusculi, fere $2 \frac{1}{4}$ poll. diametr., ex albido rosei, intus nivei nitiduli, lobi subbilabiatim dispositi late ovato-suborbiculares, $\frac{1}{2}-\frac{3}{4}$ poll. lati, duo (labium superius fingentes) reliquis paullo angustiores brevioresque, omnes obiter vel vix concavi, margine integerrimi. Stamina 4, infra faucem corollæ inserta, vix apicibus exserta, subdidynama; duo, labio inferiori respondentia, ceteris paullo longiora eorumque filamenta brevissima, superiorum duorum antheræ sessiles; filamentis tamen omnium quatuor longe in tubo, hic pilis minimis adsperso, adnato-decurrentibus. Anthere turgidæ, 3 lin. circiter longæ, dorso ad emarginaturæ sinum fixæ, loculis appositis rima laterali dehiscentibus, connectivo ultra loculos in apiculum subuliformem producto. Ovarium subcompresso-cylindricum, gibbere basali calcar versus spectante, calycis fundo oblique insidens; discus vix ullus, saltem in alabastris a me examinatis inconspicuus. Stylus gracilis, longe exsertus; stigmatis lobi hiantes. Capsula rigida, nitidulo-fusca, compressa, elongato-obovata vel obovato-oblonga, uno latere plerumque paullo ventricosa, apice obtusiusculo styli basi indurata apiculata, $3-3 \frac{1}{2}$ poll. longa, $1-1 \frac{1}{2}$ poll. lata, juxta facierum medium et margine circumcirca obtuse sulcata, nervis elevatis venulas laterales dichotomas emittentibus longitudinaliter percursa, transversim septicide bivalvis, elastice dehiscens, ob septa, valvis parallela, nunc ab axi centrali placentifera soluta et apice abortiva, inferne imperfecte quadri- superne bilocularis. Semina una cum alis $\frac{2}{3}$, majora imo $\frac{3}{4}$ poll. diam. transversali, quoad directionem in loculis horizontalia, ast quoad faciem nuclei et alæ verticaliter, i.e. valvis septisque parallele seriata, dense imbricata; alæ planæ, tenuiter membranaceæ, pallide fuscescentes sive badiæ, pellucidæ, rigidulæ, levigatæ, margine integerrimæ; nucleus turgidulus, $3-3 \frac{1}{2}$ lin. longus, brunneus. Cetera ex charactere generis.

Sésamdm (Eusesamum) Angolense, Welw. Apont. p. 588 $\$$. S. caule erecto, firmo, 3-5pedali, glabriusculo, superne parce ramoso, foliis oblongo-lanceolatis vel oblongolinearibus lingulatisve, breve petiolatis vel subsessilibus, inferioribus oppositis, superioribus et floralibus alternis, basi in petiolum angustatis, apice rotundato-obtusis vel emarginatis, margine repando undulatis, supra intense viridibus, glabriusculis, reticulato-rugulosis, subtus, nervis purpureis exceptis, albo-tomentosis; floribus

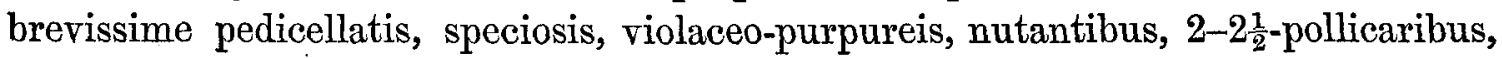
fauce bilabiatim campanulata diametri ultrapollicaris; capsula lineari-oblonga, in

* Ex supra dictis colligere licet, spinas ipsas primordiales plantæ nostræ nequaquam pro ramulis abortivis habendas, sed potius cen petiolorum transformationes considerandas esse; cui metamorphosi, uti observationes repetitæ in loco natali institutæ me edocuerunt, etiam spince (et rectce et uncinata) variarum specierum scandentium ex generibus $C_{e}$ rodendron, Combretum etc. etc. originem suam debent.

† Limbi dispositio bilabiata minus in flore expanso sed evidentius in alabastri æstivatione observanda, ubi lobi tres majores interiores, infimo intimo, et duo minores extimi inveniuntur, uti in Labiatis.

$\ddagger$ Nomen et habitus plantx atque locus natalis. 
rostrum breve demum bifidum acuminata, undique pilis raris albis adspersa; seminibus planiusculis, rugulosis, sulco utrinque acute marginato cinctis.

Habitat in dumetosis silvaticis arenosis Distr. Pungo Andongo, juxta ripas rivorum Lutete ct Luxillo, nec non prope Lombe, inter 3000 et 3500 ped. altit. Ab Octobr. ad Decembr. fiorentem et partim fructif. vidi. Loca humidiuscula amat. Exsic. Welw. Iter Angol. no. 1645.

Caulis strictim erectus, penna olorina crassior, in solo pinguiore hinc inde usque 6-pedalis, obtuse quadrangulus, inter angulos sulcatus, junior pubescens, demum glabratus, plerumque obscure purpurascens, a basi foliosus, apicem versus in ramos paucos $\frac{1}{2}-1$-pedales, erectos, oppositos vel sæpius alternos divisus; internodia inferiora 2-pollicaria, superiora circiter pollicaria. Folia quoad indumentum sat constantia, subtus semper tomento laxiusculo albido, demum exsiccatione griseo obducta, nervo mediano latiusculo venisque saturate purpureis obiter pubescentibus percursa, inferiora 4-3 poll. longa, $1 \frac{1}{4}-1$ poll. lata, superiora sensim minora, præcipue angustiora, floralia sæpius $1 \frac{1}{2}-1$-pollicaria, lingulato-spathulata et apice obtuso vel emarginato mucronata. Flores inter congeneres maximi, secundi, in racemos laxos elongatos, caulem et ramos terminantes, dispositi, magnitudine in eadem stirpe versus racemi apicem sensim decrescentes, majores $2 \frac{1}{2}$ vel imo 3 pollices longi ; bracteis inferioribus foliis caulinis homomorphis, iis florum superiorum fere linearibus et apice longius mucronato-recurvis; calyx brevis, persistens, laciniis ovato-acuminatis, piloso-pubescentibus, 3 lin. longis, inter se subæqualibus; corolla lætissime violaceo-purpurea, tubo basi curvato, in alabastro densius, sub anthesi tenuiter pubescens, limbi bilabiati latissime hiantis lobis obtusis, ciliatis, intermedio labii inferioris magis producto. Ovarium dense piloso-hispidum. Capsule quoad magnitudinem, configurationem et rostri longitudinem iis Sesami indici satis similes, sed maturitate fere glabratæ vel pilis albis distantibus obsitæ. Semina nigricantia, breviter obovata, 1 lin. longa, plano-compressa, utraque facie rugulosa, totoque ambitu sulco latiusculo pariter ruguloso et utrinque acute marginato notata.

Species florum amplitudine nec non foliis subtus albo-tomentosis ab omnibus hucusque descriptis sat distincta, simulque planta pulcherrima, Digitalem luxuriantem æmulans, cultura in hortis dignissima.

Observatio.-Species altera, ut videtur etiam indescripta, quam nomine Sesami calycini in herb. Angol. designavi, huic supra descriptæ proxima et habitu valde affinis, sed omni

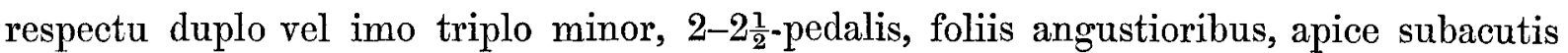
vel acutatis, corollis roseis 10-15 lin. longis (nec 2-3-pollicaribus) etc. discrepans, præcipue autem foliis subtus non incano-tomentosis, sed glabriusculis, lepidoto-glaucescentibus et calycis laciniis lanceolato-linearibus, longe acuminatis, 4 lin. longis glandulisque petiolaribus evidenter stipitatis differt. Crescit hæc species in arenosis parce et breve dumosis inter Præsidium Pungo-Andongo et Sansamanda, mense Januarii 1859 c. fl. et fr. lecta.

Exsic. Welw. Iter Angol. no. 1644.

Caules fere teretes, atque etiam fructiferi undique pilis albis adspersi. Folia quam in Ses. Angolensi duplo breviora et angustiora, floralia acuminata, omnia supra glabrescentia, intense viridia, subtus nervo mediano venisque atque venulis transverse anastomosantibus elevatim prominulis et intense purpureis percursa, ceteroquin lepidibus argenteis dense gregatis glaucescentia. Lepides hæ iis quæ in caulibus, foliis atque floribus variarum specierum Pedalinearum occurrunt, exacte similes itidemque, sed minus copiose muciparæ. Conf. Linariopsidem prostratam, hic infra descriptam. 


\section{Subordo Pedalined.}

Pterodiscus aurantiacus, Welw. n. sp. Pt. subsucculentus, foliis oblongo-lanceolatis vel obovato-spathulatis, obtusis, margine repando-sinuatis dentatisve, in petiolum longiusculum, circiter pollicarem, basi utrinque glandula ampla auctum angustatis, supra glabriusculis, subtus lepidoto-glaucescentibus; corollis vix pollicem longis, aurantiacis, tubo cylindrico, limbi subbilabiatim patentis lobo infimo majore, omnibus intus pilis crispulis adspersis, extus, uti tubus, lepidotis; fructus compresse tetragono-ovoidei alis semiorbiculatis, transverse plicato-radiatis, basi rotundata liberis, apice inter se confluentibus.

Habitat rarior in sabulosis maritimis Distr. Mossamedes, ad ripas fuminis Bero, ubi Julio 1859 c. fl. et fr. legi. Exsic. Welw. Iter Angol. no. 1658.

Herba radice crassa fusiformi perennans, tota carnosula. Caulis decumbens, scsquipedalis, inferne glaber, epidermide crassiuscula albida, facile secedente, obtectus, superne et ad ramos oppositos vel rarissime altcrnos dense sed minute albido-lepidotus. Folia opposita, patula, fragilia, majora,

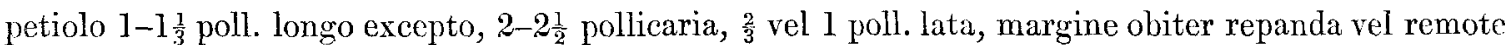
dentata aut inæqualiter crenulata, apicem caulis ramorumque versus scnsim minora; glandula* ad petiolorum basim pro more magnæ, depresso-globosæ, atropurpureæ, e nucleo compactiore et excipulo crenato arcte adpresso, sive squamulis in excipulum conmatis consistentes. Pedicelli circiter 3 lin. longi, densissime lepidoti. Flores una cum calyce profunde 5-partito 10-14 lin. longi, rigiduli, intense aurantiaci, extus undique lepidibus minutis argenteis (iis quæ ad folia et ramos novellos occurrunt, similibus sed rarioribus) obsiti ; tubus circiter $\frac{1}{2}$-pollicaris, faucem versus parum ampliatus, mox in limbum subbilabiatim $\frac{2}{5}$-lobum, patentem abiens, lobis rotundatis $3-4$ lin. longis, intus crispulopilosis, tribus (labium inferius fingentibus) paullo longioribus, eorumque medio lateralibus ampliore Filamenta basi compresso-dilatata; antheræ circumscriptione late cordiformes, connectivo apiculatæ, loculi's subreniformibus, connectivo infra apiculum insertis, inferne liberis, rimula dorsali apertis. Stigma bilobum, lobis ovatis (nec subulatis !), superiore erecto, parce vel vix stigmatoso, inferiore reflexo et ad totam superficiem internam dense stigmatoso. Fructus, qui obiter aspectus Combretacearum quarumdam fructos alatos valde simulat, in pedicello parum accreto nutans, siecus, lignose durus, badio-fuscus, compresse ovoideus, obscure quadrangulus, late quadrialatus, faciebus elevatim laxe reticulatis, alis scariosis, semiorbicularibus vel reniformibus, 5 lin. latis, basi protracta liberis, apice cruciatim connatis. Cetera generis.

Species a Pterodisco specioso Hook. et Pt. Gayi Decne.† (unicis hucusque descriptis) foliis longe petiolatis et floribus aurantiacis, quam in Pt. specioso triplo minoribus, vix pollicaribus facili negotio distinguenda, in territorio Mossamedensi admodum rara, sed probabiliter in terris ad austrum confinibus frequentius invenienda.

\section{LINARIOPsIs, Welw. gen. nov.}

Calyx quinquepartitus, lacinia superiore reliquis inter se æqualibus breviore et angustiore. Corolla tubulosa, tubo vix vel parum incurvo, intus ad staminum insertionem annulo piloso vestito, sensim in faucem subcampanulatam ampliato, limbi bilabiatim quinquelobi lobis rotundatis, infimo protracto.

* Glandulæ, lente fortiore scrutatæ, e nucleo dense carnoso, vertico non raro areola notato, ambitu squamulis pluribus brevibus, obtusis, inter se connatis vel arete adpressis involucrato, constant, et absque fere dubio flores abortivos indigitant.

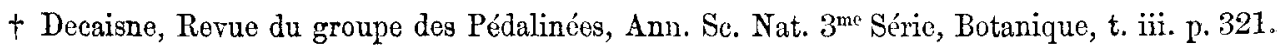


Stamina quatuor, didynama, fertilia; rudimentum quinti vix ullum; antheræ oblongæ, basi cordatæ, dorso supra sinum fixæ, introrsæ, longitudinaliter dehiscentes. Ovarium conico-ovoideum, in disco parum concavo sessile; stylus filiformis, stigmate parvo bifido, lobis angustis subacutis. Fructus calyce persistente parum aucto, laxe patulo stipatus, nucamentaceus, siccus, indehiseens vel tarde apice hians, oblongus vel subobovoideus, quadricostatus, inter costas seriatim tuberculosus, apice obtuso breviter alato-rostratus, absque omni spina, unilocularis, dispermus. Semina erecta, obovata, compressiuscula, a medio ad basim truncatam usque alato-marginata, testa membranacea, laxiuscula, levigata, endopleura tenui; embryo semini conformis; cotyledones planoconvexæ, obovatæ, apice emarginatæ, carnosæ.

Herba montium Benguellæ interioris juga altiora incolens, mucilagine copiosa scatens, radice crassa perennans, caulibus prostratis, a basi ramosis, villoso-pubescentibus ; foliis oppositis breve petiolatis, ovatis, subtus glauco-pruinosis et dense lepidotis ; floribus axillaribus solitariis, breve pedicellatis, pedicellis bibracteolatis glanduliferis ; calyce laxo, pilosulo; corolla violacea intus purpureo-striata, extus pubescente; fructu parvulo, erecto, tuberculis longitudinaliter seriatis depressis obsito, ceteroquin omnino inermi.

Genus Pedalio quidpiam affine, sed fructu uniloculari et seminibus erectis ab ipso et simul ab omnibus Pedalinearum generibus hucusque descriptis satis distinctum.

Species unica :

\section{LINARIOPSIS PROSTRATA, Welw. n. sp.}

Habitat in collinis arenoso-humosis, breve herbidis, juxta rivos Distr. Huilla, præsertim inter Mumpulla et Humpata, ad 4000-5000 ped. altit. Octobr. 1859 cum fl. et fr. legi. Exsic. Welw. Iter Angol. no. 1659 .

Herba socialis, habitu quibusdam Linarice speciebus e sectione Elatinoides non absimilis, undique plus minusve pubescens vel villosa, ast nequaquam succulenta. Radix fere digitum crassa, cylindracea vel fusiformis, fibroso-carnosa, pluriceps. Caules prostrati, circiter semipedales, teretiusculi vel obscure quadranguli ramisque oppositis elongatis parce ramellosis dense pubescenti-canescentes vel breviter patentim pilosi, apice adscendentes, undique distiche foliosi, internodiis 3-5 lin. inter se distantibus. Folia omnia opposita, penninervia, majora 5-7 lin. longa, 3-4 lin. lata, inferiora breve petiolata, ovata, basi rotundata, apice obtusiuscula, margine ciliato repanda vel remote dentata ; superiora subsessilia, angustiora magisque approximata ; omnia supra pallide viridia, pilis raris, lepidibus intermixtis aspersa, tactu asperula, subtus lepidibus densissime gregatis argenteis* glauco-pruinosa sive albicantia, plus minusve, præcipue juxta nervos venasque pubescentia. Flores semipollicares, foliis floralibus, caulinis homomorphis, vix vel parum longiores; pedicelli circiter lineam longi, in fructu incrassati, infra medium bibracteolati, bracteolis minimis, subfiliformibus, in axilla glandulam breve stipitatam gerentibus. Calycis profunde 5-partiti laciniæ lineari-lanceolatæ, obtusiusculæ, $1 \frac{1}{2}$ lin. longæ, pilosulæ, ciliatæ, subpatulæ, in fructu demum paullo auctæ eumque laxe involucrantes. Corolla vix semipollicaris, in alabastro dense cano-pubescens, demum puberula et lepidibus raris adspersa, sordide violacea, intus, excepto annulo piloso staminum basim ambiente, glabra, purpurascens, striis longitudinalibus intensius purpureis et circa faucis os punctis atropurpureis picta. Filamenta basi dilatata, purpureo-punctata; antherarum loculi glanduloso-punctati, basi liberi. Discus ovarii basim cingens concaviusculus, luteus, margine tumidulo, in fructu persistens. Stylus staminibus longior, incurvus, inclusus, deciduus; stigma pro more parvulum, lobis brevibus angustis. Nux

* Lepides hæ, lente fortiore examinatæ, frustula sistent obtuse quadrangula, e 4 vesiculis argenteo micantibus, depresse hemisphæricis, inter se connatis, composita. Lepides in quibusdam Sesami speciebus ( supra commemorato) observata, exacte ejusdem ac in Pedalineis structuræ sunt, ast mucilagine minus spissa farcta. 
$2 \frac{1}{2}-3$ lin. longa, $1 \frac{1}{2}$ lin. diametri transversalis, oblongo-subcylindrica vel obovoidea, glabriuscula, dura et tenax, costulis quatuor cruciatim oppositis hinc inde interruptis percursa, inter costulas tuberculis depressis, magnitudine et circumferentia inæqualibus, plerumque longitudinaliter seriatis obsita, apice obtuso costulis duabus oppositis magis prominulis et confluentibus breviter alato-rostrata, carpellorum marginibus introflexis, solummodo basi prominentibus, unilocularis. Semina duo, e fundo loculi erecta, $1 \frac{1}{2}$ vel vix 2 lin. longa, vertice rotundato-obtusa, basi latiuscule truncata, ibidemque ala brevi, sursum versus evanescente, marginata. Testa badia, omnino levigata, embryonem laxe vestiens. Radicula cotyledonibus multo brevior, crassiuscula, obtuse conica. Cetera generis.

Qualitates et Usus.-Herba omnibus in partibus mucilagine limpidissima simulque insipida dives, et (etiam per annos jam exsiccata et conservata) aquæ frigidæ vel tepidæ immersa, hanc mucilaginosam reddit limpidamque conservat, qua ratione herbæ hujusce infusum, aut simplex aut succo Citri mixtum vel Saccharo dulcificatum, in Tussi, Gonorrhoea, Dysenteria etc. potum admodum salubrem, nunc lenientem vel emollientem, nunc refrigerantem ægrotantibus præbet, sæpius decocto Malva vel Althare et similium præferendum.

\section{Ordo LABIAT $A$.}

\section{Trib. Ochme subtr. Plectranthea.}

Alvesia, Welw. gen. nov.

Calyx per anthesim brevissimus, subcupularis, bilabiatus, labiis rotundatis, inferiore latiore emarginato; tubus post anthesim valde auctus, membranaceus, ovoideus, inflatus, ore clauso. Corolla tubo brevi cylindrico, incluso, abrupte in faucem oblique subcampanulatam, sensu verticali compressiusculam ampliato ; limbi bilabiati labio superiore trilobo, lobo superiore reflexo, lateralibus brevissimis, latioribus, rotundato-obtusissimis, antrorsum spectantibus vel breviter reflexis, labio inferiore porrecto, concavo, obtuso, integerrimo. Stamina 4, exserta, declinata, filamentis apice adscendentibus ; antheræ biloculares, loculis divaricatis. Ovarium gynophoro subbrevi cylindrico impositum, quadrilobum; stylus filiformis, declinatus, stigmate minuto bidentato. Nucule perfectæ subsolitariæ, lato-obovoideæ, granulatæ, basi calycis vesiculoso-ampliati absconditæ.

Suffrutex 3-5-pedalis, Rosmarini facie, pubescenti-tomentosus, caule ramisque obtuse 4-gonis, sulcatis, ramulis strictis foliosis. Folia parva, oblongo-lanceolata, acuta, integerrima, supra glabriuscula, subtus tomentosa, penninervia. Verticillastri in racemos densos ramosos dispositi, laxe tomentosi, pedicellis brevibus. Flores rosei. Calyces fructiferi in pedicellis apice deflexis penduli.

Genus ob corollæ labii superioris configurationem et calycem fructiferum admodum ampliatum, vesiculoso-inflatum, inter Plectrantheas valde distinctum, dicatum velim clarissimo Bento Antonio Alves, viro humanissimo, inter horticultores Lusitanos eminenti, etiam Floræ Lusitanæ studioso, mihique olim in variis per agrum Olissiponensem peregrinationibus botanicis amcnissimo socio, amico constanti et fidelissimo.

Species unica :

Alvesta rosmarinifolia, Welw. n. sp. (Tab. XIX.)

Habitat in collinis dumetosis silvisque parum densis arenoso-humosis Distr. Huilla, inter 4000 et 5000 ped. altit., prope Mumpulla et Lopollo, fere semper in Protearum, Daphnoidearum atque Thesiorum consortio. Febr.-Apr. florentem, Junio adhuc parce fructificantem legi. Exsic. Welw. Iter Angol. no. 1636.

Suffrutex pulcher, hinc inde, solo et expositione faventibus, frutescens, caule eodem per plures annos 
virente et florente. Caules plerumque plures ex eadem radice, basi lignosi, erceti, 3-4-, rarius 5-pedales, obtusanguli, obscure rubentes, pube brevi densa tomentelli, jam a basi ramulis creberrimis abbreviatis, dense foliosis, strictiusculis, stcrilibus obsiti, superne parcius ramosi ; rami oppositi clongati, aque ac caules inferne ramulis brevibus foliosis abortientibus onusti et apice florigeri. Folia opposita, pro magnitudine stirpis parvula, majora 1-1 $\frac{1}{3}$ poll. longa, 2-3 lin. lata, lanceolata vel oblongolanceolata, rarius hinc inde fere linearia, breviter acuta, margine reflexo integerrima, supra læte viridia nitidula, subtus canescenti-tomentosa, penninervia, nervo medio et secundariis angulo acutissimo ab ipso egredientibus subparallelis, supra impressis, subtus prominulis. Verticillastri sæpius 6-flori, bracteis ovatis, obtusiusculis, quam pedicelli subbrevioribus, deciduis stipati, in racemos densos, ovato-pyramidatos, demum elongato-cylindricos, plerumque ramosos dispositi. Inflorescentia partes omnes plus minusve dense tomentosæ et rubore amœnissime roseo suffusæ. Pedicelli florigeri 2-3 lin. longi, fructiferi parum longiores, apice deflexi. Calyx sub anthesi 2 vel vix 3 lin. longus, externe dense tomentosus, interne nudus, labiis margine densissime ciliato-fimbriatis. Corolla 9-11 lin. longa, extus, tubo incluso excepto, laxe tomentosa vel lanuginosa, intus nuda. Filamenta juxta basim adnatam tenuiter pilosa, ceterum, uti antheræ, ovarium et stylus totus, glabra. Calycis fructiferi tubus admodum ampliatus, vesiculoso-inflatus, $1 \frac{1}{2}$ pollicem longus vel paullo longior, diametro pollicari, elliptico-ovoideus, deglabratus vel tenuiter puberulus, e viridi purpurascens venulisque obscurioribus laxe reticulatis percursus, labiis parum vel vix auctis sed nunc arcte clausis obtuse apiculatus. Nucule perfectæ, reliquarum abortu solitariæ, rarissime duæ, late obovatæ vel omnino globosæ, undique glandulis minutis punctiformibus, parum prominentibus obsitæ, in gynophoro parum vel vix aucto, fundo calycis insidente, sessiles. Cetera generis.

Qualitates.-Stirps quidem fere inodora, sed ob frondem gracilem discolorem florumque racemos amplos colore læte roseo superbientes Adonistis, imprimis Europæ australioris, ubi probabiliter sub divo prosperabit, magnopere commendanda.

\section{Trib. Stachydez, Subtr. Ballotez.}

AchYrospermum ethiopicum, Welw.n. sp. $A$. caule herbaceo, erecto, elato, 4-6-pedali, obtuse tetrogono, pubescente, parce ramoso ; foliis petiolatis, late ovatis vel ovato-ellipticis, basi cuneata et apice longe acuminato integris, margine grosse dentato-serratis, utrinque glabriusculis vel præcipue juxta nervos venulasque hirtulo-pubescentibus; verticillastris sub 6-floris, in spicam densam subtetragono-cylindricam, 2-4 pollices longam approximatis ; bracteis late ovatis, abrupte acuminatis, ciliatis, calyce subbrevioribus; calycis tubulosi pubescentis fauce intus puberula, dentibus 2 inferioribus reliquis paullo brevioribus; corollæ albæ, excepto limbo extus pubescente glaberrimæ, labio superiore emarginato-subbilobo, inferioris lobo medio lateralibus duplo latiore, rotundato-obtuso, concavo; styli breviter bilobi lobis æqualibus acutiusculis; nucularum paleis anguste spathulatis, apice obtuso ciliato-barbulatis.

Habitat in silvaticis umbrosis humidis Distr. Pungo Andongo ad 3200 ped. circiter altit., præ ceteris circa cataractas loco dicto Calundo, ubi Maio 1857 c. fl. et fructu necdum bene maturo legi. Exsic. Welw. Iter Angol. no. 1633.

Herba procera, Stachydis speciem luxuriantem simulans, plerumque 4-5-pedalis, hinc inde imo 7-pedalis. Caulis rectus, basi penna olorina crassior, obtuse 4-gonus, puberulus, superne teretiusculus ramisque abbreviatis densius pubescens vel pilis patentibus hirtus. Internodia inferiora 4-5 pollices inter se distantia, superiora sensim breviora. Folia membranacea, petiolis debilibus patula, majora una cum petiolo 1-1 $\frac{1}{2}$-pollicari ad 9 pollices longa, $3 \frac{1}{2}$ poll. lata, basi cuneata sensim in petiolum angustata 
ibidemque integra, margine dentibus deltoideis acutatis sursum spectantibus serrata, apice longo acuminata, acumine ipso edentulo, in utraque facie, exceptis nervis venisque puberulis, glabriuscula vel, inprimis superiora et summa ad petiolum nervosque et venas pilis rigidulis crebrioribus, nune: adpressis nunc patulis, adspersa. Verticillastri circiter 6-flori, dense spicati; spicæ in caulis ramulorumque apice terminales, solitariæ, juveniles obtuse 4-goni, florigeræ cylindraceæ, bene cvolute ad 3-4 pollices longæ, apicem versus quidpiam attenuatæ, obtusiusculæ. Folia floralia bracteæformia, subscarioso-membranacea, sessilia, late vel hine inde fere orbiculato-ovata, apice abrupte acuminat: vel cuspidata, extus puberula, margine ciliata, versus apicem spicæ angustiora et sensim acuminata, quam calyces paullo breviora, vel ipsos æquantes. Flores cujusvis verticillastri plerique sessiles, vel eorum unus aut duo brevissime pedicellati; pedicelli inæquilongi, basi bracteolis ovatis vel lanceolatis longe ciliatis stipati. Calyx membraniaceus (albidus!) tubulosus pubescens, intus pube rara adspersus, limbum versus modice ampliatus, subbilabiatim $\frac{3}{2}$-dentatus, dentibus ovatis, acutis, ciliatis, patulis, inferioribus duobus quam superiores paullo brevioribus. Corolle albæ tubus vix incurvus, inclusus, glaber; limbi extus pubescentis labium superius obcordato-emarginatum vel obiter bilobum, inferius 3-lobum, lobis lateralibus brevibus rotundatis, intermedio iis duplo majore, rotundato-obtuso et con.. cavo. Stamina ascendentia, exserta ; filamenta medio tubi inserta sed ad faucem usque adnata, nuda, ima basi in appendiculas membranaceas, tenuissime barbulatas, squamulas mentientes producta; antheræ loculis confluentibus uniloculares. Stylus staminibus fere æquilongus, apice paullo dilatato breviter bilobus, lobis æqualibus, patulis, acutiusculis. Gynophorum subquadridentatum. Nuculæe (solum immaturæ visæ) dorso et vertice paleis membranaceis crebris, imbricatim congestis, spathulatis, apice rotundato ciliato-barbatis, ipsis nuculis sesqui- vel duplo longioribus, comosæ. Aroma planta vix ullum.

Observatio.-Generis ob nuculas paleis sat conspicuis coronatas in ordine valde singularis, tres species hucusque descriptas invenio, silvas humidas insularum Java, Luzon et Madagascaria incolentes; nostra hæc, silvarum primævarum Africæ æquinoctialis civis, ab Achyrospermo densifloro Bl., cui ex descriptione cl. auctoris (Bijdrag. 84.0) affinis videtur, caule elato 3-6-pedali (nec 6-8-pollicari), spicis cylindraceis 2-4-pollicaribus (nec ovatis sesquipollicaribus), calycis fauce intus pubente (nec nuda) aliisque notis distinguitur; ab Ach. phlomoide, Bl. cui spica laxa et bractea uniflore adscribuntur, nec non ab Ach. fruticoso Benth., foliis obtusis crenatis et spica laxa insigni, longius distat.

\section{Trib. Scutellakine}

Tinnea, Kotschy et Peyr. in Kotschy, Plant. Tin. p. 25*.

Generis distinctissimi character, a clar. auctoribus $l$. $c$. egregie quidem sed secundum unicam speciem iis cognitam expositus, nunc, speciebus pluribus ex itinere Angolensi reportatis et cum typica comparatis, commode notis sequentibus ampliandus vel modificandus erit :

Calyx tubuloso-campanulatus vel globosus, bilabiatus, labiis integris, fructifer inflato-ampliatus, ventricoso-ovoideus, labiis ad basim usque fissis bivalvis, valvis singulis scaphiformibus. Corolla bilabiatie transversim modice compressæ labium superius inferiore duplo brevius, subintegrum vel sinu acuto bilobum, lobis obtusis, rectiusculis vel parum recurvis. Ovarium subsessile vel breviter stipitatum, plus minusve profunde quadrilobum. Stylus inter ovarii lobos centralis, stamina subæquans, apice subbilobus, lobo superiore brevissimo sterili vel obsoleto, inferiore majore acutiusculo dense stigma-

* Kotschy (Dr. Theod.), Plantæ Tinneanæ, Vindob. 1865, apud Gerold, fil. gr. Fol. pp. 54 cum tabb. xxv. 
toso. Nuculce clavato-obovoideæ, stipitatæ, basi intus areola oblonga concaviuscula notatæ, facie interna levigata gibbæ, dorso ala lata, elliptica vel orbiculari, e spinulis aridis radiantibus, pilorum arachnoideorum ope inter se dense contextis formata, scutellatæ. Cetera omnia conformia.

Herbæ elatæ vel suffrutices, Africam æquinoctialem cis et trans æquatorem incolentes, caulibus erectis, parce vel densius ramosis, pubescentibus vel incanis ; foliis breve petiolatis, oppositis vel ternis, vel non raro alternis in eadem stirpe simul obviis, ovalibus, integerrimis, membranaceis, glanduloso-punctatis ; bracteis latiusculis, herbaceis vel coloratis ; floribus axillaribus solitariis, in pedunculis bibracteolatis subsecundis, juxta caulis ramorumque extremitates nunc laxiuscule dispositis vel dense approximatis, fusco- vel violaceo-purpureis, grate fragrantibus.

Genus ab auctoribus in opere citato Verbenaceis adscriptum, sed ob calycem fructiferum (in una specie imo jam sub anthesi) ad basim partitum, omnino bivalvem, ovarium evidenter et, saltem in speciebus Angolensibus, sat profunde quadrilobum, nec non propter nuculas sat longe stipitatas dorsoque alato-scutellatas, inter calycem inflatum perfecte liberas et iis generis Perilomia H. B. K. omnimode analogas, ne dicam similes, potius inter Labiatas collocandum, quibus etiam a cl. Dre Thomson* et nuper a cl. Dr ${ }^{\mathrm{e}}$ Hooker $\dagger$ associatum fuit. Unam insuper specierum Angolensium jam anno 1862 loco infra citato inter Labiatas Scutellarineas enumeravi, simulque herbæ floriferæ et fructiferæ manipulum in Expositione internationali Londinensi una cum aliis plantis medicinalibus Angolæ exhibui. Tribui Scutellarinearum genus hoc subscribendum esse mihi videtur, quoniam calyx bilabiatus labiis integris demum ad basim fissis, simul cum nuculis dorso alatis nonnisi hac in Labiatarum tribu occurrit.

Species tres: una (Tinnea ethiopica Kotschy et Peyr. l. c.) Africam cisæquatorialem incolens; et duæ novæ Angolenses, nunc exponendæ.

1. Tinnea antiscorbutica, Welw. n. sp. T. caulibus herbaceis 3-5-pedalibus, strictim erectis, obtuse tetragonis, inter angulos sulcatis, dense pubescentibus, apicem versus ramosis, a basi foliosis ; foliis oppositis aut ternatis vel rarius alternis ; bracteis dense imbricatis, late ovatis, apiculatis, roseo-purpureis, calyces florigeros tubuloso-campanulatos sericeo-puberulos excedentibus; calycis fructiferi glabriusculi vel sparse pubescentis valvis antice alato-marginatis.

Catete bulla [nomen vernaculum Nigrit.]. "Planta herbacea vivaz da familia das Labiadas, do grupo das Scutellarineas etc.," Welw. Synopse explicat. 1862, p. 28.

Habitat non infrequens in silvarum primævarum subumbrosis editioribus Districtuum Golungo Alto et Pungo Andongo, inter 2000 et 3000 ped. altitud., inprimis copiose in declivibus de Serra de Alto Queta prope Sange, ubi ab autochthonibus, qui foliorum pulverem vel infusum tamquam remedium antiscorbuticum adhibent, "Catete bulla" nuncupatur. A Novemb. ad Maium flor., Febr. ad Jun. fructificat. Exsic. Welw. Iter Angol. no. 1632.

Herba perennis, radice lignescente multicipite. Caules gregarii, 5-15 ex eadem radice, stricti, plerumque 4-5-pedales, evidenter quadranguli et inter angulos obtusos late sulcati, basi simplices, apice in ramos subbreves erecto-patulos floriferos divisi, plus minusve cano-pubescentes, per totam longitudi-

* "Labiatarum novum genus; the four seeds are protected by an enveloping calyx, and feathered white in a beautiful manner; on the grassy banks of Madi, $3^{\circ} 15^{\prime} \mathrm{N}$. Frequent in forests, No. 705." (Dr. Thomson in Appendix G to Speke's ' Journal of the Discovery of the Source of the Nile,' London, 1863, p. 645.)

+ Botanical Magazine, tab. 5637. 
nem foliis, superioribus sensim minoribus, vestiti. Internodia inferiora circiter bi-, superiora 1-pollicaria, ea axis florigeri valde contracta. Folia opposita vel ternata, vel rarius et inprimis in superiore caulis parte alterna, petiolo brevi vix $2 \frac{1}{2}$ lin. longo suffulta, majora, demto petiolo, $2-2 \frac{1}{2}$ poll. longa, $1-1 \frac{1}{2}$ poll. lata, penninervia, latiuscule ovata, basi rotundato-obtusa, vel breviter in petiolum canaliculatum angustata, apice obtusiusculo abruptim in apiculam acutata, margine integro ciliolata, superne obscure viridia, glabriuscula vel rugulis minutis asperula, subtus paullo pallidiora, secus nervos venasque pubescentia, inter venas dense glanduloso-punctata, versus apicem caulis sensim minora, brevissime petiolata, obtusiora longiusque apiculata. Bracteæ membranaceæ, roseopurpureæ, foliis multo tenuiores, sub anthesi dense imbricatæ, subsessiles, late ovatæ vel suborbiculares, 6-8 lin. longæ, 4-7 lin. latæ, basi subtruncato-rotundatæ, apice obtuso apiculatæ, utrinque mollissime pubescentes, margine dense ciliatæ, calyces ipsis breviores occultantes. Pedunculi patentes, vix lineam longi, pubescentes, bracteolis duabus oppositis filiformibus pilosulis stipati. Calyx sub anthesi tubuloso-campanulatus, transversim compressus, 4-5 lin. longus, extus dense pubescens, intus tenuiter puberulus, utrinque roseo-purpurascens. Corolla 10-12 lin. longa, obscure purpurea, in alabastro pilis albidis adspersa, demum glabrata, resinoso-punctata, fauce et limbo transversim subcompressa, labio superiore obtuse bilobo quam inferius trilobum duplo breviore. Stamina labio superiore parum longiora, antheris solis exsertis; filamenta compressa, basi et ad latus internum albido-pilosa, sursum versus sensim dilatata, apice carnoso-incrassato obtuso recurva, lætissime flava ; antheræ biloculares, loculis ovoideo-globosis subdisjunctis, polline albido turgidis, longitudinaliter apertis. Ovarium in gynophoro turgido obscure crenato substipitatum, fere ad medium usque quadrilobum, lobis clavatis, erectis, levibus. Stylus staminibus paullo brevior, medio quidpiam dilatatus, apice brevissime bilobus, lobo uno minuto perbrevi, altero crassiore, longiore, intus stigmatoso. Calyx fructifer valde auctus, scariosus, ventricoso-inflatus, ovoideo-oblongus, nutans vel pendulus, 8 lin. circiter longus, 5 lin. latus, extus pube tenui hinc evanescente vestitus, intus glabriusculus, et longitudinaliter nervis pluribus crebre venulosis et prominulis percursus, valvis singulis antice in marginem semilunarem, lineam latum, planiusculum, mox leviter revolutum extensis. Nucula (Schizocarpia Kotschy, l.c.) abortu sæpius tres, scutellis dorsalibus oblongo-suborbicularibus, albidis, quoad structuram supra descriptis, 3-4 lin. longis, juxta margines laxe inter se cohærentibus absconditæ, quoad fabricam internam is speciei sequentis omnino similes, et descriptioni atque iconi speciei typicæ conformes.

2. Tinnea ertocalyx, Welw. n. sp. T. caulibus suffruticosis, 1-2-pedalibus, erectiusculis, teretibus, inferne cano-puberulis, superne albido-tomentellis, simplicibus vel parce ramosis, a basi foliosis; foliis oppositis vel alternis, rarius subverticillatim ternis; bracteis laxe imbricatis vel remotiusculis, cordato-ovatis vel sæpius cordatosuborbicularibus, apiculatis, subcrassis, rigidis, herbaceo-viridibus, calyces florigeros globosos, densissime lanuginosos vel albo-tomentosos æquantibus; calycis fructiferi ovoideo-globosi et dense lanuginosi valvis antice retusis, brevissime vel vix alatomarginatis.

Habitat in collinis breve dumosis, siccioribus et petrosis, juxta silvarum margines Distr. Huilla, frequens circa Lopollo ad 5000 ped. altit. Jan. 1860 c. flore, Martio c. fr. lecta. Exsic. Welw. Iter Angol. no. 163 s.

Suffrutex, basi ad altitudinem 3-4 poll. lignescens. Caules ex eadem radice plures, sæpius sesquipedales, erecti vel basi ascendentes, teretes vel rarius obscure angulati, absque omni sulco, molliter canopubescentes, apicem versus nunc albo-tomentosi nunc lanugine nivea obtecti, simplices vel parcius ramosi, ramis suboppositis vel sæpius alternis erecto-patulis. Folia internodiis $\frac{1}{2}-1 \frac{1}{2}$-pollicaribus dissita, alterna semper magis approximata, petiolo 1-2-lineari suffulta, majora $1 \frac{2}{3}$ poll. longa, 6-11 
lin. lata, orata, basi rotundata vel breviter cuneata in petiolum angustata, margine integra, apice ohtusiusculo vel obtuso apiculata, vel rarius sensim in apiculam brevem acutata, utrinque glandulosopunctata, supra læte viridia levigata vel minutissime rugulosa aut pube rara adspersa, subtus flavovirentia, puberula, vel densius pubescentia, nune, inprimis locis siccioribus, cano-tomentosa, nervo costisque supra parum, subtus evidentius prominulis, supcriora brevius petiolata et obtusiora, sensim in bracteas abeuntia. Bractea brevissime petiolatæ, basi plus minusve emarginatæ vel cordatæ, apice rotundato apiculatæ, herbaceo-virides, utrinque laxe vel densius tomentosæ, circiter 6 lin. longæ, 5-6 lin. latæ, quam folia quidpiam crassiores et rigidiores, in fructu persistentes. Flores subsecundi. Pedicelli circiter lineam longi, villosi, infra medium bracteolis 2 oppositis, ipsis duplo longioribus, lineari-lanceolatis, laxe villosis stipati, in fructu vix accreti. Calyces, in alabastro perfecte globosi, dense floccoso-tomentosi, sub anthesi ad 5 lin. longi, labiis truncatis transversim hiantes, jam hac periodo ad basim usque bipartibiles. Corolla violaceo-purpurea, ejusdem ac in specie antecedente magnitudinis, limbi labio supcriore æque ac in illa, obtuse bilobo. Ovarium fere ad medium usque quadrilobum, glabrum ; styli lobulus superior hac in specie non raro obsoletus. Calyx fructifer duplo subtriplove auctus, inflatus, clausus, nutans vel pendulus, ovoideo-vel ellipsoideo-globosus, extus dense lanuginoso-tomentosus, ad basim usque bivalvis; valvæ subcoriaceo-rigidæ, subæquales, intus glaberrimæ, nervis pluribus prominentibus percursæ, inter nervos elevatim venulosæ, superior primum decidua. Nucule abortu non raro tres, elongato-clavatæ, 3-4 lin. longæ, interna facie gibbæ et levigatæ, nonnisi stipitum basi excavata inter se laxe cohærentes, dorso ala arachnoidea, albicante, elliptica, 4-5 lin. longa, 3-4 lin. lata scutellatæ, bilocellatæ, locello altero minore vacuo. Semen obovatum, compressum, locelli angulo paullo infra apicem appensum ; testa membranacea, badio-flavescens, laxa, infra radiculam in filum tenue, spiraliter tortum, stipitem penetrans, prolongata. Embryo rectus, semine dimidio brevior sed parum angustior; cotyledones obovatæ, carnosulæ, leviter convexæ, applicatæ; radicula infra, brevis, obtuse conica.

\section{Ordo POLYGONACE无.}

\section{Subordo I. Polygonem.}

Trib. Pterygocarpex, Meisn., DC. Prodr. xiv. p. 3.

Oxygondm Acetoselda, Welw. n. sp. O. annuum, glabrum, glaucissimum, carnosulum; caule a basi ramoso, ramis decumbenti-ascendentibus, inferne parce ramulosis, semicylindricis vel subcompresso-angulatis; foliis lanceolatis vel lanceolato-oblongis, abrupte acuminatis, basi in petiolum longiusculum alatum sensim angustatis, margine repando- vel sinuato-dentatis; ochreis tenuiter membranaceis, truncatis, ore integerrimis vel minute remoteque denticulatis; racemis terminalibus, virgato-elongatis, gracilibus, interruptis ; pedicellis fasciculatis glabriusculis, fructiferis bracteam superantibus; acheniis oblongis, trigonis, juxta angulos subacutos membranaceoalatis, alis margine obiter repando-denticulatis vel subintegris.

Habitat frequens in collinis arenosis maritimis ex Mossamedes versus Cabo negro, inprimis loco dicto "Praia da Amelia." Junio 1859 cum flore, insequente Julio c. fructu legi. Exsic. Welw. Iter Angol. no. 1757.

Herba prostrata, caule abbreviato, jam a basi in ramos plures 2-5 poll. longos, hinc inde ramulosos, demum oblique ascendentes diviso. Folia majora ad sesquipollicem longa, medio semipollicem lata, margine nunc simpliciter repanda, nune repando-dentata vel rarius obiter sinuata aut inciso-dentata, exsiccatione utraque facie minutim verruculosa. Ochree in vivo pallidissime virentes, in sicco albidæ, horizontaliter truncatæ, ore integerrimæ vel rarius denticulis tenuibus remotis obsitæ, nunquam 
sctoso-ciliatæ. Racemi terminales, vel tardius ob rami prolongationem axillares, rectiusculi, semipedales usque pedales, rarius paullo longiores, rachi triquetra. Bractere $3-5$-floræ (floribus pluribus masculis, paucis vel unico hermaphroditis) in racemis novellis continuæ, imbricatæ, demum ad $\frac{1}{3}$ vel $\frac{3}{4}$ pollicis inter se distantes, ore nudæe vel sparsim et minute denticulatæ. Calycis limbus tenuiter membranaceus, lacteus, profunde 5-fidus, segmentis patulis obovatis, rotundato-obtusis, concariusculis, marcescenti- longe pcrsistentibus. Stanina 8 ; filamenta subulata; antheræ didymæ pallide cyanese. Stylus profunde trifidus; stigmata capitellata. Achenium (solummodo submaturum a me visum) vix 4. lin. longum, anguste ovoideum, triquetrum, angulorum alis inter se aqualibus, in vivo ex albido virentibus, margine subintegris vel tenuiter remote crenulatis sive repando-denticulatis, faciebus inter angulos longitudinaliter trinerviis.

Qualitates et Usus.-Stirpis omnes partes, sed præcipue folia tenuiter succulenta, sapore grate acidulo præditæ sunt, et a colonis Mossamedensibus hinc inde foliis Rumicis acetosa substituuntur, quapropter planta ipsa ab illis "Azedas bravas" i. e. "Rumex acetosa sylvestris" nuncupatur.

Species Oxygono Dregei Meisn., DC. Prodr. xiv. p. 38, affinis videtur, qua tamen a nostrate inprimis foliis integerrimis et ochreis ore setoso-ciliatis distinguenda.

Subordo II. BRunnichief, DC. Prodr. l.c. p. 183.

Brunnichia africana, Welw. n. sp. Br. caule frutescente, late scandente, patentim ramoso, ramis elongatis angulatis, inter angulos plurisulcatis, ramulisque horizontalibus virgatis glanduloso-pubescentibus, remote foliatis; foliis membranaceis, breve petiolatis, oblongo-ovatis vel ovato-ellipticis, basi cuneatim attenuatis rariusve subrotundatis, apice oblique acuminatis vel cuspidatis, margine integerrimis, utrinque glabris; ochreis manifestis, brevibus, truncatis, ore scarioso-membranaceis, tenuiter crispatis, demum laxiusculis; cirrhis apice bifidis, cruribus uncinatis vel demum spiraliter intortis; racemis ad ramulos laterales et apicales terminalibus, aphyllis, interruptis, bracteis 2-5-floris ; pedicellis plano-compressis, fructiferis accretis, subsecundis, nutantibus, calyce nunc semipollicari 5-7tuplo longioribus, secundum totam articuli superioris longitudinem utrinque ala membranacea, sesquilineam lata, ex apice tubi calycini decurrente, sanguineo-purpurea, in articulo inferiore sensim angustata marginatis.

Habitat in Distr. Golungo Alto editioribus (2000-2400 ped. alt.) ad oras silvarum primitivarum, præcipue juxta cataractam "de Capopa" prope "Sange," ubi stirpem, in statu fructifero ob fructos pendulos læte sanguineos sat ornatum, una cum Leea sambucina, Bombace Buonopozensi et specie indescripta generis tropico-americani "Trymatococcus" sociatam Septembri 1835 c. fl. et fr. legi. Exsic. Welw. Iter Angol. no. 1754.

Frutex gracilis, caule 10-15 pedes longo, remote ramoso, ramulis patentissimis, debilibus, cirrhorum ope sese firmantibus, late, sed vix alte scandens. Petioli 3-6 lin. longi, canaliculati, basi plerumque decurvi, eadem ac caulis et rami pubescentia, e papulis cylindraceis, brevibus, patulis, rubentibus, subviscosis, dense gregatis constante, obducti. Foliorum adultorum lamina $1 \frac{1}{2}-2$ poll. lata, $2 \frac{1}{2}-3 \frac{1}{2}$ poll. longa, supra læte viridis et lucidula, subtus pallide virescens, exsiccatione nitenti-rufescens et, excepto nervo mediano subtus modice prominente puberulo, utrinque glabra. Cirrhi graciles, supraaxillares [pedunculi abortientes?], foliis duplo triplove longiores, cruribus arcuato-divaricatis, excepta basi puberula levigati. Racemi floriferi 3-6 poll. longi, fructiferi pedales et longiores, rectiusculi vel ascendentes, rachi compressa, minutim glanduloso-pubescente. Florum fasciculi circiter semipollicem inter se distantes, bracteis ovato-acuminatis, carnosulis, membranaceo-marginatis, plerumque 3-floris. 
Caly $x$ sub anthesi obfusiformis, herbaceo-viridis, lobis crassiusculis, rigidulis, interna facie amœne roseis, tribus externis quam duo interiores latioribus, omnibus æquilongis et acute acuminatis, erectopatulis. Calyx fructifer trigono-ovoideus, inter angulos longitudinaliter pluricostulatus, fusco-purpureus, inclusis lobis nunc induratis et erectis semipollicem longus, coriaceus, achenium maturum arcte includens, demum una cum pedicelli articulo superiore tunc fere 3 pollices longo et modo supra indicato ala splendide sanguinca alato deciduus. Stamina, ovarium etc. generis.

Observatio.-Unica Brunnichice species hucusque descripta, et proinde generis typus, est Brunnichia cinphosa Banks (DC. Prodr. l.c. p. 185), Americam borealem incolens, a qua stirps præsens Africana pubescentia glandulosa, in ramis, petiolis et racemorum rachi manifesta et constante, foliis demum basi cuneatis vel rotundatis (nunquam cordatis) et non minus pedicellis fructiferis calyce 5-7tuplo (nec duplo) longioribus aliisque notis distinguenda.

\section{Ordo PROTEACEE.}

\section{Trib. Proteex.}

\section{Fadrea, Harvey.}

Generi "Faurea" a beato Harvey jam 1847 in memoriam G. Faure, botanophili Capensis instituto, nuper a clar. Meisner in DC. Prodr. xxiv. p. 344 quidpiam locupletato, sed ad unicam tunc solum cognitam speciem circumscripto, nunc, specie altera vel duabus aucto, notulæ sequentes commode addendx erunt:

Anthera nunc sessiles, nunc, imo in ipsa specie typica, filamentis brevissimis, compressis, latiusculis, apice plus minus manifeste biauriculatis insertæ, glandula parvula obtuse conica apiculate, vix unquam omnino muticæ. Squamule hypogyne non semper acutæ, sed non raro rotundato-obtusæ, vel truncatæ aut emarginatæ vel demum apice breviter bilobæ. Ovulum prope loculi medium suturæ affixum. Locum Faurea systematicum inter Proteacearum tribus quod attinet, genus hoc contra cl. Endlicheri et Meisneri opinionem, qui illud Persooniearum tribui subscribunt, potius Proteeis associandum et quidem pone Proteam ipsam collocandum esse videtur. A Persognieis calyce labiatim fisso nec 4-sepalo, antheris calycis laciniis concavis nec sepalorum medio vel basi insertis, stigmate verticali demum et ovario constanter uniloculari discrepat, dum omnibus hisce notis optime cum Proteeis concordat et ipso generi Protea adeo affine invenitur, ut ab eo, si inflorescentiam spicatam excipias, non nisi calyce unilabiatim reflexo nec bilabiatim fisso discerni queat.

Habitu suo Faurea quasdam Helicice species in Asia tropica occurrentes, etsi ob florum structuram et fructum follicularem ad tribum longe diversam spectantes, non male fingunt.

Ceteroquin Faurea inter Proteaceas Africanas facile genus unicum reapse tropicum habendum; nam genera Protea et Leucospermum, quæ itidem singulis speciebus laudati continentis circulos tropicos, et quidem ad Abyssiniam usque invadunt, in ditione Capensi magno specierum numero prædominant, dum Faurea, in Africa austro-tropica tam occidentali quam orientali pluribus speciebus earumque formis sive varietatibus numerosis repræsentata, in territorio Capensi, proprie sic dicendo, deest; nam Flora terræ Natalensis, ubi species Faureæ typica (F. saligna) primum detecta fuit, pro magna parte charactere omnino tropico eminet, et ipsa hæc Faurea saligna intra circulos tropicos ab Angola ad Zambesiam usque late diffusa reperitur.

Inter generis quoad foliorum figuram et inprimis eorum indumentum sat polymorphi formas varias, quæ Angolæ australis atque Benguellæ interioris montosa, ultra 4000 ped. elevata inter $13^{\circ}$ et $16^{\circ}$ lat. austr. inhabitant, præcipue sequentes duæ notis constantioribus distingui possunt, hine infra, etiamsi non sine aliqua hesitatione, ceu species novæ 
propositæ, quibus dein Faurea saligna Harv., in eodem territorio cum antecedentibus non infrequenter obvia, charactere specifico quidpiam ampliato vel modificato, comparationis gratia addere liceat.

1. Faurea speciosa, Welw. n. sp. (Tab. XX.) F. ramulis floriferis villoso-tomentosis; foliis molliter coriaceis breve petiolatis, oblongis vel ovato-oblongis, basi breviter attenuatis, apice obtusis rariusve acutiusculis, margine integerrimo planis, utrinque, nec non rhachi et bracteis plus minusve dense villoso- vel lanuginoso-tomentosis vel supra demum subglabratis; spicis robustis, foliis longioribus vel saltem æquilongis; calycis 9-12 lin. longi dense tomentosi lobis dorso vix sulcatis; squamulis hypogynis late abbreviato-ovalibus, apice rotundato-obtusis truncatisve vel subdenticulatis; ovario undique pilis elongatis, sericeis, penicillatim dispositis, dense barbato.

Habitat in Districtus Huilla silvestribus petrosis vel arenosis editioribus, inter 4000 et 5000 ped. alt., inprimis circa Lopollo et Humpata. Ab Aprili usque Junium florens, Maio ad Julium fructificat. Species uti videtur per Africam austro-tropicam late diffusa, etiam a cl. Kirk et Meller in Distr. Mossambicensis interioribus, inter 2000 et 3000 ped. elevatis, reperta ibidemque (secundum specimina in herb. Kewensi) non minus quam in territorio Huillensi quoad foliorum indumentum varians, propter eorum circumscriptionem vero nec non ob spicas robustas florumque magnitudinem etc. absque dubio præsenti speciei subscribenda. Exsic. Welw. Iter Angol. no. 1622 et $1622 b$.

Frutex firmus, 6-8-pedalis, nunc arbor parva 10-15-pedalis; trunco ad basim $\frac{1}{3}-\frac{2}{3}$ ped. diametro, cortice profunde rimuloso, aspero, e fusco cinerascente tecto, laxe ramoso, ramis vagis, erecto-patulis, arcuatis, ramulis curvatis vel varie tortis, rigidis, pro more robustis, foliorum delapsorum cicatricibus latis, protuberantibus exasperatis, primum tomento laxo, villis longioribus patulis intermixto obtectis, demum villo sensim delabente, plus minusve pubescentibus. Folia bene evoluta una cum petiolo 2-3 lin. longo 4-6 poll. longa, 2-3 poll. lata, plerumque ad utramque faciem tomento plus minusve denso, e villis longiusculis ruditer contexto, in facie superiore demum rarescente, sed saltem juxta nervos remanente obtecta, utrinque pallide viridia, pinnatim nervosa, nervo mediano subtus valde prominente, lateralibus crebris, obliquis, tenuibus, mox paullo supra ortum bifurcatione repetita in venulas anastomosantes sed marginem laminæ nunquam attingentes divisis. Spice florigeræ ad ramulorum apices in axillis foliorum summorum singulæ, vel internodiis ultimis valde abbreviatis binæ, rarius plures, simplices, strictiusculæ, 5-9 pollices longæ, cylindraceæ, sub plena anthesi transversim sesquipollicem crassæ, obtusiusculæ. Rhachis sulcata, firma, circiter $1 \frac{1}{2}$ lin. crassa, villoso-tomentosa, infra flores ad altitudinem semipollicis usque squamis scariosis ovato-lanceolatis, acuminatis, sursum versus sensim remotioribus et angustioribus vestita. Flores e flavo aurantiaci, dense congesti, sub anthesi horizontaliter patentes, singuli bractea squamiformi ex ovato acuminata, concava, subpatula, extus dense villosa, apice pilorum fasciculo superata, tarde decidua suffulti. Calyx fere pollicem longus, rectiusculus vel modice sursum arcuatus, dense cano-tomentosus, tubo cylindraceo medium versus parum angustato, intus nudo, lætius aurantiaco et ob filamenta adnatim decurrentia pluristriato, lobis cochleariformibus $2-2 \frac{1}{2}$ lin. longis in alabastro clavatim cohærentibus, crassiusculis, rigidis, demum una cum tubo, styli erumpentis ope longitudinaliter fisso atque reflexo, deciduis. Anthere oblongæ, sessiles vel subsessiles, calycis lobis paullo breviores iisque impressæ, basi obiter bilobæ, apice manifeste apiculatæ. Squamule hypogyne e lata basi abbreviatim ovales, vel imo semiorbiculares, apice obtuso nunc integræ, nunc subtruncatæ aut emarginatæ vel uno alterove denticulo munitæ et non raro in eodem flore inter se heteromorphæ, in vivo favæ, carnosulæ, exsiccantes subinduratæ et longius persistentes. Ovarium ovoideum, sessile, undique is elongatis, rigidulis, albidis, sericeo-nitentibus, primum in comam rectiusculam collectis, mox pentcillatim dispositis dense obsi- 
tum. Stylus filiformis, calyce vix brevior, in alabastro juxta medium curvatus, post anthesim leviter sursum arcuatus, rigidescens; stigma subcylindrico-prismaticum, obsolete 4-sulculatum, ad 2 lin. longum, stylo paullo crassior, a medio apicem versus modice clavulato-incrassatum, basi obiter strumulosum, apice obtusiusculum. Nux subglobosa, omnino sessilis, pisi minoris magnitudine, undique pilis sericeis ipsa multo longioribus, et inter pilos tomento brevi fulvo obtecta, ad plenam fere maturitatem stylo, tunc delabente, caudata, pericarpio crassiusculo tenuiter suberoso intus levigato. Semen. subglobosum, seminum Cannabis sativa circiter magnitudine, plane maturum tamen non mihi obvium.

Observatio. - Species hic proposita ad numerosam speciminum seriem in diversis locis lectorum examinata, quoad spicarum magnitudinem et formam, nec non respectu floris partium inter se proportiones sat constans videtur, quoad foliorum indumentum vero admodum ludit, ita ut varietates, notis constantioribus satis distinctx, vix et ne vix quidem statui possint. Ast ipsum hoc foliorum indumentum magis quantitate quam qualitate variat, nam semper e villis longiusculis crispatis, plus minusve rigidulis, nune laxius nune densius intertextis constat, et in ipsis foliis, quæ primo aspectu penitus glabra vel imo in facie superiore nitidula apparent, accuratiore examine saltem juxta nervum medianum vel ad costarum axillas invenitur. Colorem foliorum fere constanter pallide viridem vidi, nisi in stirpibus in locis valde umbrosis obviis, quorum folia, uti hoc in pari casu generatim occurrit, virore magis saturato tinguntur, simulque magis glabrescunt, circumscriptione vero etiam hac in varietate semper ad formam ovalem tendunt.

2. Favrea discoror, Welw. n. sp. F. ramulis floriferis cano-pubescentibus; foliis tenuiter coriaceis, breve petiolatis, lanceolatis vel lanceolato-oblongis, basi sensim attenuatis, apice acuminatis vel rarius obtusiusculis, margine recurvis, supra primum pruinoso-canescentibus, mox deglabratis, lucenti-viridibus, subtus per omnem æatatem dense cano-tomentellis; spicis folia superantibus; rhachi bracteisque et calyce 5-7 lin. longo sericeo-canescentibus, hujusce lobis dorso obiter sulcatis ; squamulis hypogynis deltoideis vel semiorbicularibus; ovario undique et dense pilis sericeis ipso triplo longioribus barbato.

Habitat in Distr. Huilla silvis claris mixtis ad 4500-5000 ped. altit. una cum Acaciis, Proteis, Parinariis variisque Combretaceis socialis sed parcius obvia. Aprili et Maio florentem vidi. Exsic. Welw. Iter Angol. no. 1594 et 1595.

Frutex plerumque humanæ altitudinis, rarius arbuscula 8-pedalis, laxe comosa. Ramuli juniores et floriferi dense cano-pubescentes, adultiores glabri, longitudinaliter rugulosi. Folia adulta discoloria, supra nempe, pubescentia juvenili nunc deglabrata lucidulo-viridia, subtus autem ob tomentum breve sed densum, subvelutinum et persistens incana, $2 \frac{1}{2}-3 \frac{1}{2}$ poll. longa, $\frac{2}{3}-1$ poll. lata, margine integra et obiter recurva, breviter calloso-apiculata. Spice in ramulis extimis terminales, circiter $4-4 \frac{1}{2}$ poll. longæ, iis speciei antecedentis graciliores et angustiores. Rhachis (pedunculus) infra flores squamis paucis distantibus vel sæpe nullis obsita. Bracteæ abbreviatæ, a basi dilatata breviter acuminatæ, patulæ. Calycis 4-5 lin. longi modice arcuati plus minusve canescentis lobi $1 \frac{1}{2}$ lin. longi, dorsi sulcis pubescentia nunc copiosiore nunc sparsiore obtectis, ast saltem in calyce deflorato semper observandis. Anthere apiculatæ. Squamule hypogyna in individuis acutifoliis deltoideæ apice indivisæ, in speciminibus foliis obtusiusculis donatis antem breviores, subsemiorbiculares. Ovarii barba ipso triplo vel rarius quadruplo longior, sericeo-splendens, strictiuscula. Stylus pro more generis calycis longitudine, barbam longe superans, juxta medium arcuatus, tarde deciduus, stigmate tenuiter clavulato, obscure prismatico, obtusiusculo, basi nunc parum nunc eridentius strumulato. Fructus non visus. 
Species, vel saltem varietas insignis, quoad spicarum formam et partium floris inter se proportiones antecedenti, quoad foliorum figuram autem sequenti magis affinis, $a b$ utraque tamen foliis ad faciem inferiorem constanter pube brevi, densa, ex albo-cinerascente cano-tomentellis* distinguenda, nihilominus posteriori peregrinatorum observationi denuo commendanda.

3. Faurea sauigna, Harvey, in Пlook. Lond. Journ. 1847 , p. 373, tab. xv. F. ramulis floriferis glabriusculis; foliis lanceolatis, longe acuminatis, in petiolum alatum sensim attenuatis, utraque facie glabris, supra nitidulis; rhachi, bracteis et calyce 4-5 lin. longo sericeo-pubescentibus vel rarius deglabratis; lobis calycinis profunde bisulcatis ; squamulis hypogynis lanceolatis, acuminatis vel apice obiter bilobis; ovario pilis sericeis longiusculis, in fructu rarescentibus barbato.

Habitat in Distr. Huilla silvaticis ad 5000 ped. alt., inprimis inter Lopollo et Menino juxta rivorum ripas, vel hinc inde in ipsis torrentium alveis una cum Salicibus socialis. Novembri usque ad Januarium et iterum Aprili florentem vidi, Maio c. fr. legi. Primum a cl. Sanderson et Burke in territorii Natalensis interioribus lecta, demum ex iisdem terris a cl. Zeyher et Drege in eorum herbariis divulgata, nuper etiam a cl. D $^{\mathrm{re}}$ Kirk e territorio Mossambicensi (fid. herb. Kew.) reportata. Exsic. Welw. Iter Angol. no. 1592 et 1593.

Frutex elongato-ramosus 5-8-pedalis, hinc inde arbor gracilis 12-20-pedalis, trunco vix unquam diametro 4 poll. excedente, inferne tum longe ramis denudato, his atque ramulis erecto-patulis, plus minusve intense purpurascentibus. Folia 3-5, rarius 6 vel 7 pollices longa, plerumque 6-9 lin. lata, vix unquam sesquipollice latiora, recta vel obiter falcata, callo parrulo vel fere lineam longo, atrorubente apiculata, margine integro plana vel obsolete repanda, laxeve undulata, jam prima ætate, excluso petiolo hinc inde sparsim puberulo, ad utramque faciem omnino glabra, levigata, læte viridia et utrinque vel saltem supra lucidula. Inflorescentia omnis quoad pubescentiæ densitatem valde varians, sed non nisi rarius penitus deglabrata. Spica graciles, 3-4 $\frac{1}{2}$ poll. longæ, rectiusculæ, foliis summis fere semper paullo breviores, ad ramulorum apices singulæ vel internodiis contractis in eodem ramulo 2 pluresve gregate. Rhachis infra flores squamis paucis, remotiusculis, acuminatis, erectopatulis, non raro jam sub anthesi deciduis munita. Bractea rigidulæ, patulæ, concavæ, eæ florum iuferiorum late ovatæ, abrupte acuminatæ, superiorum abbreviatæ, apice obtuso cuspidatæ vel fere truncatæ. Caìx (saltem in speciminibus Angolensibus) circiter 4 lineas longus, vix unquam lineis 5 longior, lobis lineam longis, dorso longitudinaliter sulcis duobus latiusculis, pro more profundis sed obtusis percursis. Squamule hypogyna quam in speciebus antecedentibus angustiores magisque acutatæ, longiores quam latæ, quondam in uno eodemque flore heteromorphæ, una vel duabus apice acuto integris, reliquis tenuiter bilobis. Antherce rarius omnino sessiles sed plerumque filamentis brevissimis sed distinctis insertæ et manifeste apiculatæ. Nux ovoidea, 2 lin. longa, $1 \frac{1}{3}$ lin. prope medium lata, obtusa, barbæ pilis nunc sparsioribus et plerumque rufescentibus hirta, stylo induratorigescente prope medium arcuato, ad plenam fere fructus maturationem persistente caudata, vel demum ejusdem basi remanente apiculata, epicarpio crassiusculo suberoso. Semen ad cavitatis latus prope medium fixum, obovoideum, testa membranacea subscariosa brunnea, laxissima vel pro parte omnino soluta.

Ceterum etiam hæc species, quemadmodum duæ præcedentes, nunc foliis longius

* "The existence or absence of pubeseence in the adult leaves cannot always be depended upon in distinguishing species; but the short tomentum, especially of their under surface, is of greater consequence than the spreading hairs."-R. BR., "On Proteacee" etc. in Transact. of the Linn. Soc. vol. x. p. 25.

VOL. XXVII. 
(4-7 lin.) petiolatis simulque angustioribus [qualis forma typica], nunc breviter vel brevissime petiolatis (petiolis vix $1-1 \frac{1}{2}$ lin. longis) et tum latioribus variat, quæ ulterior forma præsertim in individuis arborescentibus solo siceiore enatis observatur.

\section{Ordo RAFFLESIACEÆ.}

\section{Subordo I. HYD NORE}

Hydnora AFrICANa, var. longicollis, Welw. (Tab. XXI.) $H$. perigonii tubo ultra ovarium longe producto, limbi tri- rarius quadrifidi laciniis tubo brevioribus, ramentis heteromorphis, extimis densa serie approximatis, elongatis, liberis, compresso-planis, apice longe acuminatis bi- trilobisve, reliquis absque ordine sparsis, discum versus sensim brevioribus, semiadnatis, apice libero subulatis vel omnino papillæformibus; disci pulvinulis ovato-oblongis, obtusiusculis, basi dilatata subemarginatis, pulvere griseo farinaceo, mox in mucum deliquescente, obductis; annuli staminigeri medio tubi adnati lobis ovoideis erectis, ad utramque faciem antheris elongatis, varie curvatis, inæquilongis, arcte adnatis dense obtectis.

Habitat in District. Mossamedes sabulosis maritimis, ex Giraûl usque ad Cabo Negro, ad radices Euphorbiarum frutescentium nec non Zygophylli orbiculati (supra descripti) parasitica. Per totum fere annum, inprimis autem mensibus Martii ad Julium usque floret et fructificat. Exsic. Welw. Iter Angol. n. 530.

Caulis succulentus, perennis vel saltem per plures annos durans, plerumque omnino aut pro majore parte in arena volatili, basim trunci matricis ambiente, sepultus, vetustior circiter pedalis, inferne ad $\frac{2}{3}$ poll. crassus, decumbens vel ascendens, sparse remoteque ramosus, extus obscure fusco-rubens, intus carne densa pallide latericia faretus, 5-7-angulatus, secundum omnes angulos tuberculis uniseriatis, plus minusve approximatis, subglobosis, apice obtuso minus magisve evidenter concentrice rimulosis obsitus, quorum nonnulla sensim intumescentia simulque elongata formam obconicam induunt et demum in perigonia sese evolvunt, dum reliqua per totam caulis durationem fere immutata permanent, vel parum elongata in ramenta subcompressa, rigida, obtusiuscula collabuntur. Perigonium carnosum, rigidum, non raro ad limbum usque in arena absconditum, longitudine varium, 3-7-, imo 8-pollicare, basi rotundato-angustata vel paullo constricta, sessile vel brevissime pedunculatum, extus undique leproso asperulum, cinnamomeo-brunneum, rugis transversalibus, ad tubi partem cum ovario connatam crassioribus, dense approximatis, notatum. Tubus circiter $\frac{2}{3}$ poll. diametro, infra annuli staminigeri insertionem modice attenuatus, intus levigatus vel obiter striis longitudinalibus parallelis percursus et plus minusve læte rubescens. Limbi laciniæ (plerumque tres, sed hinc inde quatuor, vid. tab. fig. 3) tubo semper et plerumque multo breviores, crasso-triquetræ, arcuatæ, apicibus brevissime et obtuse acuminatis convergenti-patulæ, intus ex aurantiaco rubræ, et juxta marginis late induplicati faciem totam ramentis supra descriptis, omnibus introrsum directis, echinulatæ, earum discus glaber, sed pro majore parte pulvinulo jam supra notato obtectus, cujus superficies initio albido-pulverulenta mox post anthesim in mucum viscidulum, odore vehementer stercorario ingratum, strato mucoso Phallorum sporidia involventi adeo similem, deliquescit. Annulus staminiger tubo ad semipollicis vel imo pollicis distantiam supra stigma insertus. Anthere læatissime flavæ et admodum turgidæ, spurie biloculares. Stigma in vivo sordide albidum, in flore 3-fido tri-, in 4-fido quadrilobum, lobis abbreviatis, horizontalibus, creniformibus, rotundato-obtusis, tenuissime denseque striolatis, striis nunc obliquis, nunc, uti in stigmate quadrilobo observavi, loborum peripheriæ subparallelis, concentrice curvatis. Pericarpium globosum, diametro circiter bipollicari, dure corticatum, extus undique areolis irregulariter pentagonis, parum distantibus, exasperatum, interna facie levigatum, et sulcis te- 
nuibus verticalibus, æqualiter distantibus, plus minus manifestis [placentarum in prima juventute forsan parietalium, uti vidisse contendit cl. Endlicher*, vestigiis?], uotatum. Semina numerosissima, ad placentas deliquescentes densissime gregata, globosa sive obovoidea, seminum Papaveris somniferi magnitudine vel recentiora ipsis majora, epidermide crassiuscula, carnoso-pulposa, minutim scrobiculata, demum collabente involuta, testa brunnea tenuiter membranacea, albumini duro arcte adhærente, primum in pulpa viscidula semitransparente, pericarpii cavitatem omnino replente, nidulantia, post pulpæ exsiccationem quoad volumen diminuta, in globum subcompactum, cavitate paullo minorem, undique liberum inter se conglutinata.

Observatio.- Formam hic descriptam primum ab Hydnora capensi Thunb. specifice diversam credidi, maxime quoniam apud varios auctores plantæ Capensis tubus limbo multo brevior et parum supra ovarium protractus simulque annulus staminiger stigmati valde approximatus dicuntur vel sic picti exhibentur; postea tamen, speciminibus pluribus in diversis locis lectis inter se comparatis, proportiones allatas plus minusve variabiles et probabiliter ex majore vel minore soli, in quo plantre crescunt, profunditate ac densitate derivandas agnovi et plantam Angolensem IIydnora capensi qua varietatem subjungere malui.

Qualitates et Usus.-Omnes plantæ partes, sed inprimis caules [ab aliis " rhizomata" dicti] succo rubente, admodum adstringente scatent, qua ratione a Nigritis et colonis Mossamedensibus ad retia piscatoria variasque telas tingendas adhibentur. Ceterum Hydnora qualitates eminenter stypticæ, in sanandis ulceribus nec non in corrigendis membranæ mucosæ affectionibus morbosis probabiliter satis proficientes, medicorum Angolensium futuræ experientiæ atque observationi admodum commeudandæ.

\section{Subordo II. A podanthez.}

Prlostyles extopica, Welw. n. sp. (Tab. XXII.) $P$. floribus in involucri erumpentis primum globosi demum irregulariter rupti fundo sessilibus, singulis vel binis, basi decussatim paucibracteatis; sepalis petalisque 5-6-meris, obovato-oblongis vel suborbicularibus, margine eroso-denticulatis; petalis sub disco crasso 5-6-angulato insertis, basi tuberculato-callosis, puberulis; stylo late conico, basi disco cincto, stigmate hemisphærico, minutim ruguloso-striolato, integro vel brevissime 2-3-lobo.

Habitat parasitica ad ramulos Berlinic paniculate Benth. $\dagger$, arboris e Cesalpiniearum tribu, in Districtus Huilla montosis editis de Morro de Monino, intra 5000 et 5500 ped. altit., Aprili-Maio florens. Flores masculi frequentius quam feminei occurrunt, sed nunquam in eadem arbore simul cum femineis a me visi. Exsic. Welw. Iter Angol. no. 529 (masc.) et $529 b$ (fem.).

Arboris ramuli bi- vel triennes, quibus planta nostra innascitur, primum paullo intumescunt simulque circumcirca rimulis longitudinalibus, sæpius interruptis, in fundo materia latericia, tenuissime granulosa repletis, exasperantur. Ex his rimulis paullo post tubercula plus minusve gregata vel plerumque seriata, initio hemisphærica, mox globosa, $2-2 \frac{1}{2}$ lin. diametri, dure corticata, undique sulcis minutis concentricis vel squamulis tenerrimis pallide latericiis asperula, intus cava et levigata prorumpunt, quæ demum, jove pluvio stimulata, e vertice dimidiatim vel irregulariter dehiscentia, florem unum [vel rarius duos] in eorum cujusque fundo sessilem et quidem jamjam omnino evolutum denudant $\ddagger$.

* Conf. Endl. Gen. Plant. p. 75, Observ.

+ Transact. Linn, Soc. vol. xxv. p. 311.

¥ Tubercula hæc, quæ florum cunabula sive involucra sistunt, et utero Angiogasterum, simulque spatha Balanophorearum analoga videntur, post eorum dehiscentiam nune bilabiatim hiantia, nunc, parietis lateribus dejectis, sub forma patellæ, in centro suo florem vel fructum gerentis, persistunt, et ramulo matricali imo post florem vel fructum 
Flores dioici, roseo-sanguinei, carnosuli, excepta nimia exiguitate, Raffesias habitu omnino æmulantes, primum globosi $1 \frac{1}{2}-2$ lin. diametro, sub plena anthesi parum latiores et vertice depressi, ope calli brevissimi carnosi intus albidi centro fundi involucri rupti affixi, e perigonii verticillis duobus biseriatim arcte imbricatis columnam stamineam vel pistillum ambientibus et basi bracteis paucis amplexis constantes. Bractece 3-5, orbiculatæ vel late obovatæ, basi quidpiam incrassata, sessiles, decussatim imbricatæ, concavæ, margine toto eroso-denticulatæ, perigonii verticillo inferiore arcte adpressæ eoque breviores et eodem ac flos ipse colore sanguineo ornatæ, in fructu persistentes.

Masc. Sepala [vel si mavis bracteæ superiores, reapse juxta spiram ascendentem insertæ, sed ob hujus axim adeo abbreviatum in verticillum, calycem simulantem, approximatæ] petalis semper isomera, plerumque 6 , sed non raro, et quidem in floribus eundem ramum obsidentibus, 5 , rarissime 4 , e lata basi obovato-oblonga vel suborbicularia, margine pariter ac bractcæ tenuiter denticulata, petalis æquilonga vel iis paullo breviora, bracteas superantia. Petala sub disco crassiusculo angulato inserta, sepalis alterna, hisque quoad circumscriptionem et marginis denticulos similia, sed basim versus magis angustata et intus paullo supra basim callo tuberculiformi subspongioso, tenuissime puberulo [pulvinulis in disco laciniarum Hydnore obviis analogo?] obsita, ceterum ut flos omnis glaberrima, sub anthesi erecto-patula, pressione quidem facile secedentia, sed plerumque non nisi cum flore toto decidua. Discus, coronam faucis æmulans, carnosus, latiusculus, viscosus, angulis obtuse triquetris, prominenti-subascendentibus, petalis isomeris et cum iis alternis, sinibus petala recipientibus rotundato-obtusis. Columna staminea inclusa, cylindracea, ima basi disco cincta, sub apice quidpiam dilatata, composita est e stylo centrali [abortivo] firmo, carnoso-farcto, centro pervio, apice, stigmatis loco, pileo fungiformi, depresse hemisphærico, margine fimbriato, et e tubo staminigero, stylum totum, excluso pileo, arcte vaginante sed ab eo libero, juxta faucem truncatam pileo proximam antheras ferente, infra antheras ad discum usque longitudinaliter et minute costulatosulcato. Anthere numerosæ, circa tubi oram simplici serie adnatæ, contiguæ, uniloculares, poro apicali mox extrorsum versus dilatato dehiscentes, effœetæ demum et collapsæ tubi oram sub forma membranæ annularis breviter reflexæ cingunt. Pollen globosum, glabrum, albidum, levissimum et admodum viscosum, imo post antheras effotas harum plagis externis et adhuc majore copia fimbriis pilei, tubum antheriferum supereminentis, adhærens atque hocce modo obiter aspicienti alterum, i.e. secundum antherarum verticillum sive annulum fingens. Ovarii vestigium vix ullum, styli axis vero non raro perforatus.

FEM. Calyx et corolla maris, flos totus tamen sub anthesi quidpiam magis elongatus. Ovarium inferum, uniloculare, placentis parietalibus quatuor, multiovulatis, nonnunquam fere omnino inter se confluentibus; ovula oblongo-ovoidea, funiculo brevi, latiusculo, laterali, placentis affixo. Stylus amplus, brevis, late conicus, basi disco obtusangulo cinctus (intus tenuissime lamellosus?); stigma hemisphæricum, lata basi styli truncati apici insidens, ab ipso etiam colore obscuriore distinctum, undique rugulis striisve minutis notatum, plerumque simplex, rarius bi- vel trilobulatum, lobulis tum erectis mamillæformibus. Fructus baccatus, globosus, perigonii phyllis nunc subscariosis arctiusque imbricatis omnino obtectus. Pericarpium carnosum, crassiusculum, uniloculare, indehiscens. Semina plurima, minima, sphæroidea vel subovoidea, in pulpa mucosa viscida transparente laxe nidulantia; testa tenuiter crustacea, reticulata, pallide rubra; nucleo cellulis minimis subglobosis (homogeneis) lætius rubentibus dense repleto. Flores et fructus recentes sub pressione fortiore succum roseosanguineum, chartam eodem colore sat persistente tingentem exsudant.

Observatio.-Uti ex supra expositis patet, character genericus Pilostylis in posterum

delapsum arctissime adhærent, ast nequaquam ab ipsius matricis cortice, sed pro majore parte, nisi omnino, e membrana colorata, matricis ramulum sub epidermide, mycelii fungorum cladophilorum ad instar, obducente demumque obdurante formata inveniuntur. 
valde modificandus et ampliandus erit, quod autem non nisi specierum omnium a variis auctoribus hucusque propositarum reiterato examine fieri potest. Omnes species cognitæ, (forsitan solummodo paucarum vel imo unius ejusdemque speciei varietates?) in Leguminosarum ramulis parasitantur, omnesque crescendi modo, habitu, florum magnitudine et colore plus minusve rubescente aliisque notis satis inter se congruunt, dum characteres specifici, ab auctoribus indicati, et inprimis a stigmatis figura desumti, parum constantes videntur. Discus (sive corona faucis) in utroque sexu speciei nostræ pari modo manifestus, sed in reliquarum specierum descriptione non indicatus, neque in generis charactere commemoratus, forsitan in omnibus speciebus accuratius examinatis inveniendus. Genus "Sarna" Karst. (Linnæa, xxviii. 725. 1) absque dubio Apodantheis nec Balanophoreis adsociandum, et ab ipsa Pilostyle nullo charactere differre videtur. Generis "Apodanthes" Poit. dignitas et a Pilostyle differentia fere solum ex pericarpii cavitate tetragona, charactere forsitan non satis constante, pendent, et insuper ob flores masculos necdum cognitos dubiosæ remanent.

\section{Ordo MORE}

Morus excelsa, Welw. n. sp. (Tab. XXIII.) Mr. dioica, trunco robusto elato, ramis patentibus, ramulis petiolis nervisque foliorum subtus glabris puberulisve; foliis sublonge petiolatis, oblongis vel ovato-ellipticis, acuminatis apiculatisve, basi rotundatis, margine subundulatis integerrimis vel obiter repandis et apicem versus obscure dentatis, glabris, subtus pallidioribus, subtilissime pubentibus glabratisve (iis arboris juvenilis basi subcordatis, margine toto serrato-dentatis, supra setuloso-asperis, subtus laxe velutino-tomentosis) nervis utrinque costæ ad 15; stipulis lanceolatis subulatoacuminatis puberulis; amentis pedunculatis cylindricis, masculis 5-8 poll. longis, femineis 1-2-pollicaribus; perianthio masculo turbinato-campanulato, sericeo, quadridentato vel quadrilobo; perigonii feminei foliolis lineari-oblongis pubescentibus, apice rotundato cucullato-inflexo barbulatis; stylo excentrico, filiformi, simplici, undique supra medium stigmatoso.

Habitat frequens in silvis primævis elatioribus minus densis Distr. Golungo Alto, Dembos, Cazengo etc. ad 1300-2800 ped. altit., præsertim in declivibus humidioribus de Serra de Alto Queta circa Sange. Octobr.-Nov. floret, Dec.-Februar. fruct. maturat. A Nigritis dicitur "Mucamba-camba." Exsic. Welw. It. Angol. no. 1559.

Mucamba-camba, especie de Morus, Welw. Synopse, p. 8.

Arbor speciosa, excelsa, copiose lactescens, inter silvarum primævarum Angolæ gigantes laudanda, bene adulta 100-120-, imo hinc inde 130-pedalis et altior. Truncus rectus, cylindricus, circumferentiam 20-30-pedalem attingens, cortice pro amplitudine arboris haud profunde rimoso, griseo, in individuis vetustioribus ad 40-60 ped. ejus altitudinis ramis denudatus, apice coma late extensa, depresso-hemisphærica coronatus. Rami vagi, horizontaliter expansi, aliquanto tortuosi, griseo-fuscescentes; ramuli varie curvi, glabrati, stipularum cicatricibus semicircularibus exasperati, novelli purpurascentes, lenticellis elongatulis albidis obsiti et plus minusve puberuli vel hinc densius pubescentes. Folia annua, sed tarde decidua, penninervia, quoad circumscriptionem semper integra (i. e. nunquam lobata), respectu indumenti vero secundum arboris ætatem maxime varia; ea stirpis juvenilis quam in adulta multo majora quidem, et inprimis longiora sed brevius petiolata, petiolis circiter semipollicaribus, villosopubescentibus, lamina 6-7 poll. longa, 3-5 poll. lata, basi obiter vel profundius cordata, margine 
circumcirca dense serrato-dentata, apice abrupte in acumen fere semipollicare terminata, supra setulis sparsis aspera, subtus plus minusve dense velutino-tomentosa: in arbore adulta florigera foliorum petioli 1-1 $\frac{1}{2}$ poll. longi, glabriusculi; lamina 4-5 poll. longa, 2-3 poll. lata, basi rotundata, apice brevius acuminata vel cuspidata, margine obiter repando solum a medio apicem versus breve denticulata, supra intense viridis et glaberrima, subtus pallide virens, omnino glabra vel, inprimis juxta nervos, tenuiter puberula, rarius pube densiore, non nisi sub lente fortiore conspicua, subvelutina; costa sive nervus medius supra vix, subtus valide et obtuse prominens; nervi laterales utrinque 13 usque 17, sæpissime 15, alterni, sub angulo acuto divergentes, recti, inter se strictim paralleli, quam costa multo tenuiores, simplices, paullo ante marginem in venulas soluti, una cum costa nunc flavicantes, nunc e flavo purpurascentes. Stipule circiter 8-10 lin. longæ, caducissimæ. Flores, a me quidem semper dioici observati, non nisi in arboribus vetustioribus (saltem 15-20 annorum) obvii, ad ramulorum novellorum basin prorumpentes. Amenta mascula et feminea cylindrica atque pendula; mascula graciliora, elongata, non raro ad 7 vel 8 pollices longa, densiflora, 3-4 lin. diametro, pedunculo 3-5 lin. longo, cylindrico et pubescente ; perigonium flaccide membranaceum, albidum, campanulatim patulum, nunc 4-dentatum dentibus deltoideo-ovatis, nunc profundius 4-lobum, lobis ovatis obtusiusculis ; filamenta longe exserta, una cum antheris alba ; rudimentum ovarii constanter obvium, squamuliforme, oblongum, compressum, e centro floris erectum. Amenta feminea, non nisi in statu maturescente (syncarpia) observata, masculinis 3-4-plo breviora, sed is crassiora, 7-8 lin. diametro, densa, carnoso-turgidula sed parum succosa, e viridi flavicantia, stylis longius exsertis nunc jam exsiccatis rigidulis undique horridula; perigonii, basi pilorum circulo stipati, foliola carnoso-tumida, vix inter se cohærentia, apice obtuso, incrassato pilisque brevibus barbato, cucullatim inflexa; achenium breve stipitatum, compresso-obovoideum; stylus lateralis, achenio saltem 3-plo longior, filiformis, subflexuosus, a medio ad apicem breviter acutatum stigmatosus. Semen obovato-oblongum, linea 1 parum longius, lenticulari-compressum, umbilico prope verticem laterali, testa badia, crustacea, fragili ; embryo generi conformis ; albumen respectu embryonis voluminis parcum.

Qualitates et Usus.-Lignum recens albidum vel ex albido leviter flavescens, demum badio-fuscescens, venis latiusculis varie curvatis et undulatis obscurioribus variegatum, ob tenacitatem longamque durationem inter Angolæ autochthones et colonos Lusitanos multiplicis usus. Syncarpia numerosos passerum greges lauto pabulo sustentant; amenta mascula exsiccando chartam colore læte sulphureo tingunt.

Dorstenta (Kosaria) vivipara, Welw. n. sp. D. radice globoso-tuberosa, carnosofarcta ; caule simplici, spithameo, gracili, erectiusculo vel ascendente, cylindrico, obiter pubescente, ad nodos inferiores viviparo; foliis longiuscule petiolatis, ovatis, margine ciliolatis, basi breviter angustata integris, a medio ad apicem obtusiusculum usque obtuse dentatis, glabriusculis vel sæpius, inprimis subtus juxta nervos, puberulis ; receptaculis in foliorum superiorum axillis solitariis, longe et gracillime pedunculatis, 6-9-radiatis, radiis patulis, rectis, lanceolatis, margine ciliatis.

Habitat gregaria sed paucis locis in umbrosis humosis juxta rivulorum ripas Distr. Pungo Andongo, frequens juxta rivum Candange-camatuta, ad 3200-3500 ped. alt. supra mare. A Decembr. usque ad Febr. floret et fructificat. Exsic. Welw. It. Angol. no. 1565 .

Herba tenera, debilis, flaccidula, pallide virens. Tuber globosum, pisi majoris vel nucis avellanæ minoris mole, dense farctum et, uti omnis planta, copiose lactescens, quolibet anno perit, stirps autem ope tuberculorum in axillis foliorum infimorum sese evolventium demumque radicantium perennat. Caulis carnosulus, fragilis, subflexuosus, primum erectiusculus, mox decumbens vel ascendens, ad nodos inferiores tuberculiferos radicans. Folia penninervia, tenuiter membranacea, ovato-acuminata, basi breviter angustata, dempto petiolo gracili subpollicari $1 \frac{1}{2}-2$ poll. longa, $\frac{2}{3}-1$ poll. lata; dentes ad 
utrumque laminæ latus pauci, distantes et obtusi, sed constanter obvii. Stipula obsoletæ. Pedunculi patentes, gracillimi, leviter pubescentes, florigeri petiolis breviores, fructiferi iis semper longiores. Receptacula parra, parum succulenta, deorsum convexa, fere campaniformia, in juventute pubescentia, fructifera glabrata, herbaceo-viridia, demptis radiis 3 vel vix 4 lin. diametro, radïs singulis ad 2 vel 3 lin. longis, puberulis vel glabratis, margine semper breviter ciliatis, a lata basi sensim acuminatis, sinibus obtusis et integris separatis. Semina globoso-triquetra (vix ac ne vix quidem uncinata), testa tenuiter crustacea albida, papillis minimis undique exasperata.

Species, ut videtur, distinctissima, nulli cognitarum arctius affinis, inter Africanas etiam caule viviparo et totius planta teneritate insignis.

Dorstenia (Kosaria) Benguellensis, Welw. n. sp. D. radicis tubere depresse globoso vel placentiformi; caule centrali, firmulo, erecto, simplici, spithameo sive pedali, cylindrico, succulento, dense pubescente, inferne aphyllo; foliis a medio caulis apicem versus sparsis, sensim majoribus magisque approximatis, subsessilibus vel brevissime petiolatis, penninerviis, lanceolatis, oblongo-lanceolatis ellipticisve, basi parum angustatis, margine toto dentatis, apice obtusiusculis, utrinque pubescenti-hirtulis scabrulisve; stipulis lineari-lanceolatis, brevibus, fugacibus; receptaculis in foliorum superiorum axillis solitariis, breve pedunculatis, erectis, concaviusculis, deorsum convexis, sordide flavicantibus, subglabris, ore orbiculato truncato 7-11-radiatis, radiis patentibus, lineari-spathulatis, apice puberulo obtusis.

Habitat rarior et sporadica in pascuis parce dumetosis, arenoso-humosis, breve herbidis Distr. Huilla circa Lopollo, inter 4500 et 5200 ped. altit. Legi Decbr. 1859 c. fl. et fr. Exsic. Welw. Iter Angol. no. 1566.

Tuber plerumque placentiforme, $1-1 \frac{1}{2}$ poll. diametri, carnoso-farctum, copiose lactescens, basi circumcirca fibris elongatis, tenuibus, breve fibrillosis stipatum. Caulis (plerumque unicus, raro duo) e tuberis centro erectus, $\frac{1}{2}-1$-pedalis, pennæ anserinæ circ. crassitudine, succulentus (exsiccatione valde contractus), cylindraceus, e viridi purpurascens vel omnino purpureus, undique dense pubescens, ad 1 ejus altitudinem aphyllus vel squamulis paucis distantibus obsitus. Folia medii caulis $\frac{1}{2}-1$-pollicem inter se distantia, summa latiora et fere fasciculatim approximata, subcarnosa et rigidula, erectopatula; petioli $\frac{1}{3}-1$ lin. longi compressi ; lamina foliorum majorum 10-14 lin. longa, 3-5 lin. lata. Receptacula pauca (1-4 in quoque caule), pedunculis 2-3 lineas longis, crassiusculis, firmis suffulta, ore, demptis radiis 3-4 lin. diametro; radii singuli 3 lin. longi, medio vix semilineam lati, denticulo uno alterove interjecto separati, fere ligulæformes, apicem versus modice dilatati, rotundato-obtusi et puberuli, stellatim expansi, ceterum, uti receptaculum, sordide flavicantes et carnosuli. Pericarpia apice breviter bivalvia, post seminis ejaculationem valvulas arcte claudunt, parietum succulentorum incremento adhuc per aliquot tempus continuante crassiora fiunt et elongantur demumque flosculorum masculorum planum perforant et longe super illud, stylis suis adhuc apiculata, eminent. Semina iis speciei antecedentis omni sub respectu valde similia.

Observatio.-Caulis in omnibus speciminibus loco citato a me lectis simplex est, sed in eorum paucis folia medii caulis foliorum parvulorum fasciculum in axillis gerunt, qui forsitan tardius in ramulum evoluturus.

Dorstenia (Sychinium) Psilurus, Welw. n. sp. $D$. rhizomate cylindraceo, repente, nodoso, carnoso-farcto, ad nodos fibris longis gracilibus et hinc inde tuberculis clavatis

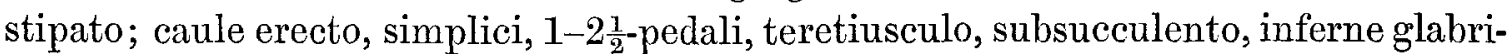
usculo et laxius, apicem versus densius foliato et pubescente ; foliis longiuscule petio- 
latis, membranaceis, penninerviis, glabriusculis vel præcipue subtus juxta nervos hirtulis, in petiolum attenuatis, sæpius in eodem specimine polymorphis, basi semper cuneatis, integris, nunc ovato-ellipticis, acuminatis, margine dentatis, nunc obovatis vel obcuneatis, apicem versus plus minus profunde inciso-dentatis vel 3-plurilobatis, lobis inæqualibus, erectis vel patulis, elongato-triangularibus, acuminatis; petiolis angustis, inferioribus elongatis stipulisque parvis lineari-lanceolatis pubescentibus; receptaculis axillaribus, subsolitariis, longe graciliterque pedunculatis, verticalibus, linearilanceolatis, bricruribus, crure uno breviore deflexo, abrupte appendiculato, altero erecto longiore, apice simplici vel rarius bifurco, sensim in appendicem ipso crure duplo triplove longiorem, subulatam, rectam prolongato.

Habitat in convallibus umbrosis ad rupium latera Distr. Pungo Andongo ad 3200 ped. circiter altitudinis, præcipue in silva primæva dicta "Mata de Pungo" prope vicum Pungo Andongo. Floret Nov.Jan., Decbr. ad Mart. fructificat. Exsic. Welw. Iter Angol. no. 1564.

Rhizoma horizontaliter repens vel oblique descendens, circiter pennæ anserinæ crassitudine, quidpiam flexuosum et hinc inde nodoso-tumidum, ad nodos præter fibras longas tenues unum vel pluria tubercula elongato-claviformia, duriuscula sed succulenta, 1-2-pollices longa, deorsum emittens. Caules e rhizomatis collo, plerumque solitarii, rarius 2-3, erecti, teretes, parum succulenti, basi glabriusculi, a medio apicem versus sensim densius pubescentes, pube pilis brevibus patulis hyalinis intermixta, subviscida. Folia inferiora $2-3$ pollices a se invicem distantia, petiolis bipollicaribus, canaliculatis, pubescentibus, versus caulis apicem sensim brevioribus, summis vix lineam longis, patulis suffulta, tenuiter membranacea, demto petiolo 4-6 pollices longa, 2-3 poll. lata, supra læte viridia, glabriuscula vel pilis brevibus raris adspersa, subtus juxta nervos hirtula multoque pallidiora, quoad figuram in eodem specimine maxime variantia, plerumque obovato-acuminata vel obcuneata, basim versus in petiolum attenuata ibidemque integra, a medio laminæ versus apicem dentata, incisa vel lobata, dentibus lobisve terminalibus tum erectis, quam laterales divergentes longioribus, omnibus plus minusve acuminatis vel acutatis sæpiusque apiculo parvo obtuso terminatis; non raro simul cum hisce formis in eodem caule etiam folia elliptico-lanceolata vel ovato-elliptica, margine remote grosse dentata, apice in acumen longiusculum elongato-triangulare producta inveniuntur. Stipule anguste lanceolatæ vel lineares, longe acuminatæ, petiolis multoties breviores, dense pubescentes, hinc margine ciliatæ. Pedunculi erecti, graciles, eorum longiores bipollicares ; receptacula herbaceoviridia, parum carnosa, in pedunculo verticalia, una cum appendice terminali 3-5 poll. longa, subsemicylindrica, sub prima anthesi latere quidpiam compressa, formam lanceolato-linearem fingentia, fructifera demum [ob ovaria turgida] longitudinaliter torulosa. Flores masculi semper monandri a me visi; perigonii tenuissimi limbus breve et irregulariter 3-4-dentatus vel fere obsoletus; filamentum e fundo tubi erectum, liberum, latiusculum, subcompressum; anthera exserta, didyma, rubro-purpurea. Ovaria quam flores masculi multo pauciora, ad utrumque latus costæ receptaculi stipiti brevi seriatim inserta, stylis solis supra florum masculorum planum breviter porrectis; stylus plerumque bicruris, cruribus tum intus stigmatosis, rarius indivisus et apice subdilatato fimbriato-papillosus. Pericarpia globosa, in receptaculi contextu arachnoideo-celluloso nidulantia, etiam maturitate vix supra planum antheriferum eminentia. Embryonis uncinati radicula abbreviato-conica, quam cotyledones obovatæ, plicato-venosæ, inæquales, in stipitem angustatæ, multoties brevior.

Qualitates.-Rhizoma omne et præcipue tubercula oleo æthereo suavissime aromatico pollent et etiam exsiccata aroma per plures annos fere immutatum conservant. Stirps proinde verisimiliter eadem ac plures Dorstenia Brasilienses virtute diaphoretica et roborante, vel forsan adhuc efficaciore gaudet, sicque medicis Angolensibus, in dysenteria morbisque affinibus sanandis, ceu remedium indigenum magnopere commendanda. 


\section{Ordo GNETACEA}

Gnetum africantm, Welw. n. sp. $G$. fruticosum, dioicum; caule cylindraceo, gracili, volubili, alte lateque scandente, remote ramoso, ramis ramulisque patentissimis vel retroflexis pendulisve, herbaceo-viridibus, levigatis, valde tenacibus, ad nodus parum incrassatis ; foliis breve petiolatis, chartaceo-rigidulis, penninerviis, ovali-vel elliptico-oblongis, rarius lanceolatis, basi sensim vel abruptius attenuatis, nune subrotundatis, apice abruptim sensimve in acumen $3-5$ lin. longum, lanceolatum vel lineare, plerumque obtusum, hine inde acutiusculum protractis, margine integris vel remote subcrenatis, utrinque levigatis, sub lente fortiore dense pellucido-punctatis, supra late viridibus nitidulis, subtus pallide virentibus; amentis masculis ad ramulos abbreviatos laterales et apicales terminalibus, solitariis, longius pedunculatis, simplicibus, rhachide compressiuscula, apice conico-subulata, verticillis remotis, globoso-capitatis, involucris cupuliformibus ore truncato subnudis; amentis femineis drupisque non visis.

Gnetum, spec. Welw., Apontam. (1858), p. 545, cum observ.

Habitat in Districtus "Golungo Alto" editioribus (2200-2400 ped.) umbrosis silvarum primitivarum de Serra do Alto Queta, ubi Januar. et Martio florentem vidi, sed stirpem femineam observare non licuit. Exsic. Welw. Iter Angol. no. 1224 \& 1225.

Trunculus in speciminibus a me observatis circiter digitum crassus, cylindraceus, subflexuosus, inferue cortice tenui cinerascente hinc inde rimulis angustissimis distantibus notato, tectus, mox ad duos vel tres pedes supra basim trichotome divisus, ramis lateralibus oppositis et intermedio caulem prolongante iterum repetito-trichotomis. Internodia inferiora vix bipollicaria, demum sursum versus sensim longiora, in caulis parte superiore ad 6-8 pollices longa, ad nodos modice tumida. Rami inferiores circiter pennæ corvinæ crassitudine, superiores et ramuli vix fili emporitici crassitudine, omnes angulo recto patentes vel retrofracti, hinc inde volubiles, extimi flagelliformes, sicque stirpem inter arborum vicinarum frondes late scandentem suspendentes vel ex altiorum arborum coronis longe penduli, pallide herbaceo-virides, rigiduli et tenacissimi, ad imam basim non raro corniculis duobus oppositis, brevibus, rigidis, patentibus, stipulas aculeiformes fingentibus sed reapse ex petiolorum basi remanente et indurata foliorum delapsorum oriundis, muniti. Folia perennia, sicque eorum vetustiora non raro ad faciem superiorem variorum Lichenum epiphyllorum orbiculis varie coloratis ornata, etiamsi vix coriacea; petioli 3-4, rarius 5lin. longi, canaliculati, plus minusve acute carinati, basi vaginante carnosulo-tumidi, hine exsiccatione plerumque transversim rugulosi, post lamine lapsum in cornicula supra notata indurati, longe persistentes, et una cum eorum vagina caulis ramorumque nodos stipantes; lamina foliorum plene evolutorum 4-5 poll. longa, 2 poll. lata, nervis supra vix, sed mediano subtus ad laminæ medium usque manifeste prominente, costis utrinque 5 vel 6 , arcuato-patentibus, sursum et marginem versus sensim evanidis, in vivo e viridi flavescentibus. Amenta mascula terminalia, solitaria, gracilia, rectiuscula vel obiter arcuata, pedunculo subcompresso circiter semipollicem longo, ima basi pilorum rufescentium circulo, supra medium bracteis 2 oppositis, ovalibus, acutis, erectis, basi vaginantibus munito, suffulta, excluso pedunculo $2-2 \frac{1}{2}$ pollices longa, verticillis $8-10$, rarissime pluribus, singulis inter se $1 \frac{1}{2}$ lin. distantibus, densifloris onusta; involucra breviter cyathiformia, ore truncato plerumque omnino nuda vel hinc: inde tenuiter crispula, staminibus pro more sat longe exsertis coronata. Filamenta simplicia, involucella longe superantia, antheris biporosis flavicantibus terminata. Rhachis amenti ultri verticillum summum in acumen elongato-conicum, plus minusve acute subulatum, $1 \frac{1}{2}-2$ lin. longum strictumque protracta. Cetera generis.

vOL. XXVII. 
Observatio.-Stirps ab autochthonibus passim " $N$-Coco" nuncupatur et rami ob eorum longitudinem et tenacitatem chordarum ad instar utuntur; folia recentiora autem cocta atque oleo palmarum condita sapidum ipsis cibum offerunt, etiam mihi in istis solitudinibus non raro graviter esurienti nequaquam ingratum. Fructus maturi, qui ex Nigritarum descriptione oblongo-ovoidei et late rubentes, nucleum pro more sat amplum includunt, ob avium simiarumque voracitatem non nisi rarius inveniendi.

\section{Ordo CYPERACEA.}

Trib. Hypolytre e, Nees, Endl. Gen. Pl. 216*.

Ascolepis, Nees.

Genus reformatum et ampliatum :

Spicula numerosissimæ in capitula densa hemisphærica vel subglobosa, longe bracteato-involucrata, dispositæ, receptaculo depresse globoso vel hemisphærico, distincte alveolato, insertæ, bisquamosæ. Squama exterior plana, angusta, acuminata, vacua, floriferam stipans eaque brevior; squama interior spongioso-turgida, basi interna in rimula hiante florifera, hermaphrodita, sursum in appendicem subulatam vel compresse subprismaticam, longitudine variam angustata. Stamina 3 vel 2 , rarius 1 ; filamentis filiformibus, antheris linearibus obtusis. Setæe hypogyna nullæ; discus nullus vel rudimentarius. Ovarium anguste ovoideum, obtuse vel acutius trigonum; stylus brevis, basi æqualis, stigmatibus 3, rarius 2, filiformibus, obtusiusculis. Caryopsis libera, anguste latiusve obovoidea, plus minus evidenter trigona vel tricostata, glabra†, vertice nuda vel brevissime apiculata aut truncata, lateribus subtilissime impresso-punctulata, quam squama fructifera multoties brevior.

Herbæ elegantulæ, perennes, erectæ, in Africa tropica cis- et transæquatoriali observatæ, cæspitosæ, glabræ, basi foliosæ. Folia filiformia vel anguste linearia. Culmi stricti, graciles, obscure angulati, rarius firmiores et sulculati, basi succulento-tumescentes, foliis laxe vaginantibus vestiti, superne longe nudi, monocephali, infra capitula modice incrassati. Capitula globosa, discoidea vel pseudoradiata, involucro polyphyllo, e foliolis inæquilongis basi dilatata membranaceo-marginatis composito, suffulta, nunc Kyllingiarum vel Eriocaulonearum, nunc quarundam Compositarum capitula radiata mire æmulantia. Spicule basi arcte imbricatæ, apice liberæ, erectæ vel patentes, coloratæ, niveæ, lacteæ, flavæ vel aureæ, nunquam omnino viridescentes, collapsæ demum varie costulatæ vel angulatæ ac plus minus rigidescentes.

Ascolepis, Nees in Plant. Schimp. Abyss. sect. iii. no. 1664.

Kyllingie spec., Steud. in Flora [B. Z.], 1842, p. 597.

Isolepidis spec., A. Rich. Tent. Flor. Abyss. ii. p. 501.

Antrolepis, Welw. Apont. p. 578.

Antrolepis, Thomson in Speke's 'Journ. of the Disc. of the Source of the Nile,' p. 654.

Genus Platylepidi Kunth affine et proximum, sed, ni fallor, bene distinctum, hucusque monotypicum, ab acutissimo Neesio ad specimina a cl. Schimper in Abyssinia lecta recognitum, ne dicam divinatum, sed vix ullibi verbis definitum. Differt autem Asco-

* Tribus Hypolytrearum a C. Neesio olim introducta, nec tamen bene limitata, postea ab Endlicherio l. c. quidpiam reformata, nune generis præsentis speciebus pluribus quodammodo illustrata, in posterum, characteribus $A s c o-$ lepidis additis, accuratins circumscribenda.

$\dagger$ Caryopsis plene matura sæpius membranula tenuissima, hyalina, arcte adglutinata, sub tritu frustulatim secedente, sed in ovario sub anthesi vix perceptibili obducta invenitur, sicque, obiter aspecta, grisea et omnino levigata, vix punctulata, apparet. 
lepis a Platylepide receptaculo hemisphærico (nec elongato-conico), squamis floriferis subcylindraceo-turgidis (nec plano-compressis), genitalibus in eorum rima basali sitis et liberis (nec intra squamæ utriculum inclusis), stylo typice trifido (nec constanter bifido), caryopsi demum trigona libera (nec biconvexa et in ipso squamæe fructiferæ utriculo inclusa.

A Kyllingia, quacum species typica [i. e. Ascolepis eriocanloides Nees] a cl. Steudel in plantis Schimperianis Abyss. Sect. II. no. 1195 et postea in Flora (Bot. Zeit.) loco supra citato conjungitur, nec non ab Isolepide, cui eadem species ab A. Rich. in Flor. Abyss. subscripta fuit, Ascolepis non solummodo genere, sed imo, uti ex supra allatis patet, tribu differt; non enim Scirpeis neque Cypereis, sed tribui Hypolytrearum prope Platylepidem adjungenda.

Vegetationis modum quod attinet, species omnes densius laxiusve cæspitosæ crescunt, earumque individua, eximie socialia, capitulis innumeris hinc vere et æstate prata paludosa, illine autumnali tempore pascua montana humidiora denso agmine decorant, hocque modo, dum vix non semper cum Xyrideis, Eriocauloneis, Commelynaceis atque Irideis pumilis, colore et elegantia æque insignibus sociatæ, pascuis illis characterem peculiarem admodum variegatum imprimunt. Species singulæe autem vix unquam in eodem loco promiscue inter se crescentes observantur, et simul etiam rhizomatis indole atque perennandi modo inter se diversæ, unde commode in duas sectiones divelluntur. Species nempe tenuiores rhizoma offerunt e culmorum basi carnoso-incrassata et bulbulis gemmæformibus, intra bulbi matricalis vaginas exteriores nascentibus fibrisque crebris gracilibus stipitatis laxe conflatum, dum contra species robustiores rhizomate gaudent lignescente, horizontali vel oblique descendente, ex quo culmi floriferi, basi itidem carnoso-tumidi, seriatim vel fasciculatim gregati assurgunt. Species rhizomate bulbulifero donatæ plerumque præcociores sunt, sed individuorum vegetatio, etiamsi jam ineunte vere incipiens, ob bulbulorum in culmos florentes evolutionem successivam, pluviarum copia vel parcitate moderatam, in variis locis non raro ad æstatis finem usque extenditur, sicque crebris temperaturæ et humiditatis vicissitudinibus exposita, unde, saltem pro parte, facies polymorpha capitulorum speciei maxime vulgaris, in diversis soli elevationibus æque frequenter occurrentis (Ascolep. protece nostræ) explicatur; species robustiores autem, rhizomate repente vel nodoso simulque profundius penetrante perennantes, tardius sese evolvunt, non nisi versus æastatis finem vel ineunte autumno florescere solent, sicque imbribus copiosioribus et longius persistentibus irrigatæ, nec non temperaturæ vicissitudini minus subjectæ, etiam quoad capitulorum magnitudinem spicularumque formam et colorem magis constantes inveniuntur.

§1. Rhizoma tenuiter fibrosum, bulbuliferum; caryopsis $\frac{1}{5}-\frac{1}{2}$ lin. longa, vertice dilatato rotundato-obtusa ${ }^{*}$.

1. Ascolepis Protea, Welw. Culmis (floriferis) 3-10 poll. altis; foliis basilaribus [i.e. e bulbulis non nisi sequente anno culmiferis enatis] fasciculatis, angustissime linea-

* Huic sectioni etiam species typica, nempe Ascolepis eriocauloides Nees, l. c. (Isolepis Ascolepis A. Rich. l.c.), in Abyssiniæ montosis primum a cl. Schimper, demum a C. Quartin Dillon lecta, inserenda. Specimina sicca hujus speciei Schimperiana, quæ in Herb. Kew. et in Museo Brit. prostant, sat bene cum descriptione Richardii conveniunt, excepta spicularum squama dorsali vacua, a Richardio prætervisa, sed certe obvia. Quoad habitum et capitulorum molem hæc species formis microcephalis Ascolepidis protece $\beta$ bellidiflorce nostræ satis similis, sed floribus 
ribus vel fere capillaribus, erectis, culmo duplo triplove brevioribus, caulinis duobus vel sæpius solitario, culmi basim laxe alteque vaginante, quam basilaria duplo latiore et plerumque arcuatim patulo ; capitulis nunc globosis $2 \frac{1}{2}-4$ lin. crassis, nunc plus minusve hemisphæricis, transversim 3-8 lin. latis; spiculis albis vel flavis; squamis floriferis ovalibus, lanceolatis vel lineari-lanceolatis, a medio apicem versus subulatis vel compresso-cylindricis, obtusis vel acutiusculis, singulis e capituli centro peripheriam versus sensim longioribus; staminibus 3 vel rarius 2 , stylo tri- vel bifido; caryopsi minima, $\frac{1}{5}-\frac{1}{4}$ lin. longa, obovoidea vel pyriformi, obscure trigona, vertice rotundato-obtuso vix apiculata, ad basim conico-attenuatam oblique truncata.

Habitat in Distr. Pungo Andongo et Huilla montosis breve herbidis subspongiosis a 3200 ad 5000 ped. altit., in demissioribus locis a Novembri ad Martii initium, in editioribus a Januario usque ad Maium florens. Etiam in Africa centrali observata.

Stirps quoad capitulorum figuram et magnitudinem squamarumque florigerarum configurationem et colorem maxime polymorpha, formis numerosis, primo aspectu inter se, uti dicere solent, toto cœlo diversis ludens, quæ tamen accuratius examinatæ et comparatæ sensim atque sensim inter se confluunt, ita ut imo varietates, characteribus aliquomodo constantioribus circumscriptæ, non nisi difficiliter et vix bene limitatæ statui queant. Sunt tamen formæ distinctiores sequentes:

a. kyllingioides: capitula virescenti-albida vel sordide lactea, sphærica vel depresse globosa, $2-3 \frac{1}{2}$ lin. crassa; squamæ floriferæ abbreviatæ, ovales vel lato-lanceolatæ, compressiusculæ (in sicco subplanæ), apice obtusæ vel parum acutatæ; stamina et stigmata 3 ; caryopsis vix unquam $\frac{1}{4}$ lin. longior, angulo uno alterove magis prominente.

Habitat in decliviis brevissime herbidis sed humidiusculis inter rupes editiores [3400 ped.] ipsius Præsidii Pungo Andongo loco dicto Tunda Quilombo, nec alibi in omni Angola a me observata. Floret Nov. Decbr. Exsic. Welw. Iter Angol. no. 1667.

Forma omnium pracocior, capitulis plus minusve globosis, compactis, sordide albentibus, Kyllingias microcephalas æmulans. Squame floriferæ quidem, uti in omnibus sequentibus, turgidæ, sed latiores et breviores simulque quidpiam compressæ, in sicco demum fere planæ apparent et extus 1-3-nerves.

Huc forsan : Isolepis Kyllingioides Rich. Tent. Abyss. ii. 502 trahenda?, sed auctor caryopsim apice acutam dicit, qualem in nulla Ascolepidis protea varietate observavi.

ß. bellidiflora: capitula splendide nivea vel lactea, depresse hemisphærica, transversim 5-8, rarius 3-4 lin. lata, centro plerumque excavata, Bellidem perennem flore pleno mire fingentia. Squamæ floriferæ graciles, elongatulæ, lanceolatæ vel lineari-lanceolatæ, apicem versus subulatæe vel compresso-cylindricæ, in sicco demum angulatæ, plerumque laxius quam in $\alpha$ et $\gamma$ imbricatæ. Caryopsis in speciminibus robustioribus $\frac{1}{2}$ lin. longa, omnino sessilis.

Habitat in Distr. Pungo Andongo ad 3000 ped. alt., Januario et Febr. florens, nec non in Distr. Huilla pascuis editis ad 5000 ped. alt., ibidemque a Febr. usque ad Maium floret. In Africa centrali durante

constanter monandris et squamis floriferis a basi latiore apicem versus longissime acuminato-subulatis differt. Specimina tamen solummodo pauca, et quidem non nisi e culmis singulis a cæspite solutis constantia, needum fructifera, examinare licuit. 
expeditione Spekcana (fid. Herb. Kew.) a cl. Capt. T. A. Grant in $5^{\circ} 26^{\prime}$ lat. austr. ad 3900 ped. altit. lecta. Exsic. Welw. Iter Angol. no. 1668 \& 1672 (formæ platycephalæ), dein 1671 \& 1667 \& (formæ microcephalæ).

Antrolepis leucantha, Welw. Apont. p. 578 (nomen cum observ.). Antrolepis, sp. n., Thomson, l.c. p. 65t*.

Capitulorum magnitudo hujus varietatis admodum variat, sed eorum figura (etiam in formis microcephalis, locis macrioribus enatis, et iis varietatis a vix majoribus) semper plus minusve depresse hemisphærica, disco ad centrum subexcavato. Squame floriferæ in formis microcephalis acutius subulatæe, rectiusculæ, in platycephalis obtusiores et frequenter sursum arcuatæ. Stamina in hac varietate non raro 2 ; stylus nune elongatulus 3- vel 2-fidus, nunc brevissimus vel fere nullus; i.e. stigmata 3 vel 2 , ovarii apici insidentia, elongata.

\%. santolinoides: capitula sulphurea aut lutea vel intense aurea, ea Santolinarum vel Anucycli aurei quodammodo simulantia, plerumque quam in varietate præcedente robustiora et magnitudine minus variantia. Squamæ floriferæ paullo turgidiores et obtusiores, excepta forma maxime serotina (exsic. no. 1673) in qua sensim longe acuminatæ occurrunt. Caryopsis circiter $\frac{1}{2}$ lin. longa.

Habitat in Distr. Pungo Andongo socialis cum var. $\beta$, paullo serius florens, et in Distr. Huilla spongiosis de Morro de Lopollo, ad 5200 ped. una cum Drosere, Utricularice, et Disce speciebus. Exsic. Welw. Iter Angol. no. 1664, 1666, et 1673.

Antrolepis sulphurea et $A$. Santolina, Welw. Apont. l. c. (nomina c. notula).

Observ.-Cespites omnium varietatum laxiusculi. Culmi in $\alpha$ et $\beta$ tenuiores et breviores, sed in omnibus varietatibus quoad longitudinem valde variantes, vix unquam tamen quam 10 vel 12 poll. longiores, basi constanter bulboso-tumidi, disco parvulo, carnoso, fibrillifero suffulti, vaginis emarcidis, basi bulbulum 1 vel plures forentibus, vestiti; bulbuli minuti, Cannabis seminibus vix majores, durante anthesi culmi matricalis folium unum vel plura fasciculata emittunt, quæ cæspitis folia basilaria sistunt, caulinis et involucralibus semper angustiora, sed longiora. Involucrum capituli basim arcte amplectens, 7-10-phyllum; foliola a basi latissima, extus profunde plurisulcata, sensim vel abruptius in laminam lineari-lanceolatam acuminata, exteriora 2-4 reflexa, infimo longiore 1-2-pollicari; interiora sensim breviora, squamæformia, spiculis adpressa, iisque æquilonga vel paullo breviora. Spicularum longitudo secundum capitulorum diametrum varians, in formis microcephalis lineam vel sesquilineam, in platycephalis, inprimis exteriores, ad $2 \frac{1}{2}-3$ lineas longæ; squamæ vacuæ tenues, lineari-lanceolatæ, planæ, basi hyalino-membranaceæ, floriferis breviores et multo angustiores, earumque dorso arcte adpressæ vel fere adglutinatæ, sicque, præcipue in exsiccatis, facile prætervisæ. Caryopsis cinereo-fuscescens vel nigricans, angulis, inprimis vertice et prope basim, non raro obscuris vel omnino evanidis.

2. Ascolepis anthemiflora, Welw. n. sp. (Tab. XXIV. fig. 9-13.) A. culmis $1-1 \frac{1}{2}-$ pedalibus, gracillimis ; foliis basilaribus anguste linearibus, culmo multo brevioribus, abrupte acutatis, caulinis paucis parum latioribus, erectiusculis; capitulis depresse hemisphæricis, radiatis, transversim (inclusis radiis) $\frac{2}{3}-1 \frac{1}{4}$ poll. latis ; spiculis aureoflavis; squamis floriferis centralibus (discum formantibus) abbreviatis, densissime congestis, erectiusculis, cylindraceis ; periphericis elongatis, ligulæformibus, stellatim

* "Four to nine inches high ; growing like white daisies, in rather moist places. Alt. $3900 \mathrm{ft.} .5^{\circ} 26^{\prime}$ S. Uncommon." (Capt. Grant, apud Speke, l.c.) Eodem modo et ego formam hane elegantissimam jam 1858 in Apont. l. c. cum Bellide perenni comparavi. 
patentibus, compressis, subtus obtuse carinatis, supra secundum medium elevatim costatis, illas disci duplo triplove excedentibus, omnibus nitidulis apiceque obtusiusculis vel abrupte subulatis; staminibus 3 ; stylo trifido; caryopsi $\frac{1}{2}$ lin. longa, elongato-obovoidea vel claviformi, obtuse trigona, minutim apiculata, basi, angulis evanidis, in stipitem brevissimum cylindricum attenuata.

Habitat in Distr. Pungo Andongo interioribus pratis palustribus juxta ripas fluminis Cuije, inter Quibinda et Quitage, una cum Striga, Scleria, atque Commelynearum specicbus socialis ; ad fin. Martii c. fl. et fr. lecta. Exsic. Welw. Iter Angol. no. 1669.

Antrolepis anthemiflora, Welw. l.c.

Cæspites angusti, laxe cohærentes. Culmi pro ipsorum longitudine admodum graciles, obsolete angulati, tenuissime striati, infra capitulum parum vel vix incrassati, sat debiles sed constanter erecti. Folic basilaria fere capillaria, 4-7 poll. longa, sed in planta florente non raro jam emarcida; caulina paullo supra basim culmi 2-3, inferiora brevivaginata, superius culmum ad 2-2즐 poll. altitudinem laxiuscule vaginans, vagina striato-sulcata, sensim in laminam linearem angustata. Involucri foliola circiter 10; exteriora basi dilatata, margine lato-membranaceo undulata, laminis inferiorum 2 vel 3 sub plena anthesi reflexis, anguste lineari-lanceolatis, apice obtusiusculis; infimo 2-3 poll. longo. Capitula constanter aureo-flava, disco valde depresso, circumcirca longe denseque radiata, Anthemidum quarundam calathia eximie simulantia. Squama floriferæ centrales 1-2 lin. longæ, densissime in discum leviter convexum vel subtruncatum congestæ; periphericæ, i.e. capituli discum circumcurrentes, 4-6 lin. longæ, horizontaliter expansæ, rigidulæ, turgidulæ sed compressæ, semilineam latæ, mox post anthesin (ob carinam et costam nunc magis prominentes) tetragono-prismaticæ, fructiferæ fuscescentes; squamæ vacuæ lineari-lanceolatæ vel lineares, sensim longe acuminatæ, floriferis tamen semper breviores. Caryopsis quam in Ascol. protea parum crassior sed longior, angulis apicem et basim versus evanidis vel obscuris, ima basi cylindricao-attenuata transverse truncata, quasi substipitata.

Species, primo aspectu, capitulorum figura admodum singularis nec non caryopsis configuratione ab Ascolepide protea discrepans, ceteris autem characteribus hujusce varietati $\gamma$ satis affinis et forsan non nisi ejusdem forma serotina, in solo ditiore et humidiore exorta. Anne Ascolepidi protece qua varietas $\delta$. anthemiflora subscribenda?

\section{§. Rhizoma repens, indurescens; caryopsis $\frac{3}{4}-1$ lineam longa, vertice angustato truncata.}

3. Ascolepis speciosa, Welw. n. sp. (Tab. XXIV. fig. 1-8.) $A$. culmis subpedalibus, firmis, lineam crassis, basi elongato-conicis, vaginis foliorum emortuorum dense vestitis; foliis ad basim culmi pluribus, erecto- vel arcuato-patulis, linearibus, culmo vix angustioribus, apice planis, obtusiusculis, minutim denticulatis, rigidulis ; capitulis depresse globosis, densissimis, transversim $\frac{3}{4}-1$ poll. latis; spiculis intense sulphureis, verniceo-nitentibus; squamis floriferis lanceolatis, a medio apicem versus cylindraceis vel subulato-attenuatis, obtusis rariusve acutiusculis, singulis a capituli peripheria centrum versus sensim brevioribus ; staminibus 3 ; stylo trifido ; caryopsi lineam longa, elongato-obovoidea, manifeste trigona, vertice angustato transversim truncata.

Habitat in Distr. Huilla pascuis breve herbidis humidiusculis prope Lopollo ad 5000 ped. altit., in $L y$ thracearum, Daphnoidearum humilium et Cyperi plurium specierum fideli societate. A fine Januarii usque ad Martium florens mox demum fructificat. Exsic. Welw. Iter Angol. no. 1674. 
Cospites lati, densissimi. Culmi sub plena anthesi plerumque pedales vel paullo altiores, basi succulenta conico-tumida vaginis foliorum tam vigentium quam emarcidorum et extcrne insuper squamis elongatis, profunde plurisulcatis, fusco-purpurascentibus vestiti, arete inter se cohærentes, fibris tenacibus stipati, rhizomati oblique descendenti demum indurescenti fasciculatim insidentes, quam in ceteris speciebus multo crassiores et rigidiores, evidenter plurisulcati, infra capitula parum vel vix incrassati. Folia culmorum stcrilium fertiliumque plura, 3-7, gregata, inæquilonga, e viridi glancescentia, fere carnosula, juniora erecta, adultiora modice arcuato-patula; vaginæ parum supra terram exsertæ, ad oram membranaceam plus minusve undulatæ, longitudinaliter sulcatæ, sensim in laminam linearem culmo vix angustiorem sed plicatam, obtuse carinatam, obiter striatam, superne explanatam, margine et (inprimis prope apicem obtusiusculum vel abrupte acutatum) anguste hyalinam et remote spinuloso-denticulatam abientes. Involucri foliola 12-15, foliis vix latiora sed acutiora, longitudine inter se admodum varia, exteriora 4-7 reflexa, infimum ad 2-3 poll. longum; interiora sensim breviora et basi angustiora vel omnino ad vaginam reducta, squamiformia. Capitula pro more generis sat ampla, bene evoluta pollice paullo latiora et fere semipollicem alta, primum omnino læete sulphurea, demum ob spiculas exteriores precocius fructificantes tumque fulvescentes bicoloria, centro nempo nunc dilutius flava, margine lato aureo-fulvo cincta, pro stirpe Cyperacea reapss. speciosa. Squama vacuæ lineares vel lineari-lanceolatæ, nervo crassiusculo, dorso obiter prominente, percursæ, inferne hyalino-membranaceæ, apicem versus longe acuminatæ vel subulatæ, ibidemque coloratæ, fertilibus fere dimidio breviores; squamæ floriferæ verniceo-nitidulæ, circumscriptione lanceolatæ, exteriores $4-4, \frac{1}{2}$ lin. longæ, fere usque ad medium rimula hiante apertæe, dorso, inprimis prope basim, nervis pluribus tenuibus percursæ, supra rimulam in appendicem cylindraceam obtusam vel acutius subulatam protractæ. Ovarii quam squama florigera multo brevioris anguli superne acutiores ; stylus basi æqualis, longitudine varians; stigmata obtusa. Caryopsis fusco-atra, circiter I lin. longa, angulis omnibus a basi ad apicem usque manifestis, subcostatis, vertice horizontaliter, basi attenuata oblique truncata, lateribus densissime seriatim foveolata.

Species omnium cognitarum robustissima, in Cyperacearum cohorte facile elegantissima, habitu quasi Armeriam capitulis sulphureis ornatam repræsentans, sicque una cum præcedente futura Adonistarum attentione non omnino indigna, a reliquis speciebus præter notas allatas simul majore rigiditate partium omnium discrepans, territorio Huillensi peculiaris videtur, nec ibidem infra 5000 ped. altit. a me visa.

4. Ascolepis elata, Welw. n. sp. A. culmis subbipedalibus, vix $\frac{3}{4}$ lin. crassis, basi parum tumida vaginis crebris foliorum emarcidorum laxe vestitis; foliis propriis et iis turionum fasciculatis, circa caulium basim congestis, erectis, 6-9 poll. longis, subfiliformibus, culmo duplo triplove angustioribus, apice planiusculo subacutis tenuiterque denticulatis, supremo patulo ceteris latiore; capitulis hemisphæricis, subdensis, transversim 8-10 lin. latis; spiculis sordide albidis, vix nitidulis; squamis floriferis lanceolatis, a medio apicem versus longe sensimque attenuatis, compresse tetragonis, longitudine, centralibus exceptis, inter se subæqualibus, acutiusculis ; staminibus 3 ; stylo trifido; caryopsi $\frac{3}{4}$ lin. longa, elongato-obovoidea, manifeste trigona, vertice parum angustato truncata.

Habitat in Distr. Pungo Andongo pratis paludosis juxta dextram ripam fluminis Cuanza, inter Condo et Quisonde ad 3600 ped. circiter altit., in Xyridearum, Drosere indice et Eriospermi specierum consortio. Ad finem Martii c. fl. et fr. lecta, sed rarius obvia.

Antrolepis elata, Welw. l. c.

Rhizoma omnino antecedentis speciei; culmi autem fere duplo altiores, nec non angustiores, abtusanguli, 
tenuiter sulcati, basi vix succulenti, sed vaginis emarcidis numerosis, profunde sulcatis, extcrioribus in fibras setiformes solutis, vestiti. Folia pallide viridia, culmo multo tenuiora, angustissime linearia, concava vel plicata, dorso sulculata sed vix carinata, apicem versus plana, hyalino-marginata et denticulata. Involucri foliola foliis saltem duplo latiora, reflexorum infimum ad 3 poll. longum. Capitula quam in ceteris speciebus evidenter laxiora; spicula quoad longitudinem inter se parum variantes, 3-4 lin. longæ, maxime centrales tamen semper breviores. Squama fertiles ad rimulæe florigeræ altitudinem usque biconvexæ, supra rimulam plus minusve cvidenter tetragonæ, angulis lateralibus acutioribus, omnibus in squama fructifera vel collapsa magis prominentibus; squame vacuæe uninerves, nervo excurrente acute subulatæ. Caryopsis griseo-fuscescens, lateribus sub lente forti densissime foveolata.

Species foliis filiformibus capitulorumque figura et colore ad Ascolepidem proteam $\beta$. bellidifloram accedens, rhizomatis indole autem nec non caryopsis configuratione $A s c$. speciosa magis affinis sed a me non nisi in paucis speciminibus iisque jam fere defloratis observata et proinde in posterum secundum specimina numerosiora in diversis habitationibus et evolutionis periodis lecta accuratius definienda.

\section{Species inquirenda vel recognoscenda.}

1. Krllingia microcephala, Steud. in Plant. Schimp. Exsice. Abyss. ii. no. 650 (nec Liebm.), sive Tsolepis Kyllingioides, A. Rich. Tent. Abyss. i. pag. 502. Secundum cl. Rich. l. c. Ascolepidi eriocauloidi affinis, ast cel. auctor squamas floriferas planas, stamina tria, caryopsim apice acutam et folia culmum æquantia vel superantia describit. Anne Ascolepidis species distincta vel forsitan Ascolepidis protece supra descriptæ varietas?

2. Isolepis Polyphylda, A. Rich. $l . c$. p. 503. Species una cum priore in Abyssiniæ provincia Chiré lecta, a cl. auctore non nisi in statu fructifero visa et breviter deseripta et quidem Ascolepidi eriocauloidi proxima habita, sed ex diagnosi nimis brevi vix rite eruenda. Etiam hujus speciei squamam fertilem planam et caryopsim obovatam, non angulatam sed acuminatam dicit cl. auctor.

Ambarum stirpium specimina sicca videre nondum licuit.

\section{Ordo GRAMINEÆ.}

Trib. IV. Stipace e, Kunth, Gram. 57.

1. Aristida prodigiosa, Welw. n. sp. (Tab. XXV.) Cæspitosa, plurennis, gracilis; culmo glabro 1-3-pedali, nodis coloratis imberbibus; foliis radicalibus angustissimis, sub-4-pollicaribus, glaucis, sub lente scabrido-puberulis, ligulis brevissimis ciliatis; panicula lineari-oblonga, multiflora, $\frac{1}{2}-1$-pedali, ramis $2-5$ fasciculatis fere a basi floriferis, spiculas plures, sub 3, lineares, pedicellatas gerentibus; glumæ subæquales acutæ, hirsutæ vel glabratæ, basi violaceo-coloratæ, ad infimam basim trinerves; flosculus, dempta arista, glumarum dimidium vix æquans, glaber; arista circumscisse decidua, stipite $1 \frac{1}{2}$ lin. longo, vix torto, glabro, conico, intus cavo, setis lateralibus nudis, intermedia basi nuda, a medio ad apicem usque plumoso-pennata, laterales duplo et ultra superante.

Habitat frequens in collinis arenosis siccissimis Distr. Mossamedes, ex Giraûl usque ad Cabo negro, inprimis 
locis sabulosis oceano proximis, v. gr. ad "Praia da Amelia," denso agmine crescens, per totum fore annum florens et fructificans (Junio, Julio et Septb. 1859 legi). Exsic. Welw. Iter Angol. no. 2000.

Rhizoma abbreviatum, mox in fibras descendentes solutum; fibræ perplures, elongatæ, cylindraceæ, simplices, pennæ corvinæ crassiores, villo albido, velutino, viscido undique obtectæ et subsucculentæ. Cæspites pro soli et expositionis ratione nunc angusti et depressi, pauciculmes, nunc ampliores et altiores, culmos 8-10 et plures emittentes. Folia radicalia dense congesta, in macrioribus arcuato-ascendentia, 1-2-pollicaria, in robustioribus erectiuscula, 3-5 pollices longa, angnstissima, arete plicata sive convoluta, subulatim acuminata, rigidula, cinereo-glaucescentia, sub lento: sulcato-striata et subtiliter scabrido-puberula, successire evoluta atque longe perennantia. Culmi simplices, a basi ascendenter erecti, inferne nodosi, nunc 1-1 $\frac{1}{2}$-pedales, gracillimi et debiles, nunc (in solo humidiusculo vel minus sterili) 2-3-pedales, pennæ corvinæ fere crassitudine et firmiores, parce foliosi ; nodi 2-4, constricti, glabri, fúsco-purpurascentes, $1-3$ pollices inter se distantes ; folia culmi radicalibus quoad figuram et indumentum similia, sed longe vaginata; vaginæ glaucescentes, tenuiter puberulæ, ad oram pilis albidis fasciculatis prompte deciduis barbulatæ, medio parum tumentes, inferiores nodos denudantes, suprema longissima, lamina abbreviata, culmum non raro ad paniculæ basim usque vesticns. Panicula erecta, nunc vix 4-pollicaris, laxior et rariflora, sed plerumque elongata, 6-12-pollicaris, densior et multiflora, rachi compresso-angulata glabra, ramis 2-5 fasciculatis levigatis, erecto-patulis, parce ramulosis. Spicula graciles, absque arista $3-4$ lin.longæ, pedicellis gracillimis, ipsis æquilongis vel longioribus, apice incrassatis suffultæ. Glumæ fere æquales, coneavæ, carinatæ, constanter acutæ, basi semper, rarius omnino violaceæ, dorso undique vel solum juxta carinam hirsutæ (nunc penitus glabratæ), basi prominenter trinerves. Palea inferior coriacea, glaberrima, trinervis; aristæ seta intermedia 1-1 $\frac{1}{3}$ poll. longa, a medio ad apicem pilis hyalinis, tenuissimis, eleganter plumosa, laterales ea dimidio saltem breviores, nudæ, divergentes, tenuissime capillares; palea superior abbreviata, obtusa, membranacea; squamule integræ, acutiusculæ, in diversis ejusdem paniculæ flosculis diversæ magnitudinis, quondam parum evolutæ. Ovarium oblongo-ovoideum, stipitatum, glabrum, stigmatibus intense flavis, pilis simplicibus hyalinis plumosis, muco copioso involutis. Caryopsis cylindracea. vertice obtuso stylorum rudimentis biapiculata, basin versus obconico-attenuata, longitudine lineam parum excedens, glaberrima, longitudinaliter unisulcata.

Observatio.-Gramen elegans sed sat polymorphum, uti in stirpe sub variis solis et expositionis conditionibus vigente expectandum. Formæ hyemales, i.e. a Junio ad Septembris initium florentes, uti et illæ in macrioribus et siccioribus obviæ, foliis angustioribus et brevioribus nec non varie curvis vel arcuatis, panicula laxiore glumisque basi intensius violaceis et dorso hirsutis gaudent, dum individua mensibus vernis vel in solo minus arido aut juxta rivorum ripas crescentia foliis longioribus, erectiusculis vel leviter arcuatis, paniculis densioribus ac glumis pallidioribus et non raro omnino glabris sese distinguunt; ast glumarum magnitudinem et figuram, earumque inter se et cum flosculo relationem nec non aristæ fabricam, in omnibus et quidem numerosis a me examinatis speciminibus semper easdem et constantes observavi. Proxima quidem et affinis hæc præsens species videtur Aristida ciliate Desf., a qua tamen ex auctoritate acutissimi Agrostologi clar. Guill. Munro, cujus benevolum consilium in stabilienda et definienda hac specie secutus sum, inprimis glumis acutis differt; ab Aristida plumosa Lin., etiam quodammodo affini, præcipue arista busi conica intus cava distinguitur.

Prodigiosum hanc Aristide speciem vocavi, quoniam illa, etiamsi ob totius plantx gracilitatem et foliorum culmorumque indumentum cinereo-glaucescens, solo arenoso quasi concolor, peregrinatoris oculis facile fugit, nihilo minus multitudini Zebrarum. 
Antilopum atque Leporum, in istis desertis ab omni reliqua vegetatione fere penitus denudatis vagantium, et imo pecorum domesticorum gregibus, optimum lætumque, et quidem durante hyemis siccissimo tempore unicum pabulum offert, et ita non minus ac Acanthosicyos supra descripta desertorum Africæ calidæ prodigiis adnumerari meretur.

\section{EXPLICATIO TABULARUM. \\ TaBula I. \\ Monodora Angolensis.}

Fig. 1. Ramulus florifer; magn. nat.

2. Flos, demtis petalis exterioribus; paullo auct.

3. Stamen a latere, et

4. a fronte visum; auct.
Fig. 5. Ovarium.

6. Idem transverse sectum; auct.

7. Fructus ; magn. nat.

8. Semen; magn. nat.

9. Idem verticaliter sectum; paullo auctum.

Tabula II.

Alsodeia (Ceranthera) ilicifolia.

Fig. 1. Ramulus florifer; magn. nat.

2. Flos; auct.

3. Idem, demto calyce, a latere visus; auct.

4. Flos vi apertus a fronte visus; auct.

5. Stamina duo a fronte, et

6. a dorso visa; auct.

7. Ovarii pars cum stylo; auct.

8. Ramulus fructifer; magn. nat.
Fig. 9. Semina; magn. nat.

10. Semen testæ parte demta, albumen exhibens; auct.

11. Albuminis pars, embryonem in situ exhibens; auct.

12. Embryo a fronte, et

13. a latere visus; auct.

TABULA III.

Oncoba Welwitschii.

Fig. 1. Ramus florifer; magn. nat.

2. Pistillum; paul. auct.

3. Ovarium transverse sectum; auct.

4. Ramulus fructifer, magn. nat., fructum unum (inferiorem) ante, et alterum (superiorem) post dehiscentiam repræsentans.

\section{Tabula IV.}

Polygala Gomesiana. Caulis pars inferior et ejusdem apex florifer, magn. nat.

Fig. 1. Flos c. bracteolis; auct.

2. Flos a fronte visus.

3. Flos sepalis demptis; auct.

4. Idem 'sepalis et carina demptis; magis auct.

5. Carina; auct.

6. Petalum laterale; auct.
Fig. 5. Semina; magn. nat.

6. Semen; auct.

7. Idem verticaliter sectum, embryonem exhibens; auct.

8. Embryo, a latere visus; valde auct.
Fig. 7. Stamen; auct.

8. Pistillum; auct.

9. Capsula; magn. nat.

10. Eadem; auct.

11. Semen; magn. nat.

12. Idem; auct.

13. Idem a latere visum; auct. 


\section{Tabula V.}

Vatica africana.

Fig. 1. Ramulus florifer; magn. nat.

2. Alabastrum; auct.

3. Flos expansus; auct.

4. Stamen a fronte, et

5. a dorso visum; auct.

6. Calyx cum pistillo; auct.

7. Pistillum dempto calyce; magis auct.
Fig. 8. Ovarium transverse sectum; magis auct.

9. Idem verticaliter sectum; auct.

10. Calyx fructifer; magn. nat.

11. Fructus verticaliter sectus; auct.

12. Vatica africana $\beta$. hypoleuca, ramulus florifer; magn. nat.

\section{Tabula VI.}

Octolobus spectabilis. Ramus florifer, magn. nat.

Fig. 1. Flos masc. vi apertus ; magn. nat.

2. Flos fem. vi apertus; magn. nat.

3. Gynæcium verticaliter sectum; auct.

4. Gynæcii stamen imperfectum, a latere, et

5. a fronte visum; auct.

6. Carpellum; auct.

7. Idem verticaliter sectum.

8. Carpellum maturum; magn. nat.
Fig. 9. Idem apertum.

10. Semen; magn. nat.

11. Idem vertical. sectum, cotyledones exhibens.

12. Idem cotyledone una dempta, plumulam exhibens.

13. Plumula cum radicula; auct.

\section{TABUla VII.}

\section{Paivaeusa dactylophylla.}

Fig. 1. Ramul. florib. masc. ; magu. nat.

2. Capitulum florum masc., et

3. Idem verticaliter sectum; auct.

4. Flos masc. singulus; valde auct.

5. Stamen; auct.

6. Ramulus florib. fem.; magn. nat.

7. Flos fem. ; auct.
Fig. 8. Idem calyce demto.

9. Ovarium transverse sectum; auct.

10. Ramus fructifer; magn. nat.

11. Fructus, necdum bene maturus, verticaliter sectus; paullo auct.

12. Ejusdem pyrenæ, altera abortiente ; magis auct.

\section{Tabula VIII.}

Myrothamnus flabellifolia.

Fig. 1. Ramus florib. masc.; magn. nat.

2. et 3 . Folia a facie et a dorso visa; auct.

4. Flos. masc.; auct.

5. Stamen; auct.

6. Ramulus florib. fem.; magn. nat.

7. Flores femin.; auct.

8. Ovarium transverse sectum; auct.
9. Ramulus fructifer; magn. nat.

10. Capsula matura; auct.

11. Carpellum singulum seminiferum; auct.

12. Semen; auct.

13. Semen verticaliter sectum, albumen et embryonem exhibens; valde auct. 


\section{TaBULA IX.}

Basananthe nummularia. Planta integra c. flore et fr., magn. nat.

Fig. 1. Folium; paullo auct.

2. Flos habitu naturali; auct.

3. Idem arte expansus; auct.

4. Idem verticaliter sectus; magis auctus.

5. Coronæ pars, fila seriei internæ appendiculata exhibens; auct.

6. Eadem pars a facie externa visa.
Fig. 7. Stamen a fronte, et

8. a dorso visum; auct.

9. Gynophorum cum pistillo; auct.

10. Capsula matura; modice auct.

11. Eadem verticaliter secta; auct.

12. Semen cum funiculo; pariter auct.

\section{Tabula X.}

Machadoa Huillensis. Planta integra c. flor. et fr., magn. nat.

Fig. 1. Flos; parum auct.

2. Idem vi aperta ; magis auct.

3. Idem dissectus et adhuc magis auct.

4. Petalum; auct.

5. Pars annuli staminiferi cum stamine; auct.
Fig. 6. Stamen a dorso visum; auct.

7. Pistillum; auct.

8. Ovarium transverse sectum; auct.

9. Semina a facie et a latere visa; magn. nat.

10. Semen; auct.

11. Idem transverse sectum.

\section{Tabula XI.}

Acanthosicyos horrida.

Fig. 1. Plantie modum crescendi exhibens; dimin.

2. Ramus sterilis, et

3. Ram. florifer masc.; magn. nat.

4. Flos masc.; auct.

5. Idem apertus ; auct.

6. Calyx cum staminibus ab interna facie visis; auct.
Fig. 7. Pars calycis verticaliter dissecti, staminis insertionem illustrans; auct.

8. Pilus singulus barbæ filamentorum; valde auct.

9. Planta juvenilis; magn. nat.

Obs. Hæc ultima figura perperam no.8. designata.

\section{Tabula XI. A.}

Acanthosicyos horrida.

Fig. 1. Ramus fructifer; magn. nat.

2. Corticis fructus fragmentum; auct.

3. et 4. Semina ; magn. nat.

5. Semen auctum, a facie, et

6. a latere visum.
Fig. 7. Semen verticaliter dissectum; auct.

8. Embryo a facie, et

9. a latere visus; paullo auct.

10. Cotyledon a facie interna visa cum plumula et radicula in situ; auct.

TabUla XII.

Corallocarpus Welwitschii.

Fig. 1. Ramus florifer et simul fructifer; magn. nat.

2. Flos masc.; auct.

3. Idem expansus; auct.

4. Idem arte apertus.

5. Flos fem.; auct.

6. Idem apertus.
Fig. 7. Ovarium transv. sectum.

8. Fructus maturus; magn. nat.

9. Idem transverse sectus; paullo auct.

10. Semen; magn. nat.

11. Idern; auct.

12. Folium alterius speciminis ejusdem speciei, lobis lineari-angustatis. 


\section{Tabula XIII.}

Musscenda splendida. Ramus florifer, magn. nat.

Fig. 1. Floris alabastrum; auct.

2. Corolla arte aperta; auct.

3. Ovarium demptis calycis lohis; auct.
Fig. 4. Idem transverse sectum; magis auct.

5. Fructus maturus; magn. nat.

\section{Tabula XIV.}

Corynanthe paniculata. Ramus florifer, magn. nat.

Hig. 1. Flos nondum apertus, et

2. Idem expansus; auct.

3. Anthera a facie, et

4. a dorso visa; auct.

5. Ovarium, et

6. Idem transverse sectum; auct.

6a. Pars paniculæ fructiferæ; magn. nat.

(N.B. Lit. $a$ in icone omissa.)
Fig. 7. Capsula matura dehiscens; auct.

8. Ejusdem valvarum una, internam faciem seminumque situm exhibens; auct.

9. Capsula paullo ante dehiscentiam trau. verse secta; auct.

10. Semen; magn. nat.

11. Idem valde auctum.

\section{Tabula XV.}

Schrebera Golungensis. Ramus florifer, magn. nat.

Fig. 1. Alabastrum; auct.

2. Corolla arte aperta; auct.

3. Stamen a latere, et

4. a facie visum; auct.

5. Pistillum; auct.

6. Ovarium verticaliter sectum; mag. auct.

7. Idem transverse sectum.

8. Capsula matura dehiscens; magnit. nat.

9. Ejusdem valvularum una, seminum situm exhibens ; magn. nat.
Fig. 10. Semen perfectum; magn. nat.

11. Semen abortivum; magn. nat.

12. Seminis pars basilaris, tegmine demptu, embryonis situm exhibens; magi. nat.

13. et 14. Embryo a facie et a latere visus; magn. nat.

15. Ejusdem pars basilaris cum radicula: auct.

\section{Tabula XVI.}

Pachypodium Lealii.

Fig. 1. Stirpes duæ integræ, speciei habitum exhibentes; diminut.

2. Ramus florifer; magnit. nat.

3. Pars rami junioris, superne folium inter spinas sessile, inferne ejusdem delapsi cicatricem exhibens; parum auct.

4. Corollæ tubus arte apertus; auct.
Fig. 5. Stamen; auct.

6. Calyx cum pistillo; auct.

7. Ramuli fructif. apex, fructus juveniles et maturos exhibens; magn. nat.

8. Semen; magnit. nat.

9. Embryo a facie et a latere visus; paruni auct.

\section{Tabula XVII.}

Faroa salutaris.

Figs. 1. et 2. Plantæ integræ florentes diversæ ætatis; magn. nat.

3. Alabastr.; auct.

4. Flos expansus; auct.

5. Idem arte apertus; magis auct.
Fig. 6. Ovarium transverse sectum; auct.

7. Ramus fructifer; magn. nat.

8. Capsula matura dehiscens; auct.

9. Eadem transverse secta; auct.

10. Semen; valde auct. 


\section{Tabula XVIII.}

Sesamothamnus Benguellensis.

Hig. 1. Imago diminuta speciminis vetustioris floriferi, fruticis habitum illustrans.

2. Apex ramuli foliiferi; magn. nat.

3. Ramulus florifer; magn. nat.

4. Corollæ pars arte aperta, staminum situm exhibens; auct.
Fig. 5. Anthera a latere et a facie visa; auct.

6. Calyx cum pistillo; auct.

7. Ovarium; auct.

8. Ramulus fructifer ; magn. nat.

9. Semen; magn. nat.

\section{Tabula XIX.}

Alvesia rosmarinifolia. A. Caulis pars cum ramo laterali florifero; magn. nat. B. Ejusdem caulis apex florifer et fructifer; magn. nat.

Fig. 1. Flos; auct.

2. Idem verticaliter sectus; magis auct.

3. Pars superior filamenti cum anthera; auct.

4. Calyx verticaliter sectus, gynophorum et pistillum exhibens.
Fig. 5. Calyx fructifer, arte dimidiatus, nuculam perfectam et abortientes exhibens; magn. naturali.

6. Nucula singula; magis auct.

\section{Tabula XX.}

Faurea speciosa. Ramus floriger, spicam unam (ad dextram) florentem, alteram (ad sinistram) jam basi fructificantem exhibens; magn. nat.

Fig. 1. Alabastrum et flos apertus; auct.

2. Pistillum cum squamulis; auct.
Fig. 3. Ovarium; magis auct.

4. Idem verticaliter sectum; itidem auct.

\section{TABULA XXI.}

Hydnora longicollis.

Fig. 1. Pars caulis subterranei cum alabastris diversæ ætatis et flore uno aperto; magn. nat.

2. Flos verticaliter sectus, ovarii et staminum situm exhibens.

3. Pericarpium submaturum, adhuc peri- anthio (hoc quidem limbo 4-fido) munitum; magn. nat.

Fig. 4. Pericarpium maturum; parum auct.

5. Idem transverse sectum, seminum conglutinatorum globulum exhibens.

\section{Tabula XXII.}

\section{Pilostyles athiopica.}

Fig. 1. Ramulus arboris e Cesalpinearum tribu (Berlinia paniculata, Benth.), quæ parasitæ matrix, floribus Pilostylis femineis onustus; magn. nat.

2. Sectio transversa ejusdem ramuli, parasitæ insertionem et evolutionem successivam illustrans; auct.

3. Flos singulus [vel magis proprie specimen singulum] adhuc involucro hiante munitus; auct.
Fig. 4. Idem magis evolutus, et

5. Idem plene evolutus; magis auct.

6. Flos bracteis sepalis petalisque demtis, ovarium exhibens; auct.

7. Ovarium verticaliter, et

8. transverse sectum; auct.

9. Ovulum singulum; magis auct. 


\section{TABULA XXII. (continuatio).}

Fig. 10. Ramus alterius arboris ejusdem Berlinice paniculate, floribus Pilostylis masculis onustus ; magn. nat.

11. Flos mase. verticaliter sectus, columnam stamineam exhibens; auct.

12. Columnæ stamineæ apex floris juvenilis, antheris necdum effetis; auct.
Fig. 13. Flos masculus centro verticaliter scetus, sepalis petalisque demptis; valde auct.

14. Columna staminea verticaliter secta; alhuc magis auct.

Obs. Petalorum etc. denticuli, nec non tubi strminei costulæ a pictore prætervisa.

\section{Tabula XXIII.}

Morus excelsa.

Fig. 1. Pars ramuli amenta masc. gerentis; magn. nat.

2. Flos masc. singulus; auct.

3. Ramus amenta feminea submatura gerens; magn. nat.

4. Flos femin.; auct.
Fig. 5. Ovarium adolescens; auct.

6. Achenium c. stylo exsiccato ; auct.

7. Idem apertum, semen exhibens; auct.

8. Semen verticaliter sectum, embryonem et albumen parcum illustrans ; auct.

9. Embryo ; magis auct.

\section{Tabula XXIV.}

\section{Ascolepis speciosa.}

Fig. 1. Planta integra florens; magn. nat.

2. Involucrum cum receptaculo spiculis denudato; quidpiam auct.

3. Spicula squamam florigeram et vacuam exhibens ; auct.
Fig. 4. Squama florig. a fronte visa; auct.

5. Pistillum et stamina; magis auct.

6. Caryopses; magn. nat.

7. Caryopsis singula; valde auct.

8. Eadem transverse secta; mag. auct.

\section{Ascolepis anthemiflora.}

Fig. 9. Capitulum florig.; magn. nat.

10. Spicula singula peripheriæ; auct.

11. Spicula singula disci; auct.
Fig. 12. Caryopses ; magnit. nat.

13. Caryopsis singula; valde auct.

\section{TABULA XXV.}

Aristida prodigiosa.

Fig. 1. Plantæ pars inferior, et

2. Culmi pars florifera; magn. nat.

3. Spicula singula juvenilis; auct.

4. Eadem evoluta; magis aucta.

5. Eadem demptis glumis; iterum auct.

5a. [numerus in icone omissus] Pistillum stamina et squamulæ; valde auct.
Fig. 6. Pistillum cum squamulis et palea superiore; valde auct.

7. Squamula singula; v. auct.

8. Palea superior; v. auct.

9. Caryopsis matura; auct. 


\section{INDEX SYSTEMATICUS.}

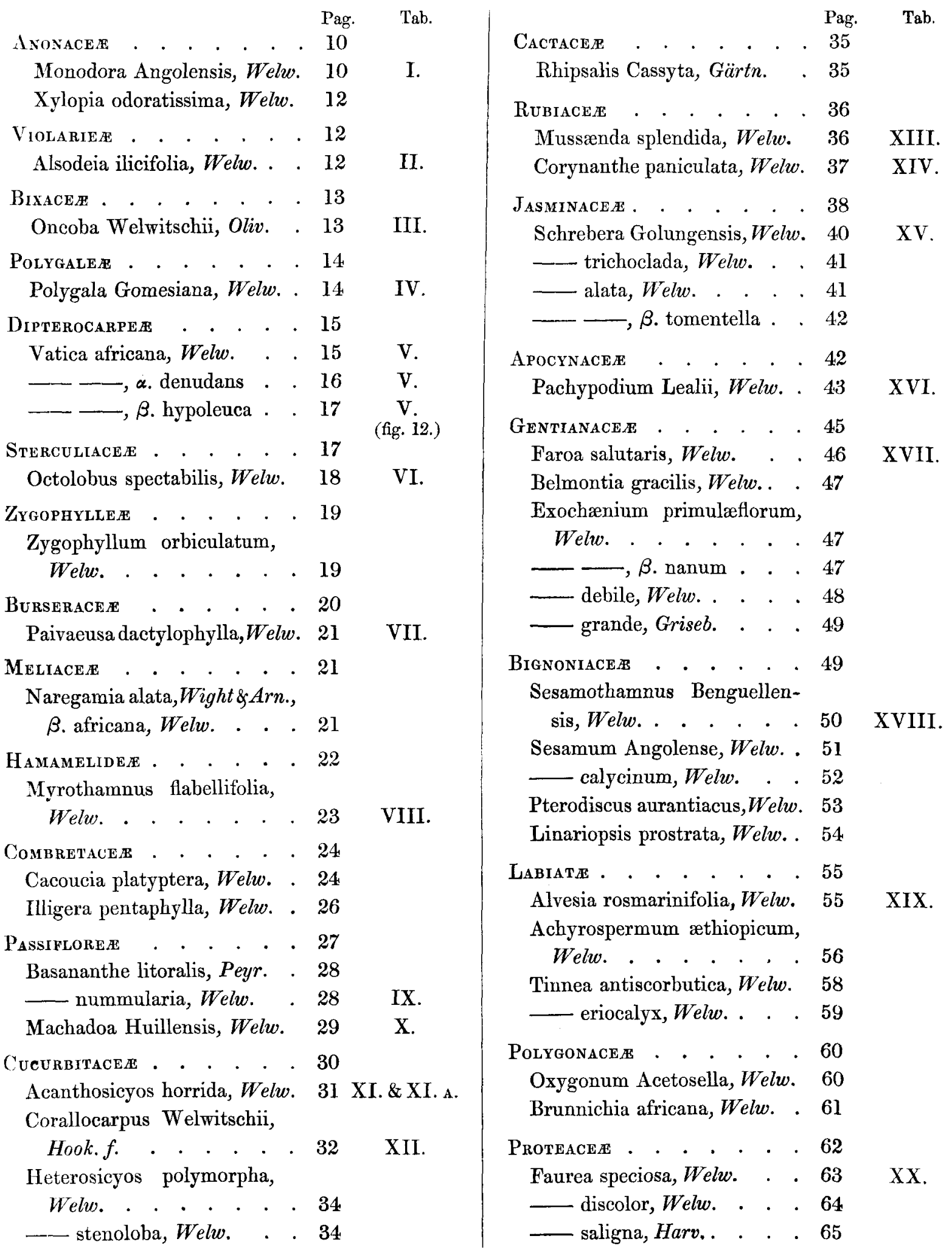




\section{INDEX SYSTEMATICUS (contin.).}

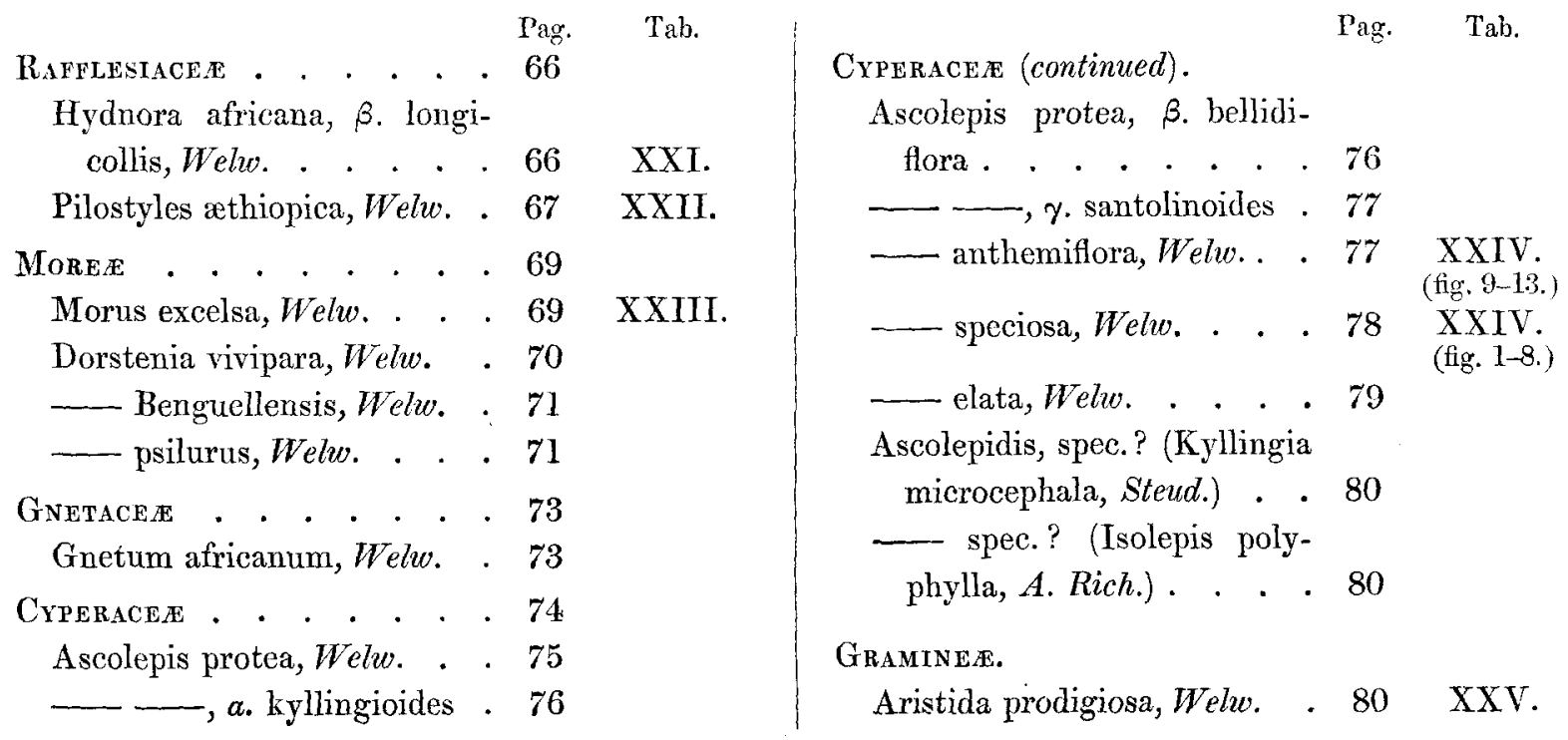

\section{INDEX ALPHABETICUS.}

Obs.--Nomina stirpium descriptarum litteris romanis (ordinalia majoribus), synonyma et nomina stirpium in observationibus commemoratarum litteris italicis traduntur.

A. Pag.

Acanthosicyos, Welw. . . . . . . . . 30

- horrida, Welw. . . . . . . . . 31

Achyrospermum æthiopicum, Welw. . . . 56

- densiflorum, Bl. . . . . . . . . 57

frutescens, Benth. . . . . . . . 57

— phlomoides, Bl. . . . . . . . . 57

Adansonia, L. . . . . . . . . . . 35

Adeniopsis, Welw. . . . . . . . . 43,45

Adenium, R. et Sch. . . . . . . . 44,45

— Honghel, Alph. DC. . . . . . . . 45

$\longrightarrow$ — Lindl. . . . . . . . . . 45

- multiflorum, Klotsch. . . . . . 44, 45

-_ Namaquanum, Wyley . . . . . 43, 45

—_speciosum, Fenzl . . . . . . . 44, 45

Achmandra conocarpa, Dalz. . . . . . 33

—_epigcea, Arn. . . . . . . . . . 33

— velutina, Dalz. . . . . . . . . 33

Alchornece spec. . . . . . . . . . . 24

Aloë arborescens, Mill. . . . . . . . 26

Alsodeia ilicifolia, Welw. . . . . . . . 12

VOL. XXVII.
Pag.

Alsodeieæ . . . . . . . . . . . 12

Alvardia spec. . . . . . . . . . . 8

Alvesia, Welw. . . . . . . . . . . 55

— rosmarinifolia, $W_{e l w .}$. . . . . . . 55

Ampelidece . . . . . . . . . . . 30

Anonacele. . . . . . . . . . . . 10

Anonce spec. . . . . . . . . . . . 17

Antrolepis anthemiflora, Welw. . . . . 78

__elata, Welw. . . . . . . . . . 79

leucantha, Welw. . . . . . . . 77

, nov. spec., Thomson . . . . . . 77

- santolina, Welw. . . . . . . . 77

— sulphurea, Welw. . . . . . . . 77

Apodantheæ . . . . . . . . . . 67

Apodanthes, Poit. . . . . . . . . . 69

Apocynace. . . . . . . . . . . 42,44

Aristida ciliata, Desf. . . . . . . . . 81

- plumosa, L. . . . . . . . . . 81

— prodigiosa, Welw. . . . . . . 80,81

Arachis hypogaa, L. . . . . . . . . 6

Ascolepis, Nees . . . . . . . . . 74,75 
INDEX ALPHABETICUS (contin.).

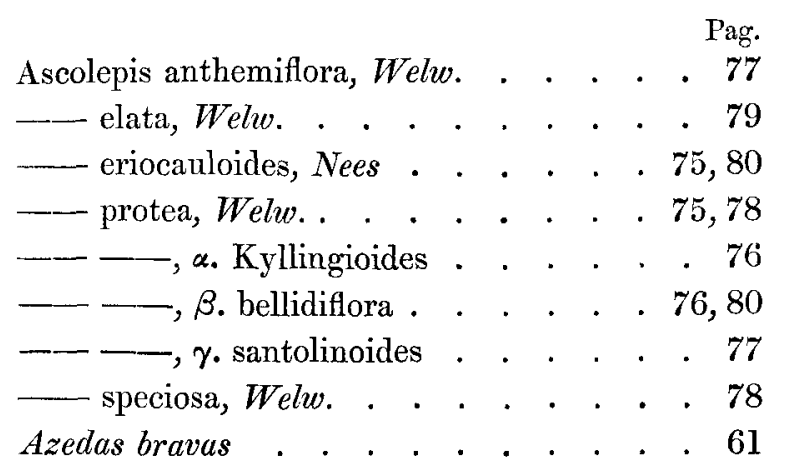

B.

Balanophorea . . . . . . . . . . 69

Baloteæ . . . . . . . . . . . . 55

Bandeircea speciosa, Welw. . . . . . . 26

Basananthe, Peyr. . . . . . . . . . . . . . 27

litoralis, Peyr. . . . . . . . . . . 28, 29

— nummularia, Welw. . . . . . . . 28,29

Belmontia, E. M. . . . . . . . . . . . 47,49

— gracilis, Welw. . . . . . . . . . 47

Berlinia paniculata, Benth. . . . . . . . . 67

Brgnoniace . . . . . . . . . . 38, 39, 49

Bombax Buonopozense, P. de B. . . . . 61

Brasenia peltata, Pursh . . . . . . . 36

Brunnichia africana, Welw. . . . . . . . 61

cirrhosa, Banks . . . . . . . . 62

Brunnichieæ . . . . . . . . . . . 61

BurseraceE . . . . . . . . . . . 20

Bursereæ . . . . . . . . . 20

C.

Cachinde candange . . . . . . . . . 24 Cacoucia, Aubl. (nec Walp.) . . . . . . . . 24

—_cocinea, Aubl. . . . . . . . . 26

— cordifolia, Walp. . . . . . . . . 24

— platyptera, Welw. . . . . . . . . . 24

— species . . . . . . . . . . . 35

Cactacex . . . . . . . . . . . . 35

Camoënsia maxima, Welw. . . . . . . . 26

Catete Bulla . . . . . . . . . . . 58

Ceratogonum, Meisn. . . . . . . . . 9

Ceranthera ilicifolia, Welw. (conf. corrig.) 19

Chloreæ . . . . . . . . . . . . 45

Cinchoneæ. . . . . . . . . . . . 37

Clematidis spec. . . . . . . . . . . 30

Cliffortia? flabellifolia, Sond. . . . . . 22

Cola acuminata . . . . . . . . . . 35
Pag.

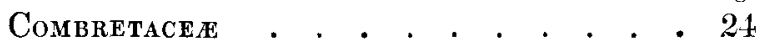

Combreteæ . . . . . . . . . . . 24

Commelynacee . . . . . . . . . 75, 78

Corallocarpus, Welw. . . . . . . . . . . 32

Welwitschii, Hook. f. . . . . . . 32

Corynanthe, Welw. . . . . . . . . . . . . 37

—— paniculata, Welw. . . . . . . . . . 37

Cressa, L. . • . . . . . . . . . . . . . 9

Cucurbitacele . . . . . . . . . . . 6,30

Cucurbiteæ . . . . . . . . . . . 30

Cuscute spec. . . . . . . . . . . . 38

Cxperace . . . . . . . . . $48,49,74$

Cyperus Papyrus, L. . . . . . . . . . 6

Cyrtandrea . . . . . . . . . . . 7

Cyrtopera longifolia, Reichb. f. . . . . . 35

D.

Dalhousiea bracteata, Wall. . . . . . . 26

Daphnoidea . . . . . . . . . . 7, 78

Dileniacex . . . . . . . . . . . . 30

Disa spec. . . . . . . . . . . . . 77

Dombeya spec. . . . . . . . . . . 42

Dorstenia Benguellensis, Welw. . . . . . . $7 \mathbf{1}$

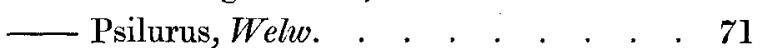

— vivipara, Welw. . . . . . . . . 70

Drosera indica, L. . . . . . . . . . . . . 79

Droserce spec. . . . . . . . . . 46,48

E.

Echiteæ . . . . . . . . . . . 42

Echites succulenta, Thunb. . . . . . . 42

Elcodendron glaucum, Pres. . . . . . . 38

Elais guineensis, L. . . . . . . . . . 7

Enicostema, Bl. . . . . . . . . . . 45

Ericacec . . . . . . . . . . . 7

Eriocaulonece . . . . . . . . . . 47,75

Eriospermi spec. . . . . . . . . . . 79

Eucinchoneæ . . . . . . . . . . 37, 38

Euclea, L. . . . . . . . . . . . . 9

Eupachypodium, Welw. . . . . . . . . . 43

Eupassifloreæ . . . . . . . . . . . 28

Eureiandra formosa, Hook. f. . . . . . . . 26

Eusesamum . . . . . . . . . . . 51

Exochænium, Griseb. . . . . . . 47, 18,49

— debile, Welw. . . . . . . . . . . . . . 48

—— grande, Griseb. $\quad$. . . . . . . . . . . 48,49 
INDEX ALPHABETICUS (contin.).

Exochænium primulæflorum, Welw. . . . 47

F.

Fabago (Sect. Zygophylli) . . . . . . .

Faroa, Welw. . . . . . . . . . . . . 45

— salutaris, Welw. . . . . . . . . . 46,47

Fici spec. . . . . . . . . . . . . 17

Faurea, Harv. .......... 62

—— discolor, Welw. $\quad . \quad$. . . . . . . . . . 64

—_ saligna, Harv. . . . . . . . . .62,63,65

—

G.

Gentianacez . . . . . . . . . . 45

Gentianeæ . . . . . . . . . . . 45

Gipepe . . . . . . . . . . . . . 11

Gloriosa abyssinica, A. Rich. . . . . . 30

superba, L. . . . . . . . . . . 30

Gnetace . . . . . . . . . . . 73

Gnetum africanum, Welw. . . . . . . 73

Gramine 8 . . . . . . . . . . . 80

Gyrocarpeæ . . . . . . . . . . . . 26

H.

Hamamelide 6 . . . . . . . . . . . 22

Hartogia capensis, Thunb. . . . . . . . . 38

Heterosicyos, Welw. . . . . . . . . . 30,33

- polymorpha, Welw. . . . . . . . 34, 35

— stenoloba, Welw. . . . . . . . . . . . . 34

Hippion, Spgl. . . . . . . . . . . . . . . 45

Hydnora africana, Thunbg. [conf. corrigenda] 67

B. longicollis, Welw. $\quad$. . . . . . 66

capensis [conf. corrig.] . . . . . . 67

Hydnoreæ . . . . . . . . . . . . 66

Hymenodyction, Wall. . . . . . . . . 37

Hypolytreæ . . . . . . . . . . 74, 75

\section{I.}

Illigera pentaphylla, Welw. . . . . . . 26

Illigera spec. . . . . . . . . . . . 27

Iridearum spec. . . . . . . . . . 7,34

Isolepis Ascolepis, A. Rich. . . . . . . 75

—Kyllingioides, A. Rich. . . . . . 76,80

— polyphylla, A. Rich. . . . . . . . 80
J. Pag.

JasminaCe

Jasmineæ . . . . . . . . . . . . 39

Jobo . . . . . . . . . . . . . . 11

Juncus, L. . . . . . . . . . . . . . . . 9

$\mathrm{K}$.

Kosaria, Hochst. . . . . . . . . . . 70,71

Kyllingia microcephala, Steud. . . . . . 80

Kyllingia spec. . . . . . . . . . . 74

L.

LABiate . . . . . . . . . . . 55

Labiatarum spec. . . . . . . . . . 7

Lagenias, E. M. . . . . . . . . . . . . . . 49

Leea sambucina, Willd. . . . . . . . . 61

Leucospermum, R. Br. . . . . . . . . 62

Liliacearum spec. . . . . . . . . . 7

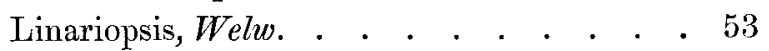

— prostrata, Welw. . . . . . . . . 54

Lythracearum spec. . . . . . . . . . 78

M.

Machadoa, Welw. $\quad$. . . . . . . . . . . $\quad 29$

- Huillensis, Welw. . . . . . . . . . 29

Macrolobii spec. . . . . . . . . . . 22

Meliace . . . . . . . . . . . . 21

Meliacearum spec. . . . . . . . . . 7

Melieæ . . . . . . . . . . . . . 21

Mesembryanthemum, L. . . . . . . . . 9

Mimosearum spec. . . . . . . . . . 7

Mitrephoreæ . . . . . . . . . . 10

M-nara . . . . . . . . . . . . 32

Modecca, Lam. . . . . . . . . . . 29

Modeccea . . . . . . . . . . . . 28

Monodora Angolensis, Welw. . . . 10,11

Myristica, Dun. . . . . . . . 10,11

MоrеÆ . . . . . . . . . . . . . 69

Morus excelsa, Welw. . . . . . . . . . . 69

Mucamba-camba . . . . . . . . . . . . 69

Mussænda (Sect. Belilla) . . . . . . . 36

—erythrophylla, Schum. . . . . . . 37

— splendida, Welw. . . . . . . . . . 36

Myrice spec. . . . . . . . . . . 23, 38

Myristica moschata, L. . . . . . . . 11

Myristicacearum spec. . . . . . . . . 7

N 2 


\section{INDEX ALPHABETICUS (contin.).}

Myrothamnus, Welw. . . . . . . . . . 22

flabellifolia, Welw. . . . . . . . . 22, 23

Myrtacearum spec. . . . . . . . . . 7

\section{N.}

Nathusia alata, Hochst. . . . . . . 39, 4I

Nara . . . . . . . . . . . . . 32

Naras . . . . . . . . . . . . . 32

Naregamia alata, W. et Arn., $\beta$. africana,Welw. 21

Nauclea, L. . . . . . . . . . . . 37

$N$-coco . . . . . . . . . . . . 74

N-pepe . . . . . . . . . . . . . 11

Nymphreacearum spec. . . . . . . . . 6

O.

Ocimeæ. . . . . . . . . . . . 55

Octolobus, Welw. $\quad$. . . . . . . . . . . . . 17

— spectabilis, Welw. . . . . . . . . . 18

Oleaceæ . . . . . . . . . . . 38,40

Oncoba Welwitschii, Oliv. . . . . . . . 13

Oncobeæ . . . . . . . . . . . . 13

Opuntieæ . . . . . . . . . . . . 35

Orchidea terrestres . . . . . . . . . . . 7

Oxygonum Acetosella, Welw. . . . . . 60

—Dregei, Meisn. . . . . . . . . 61

P.

Pachypodium, Lindl. . . . . . . . $42,44,45$

bispinosum, Lindl. . . . . . . . 45

Lealii, Welw. . . . . . . . . . . 5, 53, 45

Namaquanum, Welw. . . . . . . 45

succulentum, Alph. DC. . . . . . . 45

tuberosum, Lindl. . . . . . . . . . 45

Paivaeusa, Welw. $\quad . \quad$. . . . . . . . . 20

— dactylophylla, Welw. . . . . . . . . . 21

Palme . . . . . . . . . . . . . 7

Parinarice spec. . . . . . . . . . . 17

Passiflorex . . . . . . . . . 27, 28,30

Pedalineæ . . . . . . . . . . . . 53

Pedalium, L. . . . . . . . . . . . 54

Periloma, H. B. K. . . . . . . . . . . 58

Persooniece. . . . . . . . . . . . 62

Phaseoli spec. . . . . . . . . . . 6

Phonix spinosa, Schum. . . . . . . .8

Pilostyles æthiopica, Welw. . . . . . . 67

Piper
Pistice spec. . Pag.

Platylepis, Kunth . . . . . . . . . 74, 75

Plectrantheæ . . . . . . . . . . 55

Polygala Gomesiana, Welw. . . . . . . . 14

Polygale . . . . . . . . . . . 14

Polygonace

Populi spec. . . . . . . . . . . . 23

Protea, L. . . . . . . . . . . . . 63

Proteaced . . . . . . . . . 7,62

Protece spec. . . . . . . . . . . . 42

Proteeæ . . . . . . . . . . . 62

Protium, Burm. . . . . . . . . . . 20

Pterocarpi spec. . . . . . . . . . . 22

Pterodiscus aurantiacus, Welw. . . . . . 53

—_Gayi, Desm. . . . . . . . . . 53

— speciosus, Hook. . . . . . . . . 53

\section{R.}

Rafrlesiacere . . . . . . . . . . 66

Raphice spec. . . . . . . . . . . . 7

Rhipsalis Cassyta, Gärtn. . . . . . . . 35

Rhynchocarpa, Schrad. . . . . . . . 32

Welwitschii, Naud. . . . . . . . 32

Rosacea . . . . . . . . . . . . 23

Rublaces. . . . . . . . . . . .

Rubiacearum spec. . . . . . . . . . 7

S.

Salicinea . . . . . . . . . . . . 23

Salicis spec. . . . . . . . . . . . 65

Santalacece . . . . . . . . . . . 7

Sarna, Karst. . . . . . . . . . . . . $\quad .69$

Sauvagesia erecta, L. . . . . . . . . . . $\quad 29$

Saxifragacea . . . . . . . . . . . .

Schousboea, Schum. . . . . . . . . . 24

— cordifolia, Schum. . . . . . . . 24

—, Willd. . . . . . . . . . . . 24

Schrebera, L. . . . . . . . . . . . 38

—, Retz. . . . . . . . . . . . 38

Schrebera, Roxb. . . . . . . . . . 38

— alata, Welw. . . . . . . . . 39,41 —_, $\beta$. tomentella . . . . . . . 42 Golungensis, Welw. . . . . . . 39,40 Saundersice, Harv. . . . . . . . . 39, 41 Swietenioides, Roxb. . . . . . 39,42 trichoclada, Welw. . . . . . . 39,41 
INDEX ALPHABETICUS (contin.).

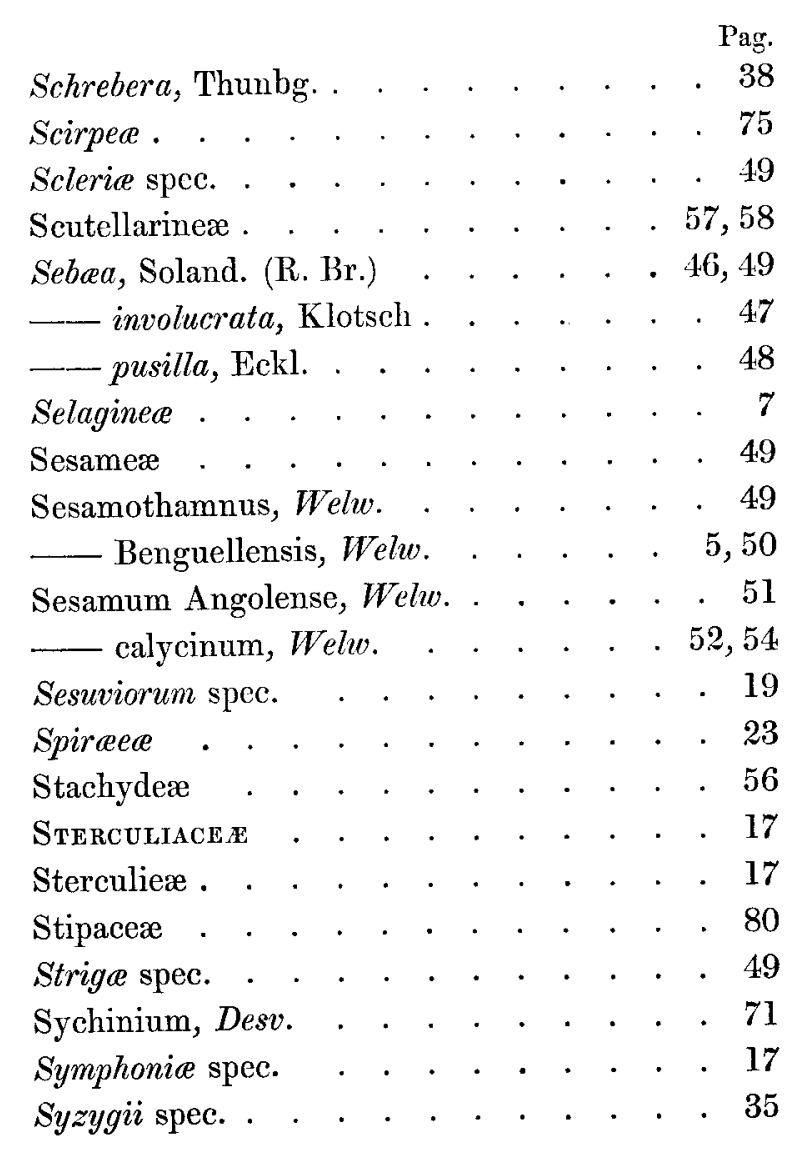

T.

Tarchonanthi spec. . . . . . . . . . 8

Tetracarpaa Tasmanica, Hook. f. . . . . 23

Tetracera, L. . . . . . . . . . . . . 30

Tinnea, Kotschy et Peyr. . . . . . . . . 57 - athiopica, Kotschy et Peyr. . . . . 58

—— antiscorbutica, Welw. . . . . . . . $\quad .58$

— eriocalyx, Welw. . . . . . . . . . . . 59

Trichomeria, Hook. f. . . . . . . . . 33

Triglochin, L. . . . . . . . . . . . . 8
Trymatococci spec. . . . . . . . . . 61

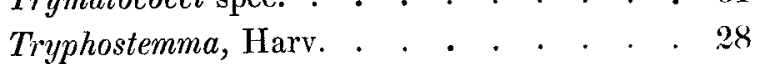

U.

Uncaria, Schreb. . . . . . . . . . 37

Utricularice spec. . . . . . . . . . . . 47

V.

Vatica africana, Welw. $\quad . \quad . \quad . \quad . \quad . \quad . \quad . \quad 15$

$\longrightarrow-\alpha$, denudans . . . . . . . 16

$\longrightarrow$ - $\_$. hypoleuca . . . . . . . 17

Viola, L. . . . . . . . . . . . . $\quad 29$

VIOLARIEA . . . . . . . . . . . 12,29

Vitis Bainesii, Hook. . . . . . . . . 5

— macropus, Welw. . . . . . . . . 5

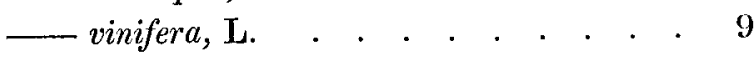

Vogelia africana, Lam. . . . . . . 9,19

W.

Welwitschia mirabilis, Hook. f. . . . . . 5

X.

Xipepe . . . . . . . . . . . . . 11

Xylopia odoratissima, Welw. . . . . . . . 12

Xylopia spec. . . . . . . . . . . . 42

Xylopieæ . . . . . . . . . . . . 12

Xyridearum spec. . . . . . . . . 47,79

Z.

Zea Mays, L. . . . . . . . . . . . . 6

ZYGophYllaceE . . . . . . . . . . . 19

Zygophyllum orbiculatum, Welw. . . . 19,66 


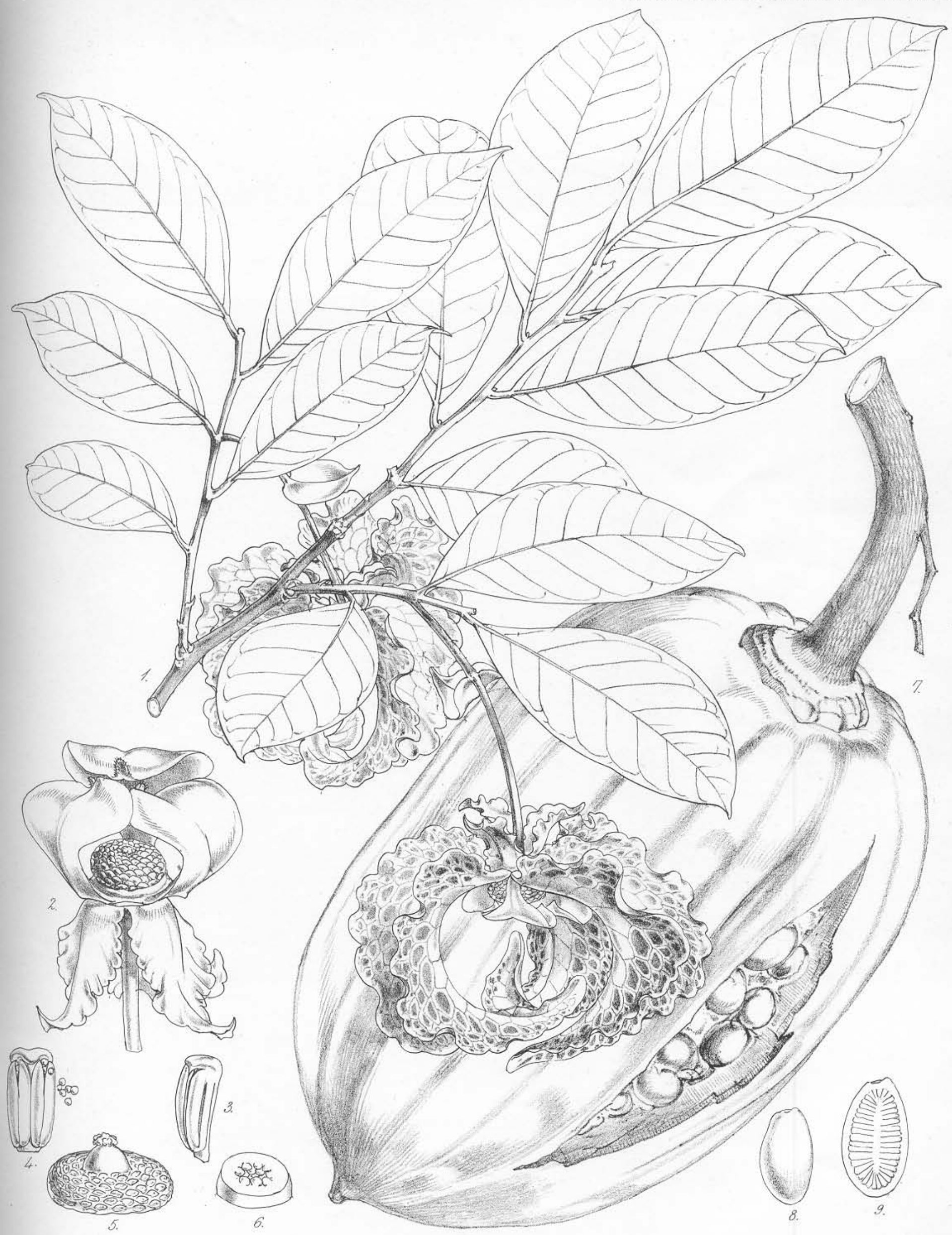

W.H Fitch, del et Iith. 
Trans. Linn. Soc. Vou. XXVII. TaB.?.

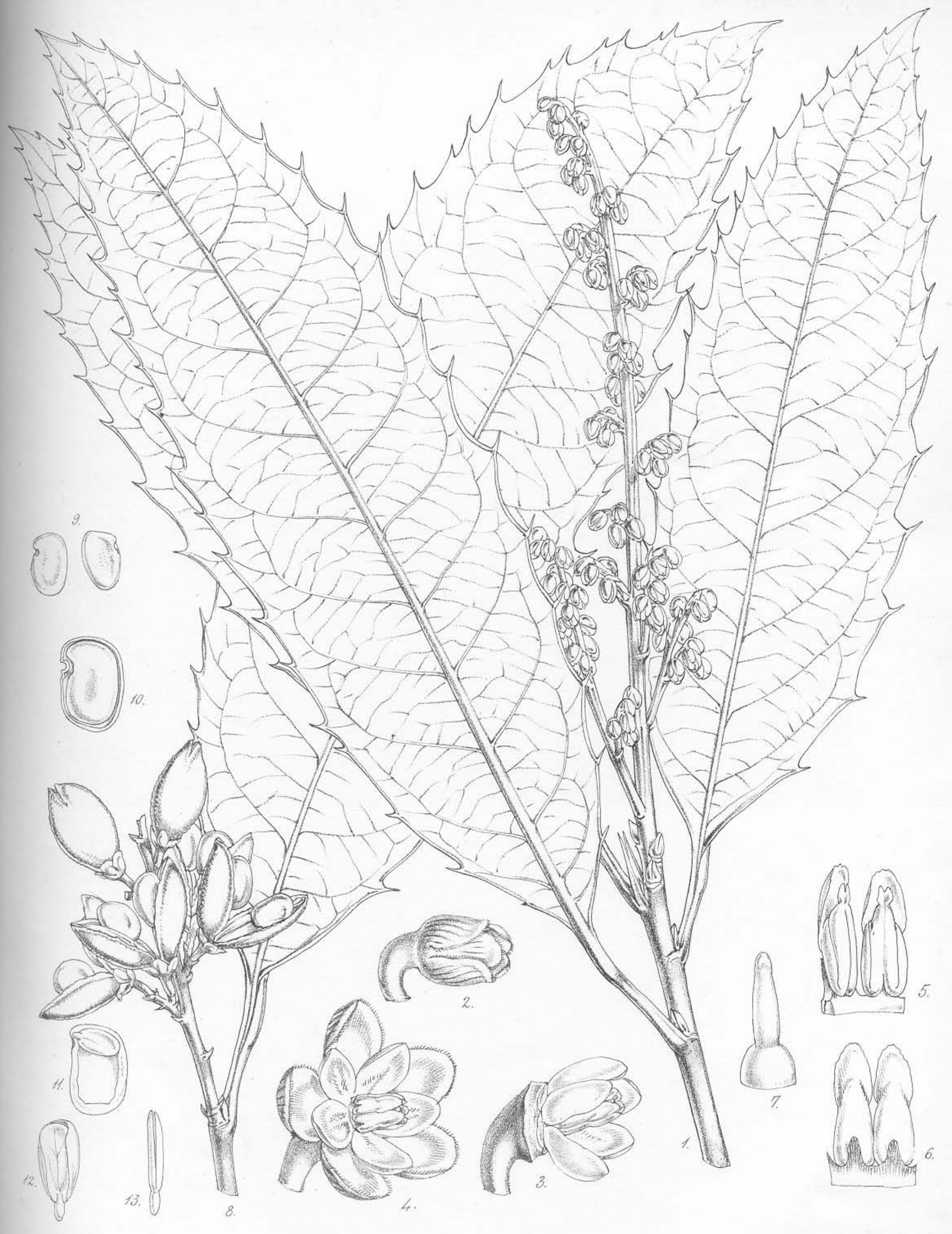


Trans. Linn. Soc. Vol. XXVII. Tab.3.

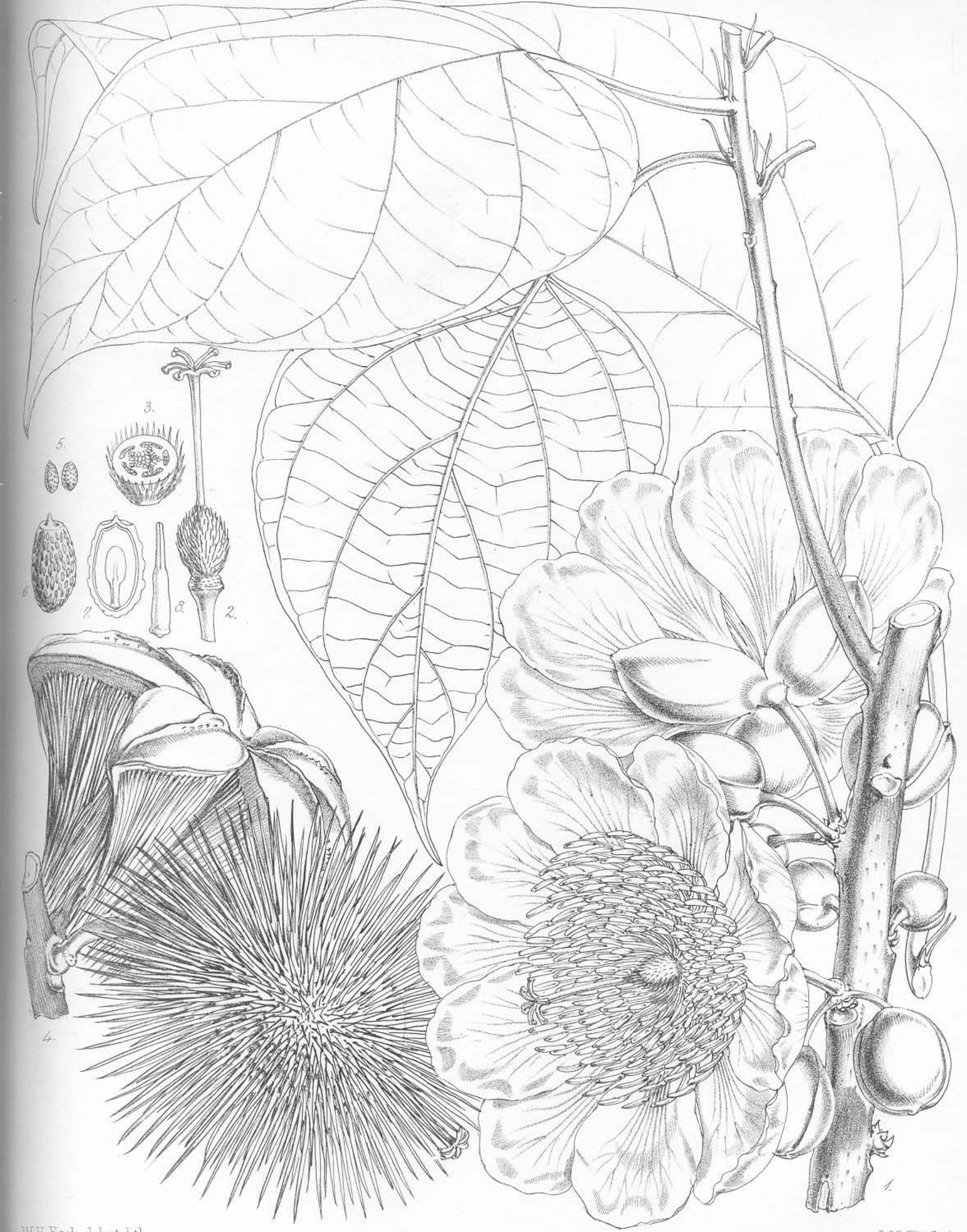

WII Fitch, del et. lith 
Trans. Linn. Soc. Vol. XXVII. Tab.4.

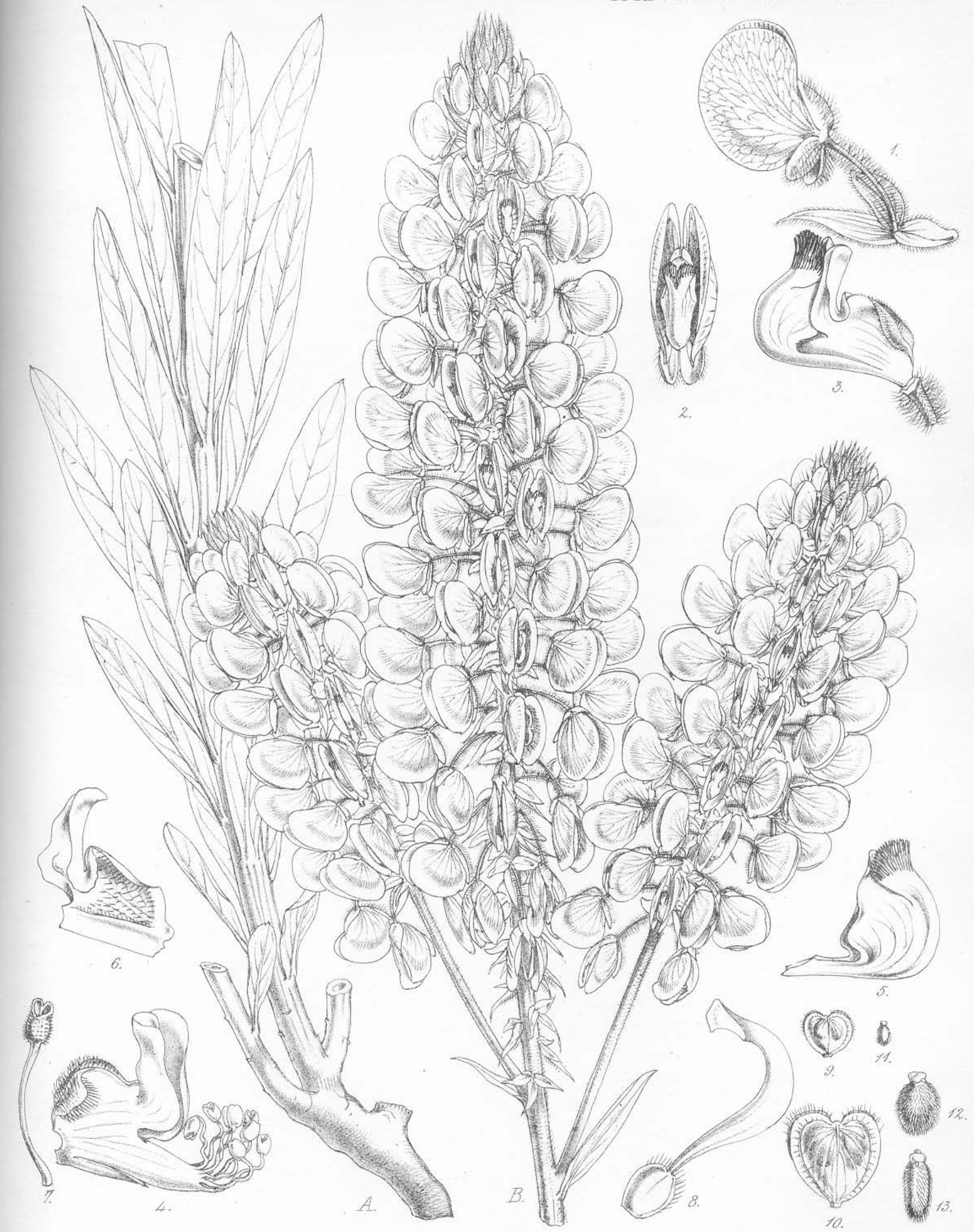

W. H. Fitsh del et lith 
Trans. Linn. Soc. Vol. XXVII. Tab.5.

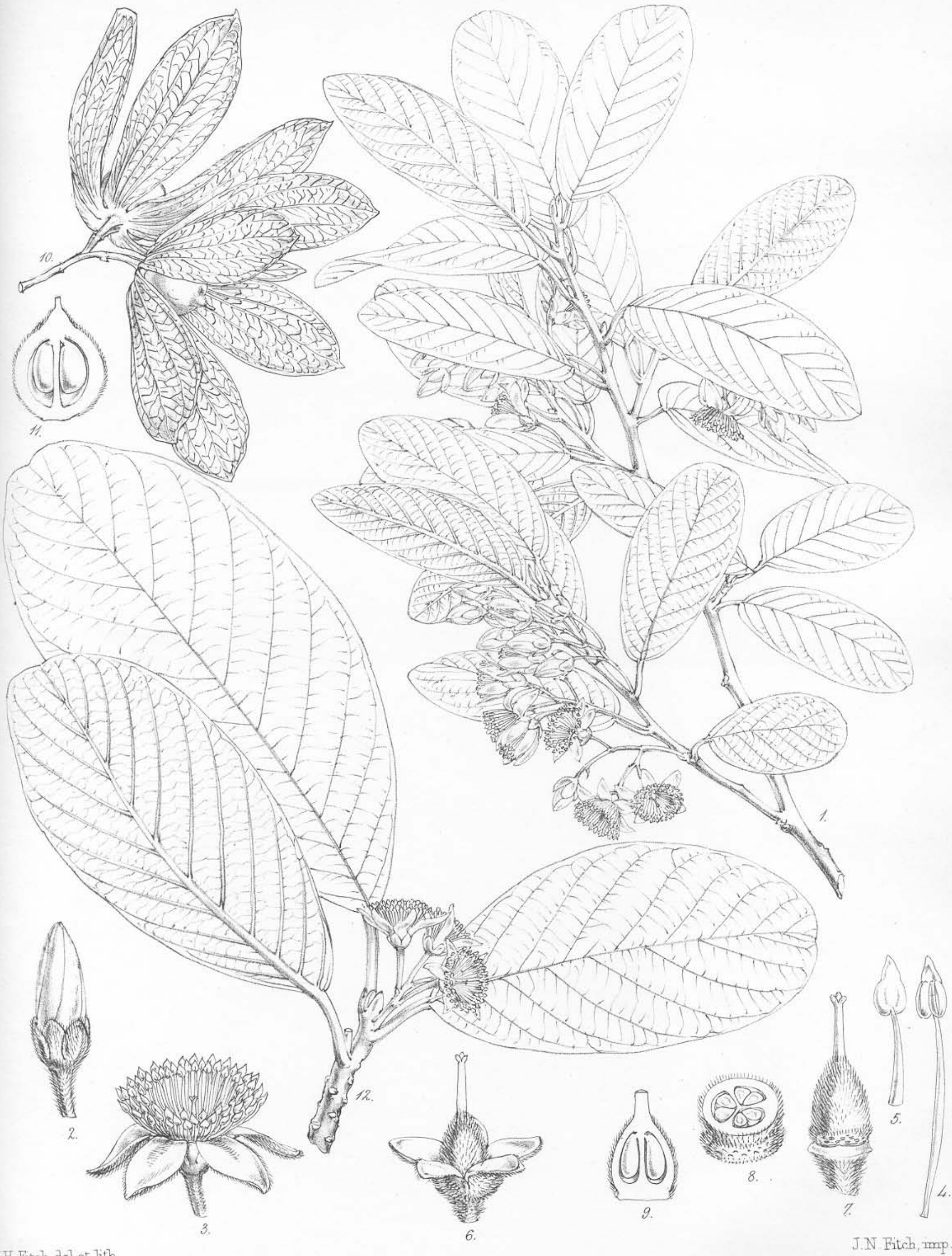

WH. Fitch, del et lith.

Vatica africana, Welw. 


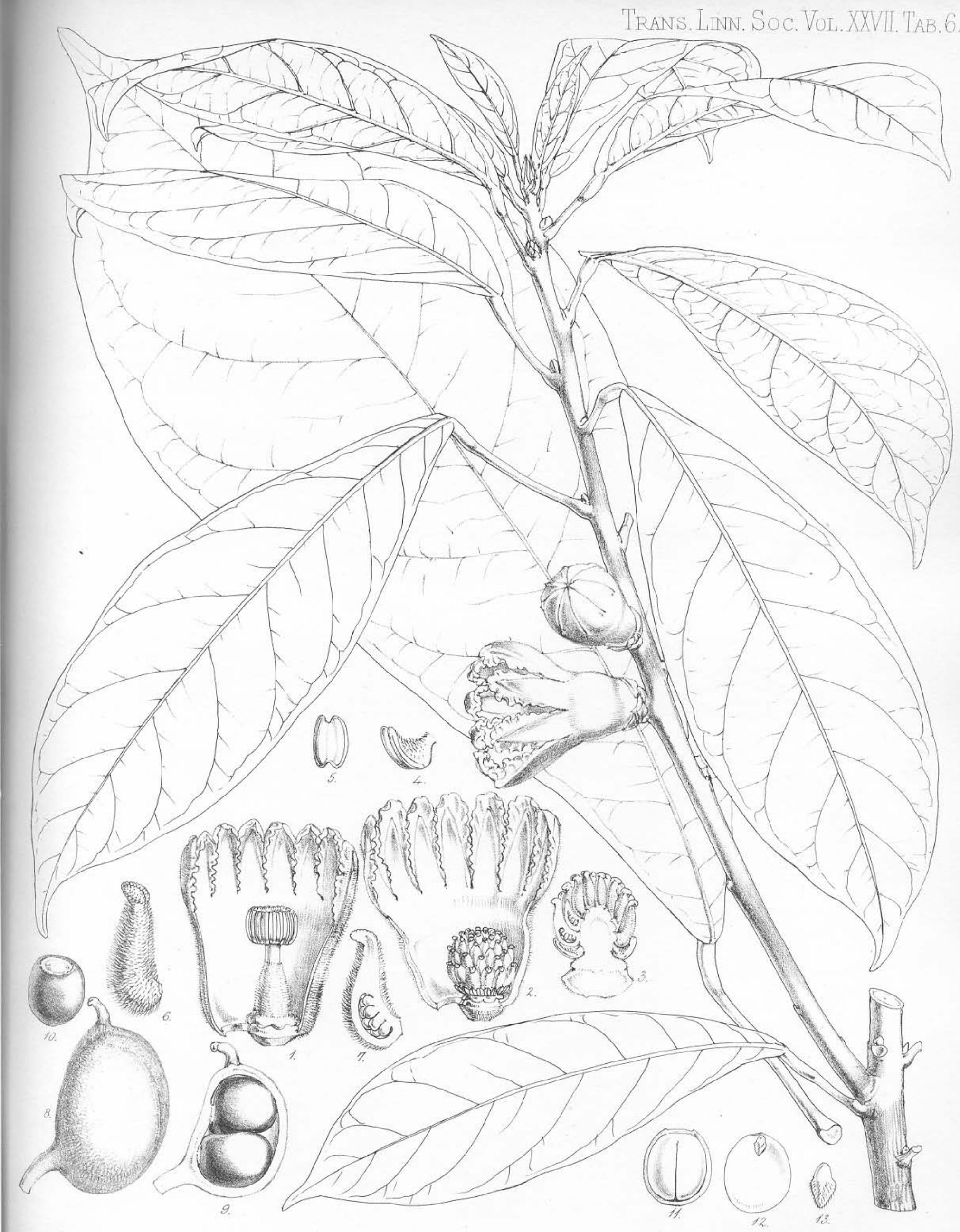

WH Fitah, del et Jith

Octolobus spectabilis, Welw. 
Trans. Linn. Soc.Vot. XXVII. Tab. T.

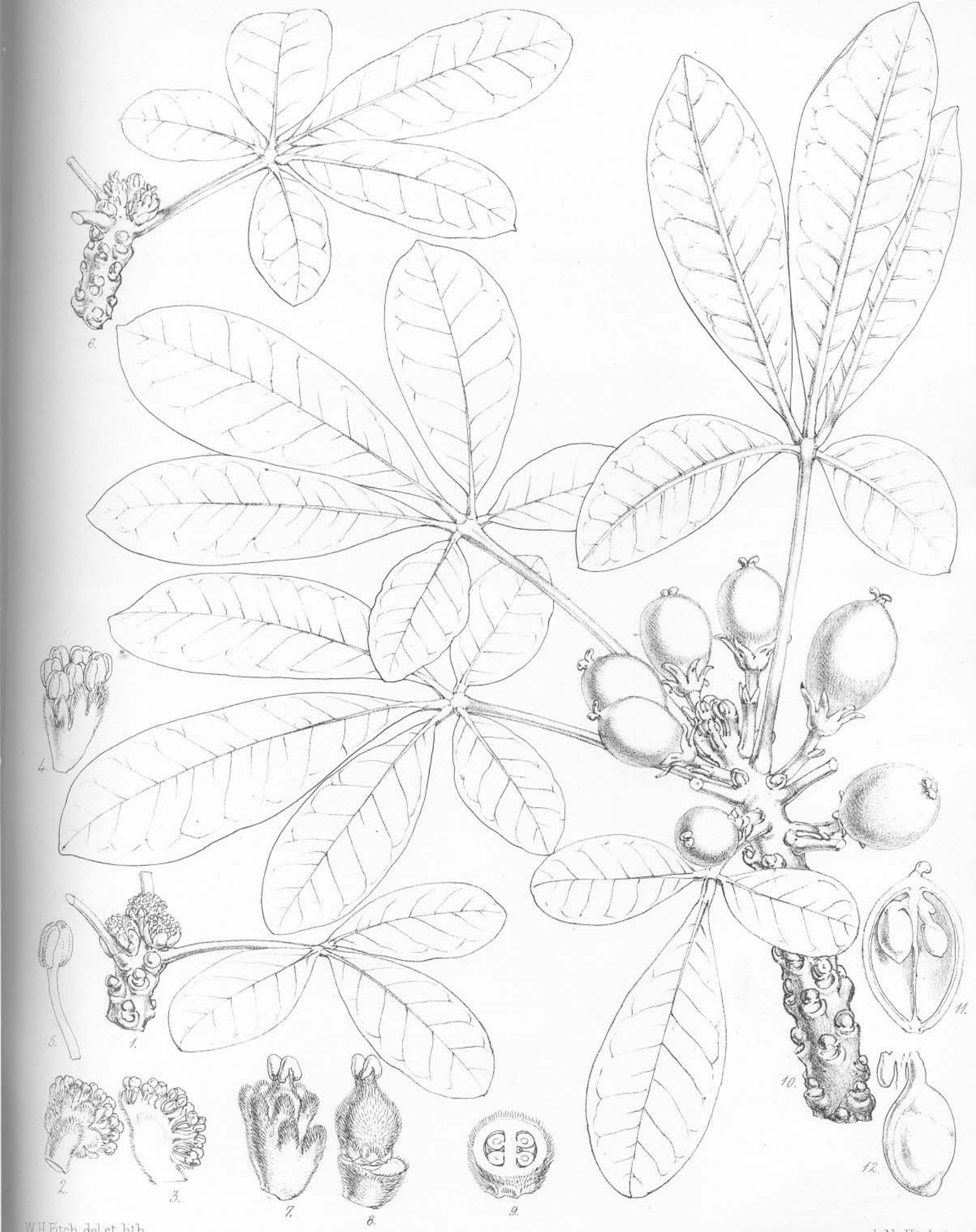

WH Fitch, delet hith.

Paivæusa dactylophylla, Welw. 
Trans. Linn. Soc. Vot.XXVII. TaB.8.

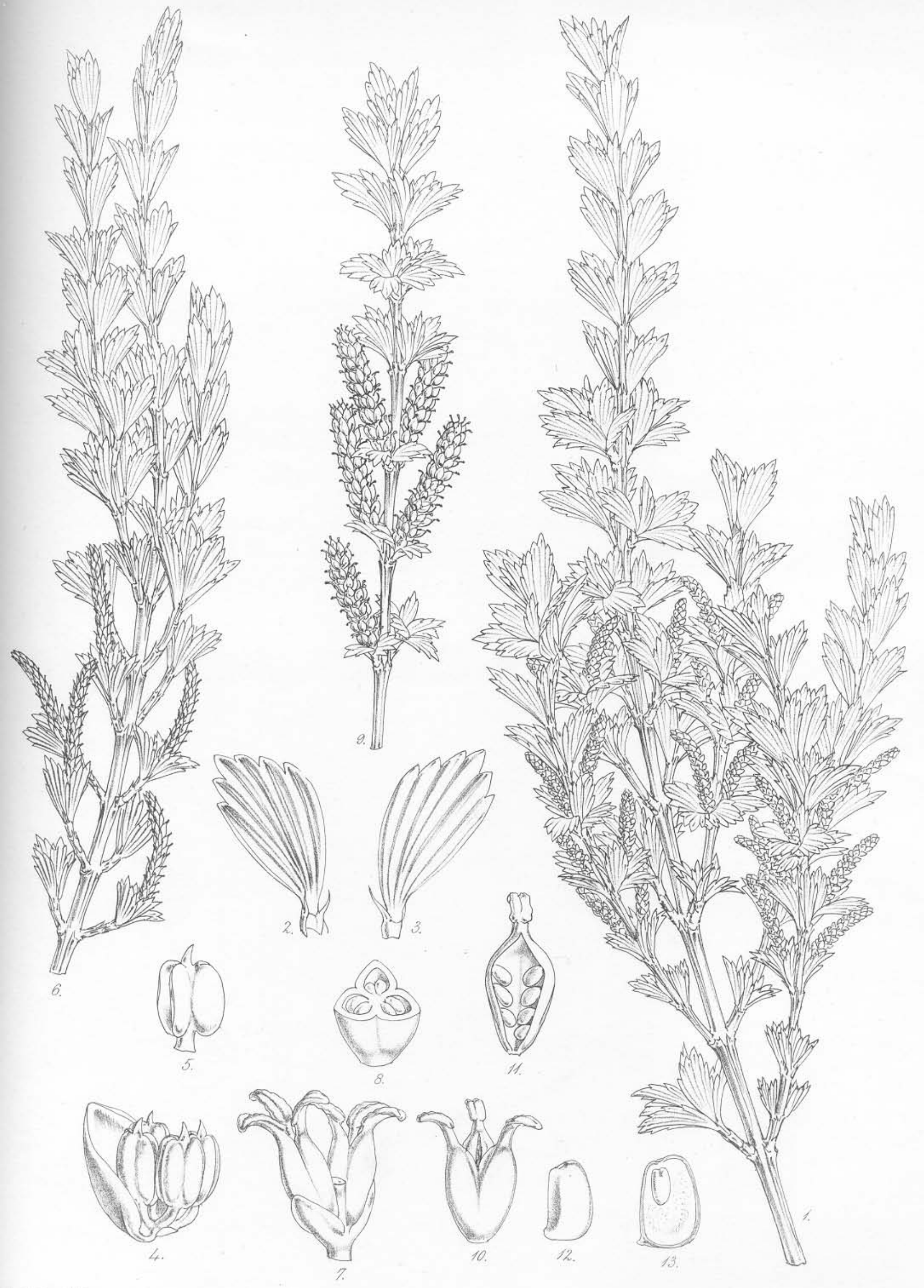

H. Fitch, del et ith 
Trans. Linn. Soc. Vot. XXVII. TAB.9.

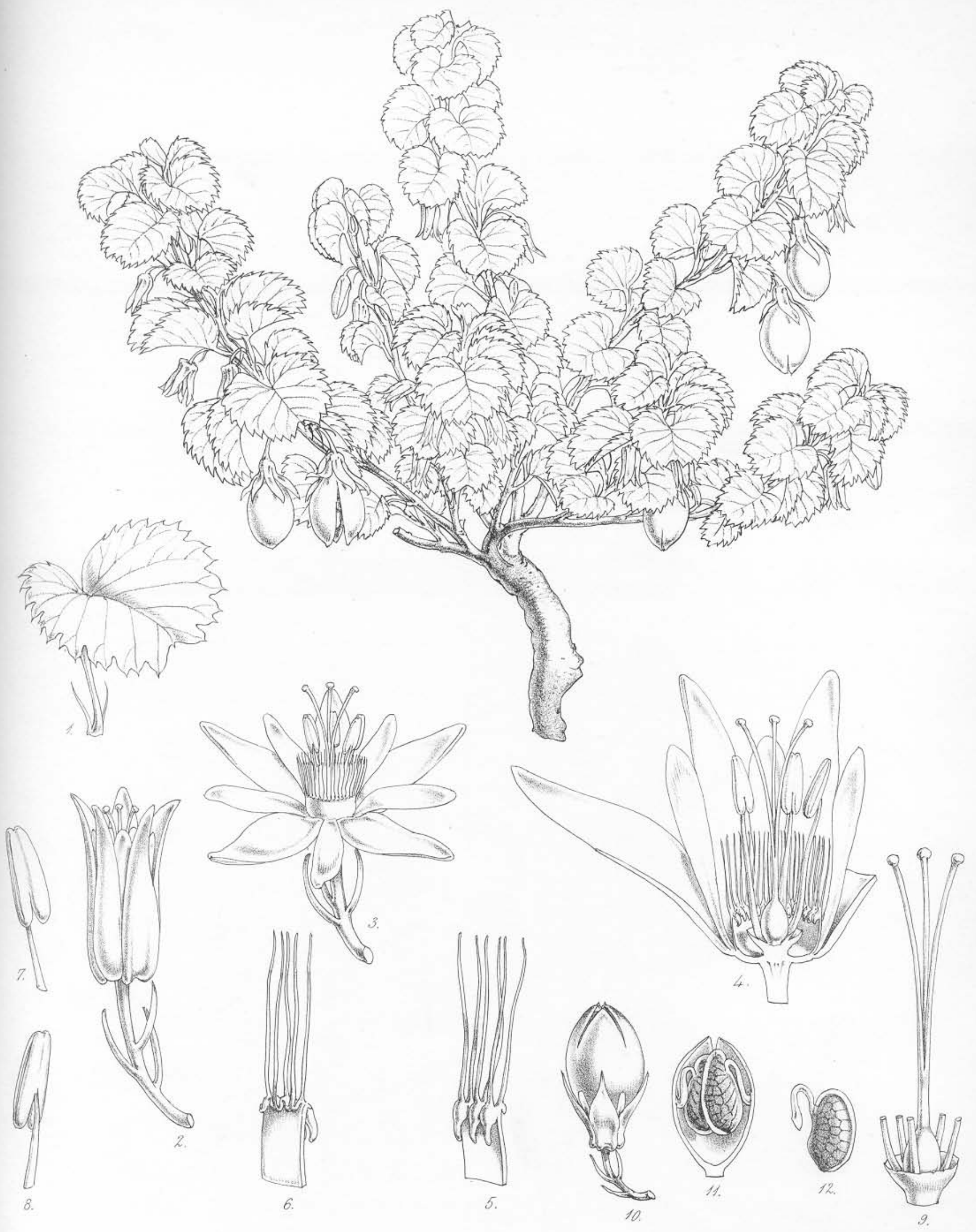

WH Fitch, del et lith 
Trans.Linn.Soc. Vol. XXVII. Tab.10.

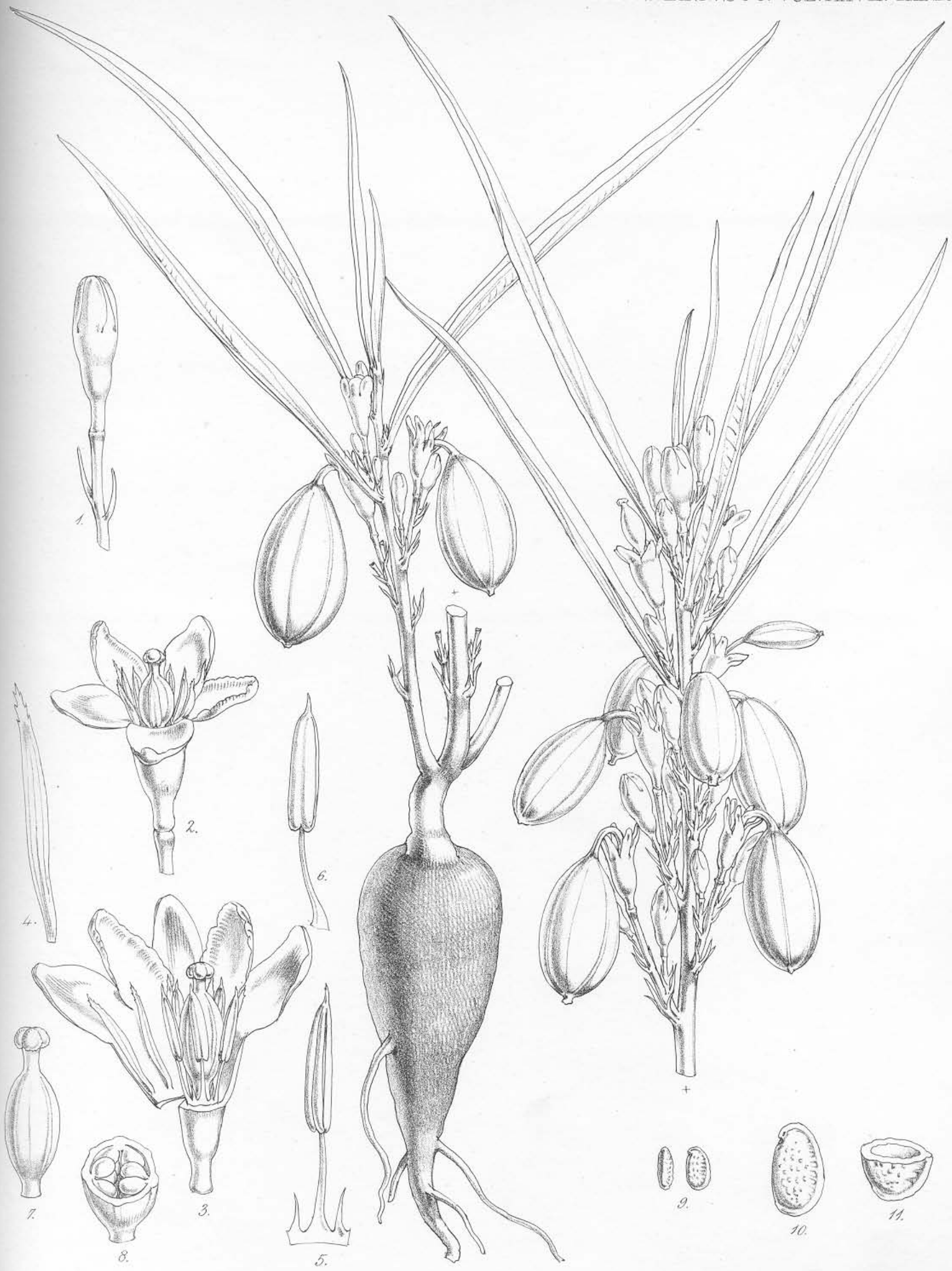




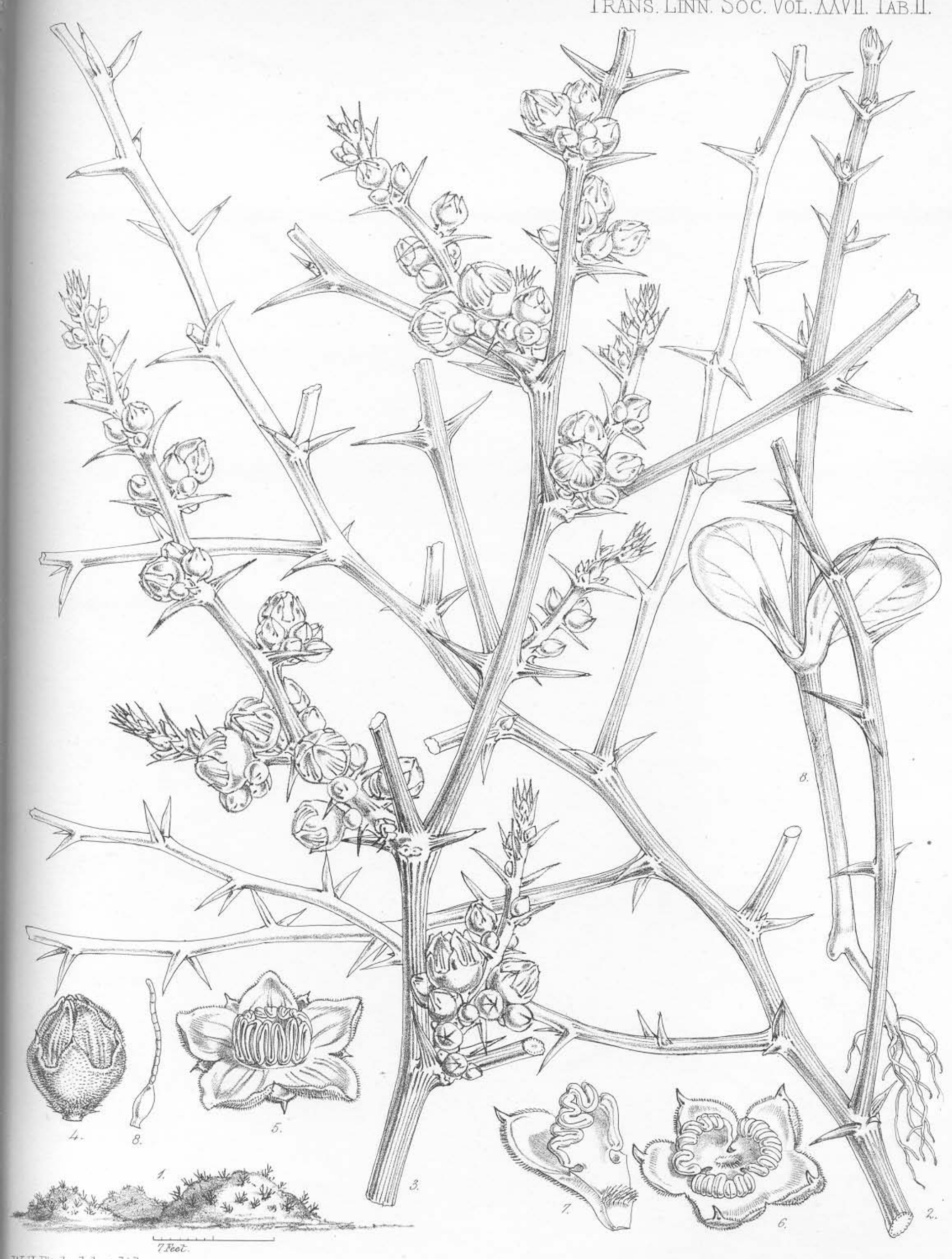

W.H.Fitch, del et.lith

J. N. Fitch, imp 

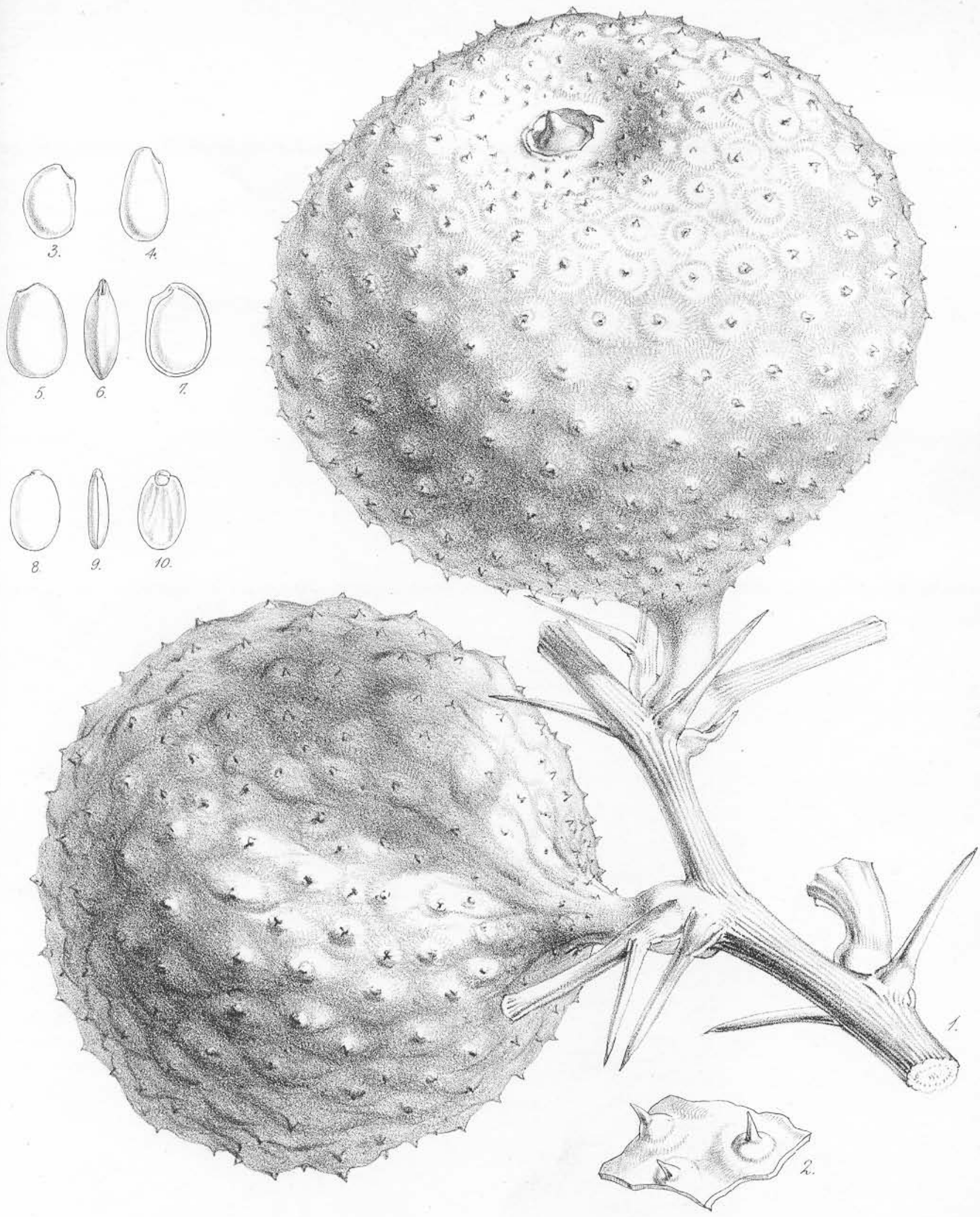
Trans. Linn. Soc. Vol. XXVII. TAB],2

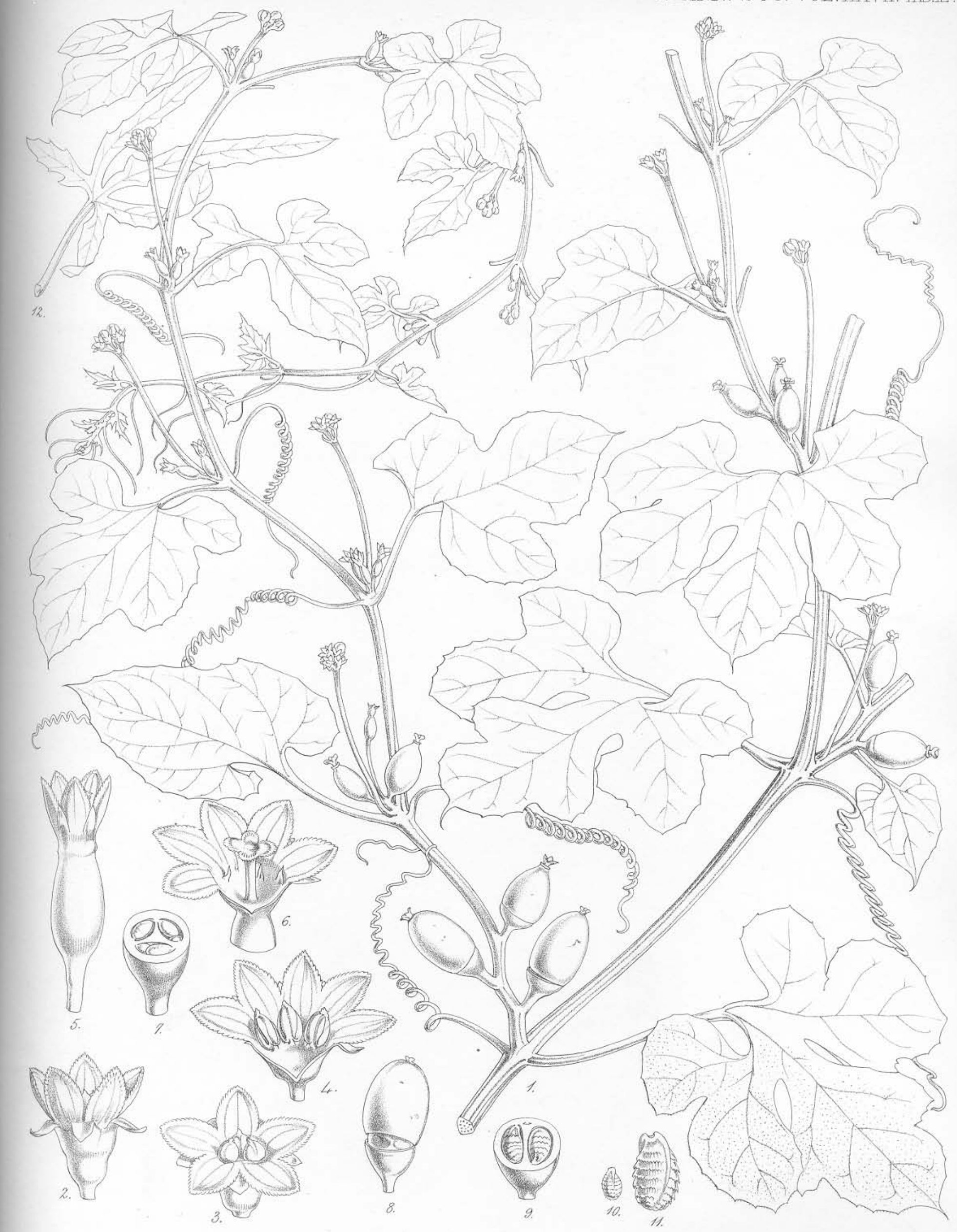

W.H. Fitch, del.et.lith.

J.N. Fitch, imp,

Corallocarpus Welwitschii, Hook.f. 
Trans. Linn. Soc. Vol. XXVII. TaB. 13.

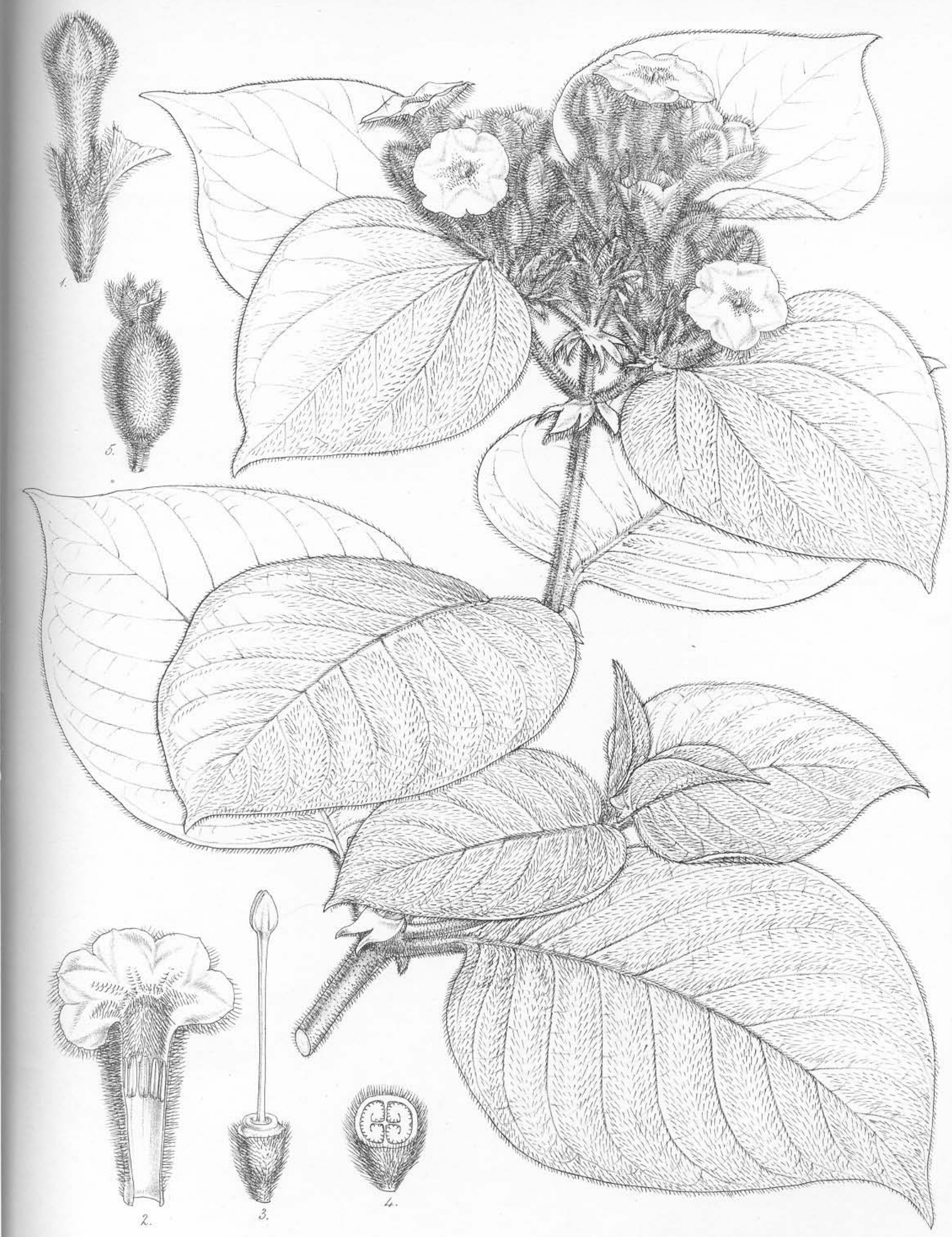




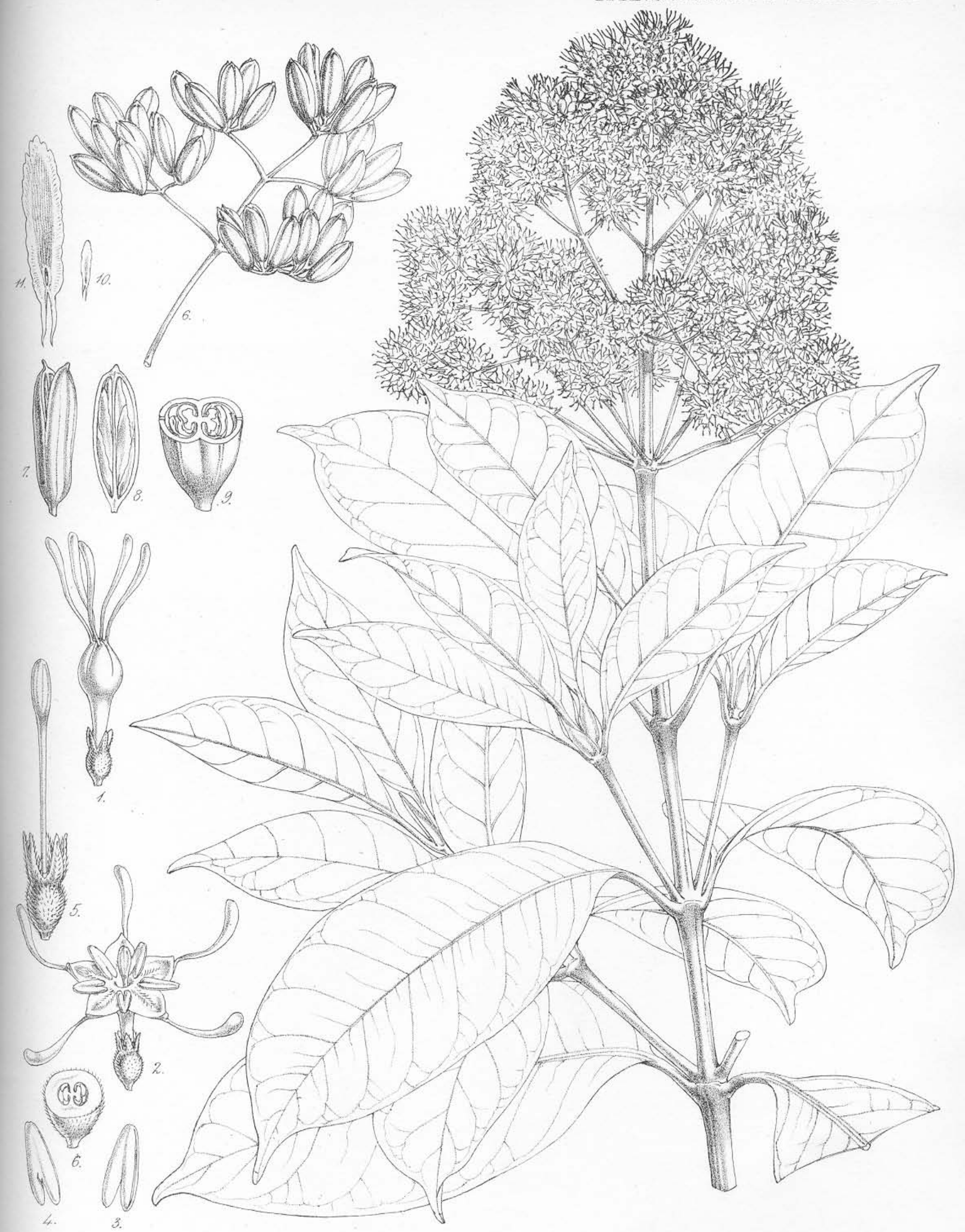

WH Fitch del et hith 


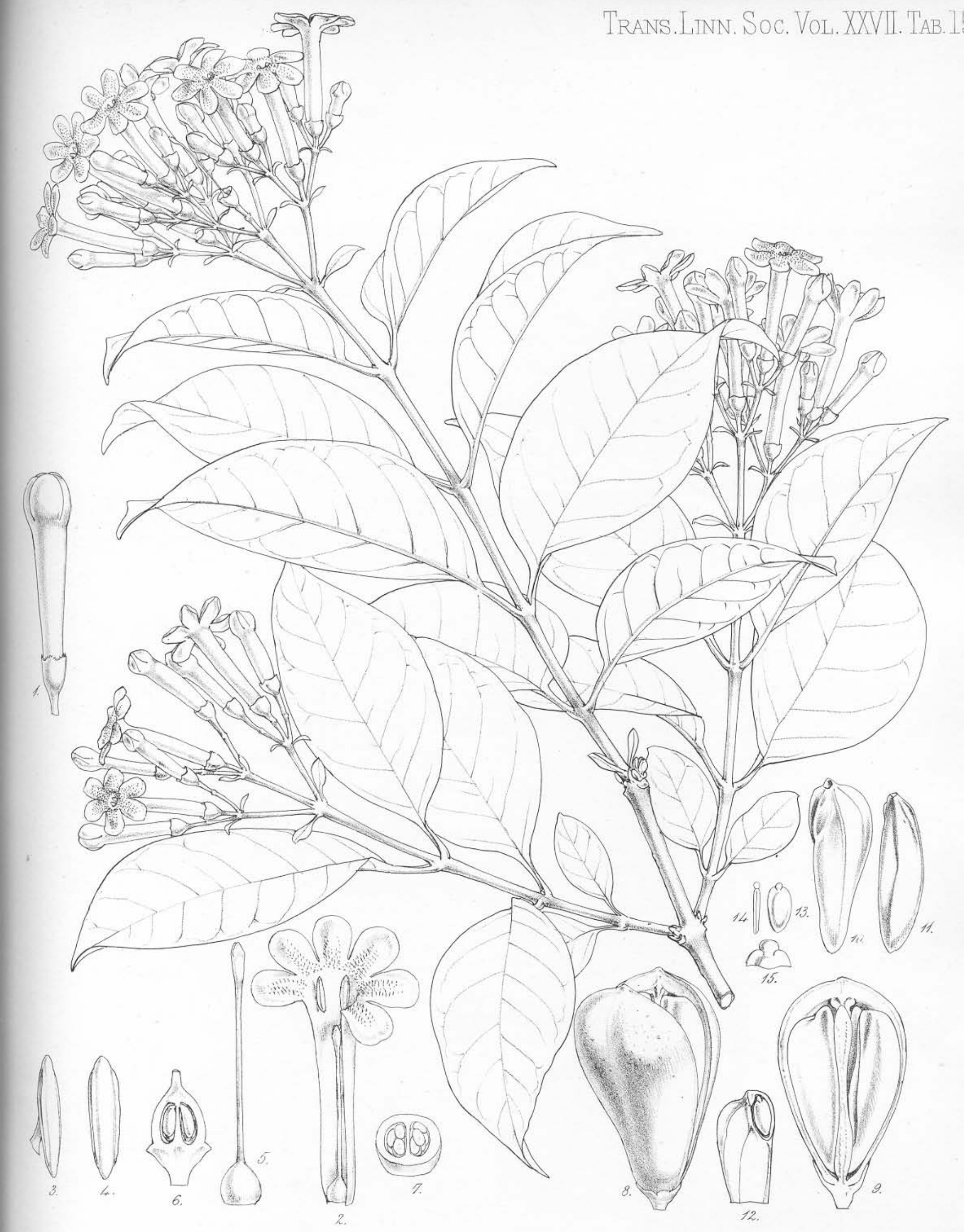


Trans. Linn Soc. Vol. XXVII. Tab.16.

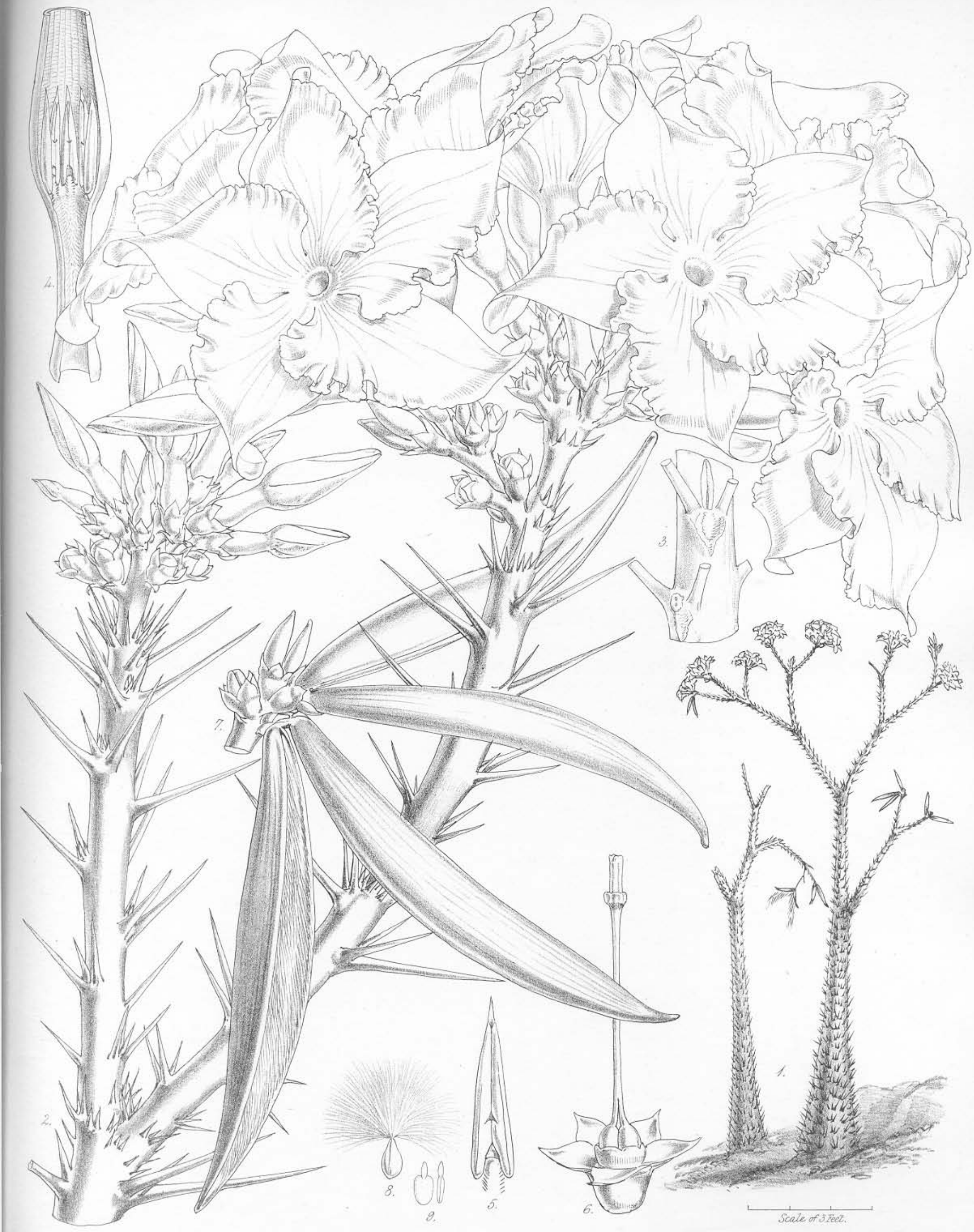

W.H Fitch delet. lith. 

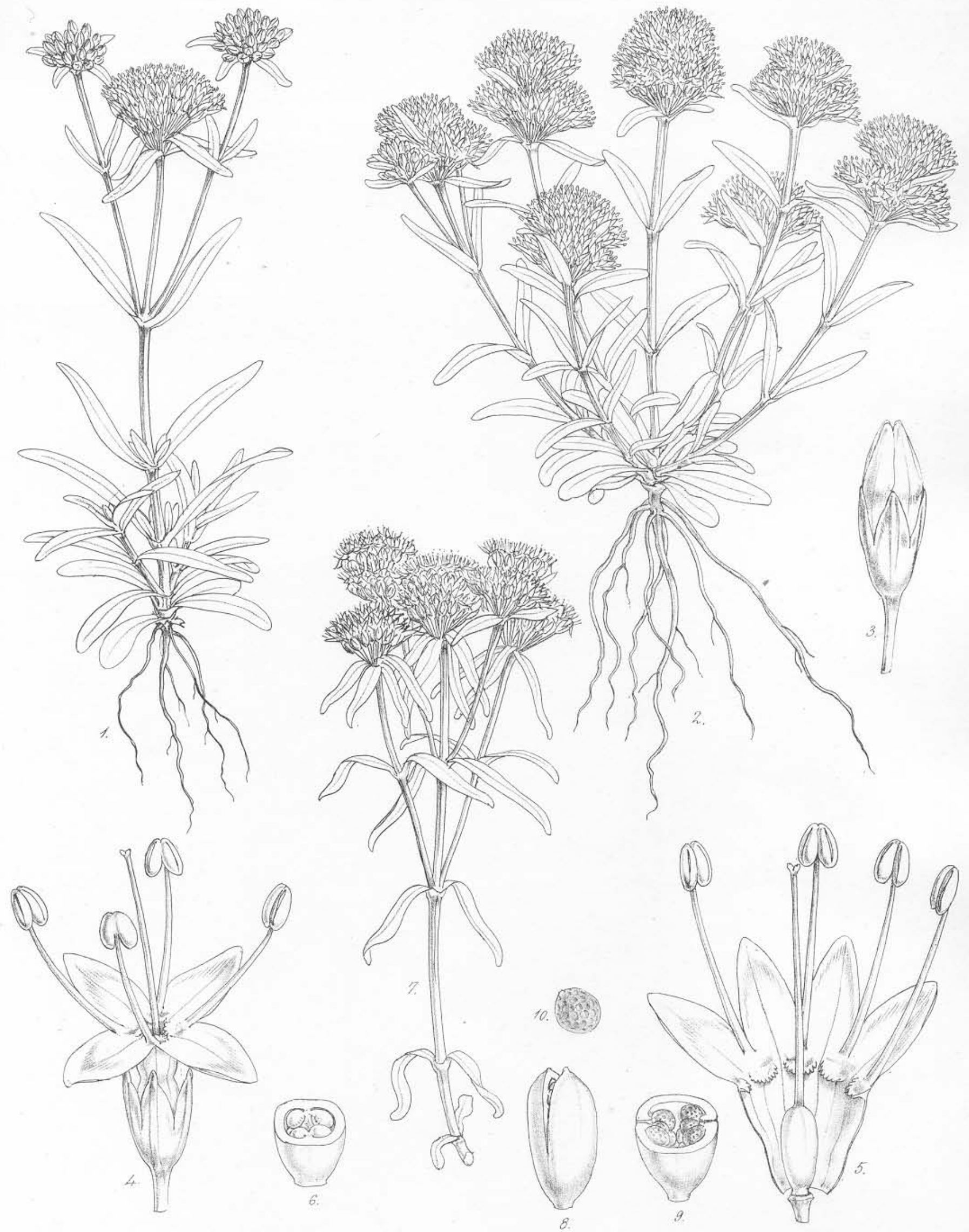

W H Fitch del et lith 
Trans.Linn. Soc. Vou. XXVII. TAB.18,

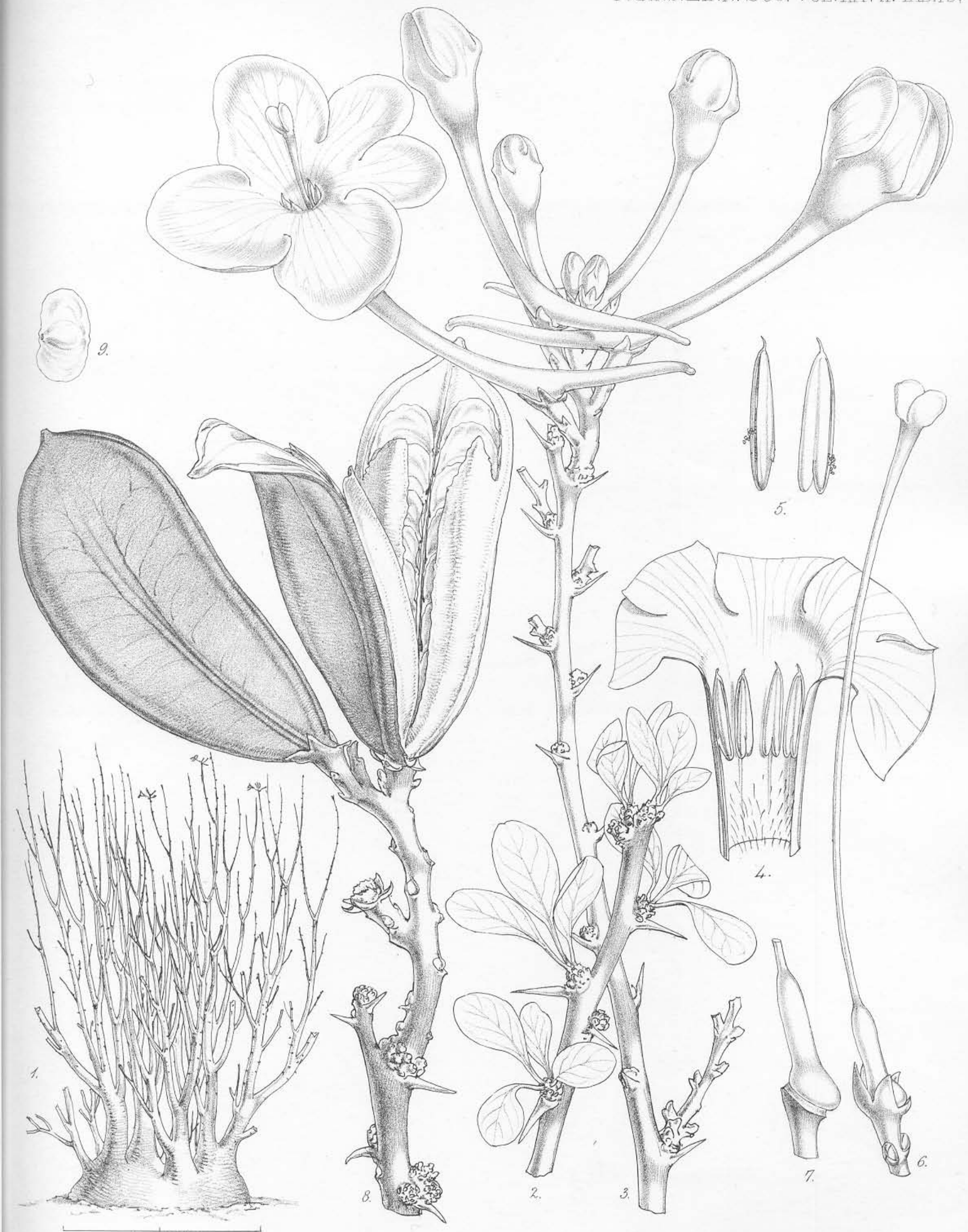

W. H. Fitch, del. et.lith

J N. Fitch,imp.

Sesamotharnnus Benguellensis, Welw. 


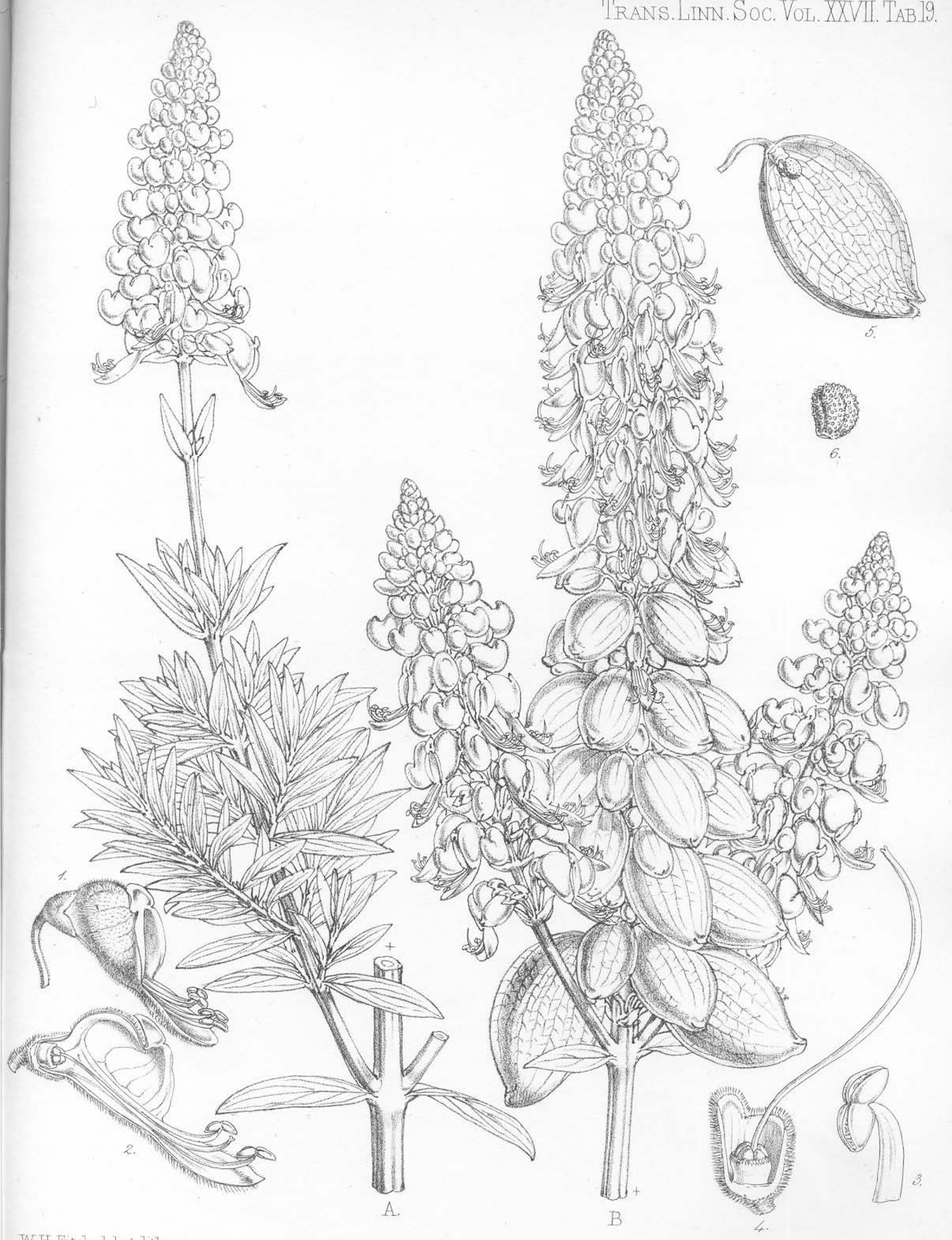

W.H. Fitch, del et, Tith. 
Trans Linn. Soc. Vol. XXVII. Tab. 21
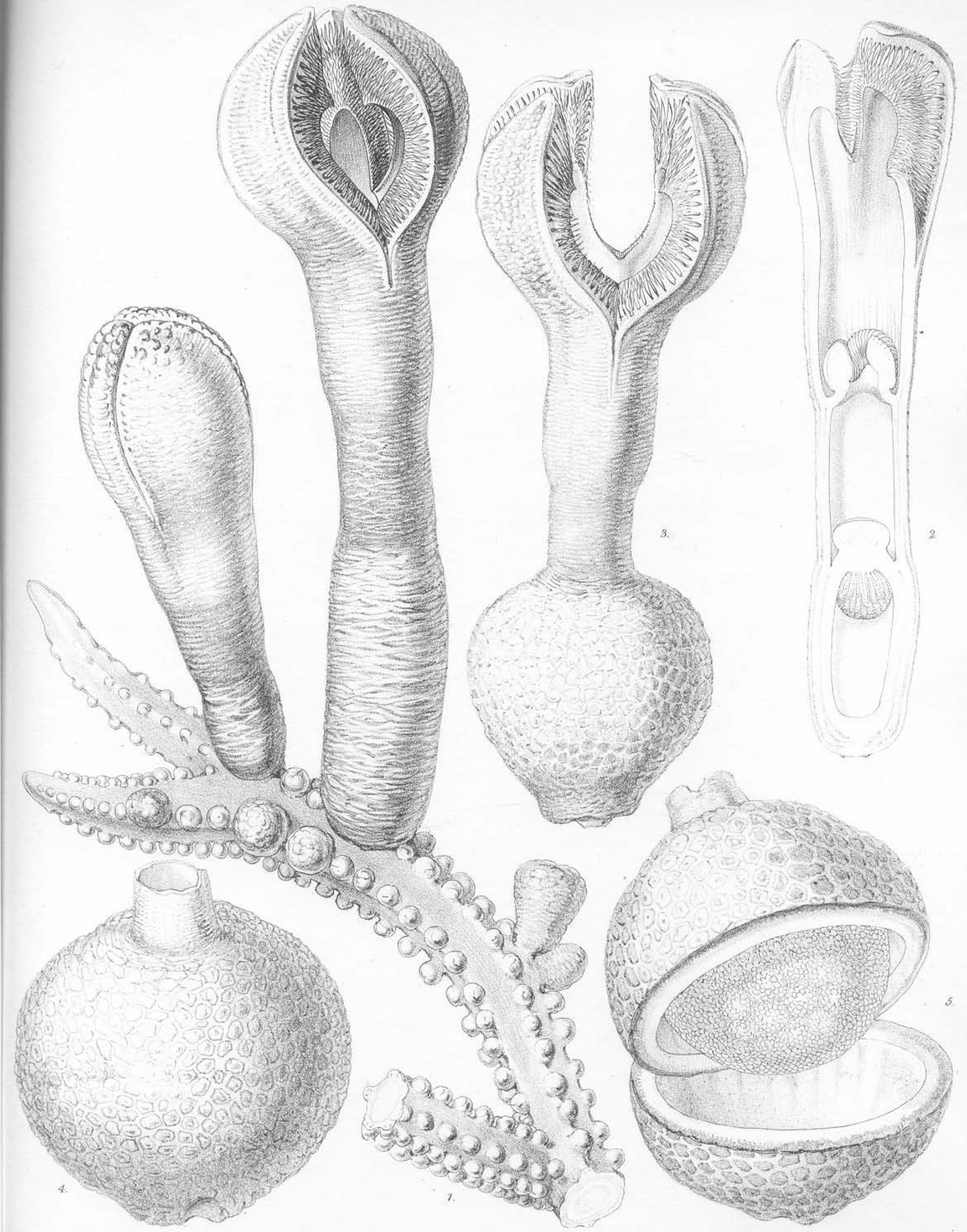

W H Fitsh del et lith. 
Trans Linn. SOC. Vol XXVII. TAB. 22.

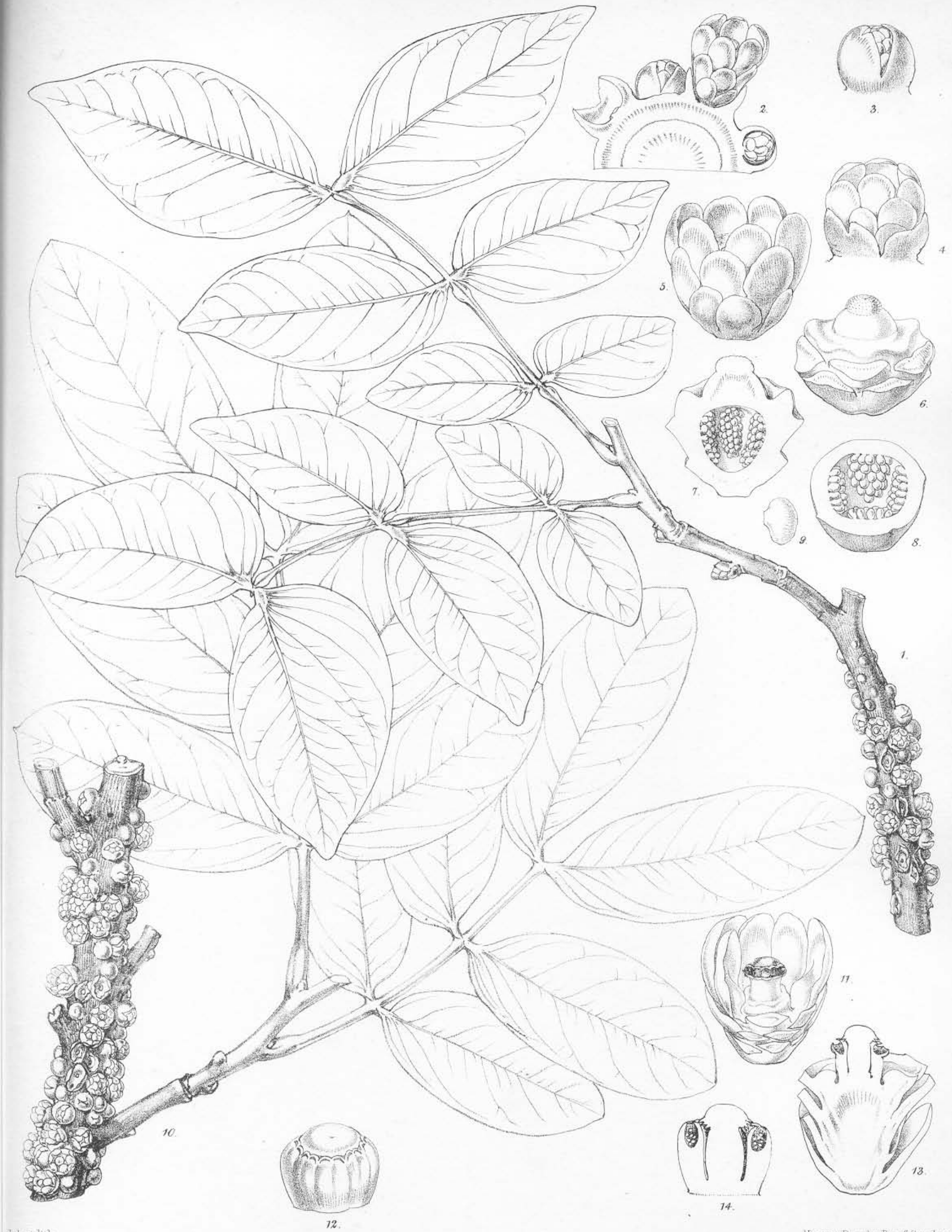

Pilostyles aethiopica. Welw. 
TRANS. LINN. SOc. VoL.XXVII. TAB.23.

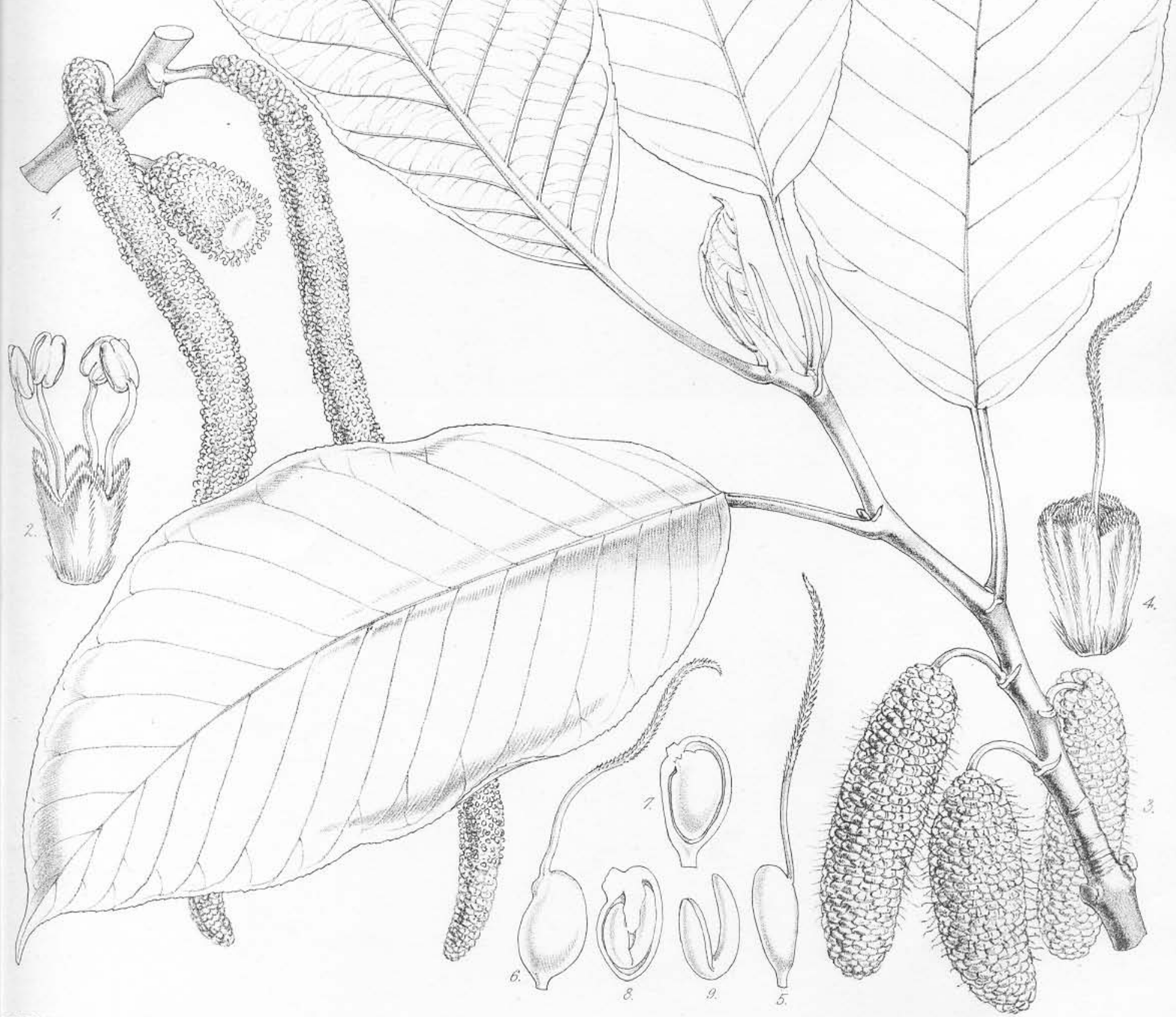

W. H. Fitch, del et.hth.

J.N.Fitch, imp.

Morus excelsa, Welw. 
Trans. Linn. Soc.Vot. XXVII. TaB24:
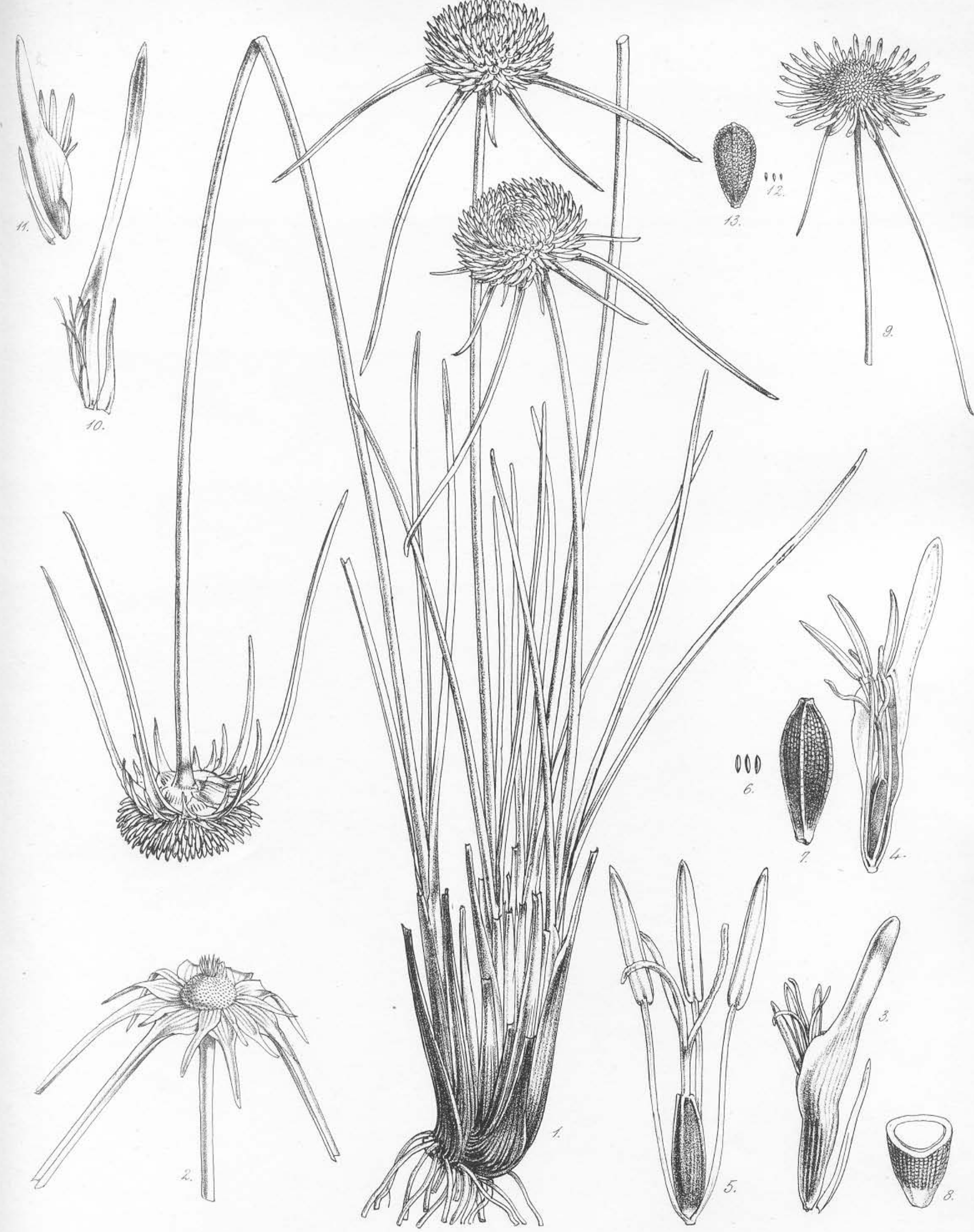
Trans. Linn. Soc.Vou. XXVII. TAB. 25.

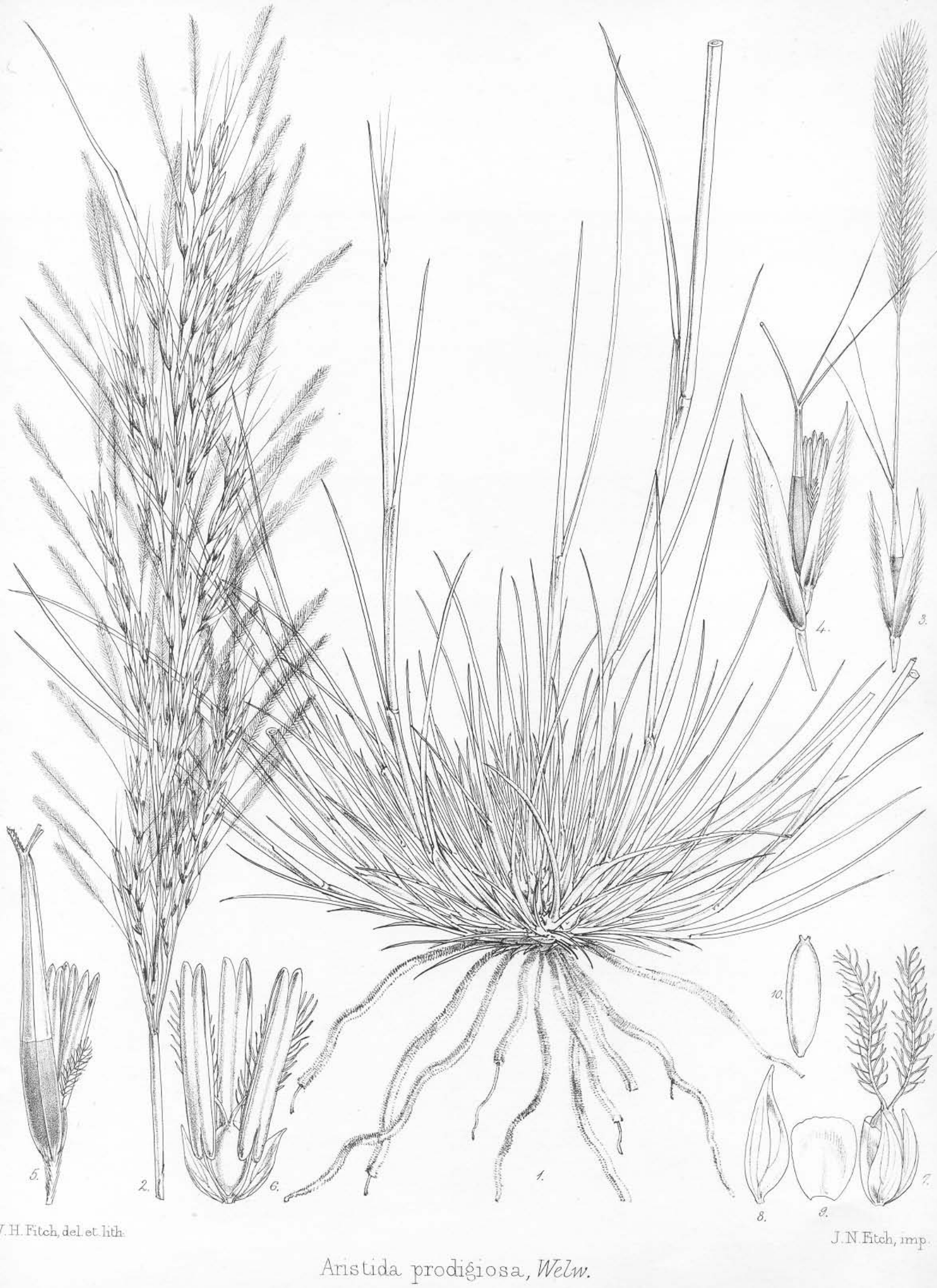




\section{ADDENDA VEL CORRIGENDA.}

Pag. 6, lin, 11, loco quos lege quas

8, 16, loco sylvatica lege siluatica

8, 30, loco hibernum lege hiemem

9, post lin. 33, adde: Quoad generalia de conformatione geognostica terrarum Angolensium conf.

"Voyage du Dr. Fr. Welwitsch dans les Royaumes d'Angola et de Benguella. (Mol-

lusques par A. Morelet.) Paris, 1868," pag. 5 et 6.

9, 34, loco vetegabilium lege vegetabilium

13, ultima, loco postero lege posterum

14, 10, loco infra lege inferne

14, 13, loco quidquam lege quidpiam

15 , 4, loco tri- lege tri-

20, 37, loco Burseracearum lege Burserearum

23, 3, loco quidquam lege quidpiam

23, 12, loco Spircearum lege Spirceearum

23, 23, loco l. c. t. viii. lege Apontam. l.e. (Tab. VIII.)

24, 40, loco Descr. lege Beskr.

28, 5, loco Tryphostemati lege Tryphostemmati.

28, 6, loco Modeccarum lege Modeccearum.

31, 4, loco Tab. XI. A et B lege (Tab. XI. et XI. A.)

31, 44, loco Tab. XI. B. lege Tab. XI. A.

34, 8, loco Trideis lege Irideis

$39, \quad 24$, loco peridermio lege spermodermio

42, 23, loco Xylopece lege Xylopia

63, 11, adde (Trichostachys speciosa, Welw. Synopse explic. pag. 19.)

67, 9, loco ab Hydnora capensi Thunb. lege a stirpe capensi (Hydnora africana Thunb.)

67,15 , loco capensi lege africance

Tab. 2, loco Ceranthera ilicifolia lege Alsodeia (Ceranthera) ilicifolia

14, loco 6 (fig. paniculæ fructiferæ adnexo) lege $6 a$

21, loco Hydnora longicollis Welw. lege: Hydnora africana Thunb. $\beta$. longicollis Welw.

Observ. De generibus speciebusve paucis, nostris supra descriptis valde affinibus vel omnino synonymis, opusculo hocce jam prelo subjecto a variis phytographis in lucem editis, mox alio loco tracturus sum. 